\title{
Ascomycetes on Para rubber (Hevea brasiliensis)
}

\section{Senwanna $\mathbf{C}^{1}$, Mapook $\mathbf{A}^{2}$, Samarakoon $\mathbf{M C}^{2}$, Karunarathna $\mathbf{A}^{\mathbf{1}}$, Wang $\mathbf{Y}^{3}$, Tang $\mathrm{AMC}^{4,5}$, Haituk $\mathrm{S}^{1}$, Suwannarach $\mathrm{N}^{6}$, Hyde $\mathrm{KD}^{2,6,7}$ and Cheewangkoon $\mathbf{R}^{1,6,8}$}

\author{
${ }^{1}$ Department of Entomology and Plant Pathology, Faculty of Agriculture, Chiang Mai University, Chiang Mai 50200, \\ Thailand \\ ${ }^{2}$ Center of Excellence in Fungal Research, Mae Fah Luang University, Chiang Rai 57100, Thailand \\ ${ }^{3}$ Department of Plant Pathology, College of Agriculture, Guizhou University, Guiyang, Guizhou 550025, China \\ ${ }^{4}$ Division of Applied Science, College of International Education, The Hong Kong Baptist University, Hong Kong, \\ People's Republic of China \\ ${ }^{5}$ Research Centre for Environment and Human Health, School of Continuing Education, The Hong Kong Baptist \\ University, Hong Kong, People's Republic of China \\ ${ }^{6}$ Research Center of Microbial Diversity and Sustainable Utilization, Chiang Mai University, Chiang Mai 50200, \\ Thailand \\ ${ }^{7}$ Innovative Institute of Plant Health, Zhongkai University of Agriculture and Engineering, Haizhu District, \\ Guangzhou, Guangdong 510225, People's Republic of China \\ ${ }^{8}$ Innovative Agriculture Research Centre, Faculty of Agriculture, Chiang Mai University, Chiang Mai 50200, Thailand
}

Senwanna C, Mapook A, Samarakoon MC, Karunarathna A, Wang Y, Tang AMC, Haituk S, Suwannarach N, Hyde KD, Cheewangkoon R 2021 - Ascomycetes on Para rubber (Hevea brasiliensis). Mycosphere 12(1), 1334-1512, Doi 10.5943/mycosphere/12/1/18

\begin{abstract}
This study focuses on ascomycetes associated with Para rubber trees, collected from plantations in Thailand. We provide descriptions and phylogenies for one new genus, seven new species, two asexual-sexual morph connections, 20 new host records, and one reference specimen. Dothideomycetes are dominant among ascomycetes on Para rubber. Only three species from our collection have previously been reported from Para rubber in the Amazon Forest, where Para rubber originates. Most taxa found on rubber trees in this study have previously been recorded in Thailand, either on Para rubber or different hosts. It is apparent that the taxa jumped from unrelated hosts to colonize rubber. A checklist of fungi and fungus-like organisms associated with Para rubber is also provided. The checklist includes references for each taxon, life mode information, and distribution. The checklist comprises 785 species and 180 taxa identified only to genus from 59 countries. The taxa in the checklist belong in 67 orders, 168 families, and 513 genera.
\end{abstract}

Key words - Ascomycota - Checklist - Dothideomycetes - Euphorbiaceae - Multi-gene phylogenetics - Sordariomycetes

\section{Table of content}

The numbers of taxa in this study are organized following the Outline of Fungi and funguslike taxa (Wijayawardene et al. 2020) and updated using recent relevant literature.

Class Dothideomycetes sensu O.E. Erikss. \& Winka 
Botryosphaeriales C.L. Schoch, Crous \& Shoemaker

Botryosphaeriaceae Theiss. \& Syd.

1. Lasiodiplodia pseudotheobromae A.J.L. Phillips, A. Alves \& Crous, Fungal Divers. 28: 8 (2008)

2. Lasiodiplodia theobromae (Pat.) Griffon \& Maubl., Bulletin de la Société Mycologique de France 25: 57 (1909)

3. Sphaeropsis eucalypticola A.J.L. Phillips, in Phillips et al., Stud. Mycol. 76: 158 (2013), new host record

Capnodiales Woron.

Mycosphaerellaceae Lindau

4. Cercospora dioscoreae-pyrifoliae J.M. Yen, Bull. Trimest. Soc. Mycol. Fr. 84: 6 (1968), new host record

Dyfrolomycetales K.L. Pang, K.D. Hyde \& E.B.G. Jones

Pleurotremataceae Walt. Watson (= Dyfrolomycetaceae K.D. Hyde et al.)

5. Dyfrolomyces sinensis Samarak., Tennakoon \& K.D. Hyde, in Hyde et al., Mycosphere 9(2): 354 (2018), new host record

Hysteriales Lindau

Hysteriaceae Chevall.

6. Gloniopsis leucaenae Jayasiri, E.B.G. Jones \& K.D. Hyde, Mycosphere 10 (1): 16 (2019), new host record and sexual morph record

7. Rhytidhysteron neorufulum Thambug. \& K.D. Hyde, in Thambugala, Hyde, Eungwanichayapant, Romero \& Liu, Cryptog. Mycol. 37(1): 110 (2016)

8. Rhytidhysteron tectonae Doilom \& K.D. Hyde, in Doilom et al., Fungal Divers. 82: 107182 (2016), new host record

Muyocopronales Mapook, Boonmee \& K.D. Hyde

Muyocopronaceae K.D. Hyde

9. Muyocopron garethjonesii Tibpromma, Karun. \& K.D. Hyde, in Tibpromma et al., Mycosphere 7(9): 1485 (2016), new host record

10. Quadrisporella Senwanna, Cheewangkoon \& K.D. Hyde, gen. nov.

11. Quadrisporella heveae Senwanna, Cheewangkoon \& K.D. Hyde, sp. nov.

Pleosporales Luttrell ex M.E. Barr

Corynesporascaceae Sivan.

12. Corynespora cassiicola (Berk. \& M.A. Curtis) C.T. Wei, Mycol. Pap. 34: 5 (1950)

Didymosphaeriaceae Munk

13. Montagnula thailandica Mapook \& K.D. Hyde, in Mapook et al., Fungal Divers. 101: 35 (2020), new host record

14. Pseudopithomyces palmicola Jun F. Li, Ariyaw. \& K.D. Hyde, in Ariyawansa et al., Fungal Divers. 75: 27-274 (2015), new host record

Hermatomycetaceae Locq.

15. Hermatomyces sphaericus (Sacc.) S. Hughes, Mycological Papers 50: 100 (1953), new host record

Lophiostomataceae Sacc.

16. Vaginatispora amygdali A. Hashim., K. Hiray. \& Kaz. Tanaka, in Hashimoto et al., Stud. Mycol. 90: 179 (2018), new host record

Neohendersoniaceae Giraldo \& Crous

17. Brevicollum hyalosporum Kaz. Tanaka \& Toy. Sato, in Tanaka et al., Mycologia 109(4): 611 (2017) 
18. Crassiparies octosporarum Senwanna, Cheewangkoon \& K.D. Hyde, sp. nov.

19. Crassiparies quadrisporus M. Matsum., K. Hiray. \& Kaz. Tanaka, in Li et al., Fungal Divers. 78: 63 (2016), new host record

Periconiaceae Nann.

20. Periconia heveae J.A. Stev. \& Imle, Mycologia 37(5): 580 (1945), reference specimen

Phaeoseptaceae Boonmee, Thambug. \& K.D. Hyde

21. Pleopunctum heveae Senwanna, Cheewangkoon \& K.D. Hyde, sp. nov.

Torulaceae Corda

22. Torula fici Crous, IMA Fungus 6 (1): 192 (2015), new host record

Venturiales Y. Zhang ter, C.L. Schoch \& K.D. Hyde

Sympoventuriaceae Y. Zhang ter, C.L. Schoch \& K.D. Hyde

23. Clavatispora thailandica Boonmee \& K.D. Hyde, in Boonmee et al., Phytotaxa 176(1): 96 (2014)

24. Verruconis heveae Huanrluek, Senwanna, Jayawardena \& K.D. Hyde, in Huanraluek et al., Bhat \& Hyde, Phytotaxa 403(1): 50 (2019)

25. Verruconis phayaoensis Senwanna, Cheewangkoon \& K.D. Hyde, sp. nov.

Class Sordariomycetes O.E. Erikss. \& Winka

Diaporthales Nannf.

Coryneaceae Corda

26. Coryneum heveanum Senwanna, Cheewangkoon \& K.D. Hyde, in Senwanna et al., MycoKeys 43: 81 (2018)

Cytosporaceae Fr.

27. Cytospora diopuiensis Q.J. Shang, J.K. Liu \& K.D. Hyde, in Shang et al., Mycosphere 11(1): 202 (2020), new host record and asexual morph record

28. Cytospora heveae Senwanna, Cheewangkoon \& K.D. Hyde, sp. nov.

29. Cytospora thailandica Norph., T.C. Wen \& K.D. Hyde, in Norphanphoun et al., MycoKeys 38: 106 (2018), new host record

Diaporthaceae Höhn. ex Wehm.

30. Diaporthe heveicola Senwanna, Cheewangkoon \& K.D. Hyde, sp. nov.

31. Diaporthe rosae Samarakoon \& K.D. Hyde, in Wanasinghe et al., Fungal Divers. 89: 1-236 (2018), new host record

Hypocreales Lindau

Nectriaceae Tul. \& C. Tul.

32. Albonectria rigidiuscula (Berk. \& Broome) Rossman \& Samuels, in Rossman et al., Stud. Mycol. 42: 105 (1999), new host record

33. Nectria pseudotrichia Berk. \& M.A. Curtis, J. Acad. Nat. Sci. Philadelphia 2, 2: 289. 1853

Coronophorales Nannf. (= Melanosporales N. Zhang \& M. Blackw.)

Nitschkiaceae (Fitzp.) Nannf.

34. Fracchiaea heveae Senwanna, Cheewangkoon \& K.D. Hyde, sp. nov.

Sporidesmiales Crous

Sporidesmiaceae Fr.

35. Sporidesmium tropicale M.B. Ellis, Mycol. Pap. 70: 58 (1958), new host record

Xylariales Nannf.

Diatrypaceae Nitschke

36. Allocryptovalsa cryptovalsoidea (Trouillas, W.M. Pitt \& Gubler) Senwanna et al., Mycosphere 8 (10): 1840 (2017), new host record 
37. Paraeutypella citricola (Speg.) L.S. Dissan., Wijayaw., J.C. Kang \& K.D. Hyde, in Dissanayake, Wijayawardene, Dayarathne, Samarakoon \& Dai, Biodiversity Data Journal 9: e63864, 14 (2021), new host record

\section{Introduction}

Hevea brasiliensis Müll. Arg. (Euphorbiaceae) is commonly known as the Para rubber tree and commercially, is the only source for the natural rubber (Jayasinghe 1999b, Lieberei 2007). Natural rubber is a secondary metabolite (cis 1,4-polyisoprene) that cannot easily be replaced by commercially produced synthetic rubber (Rippel \& Galembeck 2009, Souza et al. 2009, Zhu \& Zhang 2009). With the high economic value, rubber plantations have expanded throughout the tropics, especially in Southeast Asia (Fox et al. 2014, Ahrends et al. 2015, Warren-Thomas et al. 2015). Many forests and traditional agricultural systems in the tropics have been converted to monocultures plantations of rubber trees (Chen et al. 2016, Meijide et al. 2018). This results in significant biodiversity loss and increase the pathogen density in the ecosystem (Vongkamheng et al. 2016, Meijide et al. 2018, Nguyen et al. 2020). Para rubber plantations also contribute to climate change (Ahrends et al. 2015, Wangpimool et al. 2017).

The Para rubber tree is an exotic forest species originating from tropical rain forests in the Amazon Basin of South America, which sustains high microbial diversity (Jayasinghe 1999b, Hyde \& Soytong 2007, Orwa et al. 2009, Hytönen et al. 2019). Para rubber has highly diverse associations with microorganisms, including fungi. Several fungal pathogens (e.g., Colletotrichum spp., Corynespora cassiicola, Phytophthora palmivora) cause diseases in all growth stages of Para rubber (Déon et al. 2012a, Sunpapao \& Pornsuriya 2014, Liu et al. 2018). However, natural rubber and some rubber-based products also show higher susceptibility towards fungi (Evueh \& Ogbebor 2008, Ogbebor 2010, Gasparotto et al. 2012, Sunpapao \& Pornsuriya 2014, Liu et al. 2018b, Sterling et al. 2019). Many economically important fungal pathogens are found in forests. However due to the high diversity of other micro-organisms, pathogenicity may be suppressed (Weir 1926). In Central and South America, Leaf Blight disease (SALB) is an important and serious disease caused by Pseudocercospora ulei, which can seriously affect Para rubber plantation yields (Rands 1924, Weir 1926, Gazis \& Chaverri 2010, FAO 2011, Rocha et al. 2011). Moreover, leaf spot, leaf fall and powdery mildew disease caused by Colletotrichum spp., Corynespora cassiicola, Erysiphe necator, E. quercicola, and Oidium heveae are also important diseases in rubber plantations (Liyanage and Jacob 1992, Limkaisang et al. 2005, Ogbebor 2010, Sunpapao \& Pornsuriya 2014, Liyanage et al. 2016, Villarraga et al. 2017). However, the fungal infection process varies with physiological as well as geographical factors. Altogether, these factors affect the disease epidemiology (Weir 1926, Oghenekaro et al. 2014, Monkai et al. 2017). Therefore, the expansion of monoculture rubber plantations can affect the ecology of the plantation area through diseases epidemics and pathogenicity (Jayasinghe 1999a, b, Ploetz 2007, Narayanan \& Mydin 2012, Monkai et al. 2017). There have been several studies of endophytes, saprobes, and pathogens on Para rubber worldwide. Nonetheless, the information of the fungi on Para rubber is relatively poor and many taxa lack molecular data. Hence, a revised taxonomic approach with multi-gene phylogenetic analysis is necessary to understand the fungal diversity associated with Para rubber and its effect on related ecosystems.

Thailand is the world's largest rubber producer and exporter since 1991 (Romyen et al. 2018). Para rubber plantations expanded from the south of Thailand to the north and northeast, leading to widespread land conversion to monoculture rubber cultivation (Pansak 2015, Tongkaemkaew \& Patanothai 2015, Wangpimool et al. 2017). The fungi on Para rubber in Thailand have been relatively poorly investigated and only a few reports are available (Seephueak et al. 2011, Rodesuchit et al. 2012, Sunpapao \& Pornsuriya 2014, Trakunyingcharoen et al. 2015, Srihanant \& Petcharat 2015, Thaochan et al. 2020). Due to the fast distribution of Para rubber as well as climate change effects, it is important to investigate the fungal diversity of Para rubber plantations in Thailand. Para rubber is an exotic plant in Thailand and provides a platform to study fungal host interactions, lifestyle shifts and host jumping. In this study, we provide descriptions and 
phylogenies of ascomycetes associated with para rubber plantations in Thailand. Multi-gene phylogeny coupled with taxonomic comparison are used to identify and confirm the current taxonomic placements of these taxa. In addition, a checklist of fungi associated with Hevea brasiliensis is provided.

\section{Materials \& Methods}

\section{Collections, morphological studies, and isolation}

Fresh materials (symptomatic and asymptomatic of Para rubber) were collected from Para rubber plantations in Chiang Mai, Chiang Rai, Loei, Phayao, Ranong, and Sukhothai provinces in Thailand. The methods of this study follow Senwanna et al. (2019) and Senayanake et al. (2020).

\section{DNA extraction, PCR amplification and DNA sequencing}

Genomic DNA was extracted from fungal mycelium grown on MEA or fungal fruiting bodies, using the Biospin Fungus Genomic DNA Extraction Kit (BioFlux®, Hangzhou, P.R. China), FavorPrep Tissue Genomic DNA Extraction Mini Kit (FAVORGEN Biotech Corp., Taiwan), and the BIOMIGA Fungus Genomic DNA Extraction Kit (Biomiga Inc., USA) and E.Z.N.A.® Genomic DNA Isolation Kits (OMEGA Bio-Tek, Georgia) respectively, according to the manufacturer's protocol. Extracted DNA was stored at $-20{ }^{\circ} \mathrm{C}$. PCR amplifications were performed for selected gene regions using given primers (Table 1) and conditions as shown described in Senwanna et al. (2019).

\section{Phylogenetic analyses}

Sequences were assembled using SeqMan 5.00 and the closely related taxa for newly generated sequences were selected from GenBank ${ }^{\circledR}$ based on BLASTn searches of the NCBI nucleotide database (http://blast.ncbi.nlm.nih.gov/) as well as recent studies. The individual gene alignments were initially aligned by MAFFT version 7 (Katoh et al. 2019, http://mafft.cbrc.jp/alignment/server/) and improved manually where necessary in BioEdit v.7.0.9.1 (Hall 1999) and MEGA7 (Kumar et al. 2015). The final alignments of the combined multi-gene dataset were analyzed and inferred the phylogenetic trees based on maximum likelihood (ML) and Bayesian inference (BI) analyses.

The ML analyses were performed by using the RAxML-HPC2 on XSEDE (v. 8.2.8) (Stamatakis et al. 2008, Stamatakis 2014) via the CIPRES Science Gateway platform (Miller et al. 2010). Maximum likelihood bootstrap values equal or greater than $60 \%$ are defined above each node. The BI analyses were performed by MrBayes on XSEDE, MrBayes 3.2.6 (Huelsenbeck \& Ronquist 2001) via the CIPRES Science Gateway platform (Miller et al. 2010). Bayesian posterior probabilities (BYPP) (Rannala \& Yang 1996, Zhaxybayeva \& Gogarten 2002) were determined by Markov Chain Monte Carlo Sampling (BMCMC). Six simultaneous Markov chains were run from random trees for 1,000,000 generations or depending on individual settings for the fungal group and trees were sampled every $100^{\text {th }}$ generation. The run was stopped when the standard deviation of split frequencies was reached below 0.01 . The first $10 \%$ of generated trees representing the burn-in phase of the analysis were discarded and the remaining trees were used for calculating PP in the majority rule consensus tree. Bayesian posterior probabilities (BYPP) equal to or greater than 0.95 are defined above the nodes. The phylogenetic tree was visualized in FigTree v.1.4.3 (Rambaut 2016) and edited in Adobe Illustrator CC 2019 version 23.0.3.585 and Adobe Photoshop CS6 version 13.0. (Adobe Systems. USA). The newly generated sequences in this study were deposited in GenBank. 
Table 1 Details of gene loci sequenced and primers used for phylogenetic analyses.

\begin{tabular}{|c|c|c|c|}
\hline $\begin{array}{l}\text { Genus (number of isolates } \\
\text { used for sequencing) }\end{array}$ & Gene/locia $^{\mathbf{a}}$ & $\begin{array}{l}\text { PCR primers } \\
\text { (forward/reverse) }\end{array}$ & References for primer \\
\hline $\begin{array}{l}\text { Brevicollum (2), Clavatispora } \\
\text { (2), Corynespora (1), } \\
\text { Crassiparies (4), Dyfrolomyces } \\
\text { (1), Gloniopsis (2), } \\
\text { Hermatomyces (1), Montagnula } \\
\text { (1), Muyocopron (1), Periconia } \\
\text { (1), Pleopunctum (2), } \\
\text { Rhytidhysteron (4), } \\
\text { Sporidesmium (1), Torula (3), } \\
\text { Verruconis (4), Quadrisporella } \\
\text { (1) }\end{array}$ & $\begin{array}{l}\text { LSU } \\
\text { SSU } \\
\text { ITS } \\
\text { TEF1 } \\
\text { RPB2 }\end{array}$ & $\begin{array}{l}\text { LR0R/LR5 } \\
\text { NS1/NS4 } \\
\text { ITS5/ITS4 } \\
\text { EF1-983F/EF1-2218R } \\
\text { fRPB2-5f/fRPB2-7cR }\end{array}$ & $\begin{array}{l}\text { Vilgalys \& Hester (1990) } \\
\text { White et al. (1990) } \\
\text { White et al. (1990) } \\
\text { Rehner (2001) } \\
\text { Liu et al. (1999) }\end{array}$ \\
\hline Cercospora $(2)$ & $\begin{array}{l}\text { ITS } \\
\text { TEF1 } \\
\text { ACT }\end{array}$ & $\begin{array}{l}\text { ITS5/ITS4 } \\
\text { EF1-728F/EF1-986R } \\
\text { ACT512F/ACT783R }\end{array}$ & $\begin{array}{l}\text { White et al. (1990) } \\
\text { Carbone \& Kohn (1999) } \\
\text { Carbone \& Kohn (1999) }\end{array}$ \\
\hline Coryneum (2) & $\begin{array}{l}\text { ITS } \\
\text { LSU } \\
\text { TEF1 }\end{array}$ & $\begin{array}{l}\text { ITS5/ITS4 } \\
\text { LR0R/LR5 } \\
\text { EF1-728F/EF1-986R }\end{array}$ & $\begin{array}{l}\text { White et al. (1990) } \\
\text { Vilgalys \& Hester (1990) } \\
\text { Carbone \& Kohn (1999) }\end{array}$ \\
\hline Cytospora (5) & $\begin{array}{l}\text { ITS } \\
\text { LSU } \\
\text { ACT } \\
\text { TEF1 } \\
\end{array}$ & $\begin{array}{l}\text { ITS5/ITS4 } \\
\text { LR0R/LR5 } \\
\text { ACT512F/ACT783R } \\
\text { EF1-728F/EF2 } \\
\end{array}$ & $\begin{array}{l}\text { White et al. (1990) } \\
\text { Vilgalys \& Hester (1990) } \\
\text { Carbone \& Kohn (1999) } \\
\text { Carbone \& Kohn (1999), } \\
\text { O’Donnell et al. (1998) }\end{array}$ \\
\hline Diaporthe (2) & $\begin{array}{l}\text { ITS } \\
\text { TEF1 } \\
\text { TUB2 }\end{array}$ & $\begin{array}{l}\text { ITS5/ITS4 } \\
\text { EF1-728F/EF2 } \\
\text { Bt-2a/Bt-2b }\end{array}$ & $\begin{array}{l}\text { White et al. (1990) } \\
\text { Carbone \& Kohn (1999), } \\
\text { O’Donnell et al. (1998) } \\
\text { Glass \& Donaldson (1995) }\end{array}$ \\
\hline $\begin{array}{l}\text { Diatrypaceae: Allocryptovalsa } \\
\text { (1), Eutypella (1) }\end{array}$ & $\begin{array}{l}\text { ITS } \\
\text { TUB2 }\end{array}$ & $\begin{array}{l}\text { ITS5/ITS4 } \\
\text { T1/Bt-2b }\end{array}$ & $\begin{array}{l}\text { White et al. (1990) } \\
\text { O’Donnell \& Cigelnik (1997), } \\
\text { Glass \& Donaldson (1995) }\end{array}$ \\
\hline Fracchiaea (1) & $\begin{array}{l}\text { LSU } \\
\text { TEF1 } \\
\text { RPB2 }\end{array}$ & $\begin{array}{l}\text { LR0R/LR5 } \\
\text { EF1-526F/ EF1-1526R } \\
\text { fRPB2-5f/fRPB2-7cR }\end{array}$ & $\begin{array}{l}\text { Vilgalys \& Hester (1990) } \\
\text { Rehner (2001) } \\
\text { Liu et al. (1999) }\end{array}$ \\
\hline Lasiodiplodia (5) & $\begin{array}{l}\text { ITS } \\
\text { TEF1 } \\
\text { TUB2 } \\
\end{array}$ & $\begin{array}{l}\text { ITS5/ITS4 } \\
\text { EF1-688F/EF1-986R } \\
\text { Bt-2a/Bt-2b }\end{array}$ & $\begin{array}{l}\text { White et al. (1990) } \\
\text { Alves et al. (2008), Carbone \& } \\
\text { Kohn (1999) } \\
\text { Glass \& Donaldson (1995) }\end{array}$ \\
\hline $\begin{array}{l}\text { Nectriaceae: Albonectria (1), } \\
\text { Nectria (1) }\end{array}$ & $\begin{array}{l}\text { ITS } \\
\text { LSU } \\
\text { RPB1 } \\
\text { TUB2 }\end{array}$ & $\begin{array}{l}\text { ITS5/ITS4 } \\
\text { LR0R/LR5 } \\
\text { RPB1-Ac/RPB1-Cr } \\
\text { Bt-2a/Bt-2b }\end{array}$ & $\begin{array}{l}\text { White et al. (1990) } \\
\text { Vilgalys \& Hester (1990) } \\
\text { Matheny et al. (2002) } \\
\text { Glass \& Donaldson (1995) }\end{array}$ \\
\hline Pseudopithimyces (1) & $\begin{array}{l}\text { LSU } \\
\text { ITS } \\
\text { RPB2 }\end{array}$ & $\begin{array}{l}\text { LR0R/LR5 } \\
\text { ITS5/ITS4 } \\
\text { fRPB2-5f/fRPB2-7cR }\end{array}$ & $\begin{array}{l}\text { Vilgalys \& Hester (1990) } \\
\text { White et al. (1990) } \\
\text { Liu et al. (1999) }\end{array}$ \\
\hline Sphaeropsis (1) & $\begin{array}{l}\text { ITS } \\
\text { TEF1 } \\
\text { TUB2 }\end{array}$ & $\begin{array}{l}\text { ITS5/ITS4 } \\
\text { EF-728F/EF2 } \\
\text { Bt-2a/Bt-2b }\end{array}$ & $\begin{array}{l}\text { White et al. (1990) } \\
\text { Carbone \& Kohn (1999), } \\
\text { O’Donnell et al. (1998) } \\
\text { Glass \& Donaldson } \\
\text { (1995) }\end{array}$ \\
\hline
\end{tabular}

a ACT: Actin, ITS: Part of rDNA 18S (3' end), the first internal transcribed spacer (ITS1), the 5.8S rRNA gene, the second ITS region (ITS2), and part of the 28S rRNA (5' end); LSU: 28S large subunit rDNA; SSU: 18S small subunit rDNA; TEF1: translation elongation factor 1-alpha gene; RPB1: RNA polymerase II largest subunit; RPB2: RNA polymerase II second largest subunit; TUB2: $\beta$-tubulin 


\section{Results}

\section{Taxonomy}

Phylum Ascomycota Caval.-Sm.

Class Dothideomycetes sensu O.E. Erikss. \& Winka

Botryosphaeriales C.L. Schoch, Crous \& Shoemaker

Botryosphaeriaceae Theiss. \& Syd.

Botryosphaeriaceae are endophytes, pathogens, and saprobes of a wide range of hosts in temperate, tropical and subtropical regions (Burgess et al. 2006, Phillips et al. 2013, Slippers et al. 2013, Dissanayake et al. 2017a, Wu et al. 2021). Some pathogenic taxa are associated with cankers, dieback and rot diseases on ecologically and economically important plants (Phillips et al. 2013, Trakunyingcharoen et al. 2015a, b, Marin-Felix et al. 2017, Karunanayake \& Adikaram 2020, Batista et al. 2021). Currently, 22 genera are listed in this family (Phillips et al. 2019, Hongsanan et al. 2020b). In this study, four collections belonging to Lasiodiplodia pseudotheobromae (1) and $L$. theobromae (3) were made and identified (Fig. 1). The asexual morphs of Lasiodiplodia are characterized by hyaline and aseptate conidia becoming brown and 1-septate when mature, with longitudinal striations on the conidial surface (Hyde et al. 2013, Phillips et al. 2013). Many species are pathogens of various hosts (Burgess et al. 2006, Phillips et al. 2013, Trakunyingcharoen et al. 2015a, Rosado et al. 2016, Karunanayake \& Adikaram 2020). In addition, Sphaeropsis eucalypticola is newly recorded on Hevea brasiliensis in Thailand.

Lasiodiplodia pseudotheobromae A.J.L. Phillips, A. Alves \& Crous, Fungal Divers. 28: 8 (2008)

Index Fungorum number: IF510941

Saprobic on seed cover of Hevea brasiliensis. Sexual morph: Undetermined. Asexual morph: Conidiomata (170-)190-300 $\mu \mathrm{m}$ diam. $(\bar{x}=234 \mu \mathrm{m}, \mathrm{n}=10)$, superficial, solitary to gregarious, globose or subglobose, dark brown to black, with a central ostiole. Peridium composed of cells of textura angularis, outer layers dark brown to black, inner layers hyaline, thin-walled. Pseudoparaphyses (27-)35-55(-60) $\mu \mathrm{m}$ long, 1.8-3.5 $\mu \mathrm{m}$ wide, hyaline, aseptate, cylindrical, widest at the base, tapering towards the ends. Conidiophores reduced to conidiogenous cells. Conidiogenous cells (6.8)7.5-11.2 $\times(2-) 3.2-4.7 \mu \mathrm{m}(\bar{x}=9 \times 4 \mu \mathrm{m}, \mathrm{n}=20)$, holoblastic, hyaline, thin-walled, smooth-walled, cylindrical. Conidia (16.7-)22-28(-31.5) $\times(9.5-) 11-14.5 \mu \mathrm{m}(\bar{x}=26$ $\times 13 \mu \mathrm{m}, \mathrm{n}=40$ ), hyaline, aseptate when immature, medianly 1-euseptate, dark brown, thickwalled, ellipsoid to obovoid, base truncate or rounded, with longitudinal striations from apex to base when mature.

Culture characteristics - Conidia germinating on MEA within 24 hours at room temperature and germ tubes produced from apex. Colonies on MEA circular, velvety, moderately fluffy, white at first, becoming greyish white to black.

Material examined - Thailand, Phayao Province, Mueang District, on seed cover of Hevea brasiliensis (Euphorbiaceae), 3 January 2017, C. Senwanna, RBPY32 (MFLU 21-0202), living culture MFLUCC 17-0349.

Host and distribution - Wide host range, widely distributed in tropical and subtropical regions.

GenBank numbers - MFLUCC 17-0349: ITS = OL782124, LSU = OL782046, TEF1 = OL944420, TUB2 = OL840994.

Notes - Phylogenetic analyses show that strain MFLUCC 17-0349 grouped within the Lasiodiplodia pseudotheobromae clade (Fig. 1). In the BLASTn search, the closest match to the ITS, TEF1 and TUB2 sequences with 100\% similarity was L. pseudotheobromae. The morphology from our collection (MFLU 21-0202) is similar to the asexual morph of the holotype (Pavlic et al. 2008) and the collection from Para rubber (Trakunyingcharoen et al. 2014). We, therefore, name our collections as L. pseudotheobromae. 


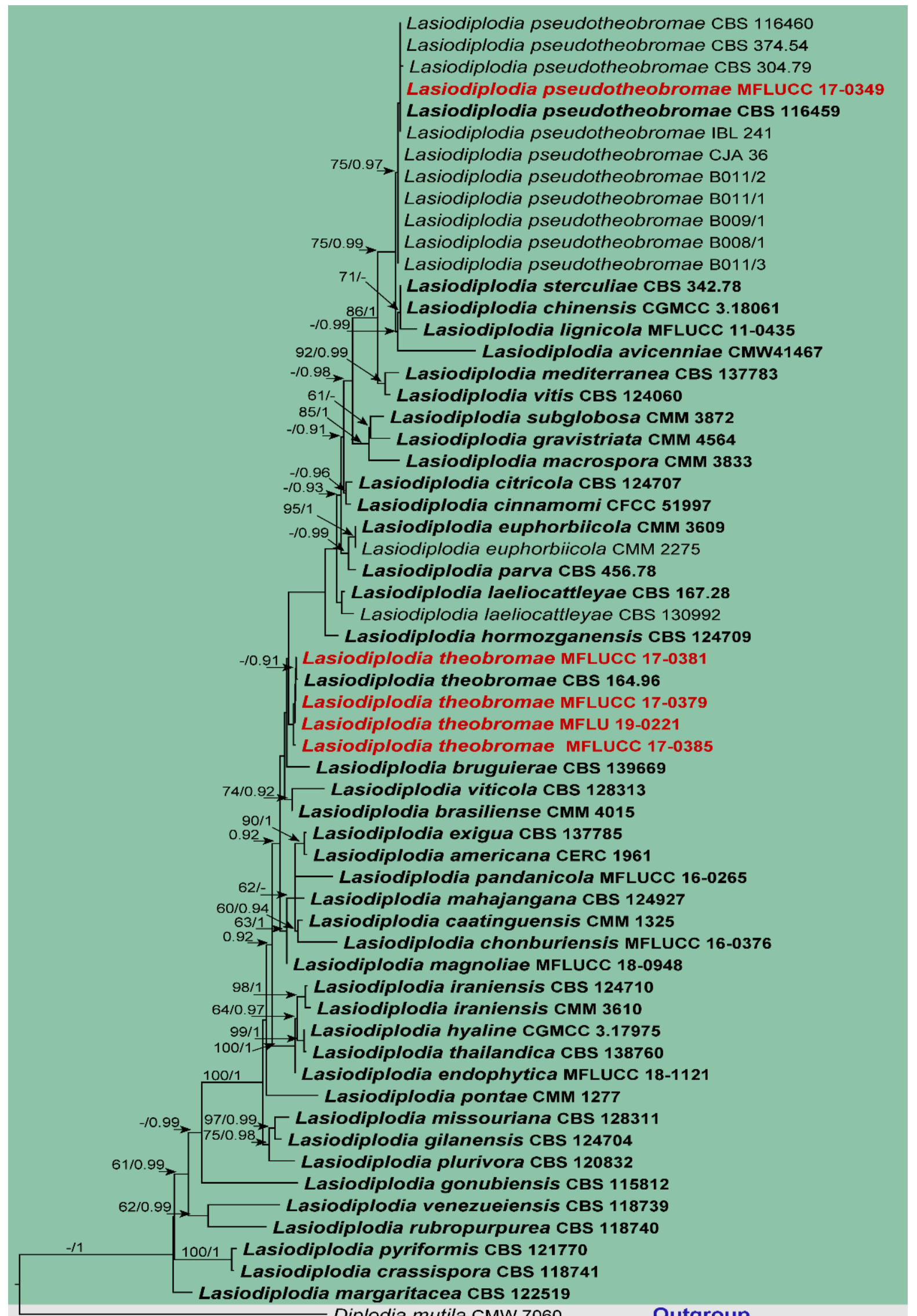
Diplodia mutila CMW 7060

0.02

Figure 1 - RAxML tree of Lasiodiplodia based on analyses of a combined ITS, TEF1 and TUB2 sequence data. Sixty strains are included in the combined sequence analysis, which comprise 1272 characters with gaps. Tree topology of the ML analysis was similar to the BYPP. The best scoring 
RAxML tree with a final likelihood value of -4820.523529 is presented. The matrix had 350 distinct alignment patterns, with $18.51 \%$ of undetermined characters or gaps. Estimated base frequencies were as follows: $\mathrm{A}=0.209484, \mathrm{C}=0.303163, \mathrm{G}=0.256114, \mathrm{~T}=0.231239$; substitution rates: $\mathrm{AC}=1.381847, \mathrm{AG}=3.568230, \mathrm{AT}=1.705303, \mathrm{CG}=1.053067, \mathrm{CT}=$ 5.370543, GT $=1.000000$; gamma distribution shape parameter $\alpha=0.659489$. Bootstrap support values for ML equal to or greater than $60 \%$ and BYPP equal to or greater than 0.90 are defined as ML/BYPP above the nodes. Newly generated sequences are in red bold and type species are in bold. Diplodia mutila (CMW 7060) is used as the outgroup taxon.
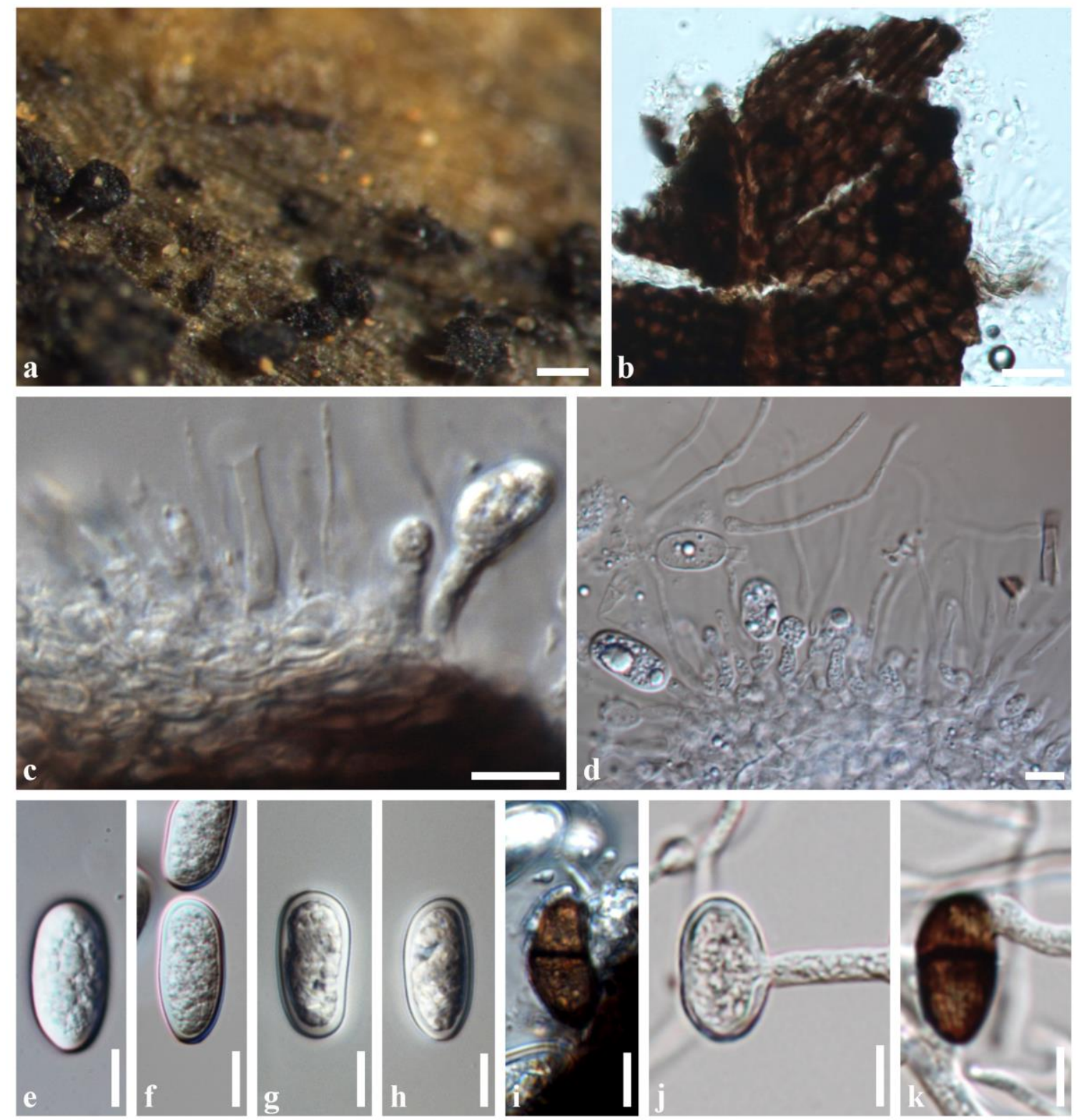

Figure 2 - Lasiodiplodia pseudotheobromae (MFLU 21-0202). a Conidiomata on substrate. b Squash mounts showing the peridium. c, d Paraphyses and conidiogenesis. e-i Conidia. j, k Germinated spores. Scale bar: $\mathrm{a}=200 \mu \mathrm{m}, \mathrm{b}=20 \mu \mathrm{m}, \mathrm{c}-\mathrm{k}=10 \mu \mathrm{m}$.

Lasiodiplodia theobromae (Pat.) Griffon \& Maubl., Bulletin de la Société Mycologique de France 25: 57 (1909) Fig. 3

Index Fungorum number: IF805924

Saprobic on dried petiole, associated with dieback of twig (attached on tree) and stem of Hevea brasiliensis. Sexual morph: Undetermined. Asexual morph: Conidiomata (160-)170- 
$390(-405) \times(155-) 165-300 \mu \mathrm{m}(\bar{x}=263 \times 236.5 \mu \mathrm{m}, \mathrm{n}=19)$, immersed to semi-immersed, becoming raised to erumpent through the host tissue, uni- to multi-locular, solitary to gregarious, globose or subglobose, dark brown to black, with a central ostiole. Peridium 12-66 $\mu \mathrm{m}$ wide, cell of textura angularis, outer layers dark brown to black, inner layers hyaline, thin-walled. Pseudoparaphyses up to 29-70 $\mu \mathrm{m}$ long, 2.7-4 $\mu \mathrm{m}$ wide, hyaline, aseptate, cylindrical, occasionally branched, ends rounded. Conidiophores reduced to conidiogenous cells. Conidiogenous cells 7-15 $\times 2.5-6 \mu \mathrm{m}(\bar{x}=11 \times 4 \mu \mathrm{m}, \mathrm{n}=10)$, holoblastic, hyaline, thin-walled, smooth-walled, cylindrical. Conidia (18-)21-29 × 10.5-14(-17) $\mu \mathrm{m}(\bar{x}=24.5 \times 13 \mu \mathrm{m}, \mathrm{n}=56)$, hyaline, aseptate when immature, medially 1-euseptate, dark brown, thick-walled, ellipsoid to obovoid, base truncate or rounded, with longitudinal striations from apex to base when mature.

Culture characteristics - Conidia germinating on MEA within 24 hours at room temperature and germ tubes produced from apex. Colonies on MEA circular, velvety, moderately fluffy, cultures white at first, becoming greyish white to black.

Material examined - Thailand, Chiang Mai Province, Mueang District, on dried petiole of Hevea brasiliensis (Euphorbiaceae), 22 September 2016, C. Senwanna, RBCM02 (MFLU 190219), living culture MFLUCC 17-0379; ibid., on stem of Hevea brasiliensis (Euphorbiaceae), 22 September 2016, C. Senwanna, RBCM04 (MFLU 19-0221), living culture MFLUCC 17-0381; ibid., on branch (attached to the tree) of Hevea brasiliensis (Euphorbiaceae), 22 September 2016, C. Senwanna, RBCM08 (MFLU 19-0225), living culture MFLUCC 17-0385.

Host and distribution - Wide host range, widely distributed in tropical and subtropical regions.

GenBank number - MFLUCC 17-0379: ITS = OL782125, LSU = OL782047, TEF1 = OL944421, TUB2 = OL840995; MFLU 19-0221: ITS = OL782126; MFLUCC 17-0381: ITS = OL782127; MFLUCC 17-0385: ITS = OL782128, TEF1 = OL944422, TUB2 = OL840996.

Notes - In the BLASTn search, the closest matches to the ITS, TEF1 and TUB2 sequences of our strains with $100 \%$ similarity were Lasiodiplodia theobromae. Lasiodiplodia theobromae is a common opportunistic pathogen that occurs on many host plants (i.e., Myrtaceae, Pinaceae, Proteaceae, Sapotaceae) worldwide and is similar to L. pseudotheobromae in having hyaline, ellipsoid, aseptate conidia, becoming dark brown with a median single septum and having longitudinal striations when mature, but they differ in conidia size (Alves et al. 2008, Trakunyingcharoen et al. 2015b). The species has also been reported as saprobic and pathogenic on Para rubber (Dingley et al. 1981, Saikia 1982, Seephueak et al. 2011). In this study, the phylogenetic analysis shows that four strains MFLUCC 17-0379, MFLUCC 17-0381, MFLUCC 17-0385 and MFLU 19-022 grouped with Lasiodiplodia theobromae (CBS 164.96, type strain) (Fig. 1). The morphology of our strains are also similar to L. theobromae (Griffon \& Maublanc 1909). We, therefore, name our collections as L. theobromae.

Sphaeropsis eucalypticola A.J.L. Phillips, in Phillips et al., Stud. Mycol. 76: 158 (2013) Fig. 5 $\equiv$ Sphaeropsis chromolaenicola Mapook \& K.D. Hyde, in Mapook et al., Fungal Divers. 101: 113 (2020)

Index Fungorum number: IF 805924

Associated with cankers on twig (attached on tree) of Hevea brasiliensis. Sexual morph: Ascomata 200-245 $\times 170-250 \mu \mathrm{m}(\bar{x}=223 \times 212.3 \mu \mathrm{m}, \mathrm{n}=10)$, appearing as black to dark brown spots, solitary or scattered, convex on host tissue, initially immersed in tissue, becoming semiimmersed, globose, coriaceous, with a central ostiole. Peridium 31-40 $\mu \mathrm{m}(\bar{x}=34.4 \mu \mathrm{m}, \mathrm{n}=10)$ wide, cells of textura angularis, dark brown to black. Pseudoparaphyses $3.4-5.8 \mu \mathrm{m}(\bar{x}=4.6 \mu \mathrm{m}, \mathrm{n}$ $=20)$ wide, oblong to cylindrical, septate, constricted at the septum. Asci (52-)70-120(-127.5) $\times$ (12-)19-32(-41) $\mu \mathrm{m}(\bar{x}=90 \times 26.2 \mu \mathrm{m}, \mathrm{n}=19), 8$-spored, bitunicate, fissitunicate, cylindricclavate or clavate, with a short pedicel, apically rounded with an ocular chamber. Ascospores (21.5) 24-30 $(-32) \times 10-15.5 \mu \mathrm{m} \mu \mathrm{m}(\bar{x}=27.5 \times 13 \mu \mathrm{m}, \mathrm{n}=38)$, overlapping biseriate, hyaline to yellowish brown when immature, becoming brown to dark brown when mature, ellipsoid to ovoid, 
aseptate, ends rounded, with an apiculus at each end, widest at the center and tapering towards the narrow ends, with granular appearance. Asexual morph: Undetermined.

Culture characteristics - Ascospores germinating on MEA within 24 hours at room temperature and germ tubes produced from apex. Colonies on MEA circular, velvety, moderately fluffy, cultures white at first, becoming greyish white to dark olivaceous and dark in reverse.

Material examined - Thailand, Phayao Province, Muang District, on twig (attached on tree) of Hevea brasiliensis (Euphorbiaceae), 2 October 2016, C. Senwanna, RBPY05 (MFLU 19-0236), living culture MFLUCC 17-0324 (new host record).

Host and distribution - Bauhinia purpurea (Thailand; Phookamsak et al. 2019), Chromolaena odorata (Thailand; Mapook et al. 2020), Eucalyptus sp. (Thailand; Liu et al. 2012), Hevea brasiliensis (Thailand; this study), Tectona grandis (Thailand; Doilom et al. 2015).

GenBank number - MFLUCC 17-0324: ITS $=$ OL782129, LSU $=$ OL782045, SSU $=$ OL780518, TEF1 = OL944419, TUB2 = OL944406.

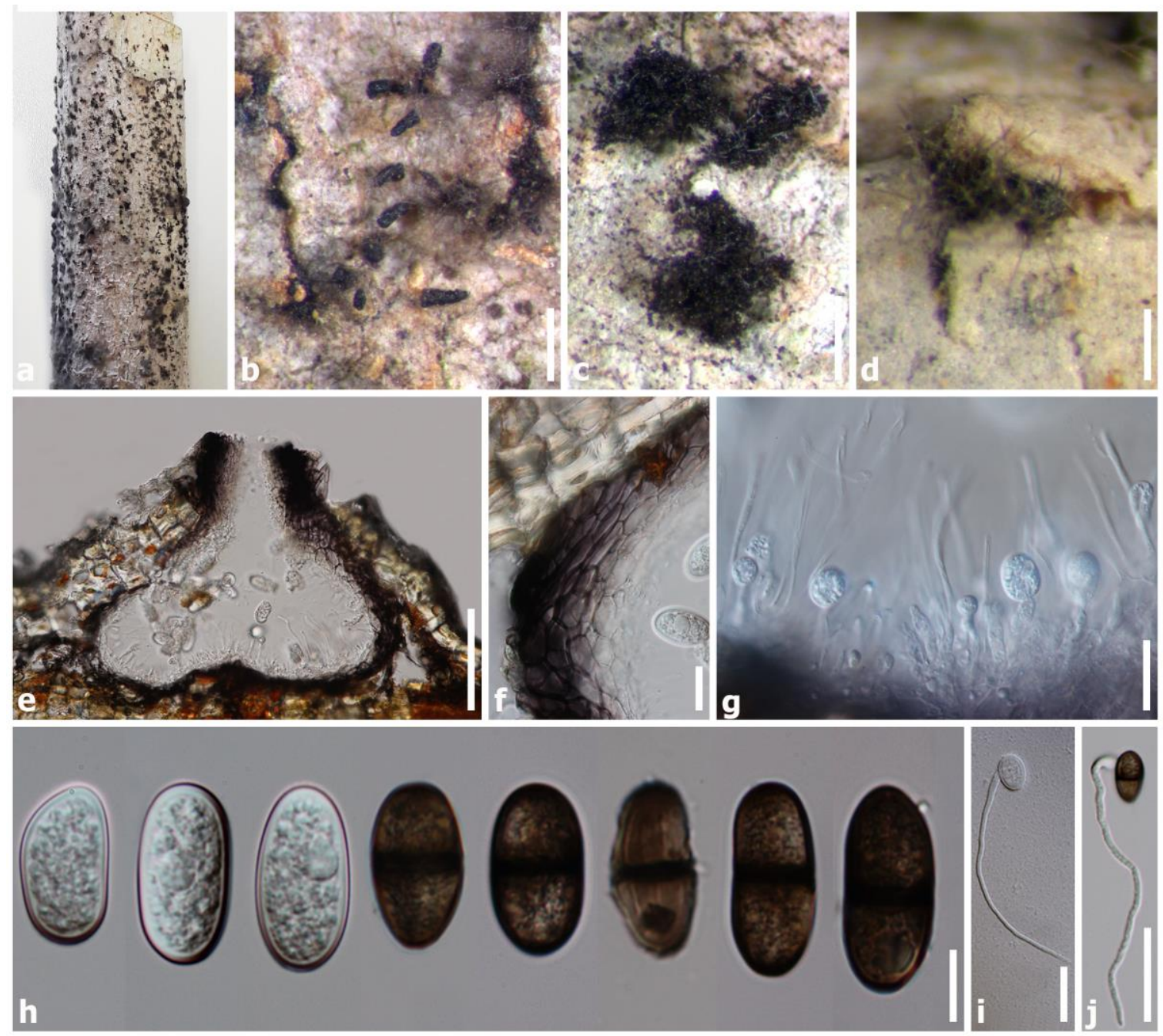

Figure 3 - Lasiodiplodia theobromae (MFLU 19-0225). a Substrate. b-d Conidiomata on the substrate. e Section through the conidioma. f Peridium. g Paraphyses and conidiogenesis. h Conidia. i, j Germinated spores. Scale bars: $\mathrm{a}=500 \mu \mathrm{m}, \mathrm{b}=50 \mu \mathrm{m}, \mathrm{c}-\mathrm{j}=20 \mu \mathrm{m}$.

Notes - Sphaeropsis was introduced by Saccardo (1880b) and characterized by brown, aseptate ascospores with a small apiculus at either end. In the BLASTn search, the closest match to the ITS and LSU sequences with 100\% similarity (MT214366 and MT214460) were $S$. chromolaenicola (MFLUCC 17-1499) and S. eucalypticola (MFLUCC 12-0171; MK108956, CBS 133993; MH866075 and MFLUCC 11-0654; JX646803), while the closest match to TEF1 and 
TUB2 sequences with 100\% (KX646363), and 99.67\% (KX671965) similarity, were $S$. eucalypticola (strain MFLUCC 13-0701). A comparison of the LSU gene region of our strain (MFLUCC 17-0324), S. chromolaenicola (MFLUCC 17-1499, type strain) and S. eucalypticola (MFLUCC 11-0579, type strain) reveals one base pair difference (0.12\%) across 835 nucleotides, while a comparison of the ITS $(+5.8 \mathrm{~S})$ gene region shows that $S$. chromolaenicola is not significantly different from $S$. eucalypticola $(0 / 491 \mathrm{bp})$. In addition, comparison of the TEF1 and TUB2 gene regions show that our strain (MFLUCC 17-0324) is not significantly different from $S$. eucalypticola. However, we could not compare the TEF1 and TUB2 gene region of $S$. chromolaenicola (MFLUCC 17-1499) due to a lack of sequences. We, therefore, synonymized $S$. chromolaenicola as S. eucalypticola based on phylogenetic analyses. Our strain of Sphaeropsis eucalypticola (MFLUCC 17-0324) was isolated from a twig of Hevea brasiliensis. This is wellsupported in the phylogenetic tree (Fig. 4) and in agreement with the type descriptions (Liu et al. 2012). However, the asci of our strain and that of Chromolaena odorata (Mapook et al. 2020) are broader than reported by Liu et al. (2012). This may be due to distribution and morphological variability within the species. Sphaeropsis eucalypticola has been reported from different hosts (Liu et al. 2012, Doilom et al. 2017, Phookamsak et al. 2019, Mapook et al. 2020), but this is the first report from Hevea brasiliensis.

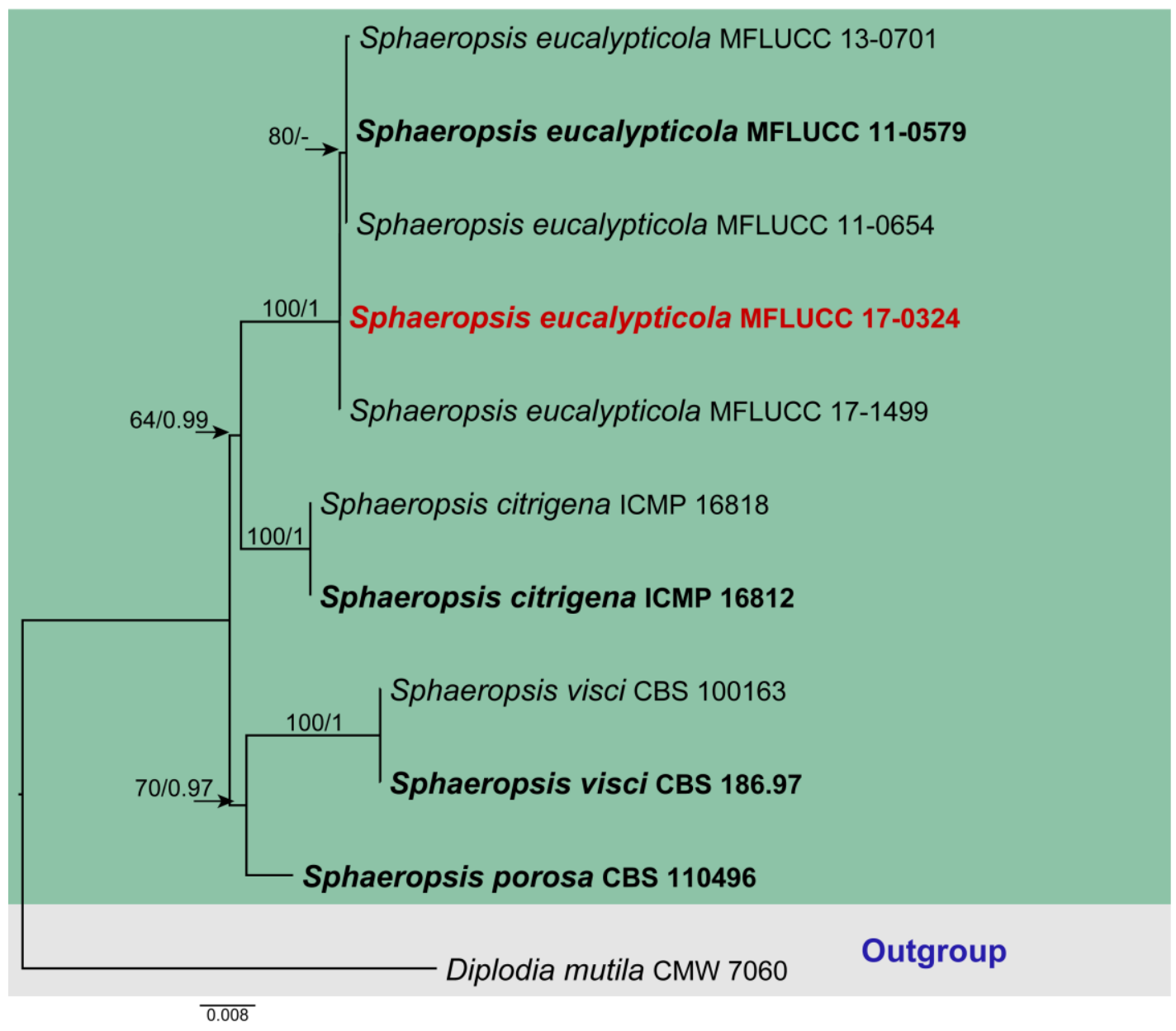

Figure 4 - RAxML tree of Sphaeropsis based on analyses of a combined LSU, ITS, TEF1 and TUB2 sequence data. Eleven strains are included in the combined sequence analysis, which comprise 2175 characters with gaps. Tree topology of the ML analysis was similar to the BYPP. The best scoring RAxML tree with a final likelihood value of -4157.744015 is presented. The matrix had 158 distinct alignment patterns, with $8.88 \%$ of undetermined characters or gaps. Estimated base frequencies were as follows: $\mathrm{A}=0.224679, \mathrm{C}=0.269908, \mathrm{G}=0.285826, \mathrm{~T}=$ 0.219587; substitution rates: $\mathrm{AC}=1.410032, \mathrm{AG}=2.214590, \mathrm{AT}=0.406236, \mathrm{CG}=1.511840, \mathrm{CT}$ 
$=5.536141, \mathrm{GT}=1.000000$; gamma distribution shape parameter $\alpha=2.466509$. Bootstrap support values for ML equal to or greater than $60 \%$ and BYPP equal to or greater than 0.90 are defined as ML/BYPP above the nodes. Newly generated sequences are in red bold and type species are in bold. Diplodia mutila (CMW 7060) is used as the outgroup taxon.
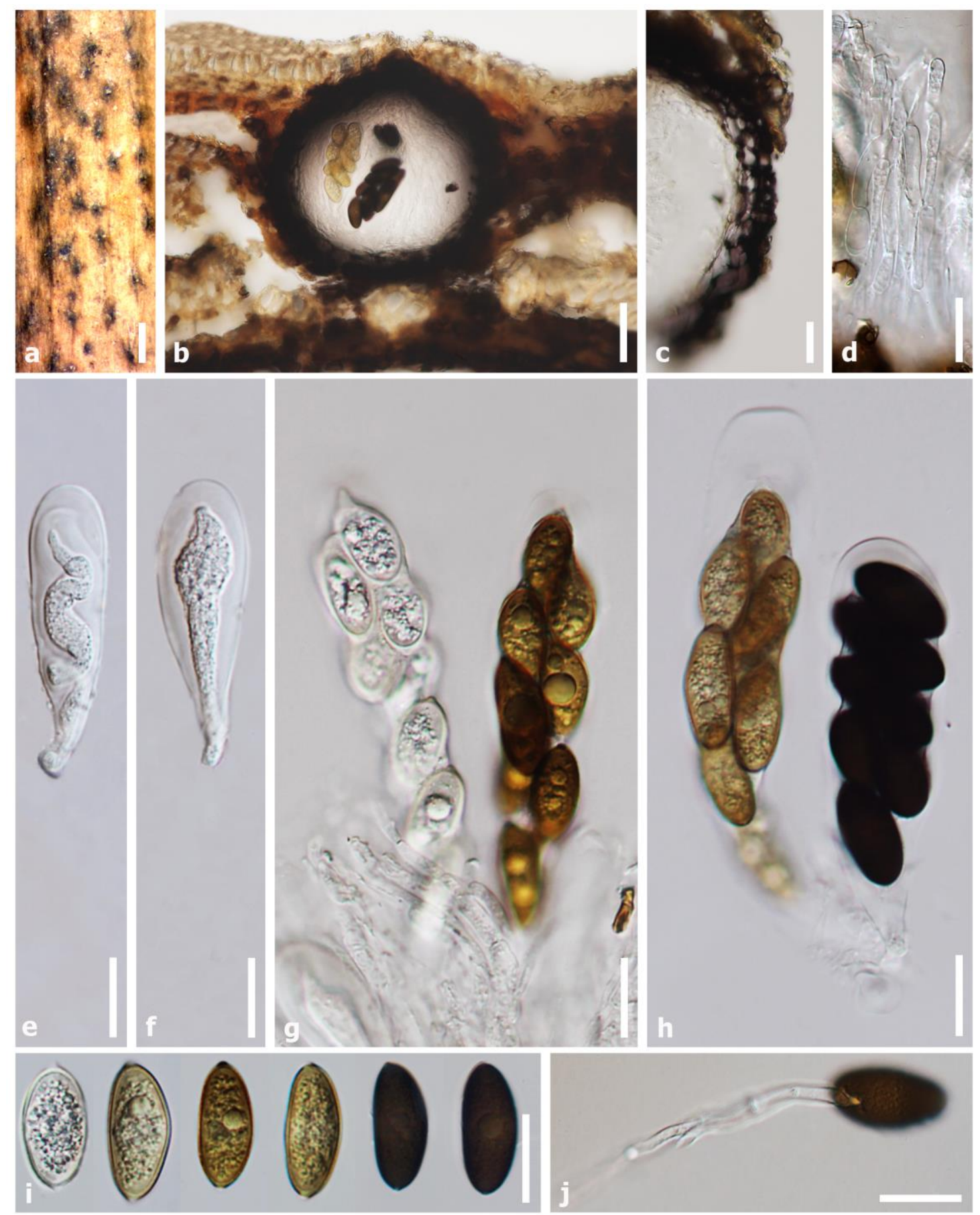

Figure 5 - Sphaeropsis eucalypticola (MFLU 19-0236, new host record). a Habit on substrate. b Section through the ascoma. c Peridium. d Pseudoparaphyses. e-h Asci. i Ascospores. j Germinated spore. Scale bars: $\mathrm{a}=500 \mu \mathrm{m}, \mathrm{b}=50 \mu \mathrm{m}, \mathrm{c}-\mathrm{j}=20 \mu \mathrm{m}$.

\section{Capnodiales Woron.}

Mycosphaerellaceae Lindau

Mycosphaerellaceae is highly diversified in morphology and lifestyles (Videira et al. 2017, 2018). Several genera are economically relevant species causing diseases on a wide range of plants, 
e.g. Pseudocercospora spp. causing sigatoka diseases on banana worldwide, Ps. angolensis causing fruit and leaf spot disease of citrus, Nothopassalora personata causing foliar diseases of groundnut, Cercospora apii causing leaf spot disease of celery (Videira et al. 2017, 2018, Świderska-Burek et al. 2020). Currently, 112 genera and 107 doubtful genera are accepted in the family (Videira et al. 2017, 2018, Hongsanan et al. 2020b). Cercospora is one of the most devastating genera causing diseases on various plant hosts worldwide (Videira et al. 2018, Jayawardena et al. 2020, Meswaet et al. 2021). The genus is characterized by pigmented conidiophores, thickened and darkened conidiogenous loci and conidial hila and hyaline conidia (Groenewald et al. 2013). In this study, Cercospora dioscoreae-pyrifoliae was collected from Para rubber.

Cercospora dioscoreae-pyrifoliae J.M. Yen, Bull. Trimest. Soc. Mycol. Fr. 84: 6 (1968)

Fig. 7 Index Fungorum number: IF327742

Associated with leaf spots of leaves of Hevea basiliensis, distinct, subcircular to circular, pale brown to brown on upper surface with dark brown margin, surrounded by yellowish halo, light brown on lower surface. Sexual morph: Undetermined. Asexual morph: Caespituli epiphyllus, scattered. Stromata substomatal to intraepidermal, dark brown to black, erumpent, $89-118 \mu \mathrm{m}$ diam. giving rise to fascicle of conidiophores (fascicles up to $50 \mu \mathrm{m}$ ). Conidiophores $(27-) 57-75(-$ 86) $\times(3.5-) 4-5 \mu \mathrm{m}(\bar{x}=66 \times 4.7 \mu \mathrm{m}, \mathrm{n}=20), 2-4$-septate, erumpent through the cuticle, pale to medium brown, straight, smooth, wall thin to slightly thickened, unbranched. Conidiogenous cells $(7-) 17-30(-34) \times(3.5-) 4-5.5 \mu \mathrm{m}(\bar{x}=24 \times 4.6 \mu \mathrm{m}, \mathrm{n}=15)$, integrated, terminal, conidiogenous loci conspicuous, 2.5-3(-3.6) $\mu \mathrm{m}$ wide, apical, darkened, thickened. Conidia (40-)63-164(-183) $\times$ (3.5-)4-5 $\mu \mathrm{m}(\bar{x}=114 \times 5 \mu \mathrm{m}, \mathrm{n}=20)$, solitary, hyaline, subcylindrical, straight to slight curved, tapering from the middle of the conidium to an acutely rounded apex, (3-)5-7(-11)-septate, hilum truncate, 2-3 $\mu \mathrm{m}$ wide, thickened and darkened.

Culture characteristics - Conidia germinating on MEA within 24 hours at room temperature and germ tubes produced from every cell of conidium. Colonies on MEA circular, slightly raised, surface smooth with entire edge, whitish grey at the surface with white margin and dark brown from the centre of the colony in reverse with white margin.

Material examined - Thailand, Phayao Province, Muang, on leaf spot of Hevea brasiliensis (Euphorbiaceae), 3 January 2017, C. Senwanna, RBPY24 (MFLU 19-0250), living culture MFLUCC 17-0343) (new host record).

Host and distribution - Dioscorea bulbifera (India; Kamal 2010), D. esculenta (Papua New Guinea; Groenewald et al. 2013), D. pyrifolia (Singapore; Braun et al. 2014), D. tokoro (Japan; Nakashima et al. 2011), D. rotundata (Papua New Guinea; Groenewald et al. 2013), Hevea brasiliensis (Thailand; this study).

GenBank numbers - MFLU 19-0250: ITS = OL782131, TEF1 = OL944424, ACT = OM000383; MFLUCC 17-0343: ITS = OL782130, TEF1 = OL944423, ACT = OM000382.

Notes - In a BLASTn search, the closest matches of the ITS sequences with $100 \%$ similarity were Cercospora glycinicola (CPC 23912; NR_147293), C. belicola (CBS16456; NR_121315), C. corchori (MUCC 585; NR_120172) and C. fagopyri (CBS 132623; NR_147263). The TEF1 sequences were $100 \%$ similar to Cercospora cf. sigesbeckiae (CBS 132641; JX143412), while the ACT sequences were $100 \%$ similar to was C. pileicola (CBS 132607; JC143147). Phylogenetic analyses show that MFLU 19-0250 and MFLUCC 17-0343 grouped with C. dioscoreae-pyrifoliae clade (Fig. 6). The morphology from our collection (MFLU 19-0250) is similar to C. dioscoreaepyrifoliae described by Sivanesan (1985) and Braun et al. (2014). However, our collection has shorter conidiophores $(27-86 \times 3.5-5$ vs $60-150 \times 4-5$ vs $(10-) 40-200 \times 3-7 \mu \mathrm{m})$ and number of septa of conidiophores (2-4 vs $0-3$ vs $0-8$ septate) and conidia $((3-) 5-7(-11)$ vs $2-18$ vs $3-18$ septate). Thus, we name our collection as $C$. dioscoreae-pyrifoliae which is a new host record for Hevea brasiliensis in Thailand.

Dyfrolomycetales K.L. Pang, K.D. Hyde \& E.B.G. Jones

Pleurotremataceae Walt. Watson (= Dyfrolomycetaceae K.D. Hyde et al.) 
Pleurotremataceae comprises three genera viz. Dyfrolomyces, Pleurotrema and Melomastia which have been collected from aquatic, mangrove and terrestrial habitats (Hongsanan et al. 2020a). In this study, a new host record of Dyfrolomyces sinensis collected from Para rubber is reported. Dyfrolomyces was introduced by Pang et al. (2013) to accommodate species having immersed, globose or subglobose, coriaceous, clypeate, ostiolate, papillate ascomata, bitunicate, fissitunicate, cylindrical asci and broadly fusiform, symmetrical, hyaline, septate ascospores, with or without a mucilaginous sheath.

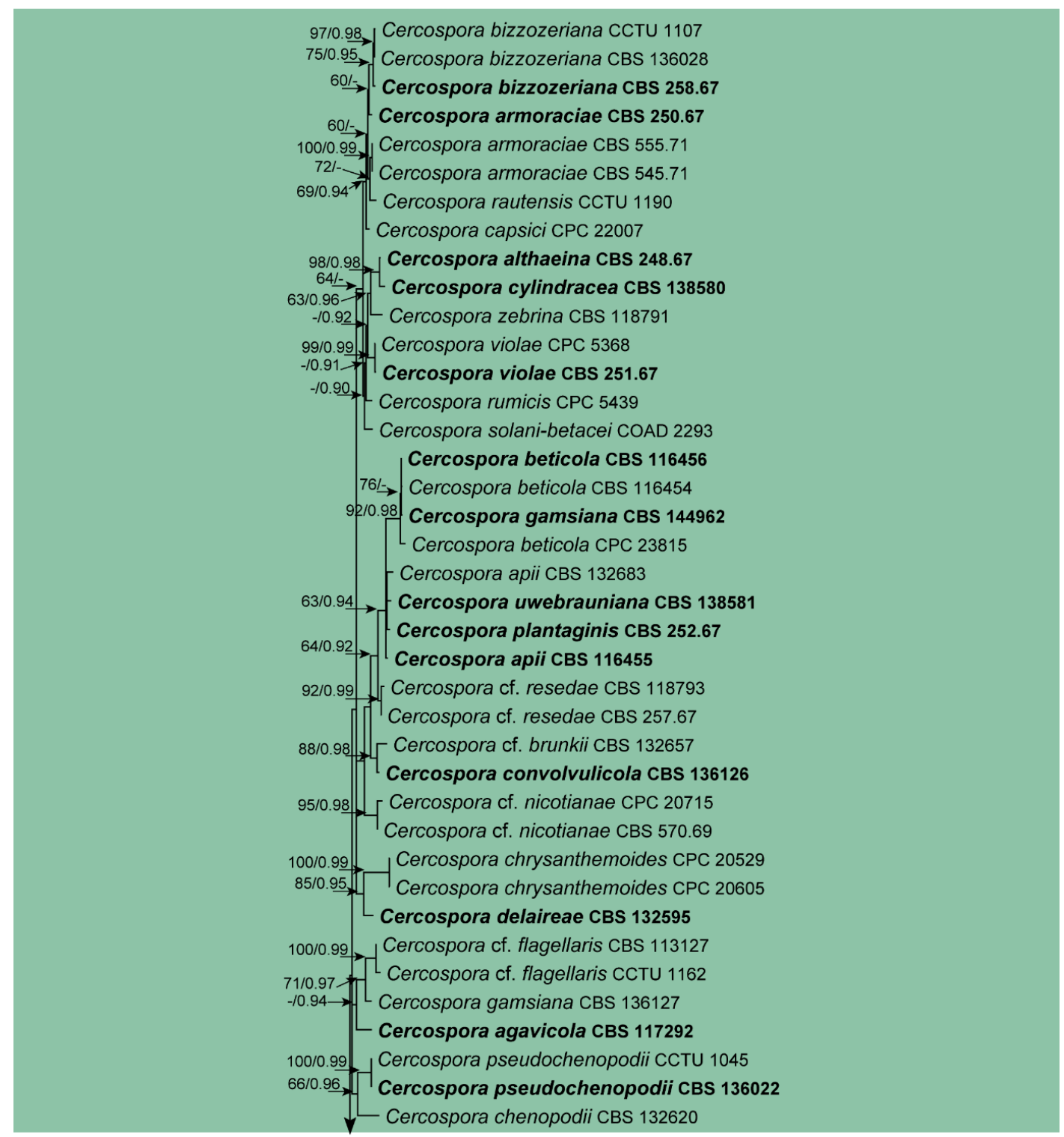

Figure 6 - RAxML tree of Cercospora based on analyses of a combined ITS, TEF1, ACT, CAL and His3 sequence data. Ninety-eight strains are included in the combined sequence analysis, which comprise 1764 characters with gaps. Tree topology of the ML analysis was similar to the BYPP. The best scoring RAxML tree with a final likelihood value of -14889.898786 is presented. The matrix had 675 distinct alignment patterns, with $20.44 \%$ of undetermined characters or gaps. Estimated base frequencies were as follows: $\mathrm{A}=0.230414, \mathrm{C}=0.305071, \mathrm{G}=0.249835, \mathrm{~T}=$ 0.214680; substitution rates: $\mathrm{AC}=1.512332, \mathrm{AG}=3.895838, \mathrm{AT}=1.275323, \mathrm{CG}=1.116955, \mathrm{CT}$ $=5.847230, \mathrm{GT}=1.000000$; gamma distribution shape parameter $\alpha=0.559200$. Bootstrap support values for ML equal to or greater than $60 \%$ and BYPP equal to or greater than 0.90 are defined as ML/BYPP above the nodes. Newly generated sequences are in red bold and type species are in bold. Pseudocercospora chiangmaiensis (AGI094.3 and CBS 123244) are used as outgroup taxa. 


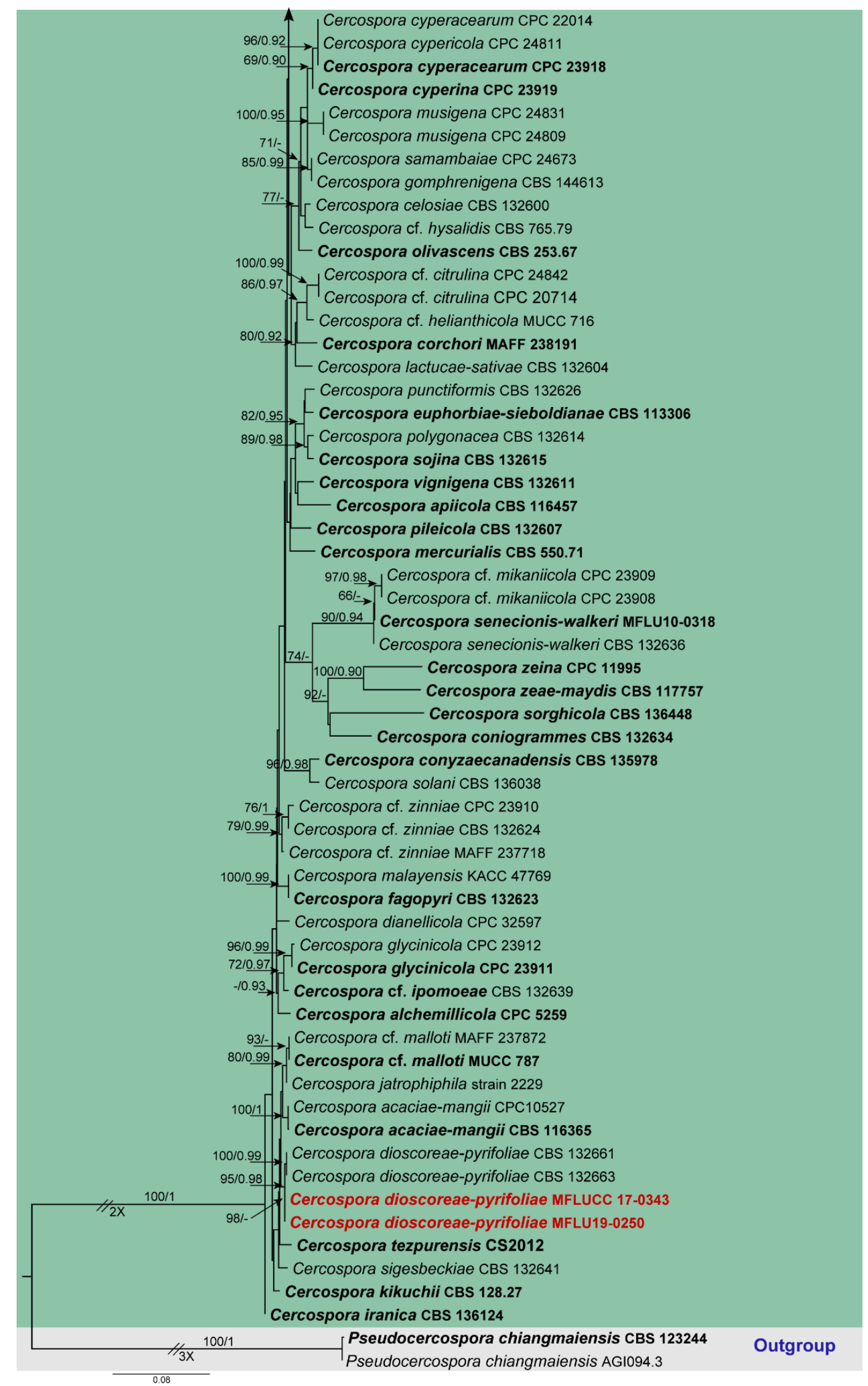

Figure 6 - continued. 

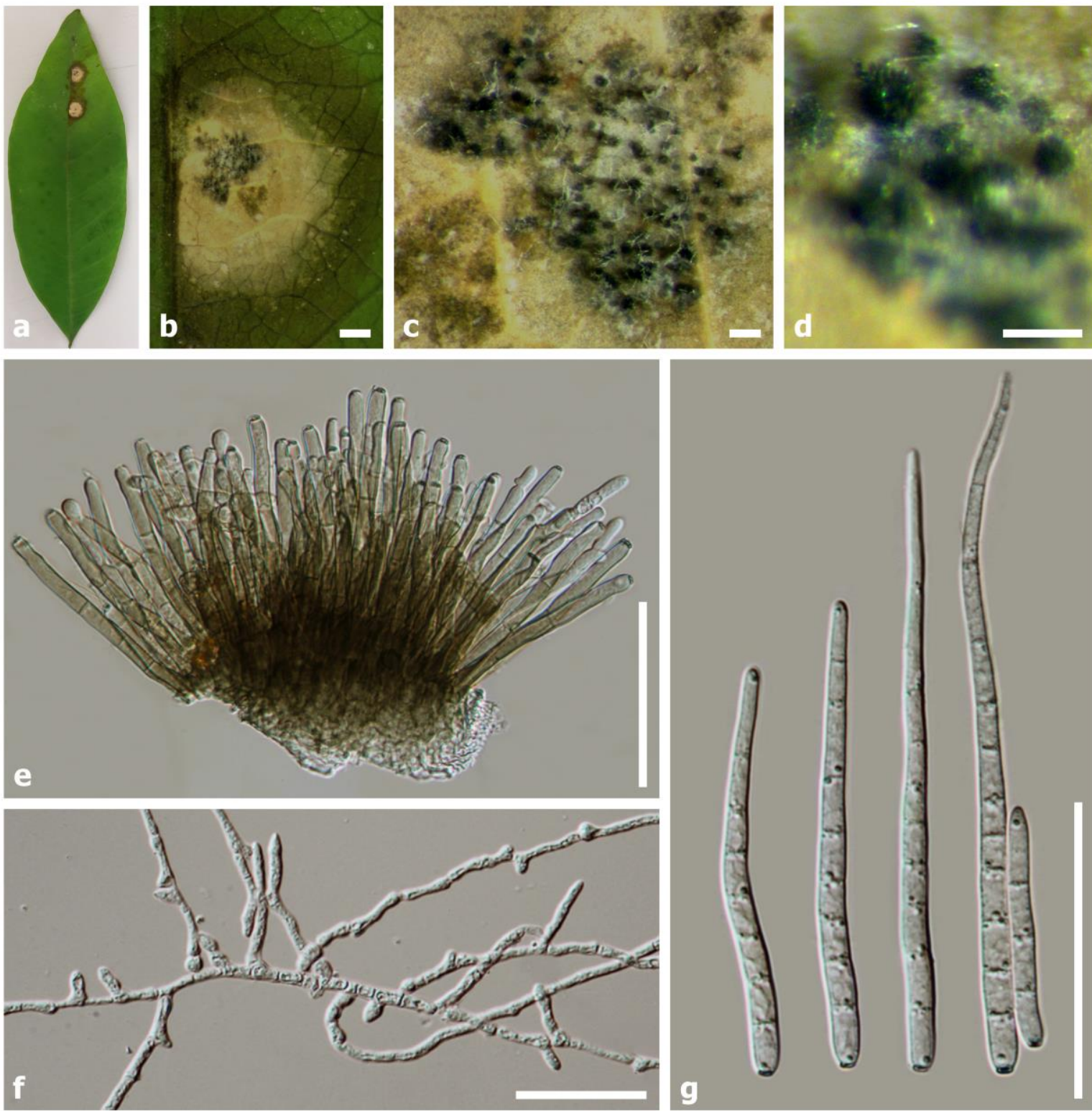

Figure 7 - Cercospora dioscoreae-pyrifoliae (MFLU 19-0250, new host record). a Leaf spots. b-d Close-up lesion with stromata. e Conidiophores. f Germinated spores. g Conidia. Scale bar: b, $\mathrm{d}=100 \mu \mathrm{m}, \mathrm{c}=500 \mu \mathrm{m}, \mathrm{e}, \mathrm{g}=50 \mu \mathrm{m}, \mathrm{f}=30 \mu \mathrm{m}$.

Dyfrolomyces sinensis Samarak., Tennakoon \& K.D. Hyde, in Hyde et al., Mycosphere 9(2): 354 (2018)

Index Fungorum number: IF554110

Fig. 9

Saprobic on branch of Hevea brasiliensis. Sexual morph: Ascomata up to $570 \mu \mathrm{m}$ diam. $\times$ $590 \mu \mathrm{m}$ high, solitary, immersed, globose to subglobose, dark brown to black, ostiolate. Peridium 40-76 $\mu \mathrm{m}(\bar{x}=55.6 \mu \mathrm{m}, \mathrm{n}=15)$ wide, composed of cells of textura angularis, outer layers dark brown to black, thick-walled, inner layers thin-walled. Pseudoparaphyses $2.2-5 \mu \mathrm{m} \mu \mathrm{m}(\bar{x}=3.5$ $\mu \mathrm{m}, \mathrm{n}=20)$ wide, numerous, hyaline, septate, embedded in a gelatinous matrix. Asci (123-)145$214(-230) \times 6-11 \mu \mathrm{m}(\bar{x}=181.7 \times 8.6 \mu \mathrm{m}, \mathrm{n}=30), 8$-spored, bitunicate, cylindrical, shortpedicellate, with a thickened apex. Ascospores $(15-) 17-24(-27) \times 5-8 \mu \mathrm{m}(\bar{x}=21 \times 6.4 \mu \mathrm{m}, \mathrm{n}=$ 50), uniseriate, hyaline, ellipsoid, pointed at the ends, cylindrical, mostly 5-7-septate, with several small guttules, slightly constricted at septa when mature. Asexual morph: Undetermined.

Culture characteristics - Ascospores germinating on MEA within 24 hours at room temperature and germ tubes produced from one or both ends. Colonies on MEA circular, mycelium 
slightly raised, entire, cultures white at first, becoming greyish white from the centre with dark brown margin from above, with dark brown aerial mycelium and dark brown to black in reverse with dark brown aerial mycelium.

Material examined - Thailand, Chiang Rai Province, Wiang Chiang Rung District, on branch of Hevea brasiliensis (Euphorbiaceae), 1 November 2016, C. Senwanna, RBCR20 (MFLU 190232), living culture MFLUCC 17-2606 (new host record).

Host and distribution - Camellia sinensis (Thailand; Hyde et al. 2018), Hevea brasiliensis (Thailand; this study).

GenBank numbers - MFLUCC 17-2606: ITS = OL782132, LSU = OL782048, TEF1 = OL875098.

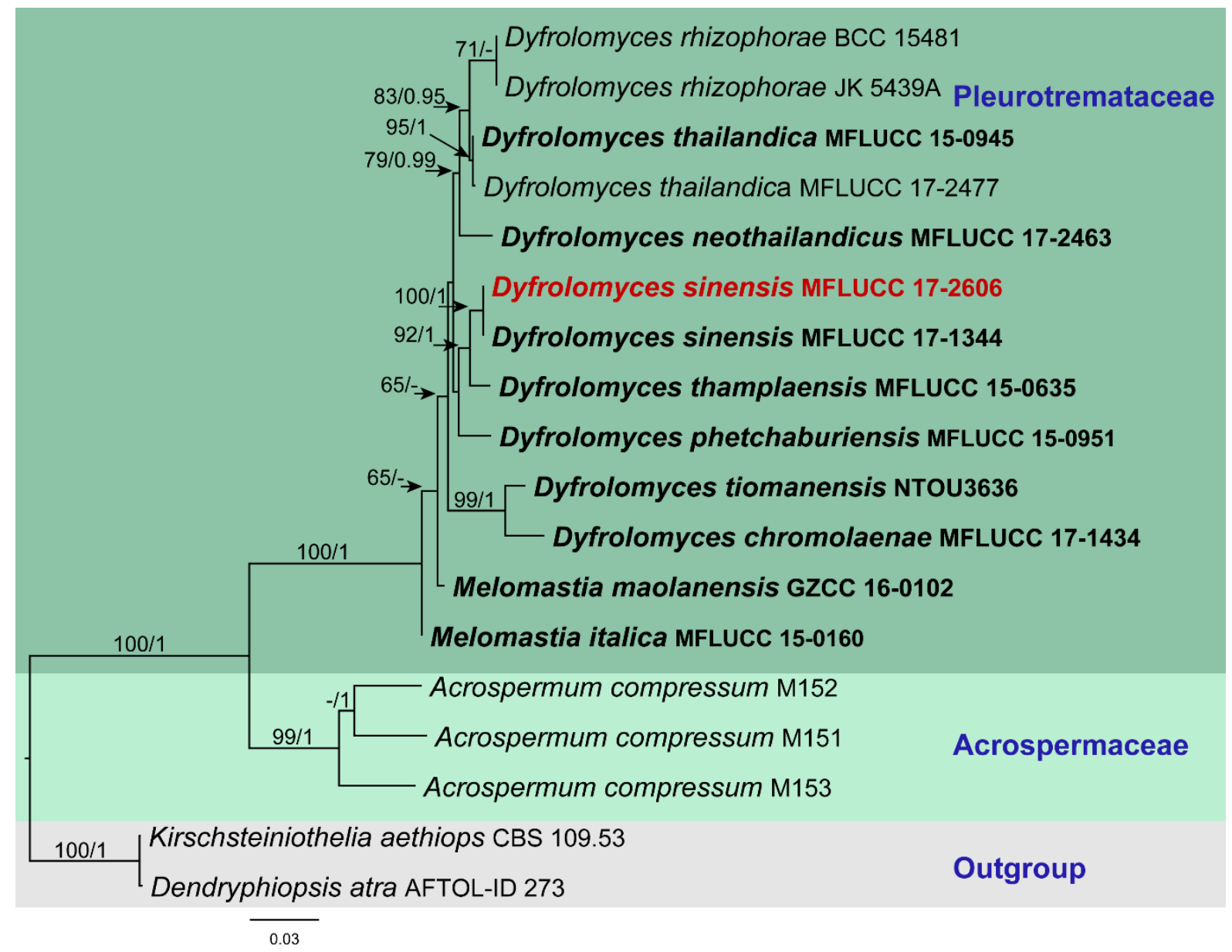

Figure 8 - RAxML tree of Dyfrolomyces based on analyses of a combined ITS, and SSU sequence data. Eighteen strains are included in the combined sequence analysis, which comprise 1974 characters with gaps. Tree topology of the ML analysis was similar to the BYPP. The best scoring RAxML tree with a final likelihood value of -6132.007847 is presented. The matrix had 413 distinct alignment patterns, with $16.04 \%$ of undetermined characters or gaps. Estimated base frequencies were as follows: $\mathrm{A}=0.246371, \mathrm{C}=0.237857, \mathrm{G}=0.301813, \mathrm{~T}=0.213958$; substitution rates: $\mathrm{AC}=1.102533, \mathrm{AG}=3.032887, \mathrm{AT}=0.905777, \mathrm{CG}=1.489388, \mathrm{CT}=$ 8.402890, GT $=1.000000$; gamma distribution shape parameter $\alpha=0.971894$. Bootstrap support values for ML equal to or greater than $60 \%$ and BYPP equal to or greater than 0.90 are defined as ML/BYPP above the nodes. Newly generated sequences are in red bold and type species are in bold. Dendryphiopsis atra (AFTOL-ID 273) and Kirchsteiniothelis aethiops (CBS 109.53) are used as outgroup taxa.

Notes - A phylogenetic analysis based on a combined dataset of LSU, SSU and TEF1 sequence data shows that our strain (MFLUCC 17-2606) groups with Dyfrolomyces sinensis with 
100\% ML statistical support (Fig. 8). In a BLASTn search, the closest match of LSU sequences with 97.29\% similarity was D. neothailandicus (MFLU 17-2589; MN017857). The morphology of our collection (MFLU 19-0232) is similar to the holotype from Camellia sinensis (Hyde et al. $2018)$ in having a similar shape and size of asci $(123-230 \times 6-11$ vs $160-220 \times 8-10)$ and ascospores $(15-27) \times 5-8 \mu \mathrm{m}$ vs $18-30 \times 5-8)$. We report our collection as a new host record of Dyfrolomyces sinensis from Hevea brasiliensis.

\section{Hysteriales Lindau \\ Hysteriaceae Chevall.}

Hongsanan et al. (2020b) accepted Actidiographium, Gloniella, Gloniopsis, Hysterium, Hysterobrevium, Hysterocarina, Hysterodifractum, Hysteroglonium, Oedohysterium, Ostreichnion, Pseudoscypha, Psiloglonium and Rhytidhysteron in Hysteriaceae. In the present study, Gloniopsis leucaenae, Rhytidhysteron neorufulum and Rhytidhysteron tectonae is documented with a description and illustrations (Fig. 10).

Gloniopsis leucaenae Jayasiri, E.B.G. Jones \& K.D. Hyde, Mycosphere 10 (1): 16 (2019) Fig. 11 Index Fungorum number: IF555527

Saprobic on branches of Hevea brasiliensis. Sexual morph: Hysterothecia 740-2140 $\mu \mathrm{m} \times$ 115-184 $\mu \mathrm{m} \times 152-176 \mu \mathrm{m}(\bar{x}=1283 \times 147 \times 168 \mu \mathrm{m}, \mathrm{n}=10)$, navicular, black, with tapered ends, semi-immersed to superficial, scattered, straight or irregularly curved, with a prominent longitudinal slit. Peridium 20-37 $\mu \mathrm{m},(\bar{x}=27, \mathrm{n}=10)$ wide, composed of cells of textura angularis, outer dark brown to black, thick-walled, inner layer hyaline, thin-walled. Pseudoparaphyses 1.2$2.8 \mu \mathrm{m}(\bar{x}=1.85, \mathrm{n}=15)$ wide, hyaline, dense, septate, branched, filiform. Asci (56-) 60-76 (-117) $\times 13-17(-19) \mu \mathrm{m}(\bar{x}=71.5 \times 16.3 \mu \mathrm{m}, \mathrm{n}=13), 8$-spored, bitunicate, subcylindrical to cylindrical, with a short pedicel, apically rounded, sometimes without a distinct ocular chamber. Ascospores $17-22(-26) \times(5-) 7-19 \mu \mathrm{m}(\bar{x}=20 \times 7.5 \mu \mathrm{m}, \mathrm{n}=30)$, biseriate to crowded, hyaline, subglobose and 1-septate when immature, becoming pale brown to dark brown, 7-11 transverse and 1-2 vertical septa, dictyospore, constricted at the central septa, slightly asymmetric in outline, smoothwalled when mature. Asexual morph: Undetermined.

Culture characteristics - Ascospores germinating on MEA within 24 hours at room temperature and germ tubes produced from end of ascospores. Colonies on MEA circular, mycelium slightly raised, fluffy, entire, cultures whitish grey to grey at the surface from the center of the colony at the surface with white margin, dark brown from the center of the colony in reverse with white margin.

Material examined - Thailand, Phayao Province, Muang District, on branch of Hevea brasiliensis (Euphorbiaceae), 3 January 2017, C. Senwanna, RBPY31 (MFLU 21-0201), living culture MFLUCC 17-0348 (new host record and sexual morph record).

Host and distribution - Leucaena sp. (Fabaceae) (Thailand; Jayasiri et al. 2019), Hevea brasiliensis (Thailand; this study).

GenBank numbers - MFLUCC 17-0348: ITS = OL782133, LSU = OL782049, SSU = OL780519, TEF1 = OL875099; MFLU 21-0201: ITS = OL782134, LSU = OL782050, SSU = OL780520, TEF1 = OL875100.

Notes - In a BLASTn search of NCBI GenBank, the closest match to the LSU and TEF1 sequences with 99.88\% (KX646363), and 98.42\% (KX671965) similarity were G. calami, while the closest match of the ITS sequences with $100 \%$ (MK347750) was G. leucaenae. In the present phylogenetic analysis, our strains (MFLUCC 17-0348 and MFLU 21-0201) clustered with $G$. leucaenae (MFLUCC 17-2425) with 100\% ML/1 PP support (Fig. 10). However, we could not compare the morphological characteristics of our strains with those of G. leucaenae, which is only known as an asexual morph species with isolates from Leucaena sp. (Jayasiri et al. 2019), while our strain is found as a sexual morph in nature, and we could not obtain its asexual morph in culture. Gloniopsis was introduced by Boehm et al. (2009) and is characterized by dictyospores, hyaline to yellow ascospores, multi-septate, with one or more longitudinal septa. The morphology of our 
collection (MFLU 21-0201, Fig 11) is similar to the description by Boehm et al. (2009) in having dictyospores, hyaline to yellow ascospores, multi-septate, with one or more longitudinal septa. We, therefore, name our collection as G. leucaenae and this is the first report of the sexual morph of $G$. leucaenae.
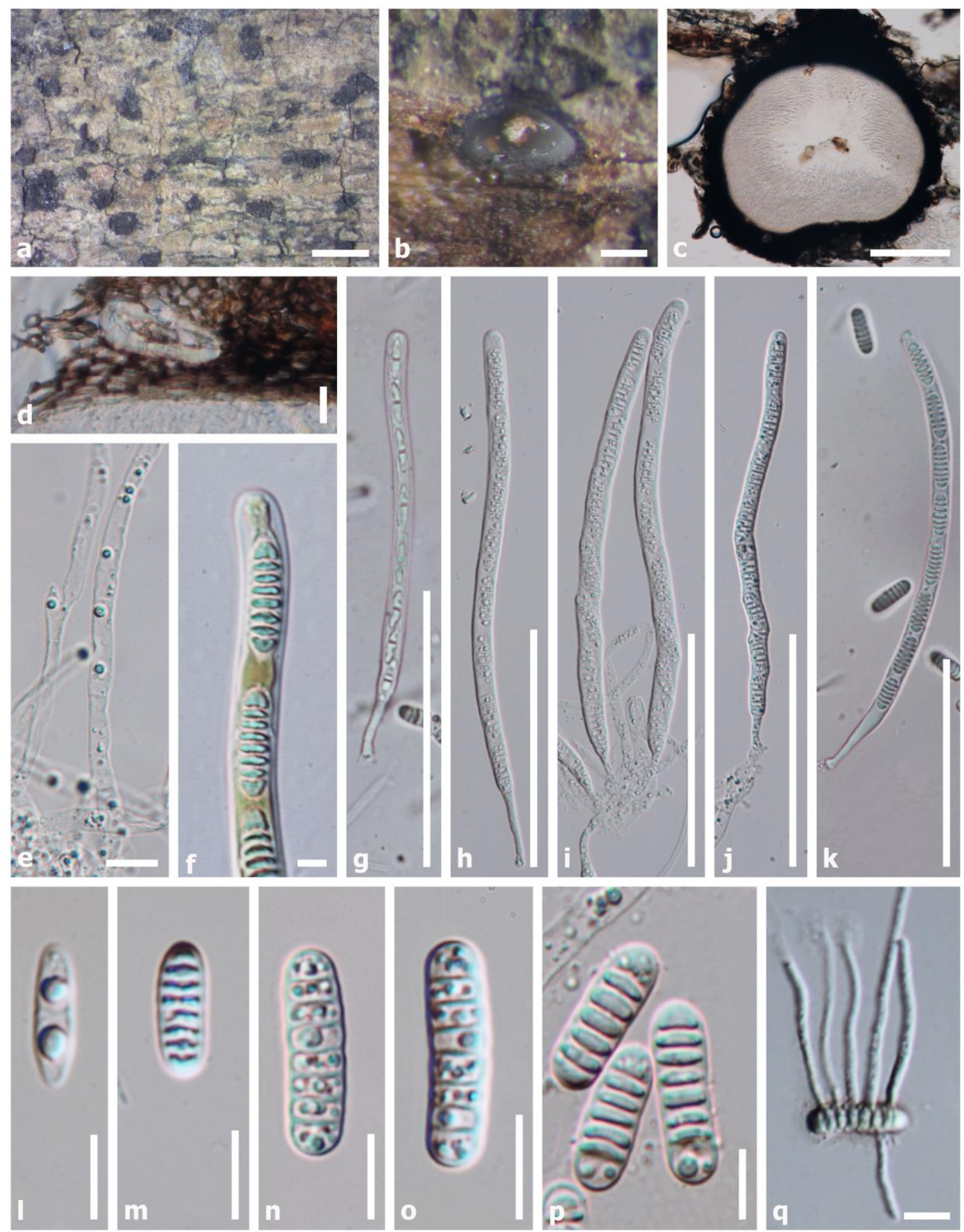

Figure 9 - Dyfrolomyces sinensis (MFLU 19-0232, new host record). a, b Ascomata on the host surface. c Vertical section through ascoma. d Peridium. e Pseudoparaphyses. f Apex of an ascus (mounted in Melzer's reagent). g-k Asci. l-p Ascospores. q Germinating ascospore. Scale bars a $=$ $1000 \mu \mathrm{m}, \mathrm{b}-\mathrm{c}=500 \mu \mathrm{m}, \mathrm{d}-\mathrm{f}, \mathrm{l}-\mathrm{q}=10 \mu \mathrm{m}, \mathrm{g}-\mathrm{k} 10 \mu \mathrm{m}$. 


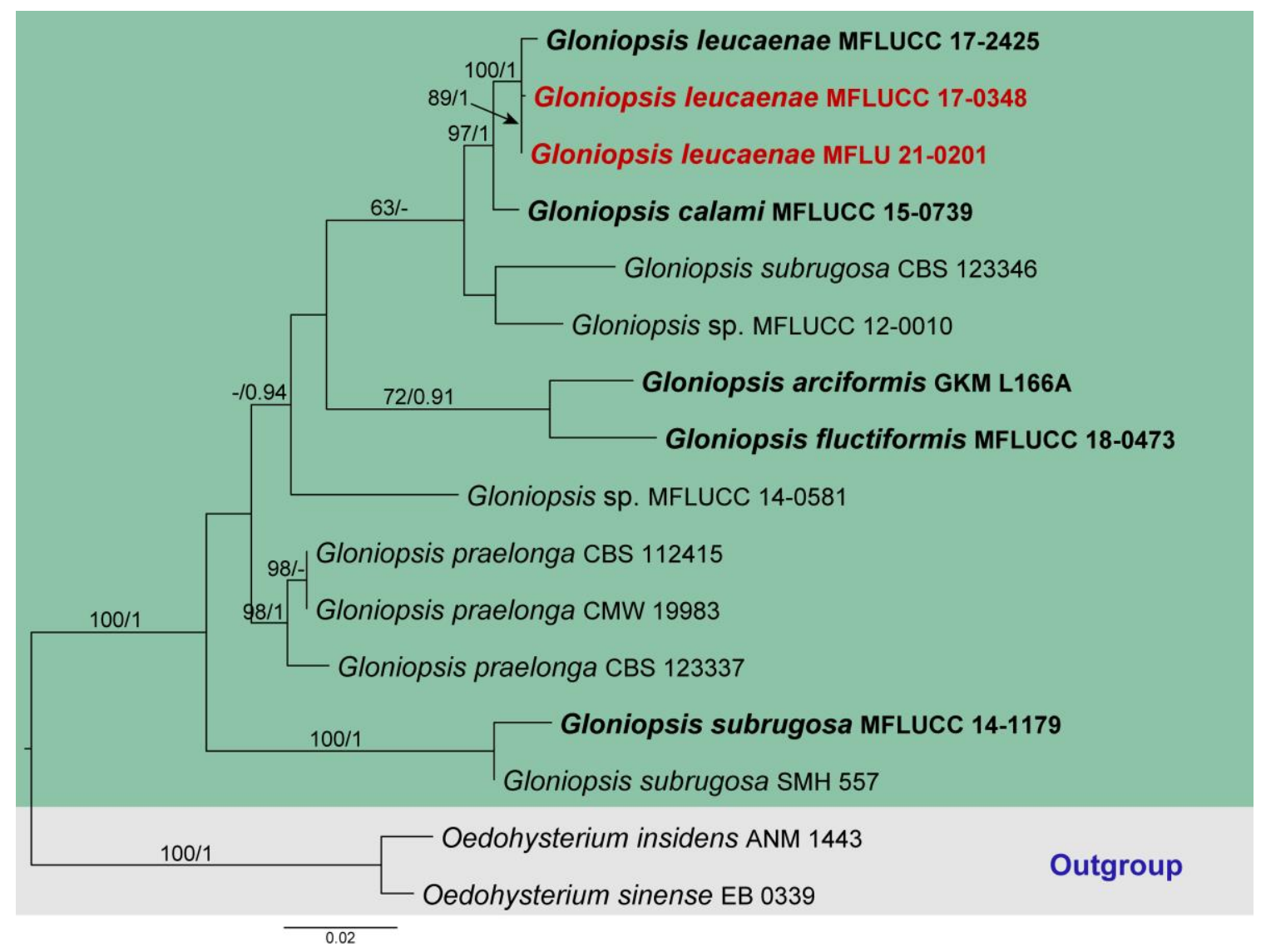

Figure 10 - RAxML tree of Gloniopsis based on analyses of a combined LSU, SSU, ITS and TEF1 sequence data. Sixteen strains are included in the combined sequence analysis, which comprise 3676 characters with gaps. Tree topology of the ML analysis was similar to the BYPP. The best scoring RAxML tree with a final likelihood value of -8764.622064 is presented. The matrix had 455 distinct alignment patterns, with $31.40 \%$ of undetermined characters or gaps. Estimated base frequencies were as follows: $\mathrm{A}=0.243241, \mathrm{C}=0.240094, \mathrm{G}=0.279186, \mathrm{~T}=0.237479$; substitution rates: $\mathrm{AC}=1.224503, \mathrm{AG}=2.349991, \mathrm{AT}=0.958589, \mathrm{CG}=0.597298, \mathrm{CT}=$ 8.026386, GT $=1.000000$; gamma distribution shape parameter $\alpha=0.661483$. Bootstrap support values for ML equal to or greater than $60 \%$ and BYPP equal to or greater than 0.90 are defined as ML/BYPP above the nodes. Newly generated sequences are in red bold and type species are in bold. Oedohysterium insidens (ANM 1443) and O. sinense (EB 0339) are used as outgroup taxa.

Rhytidhysteron neorufulum Thambug. \& K.D. Hyde, in Thambugala, Hyde, Eungwanichayapant, Romero \& Liu, Cryptog. Mycol. 37(1): 110 (2016)

Index Fungorum number: IF551865

Saprobic on branches and stems of Hevea brasiliensis. Sexual morph: Hysterothecia 1470 $2786 \times 480-715 \times 414-724 \mu \mathrm{m}(\bar{x}=2113 \times 592 \times 561 \mu \mathrm{m}, \mathrm{n}=15)$, navicular, black, with tapered ends, solitary to aggregated, semi-immersed to superficial, straight or irregularly curved, with a prominent longitudinal slit. Exciple 46-94 $\mu \mathrm{m},(\bar{x}=70.5, \mathrm{n}=18)$, composed of cells of textura angularis, outer brown to dark brown, thick-walled, inner layer hyaline, thin-walled. Pseudoparaphyses 1.5-2.7 $\mu \mathrm{m}(\bar{x}=2, \mathrm{n}=16)$ wide, dense, hyaline, septate, filiform, forming light brown to yellow epithecium above the asci and enclosed in a gelatinous matrix. Asci (154.5-)163$209(-215) \times 9-14(-16) \mu \mathrm{m}(\bar{x}=190 \times 13 \mu \mathrm{m}, \mathrm{n}=20), 8$-spored, bitunicate, subcylindrical to cylindrical, pedicellate, apically rounded, sometimes without a distinct ocular chamber. Ascospores $(21-) 24-31 \times 8-12 \mu \mathrm{m}(\bar{x}=27.3 \times 10.1 \mu \mathrm{m}, \mathrm{n}=42)$, uni-seriate, slightly overlapping, hyaline to pale brown, subglobose, 1-septate when immature, pale brown to dark brown, ellipsoidal to 
fusiform, 2-3-septate, slightly rounded or pointed at both ends, constricted at the central septum, smooth-walled when mature. Asexual morph: Undetermined.

Culture characteristics - Ascospores germinating on MEA within 24 hours at room temperature and germ tubes produced from end of ascospores. Colonies on MEA circular, mycelium slightly raised, fluffy, entire, cultures white at the surface and creamy-white from the centre of the colony in reverse with white margin.
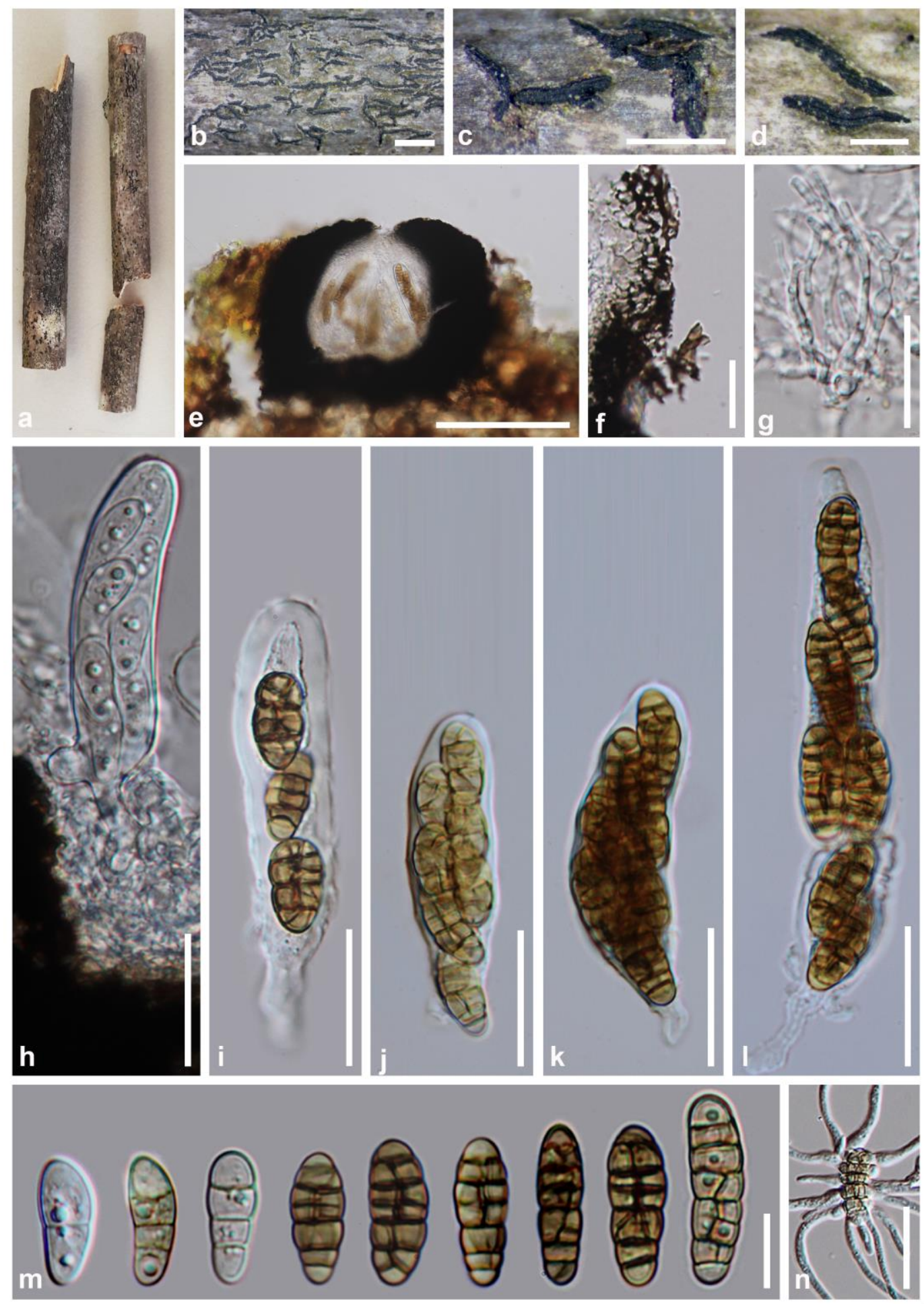

Figure 11 - Gloniopsis leucaenae (MFLU 21-0201, new host record and sexual morph record). a Substrate. b-d Ascomata on the host surface. e Section through the ascoma. f Peridium. g Pseudoparaphyses. $\mathrm{h}-1$ Asci. $\mathrm{m}$ Ascospores. $\mathrm{n}$ Germinated ascospore. Scale bars: $\mathrm{b}=1000 \mu \mathrm{m}$, $\mathrm{c}-\mathrm{d}=500 \mu \mathrm{m}, \mathrm{e}=100 \mu \mathrm{m}, \mathrm{f}=20 \mu \mathrm{m}, \mathrm{g}, \mathrm{m}, \mathrm{n}=10 \mu \mathrm{m}, \mathrm{h}-\mathrm{l}=10 \mu \mathrm{m}$. 
Material examined - Thailand, Phayao Province, Muang District, on stem of Hevea brasiliensis (Euphorbiaceae), 2 October 2016, C. Senwanna, RBPY01 (MFLU 19-0233), living culture MFLUCC 17-0321), RBPY02 (MFLU 19-0234); ibid, Chiang Rai Province, Wiang Chiang Rung District, on branches of Hevea brasiliensis (Euphorbiaceae), 1 November 2016, C. Senwanna, RBCR04 (MFLU 19-0226), living culture MFLUCC 17-0370.

Host and distribution - undetermined hosts (Brazil; Almeida et al. 2014, Europe, Ghana; Boehm et al. (2009), undetermined dead stem (Thailand; Thambugala et al. 2016), Hevea brasiliensis (Thailand; Huanraluek et al. 2020, this study).

GenBank numbers - MFLUCC 17-0321: ITS = OL782135, LSU = OL782051, SSU = OL780521; MFLU 19-0234: ITS = OL782136, LSU = OL782052; MFLUCC 17-0370: ITS = OL782137, LSU = OL782053, SSU = OL780522.

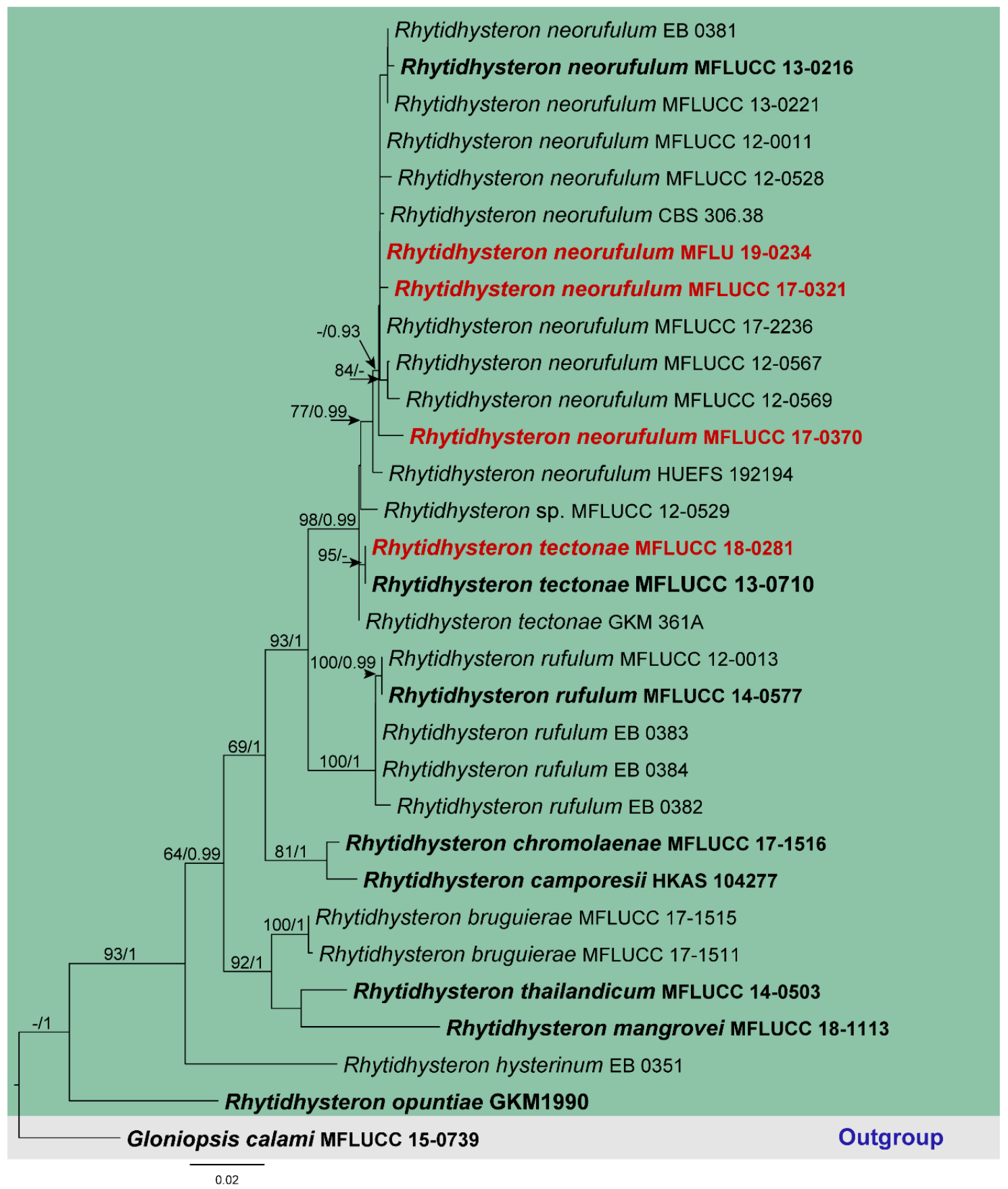

Figure 12 - RAxML tree of Rhytidhysteron based on analyses of a combined LSU, SSU, ITS and TEF1 sequence data. Thirty-one strains are included in the combined sequence analysis, which comprise 3558 characters with gaps. Tree topology of the ML analysis was similar to the BYPP. 
The best scoring RAxML tree with a final likelihood value of -8867.131361 is presented. The matrix had 599 distinct alignment patterns, with $36.56 \%$ of undetermined characters or gaps. Estimated base frequencies were as follows: $\mathrm{A}=0.243152, \mathrm{C}=0.241115, \mathrm{G}=0.281797, \mathrm{~T}=$ 0.233935; substitution rates: $\mathrm{AC}=1.671070, \mathrm{AG}=2.409632, \mathrm{AT}=1.117689, \mathrm{CG}=0.930433, \mathrm{CT}$ $=7.216656, \mathrm{GT}=1.000000$; gamma distribution shape parameter $\alpha=0.492267$. Bootstrap support values for ML equal to or greater than $60 \%$ and BYPP equal to or greater than 0.90 are defined as ML/BYPP above the nodes. Newly generated sequences are in red bold and type species are in bold. Gloniopsis calami (MFLUCC 15-0739) is used as the outgroup taxon.
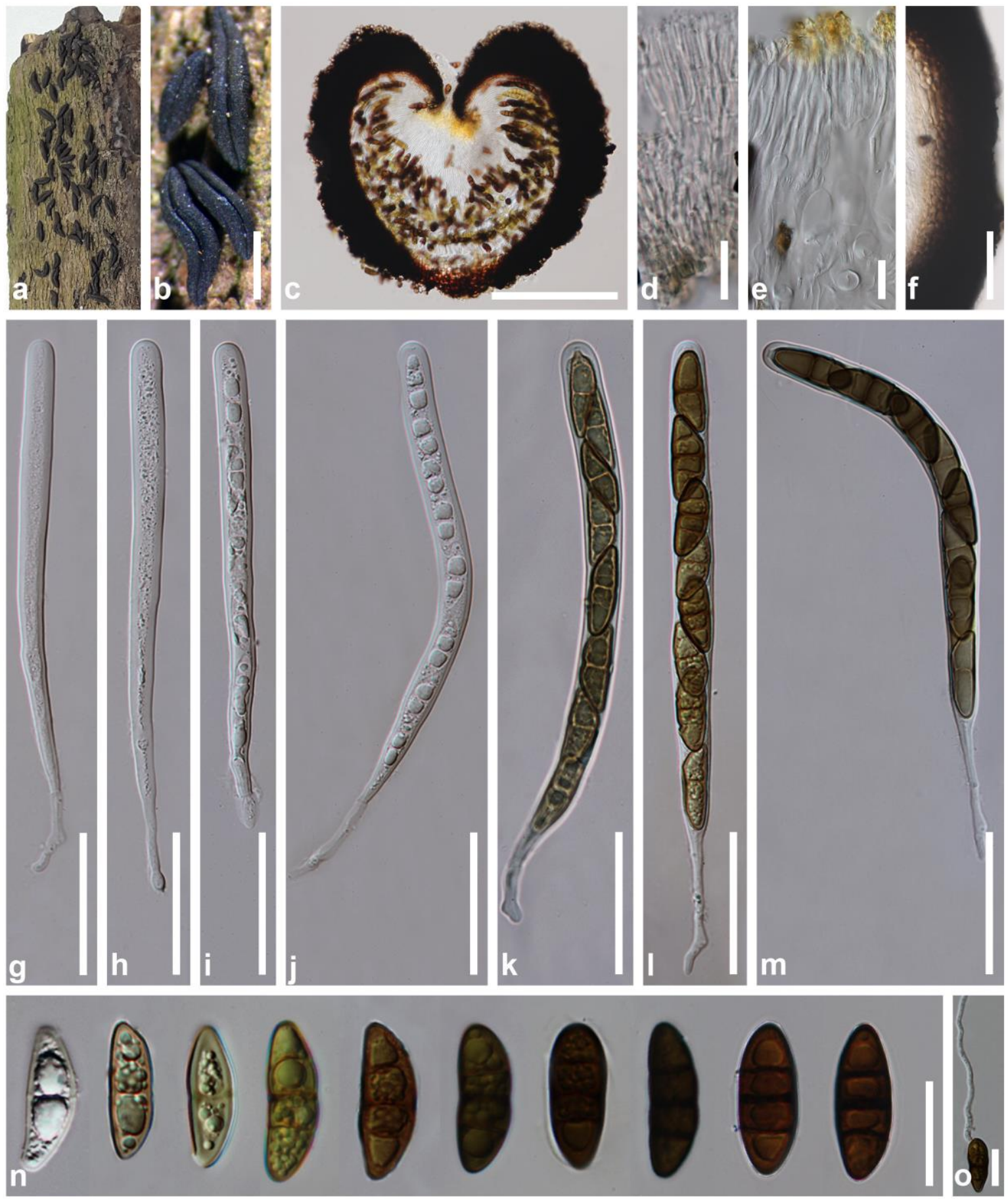

Figure 13 - Rhytidhysteron neorufulum (MFLU 19-0233). a-b Ascomata on the host surface. c Section through ascoma. d-e Pseudoparaphyses. f Exciple. g-m Asci. $n$ Ascospores. o Germinated ascospore. Scale bars: $\mathrm{b}=500 \mu \mathrm{m}, \mathrm{c}=100 \mu \mathrm{m}, \mathrm{d}, \mathrm{g}-\mathrm{m}=50 \mu \mathrm{m}, \mathrm{e}-\mathrm{f}, \mathrm{n}-\mathrm{o}=20 \mu \mathrm{m}$. 
Notes - Strains MFLUCC 17-0321, MFLU 19-0234, MFLUCC 18-0281 and MFLUCC 170370 are phylogenetically related to Rhytidhysteron neorufulum. In a BLASTn search, the ITS and LSU sequence of our four strains were R. neorufulum (MFLUCC 13-0216; KU377561 and KU377566) with $99 \%$ and $100 \%$ similarity. When comparing our strain with the type specimen of $R$. neorufulum (MFLUCC 13-0216), they are similar in morphology in having hysterothecia, and ellipsoidal to fusiform ascospores with 2-3-septate. However, our strain has larger hysterothecia, shorter exciple $(46-94$ vs 60-160 $\mu \mathrm{m})$, wider asci $(154.5-215 \times 9-16$ vs $185-220 \times 9.5-13 \mu \mathrm{m})$ and larger ascospores $(21-31 \times 8-12$ vs $27-34 \times 6.5-10.6 \mu \mathrm{m})$ compared to the type strain (Thambugala et al. 2016).

Rhytidhysteron tectonae Doilom \& K.D. Hyde, in Doilom et al., Fungal Divers. 82: 107-182 (2016)

Index Fungorum number: IF551964

Fig. 14

Saprobic on branches of Hevea brasiliensis. Sexual morph: Hysterothecia (395-)700-2055($2920) \times(540-) 690-1210(-1250) \times(280-) 630-1310(-1330) \mu \mathrm{m}(\bar{x}=1156 \times 995 \times 983 \mu \mathrm{m}, \mathrm{n}=$ 16), navicular, black, with tapered ends, solitary to aggregated, semi-immersed to superficial, carbonaceous, straight or irregularly curved, with a prominent longitudinal slit. Exciple 65-156 $\mu \mathrm{m}$, $(\bar{x}=89, \mathrm{n}=20)$, composed of cells of textura angularis, outer layers brown to dark brown, thickwalled, inner layer hyaline, thin-walled. Pseudoparaphyses 1.3-2.6 $\mu \mathrm{m}(\bar{x}=1.99, \mathrm{n}=25)$ wide, hyaline, dense, septate, filiform, forming light brown to yellow epithecium above the asci and enclosed in a gelatinous matrix. Asci (153-)170-207(-208) $\times 8-13(-15.5) \mu \mathrm{m}(\bar{x}=187 \times 11.4 \mu \mathrm{m}$, $\mathrm{n}=20)$, 8-spored, bitunicate, subcylindrical to cylindrical, with a pedicel, apically rounded. Ascospores (24-)26-30(-32) $\times(7-) 9-11(-12) \mu \mathrm{m}(\bar{x}=28 \times 9.8 \mu \mathrm{m}, \mathrm{n}=45)$, uni-seriate, slightly overlapping, hyaline to pale brown or golden brown, subglobose, 1-septate when immature, becoming brown to dark brown, ellipsoidal to fusiform, mostly 3 -septa, slightly rounded or pointed at both ends, constricted at the central septum, smooth-walled when immature. Asexual morph: Undetermined.

Culture characteristics - Ascospores germinating on MEA within 24 hours at room temperature and germ tubes produced from end or each cell of ascospores. Colonies on MEA circular, mycelium slightly raised, fluffy, entire, cultures white or light brown at the surface and dark brown to black from the center of the colony in reverse and white at the margin.

Material examined - Thailand, Phayao Province, Chiang Kam District, on branches of Hevea brasiliensis (Euphorbiaceae), 26 July 2017, C. Senwanna, RBPY53 (MFLU 21-0195), living culture MFLUCC 18-0281 (new host record).

Host and distribution - Tectona grandis - Thailand (Doilom et al. 2017), Hevea brasiliensis (Thailand; this study).

GenBank numbers - MFLUCC 18-0281: ITS = OL782138, LSU = OL782054.

Notes - In a BLASTn search, the closest match of the LSU and ITS sequences with $99 \%$ and 97.62\% similarity were Rhytidhysteron neorufulum (MFLUCC 13-0216), while the closest match of the TEF1 sequences with 95\% was $R$. mangrovei (strain MFLUCC 18-1103). In the phylogenetic analysis, our strain (MFLUCC 18-0281) clusters with R. tectonae (MFLUCC 13-0710) with 95\% ML bootstrap support (Fig. 12). The morphology of our collection (MFLU 21-0195, Fig. 14) is similar to R. tectonae from Tectona grandis as described by Doilom et al. (2017). We, therefore, name our collection as $R$. tectonae and this is the first report of this species on Hevea brasiliensis.

Muyocopronales Mapook, Boonmee \& K.D. Hyde

Muyocopronaceae K.D. Hyde

Muyocopronaceae was introduced by Luttrell (1951) to accommodate species having black, superficial, coriaceous to carbonaceous, ostiolate ascomata, without mycelium and bitunicate, ovoid to obclavate asci, containing subglobose to ellipsoidal, hyaline ascospores. Currently, Muyocopronaceae comprises Arxiella, Leptodiscella, Mycoleptodiscus, Muyocopron, Neocochlearomyces, Neomycoleptodiscus, Paramycoleptodiscus, Setoapiospora and 
Pseudopalawania (Hongsanan et al. 2020a, Mapook et al. 2020). In this study, Quadrisporella is introduced as a new genus with its type species, Quadrisporella heveae from Thailand. This is based on evidence from morphology and molecular data (Figs 15, 17). In addition, a new host and geographical records for Muyocopron garethjonesii is reported (Figs 15, 16).
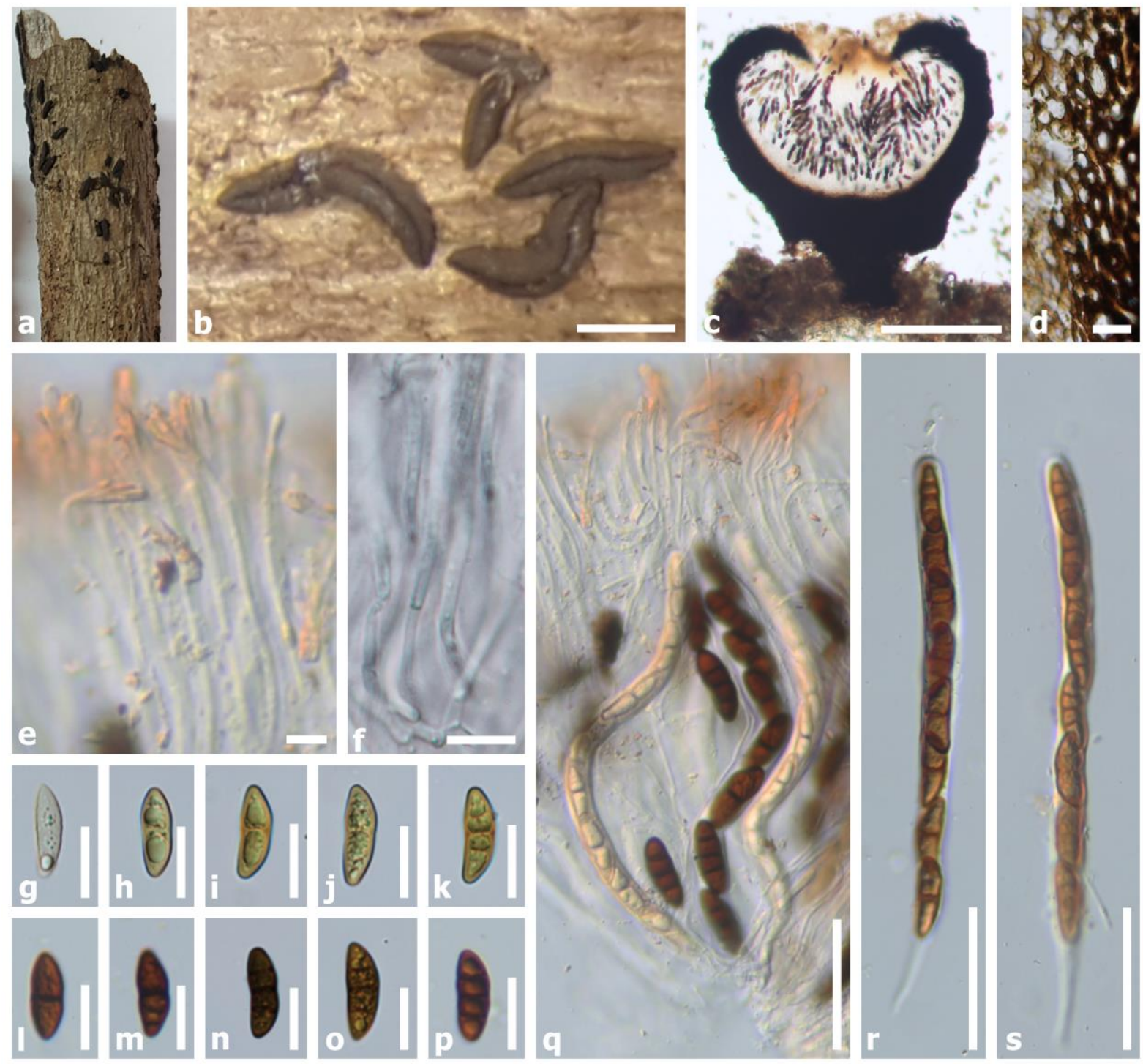

Figure 14 - Rhytidhysteron tectonae (MFLU 21-0195, new host record). a-b Ascomata on host surface. c Section through the ascoma. d Exciple. e-f Pseudoparaphyses. g-p Ascospores. q-s Asci. Scale bars: $\mathrm{b}=1000 \mu \mathrm{m}, \mathrm{c}=300 \mu \mathrm{m}, \mathrm{d}-\mathrm{f}=10 \mu \mathrm{m}, \mathrm{g}-\mathrm{p}=20 \mu \mathrm{m}, \mathrm{q}-\mathrm{s}=50 \mu \mathrm{m}$.

Muyocopron garethjonesii Tibpromma, Karun. \& K.D. Hyde, in Tibpromma et al., Mycosphere 7(9): 1485 (2016)

Fig. 16

Index Fungorum number: IF552529

Saprobe on dried twig (attached on tree) of Hevea brasiliensis. Sexual morph: Colonies dry, black, circular, raised to umbonate on the host surface, without a subiculum, easily removed from the host, clustered, gregarious, ostiolate. Ascomata $(21-) 44-65(-89)$ high $\times 170-405(-480) \mu \mathrm{m}$ diam. $(\bar{x}=55.4 \times 322, \mathrm{n}=12)$, superficial, raised, dimidiate to conical, black, rough-walled, glabrous, black, with a central irregular ostiole. Peridium $(12-) 14-20(-37) \mu \mathrm{m}$ thick $(\bar{x}=18.8, \mathrm{n}=$ 22 ), thick-walled of unequal thickness, poorly developed at the base, slightly thick at the sides towards the apex, comprising two type cell layers; an outer layer thick-walled, composed of black, brittle carbonaceous cells, an inner layer comprised dark brown pseudoparenchymatous cells of textura angularis. Hamathecium of numerous, $2-3 \mu \mathrm{m}$ wide, septate, branched, broadly cellular 
pseudoparaphyses. Asci (20-)52-74 (-82) $\times(12-) 21-29.5 \mu \mathrm{m}(\bar{x}=62 \times 23 \mu \mathrm{m}, \mathrm{n}=20), 8$-spored, bitunicate, broadly cylindrical to avoid, long pedicellate, apically rounded, with an ocular chamber. Ascospores (13-)15-20.5 × 8-11.5 $\mu \mathrm{m}(\bar{x}=18 \times 10 \mu \mathrm{m}, \mathrm{n}=30)$, irregularly arranged, overlapping, ellipsoid to obovoid, hyaline, one-celled, with granular appearance, rough-walled.

Material examined - Thailand, Phayao Province, Chiang Kam District, on dried twig (attached on tree) of Hevea brasiliensis (Euphorbiaceae), 26 July 2017, C. Senwanna, RBPY60 (MFLU 21-0192) (new host record).

Host and distribution - Pandanus sp. (Thailand; Tibpromma et al. 2016), Hevea brasiliensis (Thailand; this study).

GenBank numbers - MFLU 21-0192: $\mathrm{ITS}=$ OL782139, LSU = OL782055, SSU $=$ OL780523.

Notes - In a BLASTn search of GenBank, the closest match of the LSU sequence of RBPY60 is Muyocopron garethjonesii (MFLU 16-2664a) with 99.88\% similarity, while the closest match of the ITS sequence is M. laterale (ATCC: 200213) with $94.93 \%$ similarity. A comparison of the LSU gene region of Muyocopron garethjonesii (MFLU 16-2664a) and our collection reveals 1 base pair difference (1/844). Based on the multi-gene analyses, Muyocopron garethjonesii (MFLU 21-0192) has a close phylogenetic relationship and similar morphological characters with $M$. garethjonesii in having broadly cylindrical to avoid asci with a long pedicel and ellipsoidal ascospores (Tibpromma et al. 2016) (Fig. 16). However, our collection has shorter asci $(20-82 \times 12-29.5$ vs $60-120 \times$ 19-35 $\mu \mathrm{m})$ and ascospores $(13-20.5 \times 8-11.5$ vs 9-25 $\times 11-13)$ than the type species. We, therefore, name our collection as M. garethjonesii and this is the first report on Hevea brasiliensis to obovoid.

Quadrisporella Senwanna, Cheewangkoon \& K.D. Hyde, gen. nov.

Index Fungorum number: IF559357

Etymology - The generic epithet reflects the 4-spored asci

Saprobic on Hevea brasiliensis. Sexual morph: Ascomata black, raised to umbonate on the host surface, without a subiculum, easily removed from the host, superficial to semi-immersed, solitary or scattered, carbonaceous, appearing as dark brown to black spots. Ostiole central. Peridium thick-walled of unequal thickness, poorly developed at the base, slightly thick at the sides towards the apex, comprising two type cell layers; an outer thick-walled layer, composed of black, brittle carbonaceous cells, an inner hyaline layer comprised pseudoparenchymatous cells of textura angularis. Hamathecium with cylindrical to filiform, septate, pseudoparaphyses. Asci 4-spored, bitunicate, cylindrical, pedicellate, straight or slightly curved, with an ocular chamber. Ascospores overlapping, irregularly, oblong to broadly fusiform, hyaline, 1-septate, constricted at the septum, guttulate, smooth-walled. Asexual morph: Undetermined.

Type species - Quadrisporella heveae Senwanna, Cheewangkoon \& K.D. Hyde

Notes - In a BLASTn search, the closest match of the LSU and ITS sequences with $95.82 \%$ and $82.32 \%$ similarity was Setoapiospora thalilandica (MFLUCC 17-1426). The closest match of the TEF1 sequences with $87.96 \%$ similarity was Muyocopron laterale (FMR 13797). In the phylogenetic analysis, Quadrisporella heveae (MFLUCC 18-0308) is closely related to Setoapiospora thailandica (MFLUCC 17-1426) with 100\% ML and 1 BYPP bootstrap support (Fig. 15). Quadrisporella shares several similarities with Setoapiospora in having superficial to semi-immersed, carbonaceous ascomata which appear as dark brown to black spots on the host surface and hyaline ascospores, However, our new genus differs by ascomata without external setae, 4-spored asci and oblong to broadly fusiform, hyaline ascospores which are 1-septate at the middle (Hyde et al. 2020a). We, therefore, introduce Quadrisporella as a new genus to accommodate a new species Quadrisporella heveae based on morphology and phylogenetic evidence. 


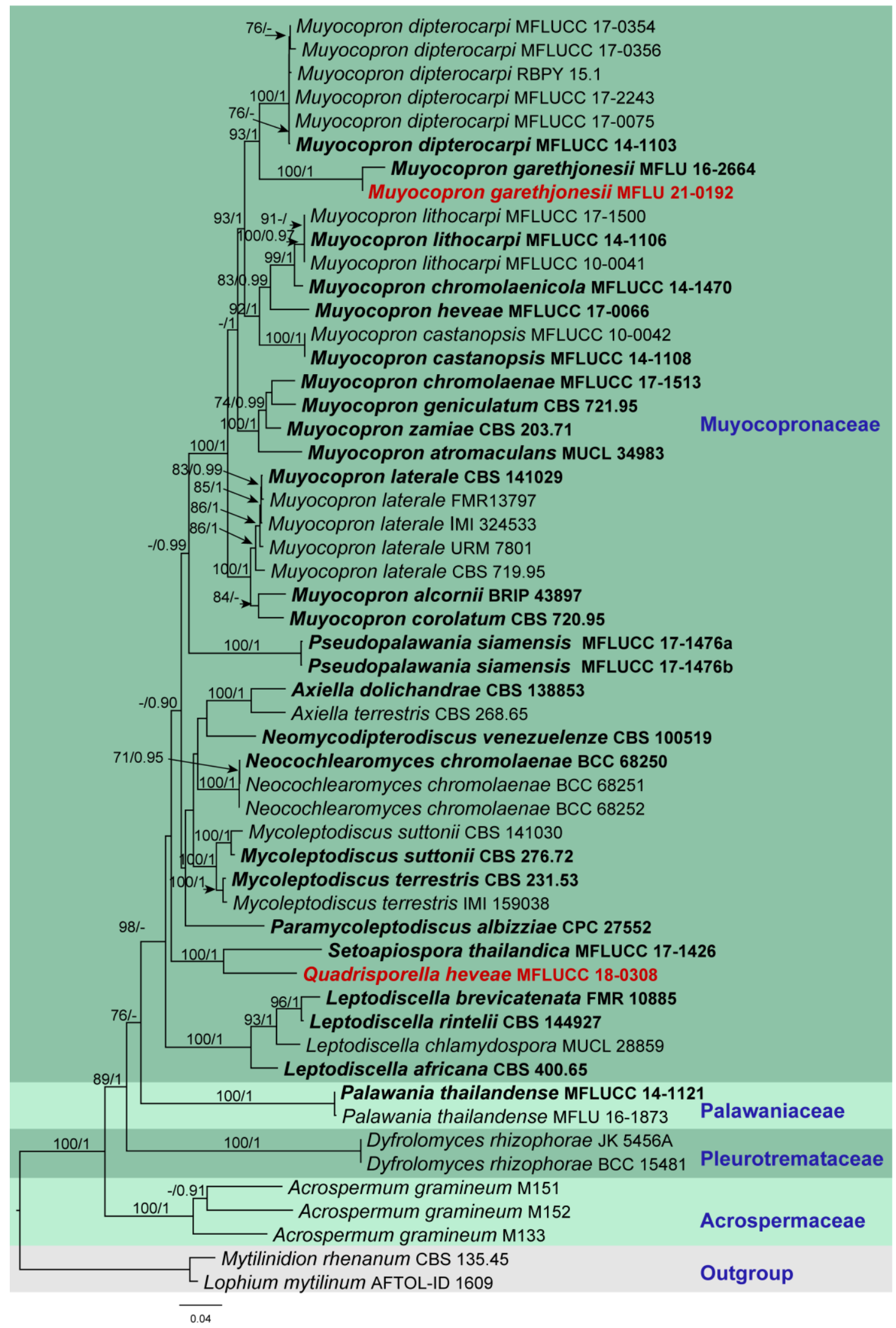

Figure 15 - RAxML tree of Muyocopronaceae based on analyses of a combined LSU, SSU, ITS and TEF1 sequence data. Fifty-four strains are included in the combined sequence analysis, which comprise 4426 characters with gaps. Tree topology of the ML analysis was similar to the BYPP. The best scoring RAxML tree with a final likelihood value of -23433.134290 is presented. The matrix had 1534 distinct alignment patterns, with $50.72 \%$ of undetermined characters or gaps. Estimated base frequencies were as follows: $\mathrm{A}=0.240134, \mathrm{C}=0.243034, \mathrm{G}=0.294580, \mathrm{~T}=$ 
0.222252; substitution rates: $\mathrm{AC}=1.270158, \mathrm{AG}=2.748820, \mathrm{AT}=1.647779, \mathrm{CG}=1.110155, \mathrm{CT}$ $=6.389605, \mathrm{GT}=1.000000$; gamma distribution shape parameter $\alpha=0.486598$. Bootstrap support values for ML equal to or greater than $60 \%$ and BYPP equal to or greater than 0.90 are defined as ML/BYPP above the nodes. Newly generated sequences are in red bold and type species are in bold. Lophium mytilinum (AFTOL-ID 1609) and Mytilinidion rhenanum (CBS 135.45) are used as outgroup taxa.
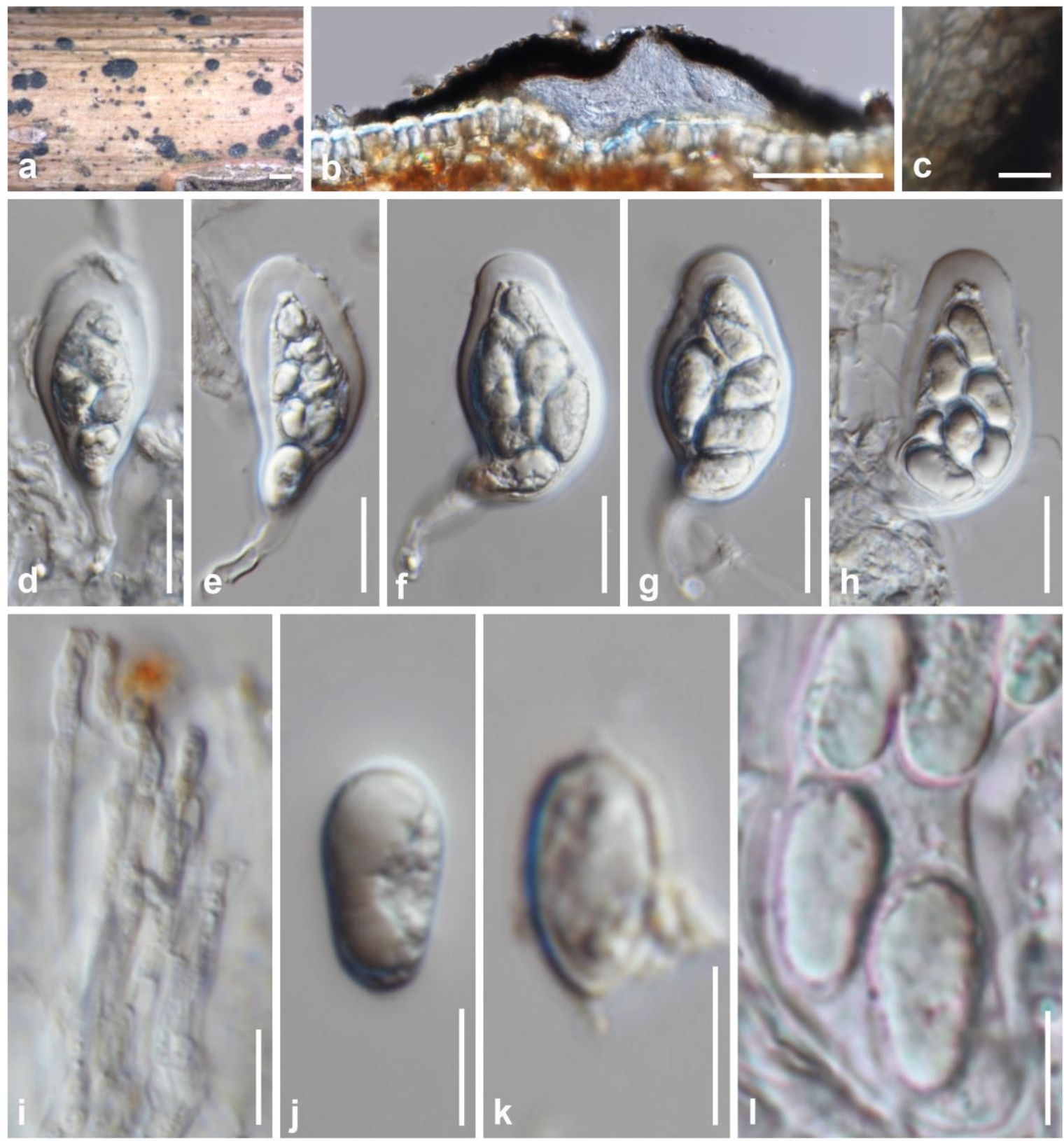

Figure 16 - Muyocopron garethjonesii (MFLU 21-0192, new host record). a Ascomata on host substrate. b Section through the ascoma. c Peridium. $d-h$ Ascospores. i Pseudoparaphyses. $j-1$ Asci. Scale bars: $\mathrm{a}=500 \mu \mathrm{m}, \mathrm{b}=100 \mu \mathrm{m}, \mathrm{c}, \mathrm{i}-\mathrm{l}=10 \mu \mathrm{m}, \mathrm{d}-\mathrm{h}=20 \mu \mathrm{m}$.

Quadrisporella heveae Senwanna, Cheewangkoon \& K.D. Hyde, sp. nov.

Fig. 17 Index Fungorum number: IF559358

Etymology - Name reflects the host genus Hevea, from which the species was collected.

Saprobe on dried twig (attached on tree) of Hevea brasiliensis. Sexual morph: Ascomata (350-)430-625(-650) $\mu \mathrm{m}$ diam. $\times(185-) 205-365 \mu \mathrm{m}$ diam. $(\bar{x}=510 \times 268 \mu \mathrm{m}, \mathrm{n}=11)$, dry, black, raised to umbonate on the host surface, without a subiculum, easily removed from the host, 
superficial to semi-immersed, solitary or scattered, carbonaceous, appearing as dark brown to black spots. Ostiole central. Peridium thick-walled of unequal thickness, poorly developed at the base, 21-29 $\mu \mathrm{m}$ thick $(\bar{x}=26, \mathrm{n}=7)$, slightly thick at the sides towards the apex, 57-65(-72) $\mu \mathrm{m}$ thick $(\bar{x}$ $=63, \mathrm{n}=7$ ), comprising two type cell layers; an outer thick-walled layer, composed of black, brittle carbonaceous cells, an inner hyaline layer comprised pseudoparenchymatous cells of textura angularis. Hamathecium comprising 1.5-3.5 $\mu \mathrm{m}$ wide, cylindrical to filiform, septate, pseudoparaphyses. Asci (90-)100-135 (-138) × (21-)34-39 $\mu \mathrm{m}(\bar{x}=120.6 \times 29.2 \mu \mathrm{m}, \mathrm{n}=23)$, 4spored, bitunicate, cylindrical, pedicellate, straight or slightly curved, with an ocular chamber. Ascospores (32-)36-44(-47) $\times(12-) 14-20 \mu \mathrm{m}(\bar{x}=41.5 \times 17.3 \mu \mathrm{m}, \mathrm{n}=40)$, irregularly overlapping, oblong to broadly fusiform, hyaline, 1-septate, constricted at the septum, guttulate, smooth-walled.

Material examined - Thailand, Ranong Province, La-un District, on branch (attached on tree) of Hevea brasiliensis (Euphorbiaceae), 1 October 2017, C. Senwanna, RBRN01 (MFLU 21-0194, holotype), ex-type living culture MFLUCC 18-0308 = MFLUCC 18-0309.

GenBank numbers - MFLUCC 18-0308: ITS = OL782140, LSU = OL782057, TEF1 = OL875101, RPB2 = OL828755.
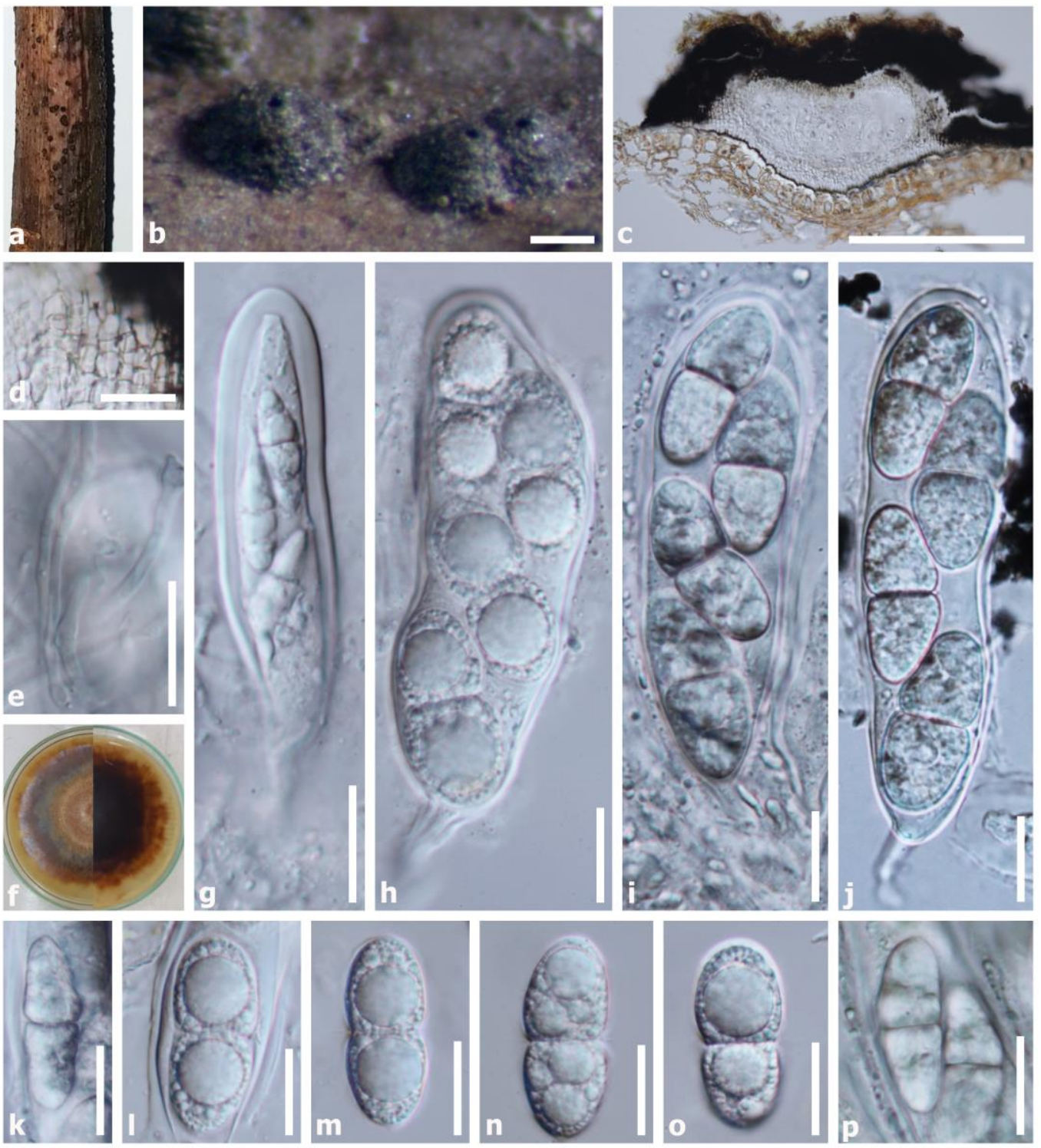

Figure 17 - Quadrisporella heveae (MFLU 21-0194, holotype). a-b Ascomata on host surface. c Section through the ascoma. d Peridium. e Pseudoparaphyses. f Culture on PDA for 30 days. $\mathrm{g}-\mathrm{j}$ Asci. k-p Ascospores. Scale bars: $\mathrm{b}-\mathrm{c}=200 \mu \mathrm{m}, \mathrm{d}-\mathrm{p}=20 \mu \mathrm{m}$. 


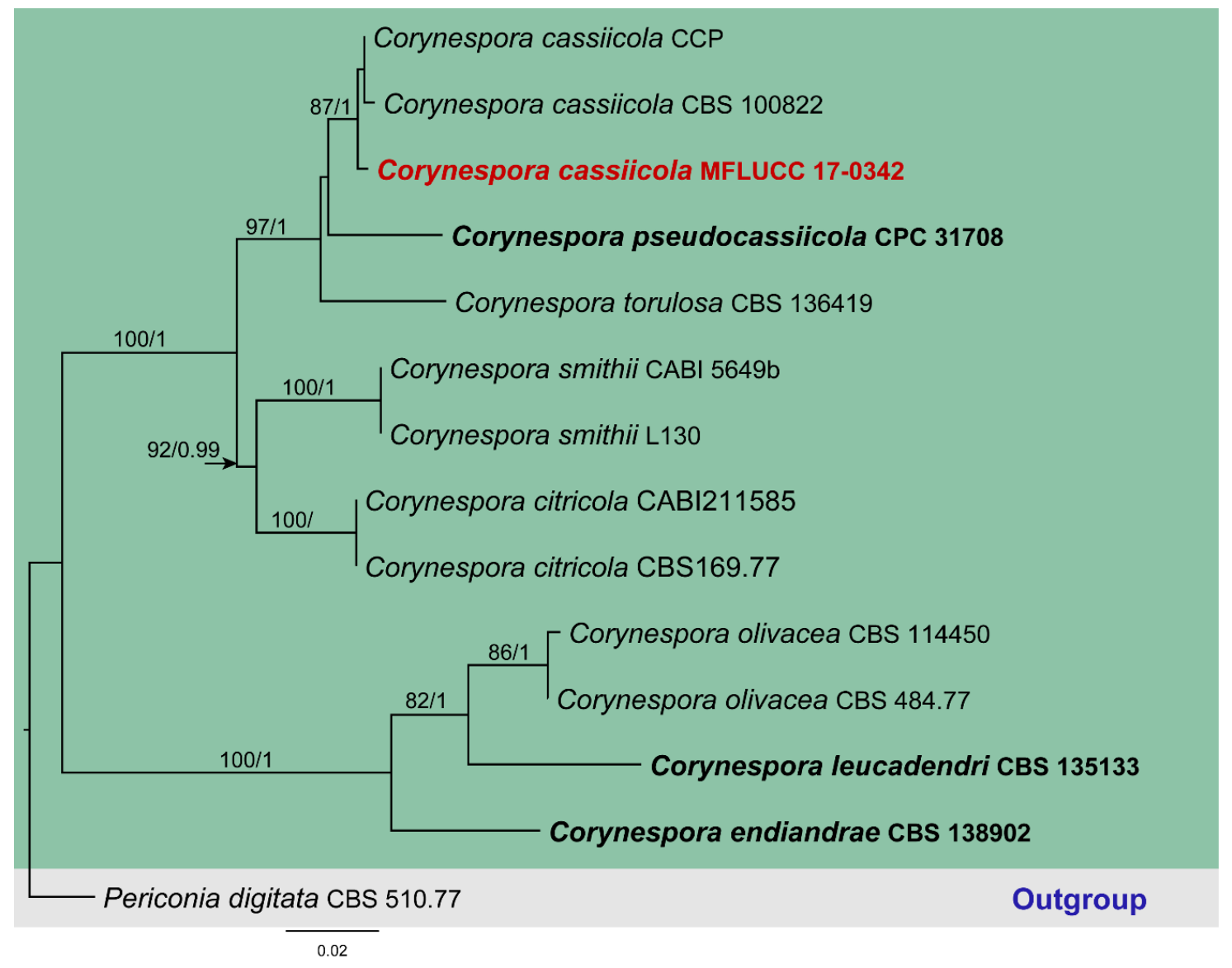

Figure 18 - RAxML tree of Corynespora based on a combined LSU, ITS, SSU, TEF1 and RPB2 sequence dataset. Fourteen strains are included in the combined sequence analysis, which comprise 4458 characters with gaps. Tree topology of the ML analysis was similar to the BYPP. The best scoring RAxML tree with a final likelihood value of -9638.498558 is presented. The matrix had 445 distinct alignment patterns, with $56.67 \%$ of undetermined characters or gaps. Estimated base frequencies were as follows: $\mathrm{A}=0.242462, \mathrm{C}=0.255781, \mathrm{G}=0.275101, \mathrm{~T}=0.226655$; substitution rates: $\mathrm{AC}=1.889016, \mathrm{AG}=2.161405, \mathrm{AT}=1.233890, \mathrm{CG}=1.20144, \mathrm{CT}=8.355785$, $\mathrm{GT}=1.000000$; gamma distribution shape parameter $\alpha=4.537830$. Bootstrap support values for ML equal to or greater than $60 \%$ and BYPP equal to or greater than 0.90 are defined as ML/BYPP above the nodes. Newly generated sequences are in red bold and type species are in bold. Periconia digitata (CBS510.77) is used as the outgroup taxon.

Pleosporales Luttrell ex M.E. Barr

Corynesporascaceae Sivan.

The member of Corynesporascaceae cause foliar diseases in many plants in the tropics and subtropics (Hyde et al. 2013, Kumar et al. 2016). Corynespora cassiicola is an important pathogenic with high genetic diversity that causes leaf spot, target spot and leaf fall of economic plants such as cotton, cucumber, rubber, soybean, tomato, worldwide (Silva et al. 2003, Cai et al. 2006, Lopez et al. 2018, MacKenzie et al. 2018, Sumabat et al. 2018, Rondon \& Lawrence 2021). In addition to being a plant pathogen, the species can infect animal and humans as well as play a role as endophytes and saprobes (Déon et al. 2012a, b, 2014, Sumabat et al. 2018, Lopez et al. 2018). Hongsanan et al. (2020a) accepted Corynespora Güssow and Corynesporasca Sivan. in Corynesporascaceae.

Corynespora cassiicola (Berk. \& M.A. Curtis) C.T. Wei, Mycol. Pap. 34 : 5 (1950)

Fig. 19 Index Fungorum number: IF296024 
Associated with spots on leaves of Hevea basiliensis seedlings. Leaf spots subcircular to circular, pale brown to brown on upper surface with dark brown margin surrounded by yellowish halo, light brown on lower surface. Sexual morph: Undetermined. Asexual morph: Colonies effuse, grey to dark brown, hairy. Conidiophores solitary to small group, erect, straight, subcylindrical, unbranched, brown, base bulbous, 9-15.5 $\mu \mathrm{m}$ diam. $(\bar{x}=11.5 \mu \mathrm{m}, \mathrm{n}=15)$, stipe (94-)118-192($223) \times 5-12 \mu \mathrm{m}(\bar{x}=166 \times 10 \mu \mathrm{m}, \mathrm{n}=15), 3-7$-septate. Conidiogenous cells integrated, terminal, proliferating percurrently. Conidia (81-)102-222(-313) $\times(4-) 6-10(-13) \mu \mathrm{m}(\bar{x}=166 \times 8 \mu \mathrm{m}, \mathrm{n}=$ 26), cylindrical, obclavate, straight to slightly curved with a rounded apex and base truncate, $3-12$ pseudoseptate, pale brown, hilum darkened, thickened, 2-6 $\mu \mathrm{m}$ wide.
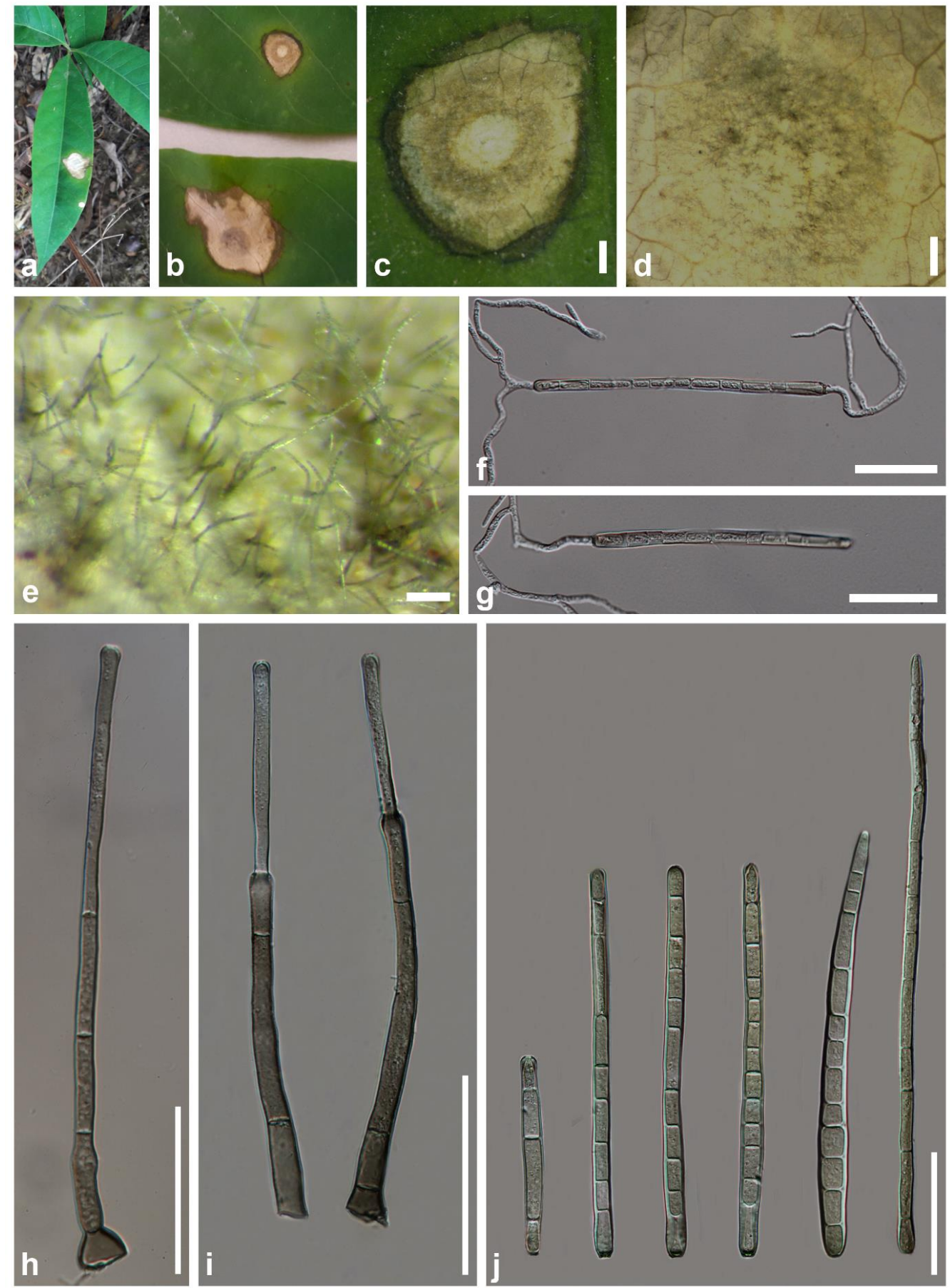

Figure 19 - Corynespora cassiicola (MFLU 19-0249). a-b Leaf spots on seedling. c-e Close-up of lesion. $\mathrm{f}-\mathrm{g}$ Germinated spores. $\mathrm{h}-\mathrm{i}$ Conidiophores. $\mathrm{j}$ Conidia. Scale bars: $\mathrm{c}-\mathrm{d}=500 \mu \mathrm{m}, \mathrm{e}=100$ $\mu \mathrm{m} . \mathrm{f}-\mathrm{g}=50 \mu \mathrm{m}$. 
Culture characteristics - Conidia germinating on MEA within 24 hours at room temperature and germ tubes produced from one or both ends. Colonies on MEA circular, mycelium slightly raised, entire, cultures greyish white at the surface and white at the margin and light brown from the centre of the colony in reverse and creamy-white at the margin.

Material examined - Thailand, Phayao Province, Muang, leaf spots on seedling leaves of Hevea brasiliensis (Euphorbiaceae), 3 January 2017, C. Senwanna, RBPY23 (MFLU 19-0249), living culture MFLUCC 17-0342.

Host and distribution - Wide host range, widely distributed in tropical and subtropical regions.

GenBank numbers - MFLUCC 17-0342: ITS $=$ OL782141, LSU $=$ OL782058, SSU $=$ OL780524, RPB2 = OL828752.

Notes - In Para rubber Corynespora cassiicola causes Corynespora leaf fall (CLF) disease, which affects rubber production in Asia and Africa and Latin America (Manju et al. 2001, Déon et al. 2014, Florence \& Fashoranti 2018, Lopez et al. 2018). In this study, our strain MFLUCC 170342 grouped with $C$. cassiicola with $87 \%$ ML and 1 BYPP bootstrap support (Fig. 18). When comparing our strain with the description of Wei (1950), they are similar in morphology. We, therefore, name our collection as C. cassiicola.

\section{Didymosphaeriaceae Munk}

Currently, 32 genera are accepted in Didymosphaeriaceae (Hongsanan et al. 2020a). The family are saprobes, endophytes and pathogens on various substrates in terrestrial and aquatic habitats (Hyde et al. 2013, Ariyawansa et al. 2014, Hongsanan et al. 2020a). In the present study, new host records of Montagnula thailandica and Pseudopithomyces palmicola from Para rubber are reported.

Montagnula thailandica Mapook \& K.D. Hyde, in Mapook et al., Fungal Divers. 101: 35 (2020)

Index Fungorum number: IF557299

Saprobic on dried twigs of Hevea brasiliensis. Sexual morph: Ascomata 160-350 $\mu \mathrm{m}$ high $\times$ 130-330 $\mu \mathrm{m}$ diam., solitary, scattered to clustered, immersed to semi-immersed, visible as slightly raised, ostiole central. Peridium 18-27 $\mu \mathrm{m}$ wide, slightly thin at the base, composed of thickwalled, dark brown to black cells of textura angularis. Pseudoparaphyses $1.5-2.5 \mu \mathrm{m}$ wide $(\bar{x}=$ 2.07, $\mathrm{n}=35)$, hyaline, dense, filiform. Asci (63-)69-90(-94) $\times 10-13(-14) \mu \mathrm{m}(\bar{x}=79 \times 12.2 \mu \mathrm{m}$, $\mathrm{n}=25), 8$-spored, bitunicate, fissitunicate, clavate, long pedicellate, apically rounded, sometimes without a distinct ocular chamber. Ascospores $(12-) 14-16(-17.5) \times 4.5-7 \mu \mathrm{m}(\bar{x}=15.5 \times 5.5 \mu \mathrm{m}, \mathrm{n}$ $=40$ ), overlapping 1-2-seriate, initially hyaline to pale brown, becoming brown to dark brown at maturity, ellipsoidal to fusiform, slightly rounded or pointed at both ends, 1-septate, constricted at the septa, smooth-walled, with guttules. Asexual morph: Undetermined.

Culture characteristics - Ascospores germinating on MEA within 24 hours at room temperature and germ tubes produced from end of ascospores. Colonies on MEA irregular, mycelium slightly raised, cultures dark brown to black from the centre of the colony and white at the margin.

Material examined - Thailand, Phayao Province, Muang District, on dried twigs of Hevea brasiliensis (Euphorbiaceae), 2 March 2017, C. Senwanna, RBPY45 (MFLU 21-0191), living culture MFLUCC 17-0363 (new host record).

Host and distribution - Chromolaena odorata (Thailand; Mapook et al. 2020), Hevea brasiliensis (Thailand; this study), dead stems of undetermined hosts (Thailand; Boonmee et al. 2021).

GenBank numbers - MFLUCC 17-0363: ITS $=$ OL782142, LSU $=$ OL782059, SSU $=$ OL780525, TEF1 = OL875102, RPB2 = OL828754.

Notes - In a BLASTn search, the closest match of the ITS, SSU and TEF1 sequences of the strain with 100\%, 99.81\% and 99.43\% similarity, respectively, was Montagnula thailandica 
(MFLUCC 17-1508), while the closest match to the LSU sequences with $100 \%$ similarity, was $M$. chromolaenicola (MFLUCC 17-1469). Montagnula species are saprobic in terrestrial habitats and characterized by globose to subglobose, immersed ascomata, claviform asci, fusoid or ellipsoid, phragmosporous or muriform ascospores (Barr 1990, Ariyawansa et al. 2014). In the present phylogenetic analysis, MFLUCC 17-0363 clustered with M. thailandica (MFLUCC 17-1508) (Fig. 20). The morphology of our strain is similar to M. thailandica described by Mapook et al. (2020). We, therefore, name our collection as $M$. thailandica which is a new host record for Hevea brasiliensis in Thailand.

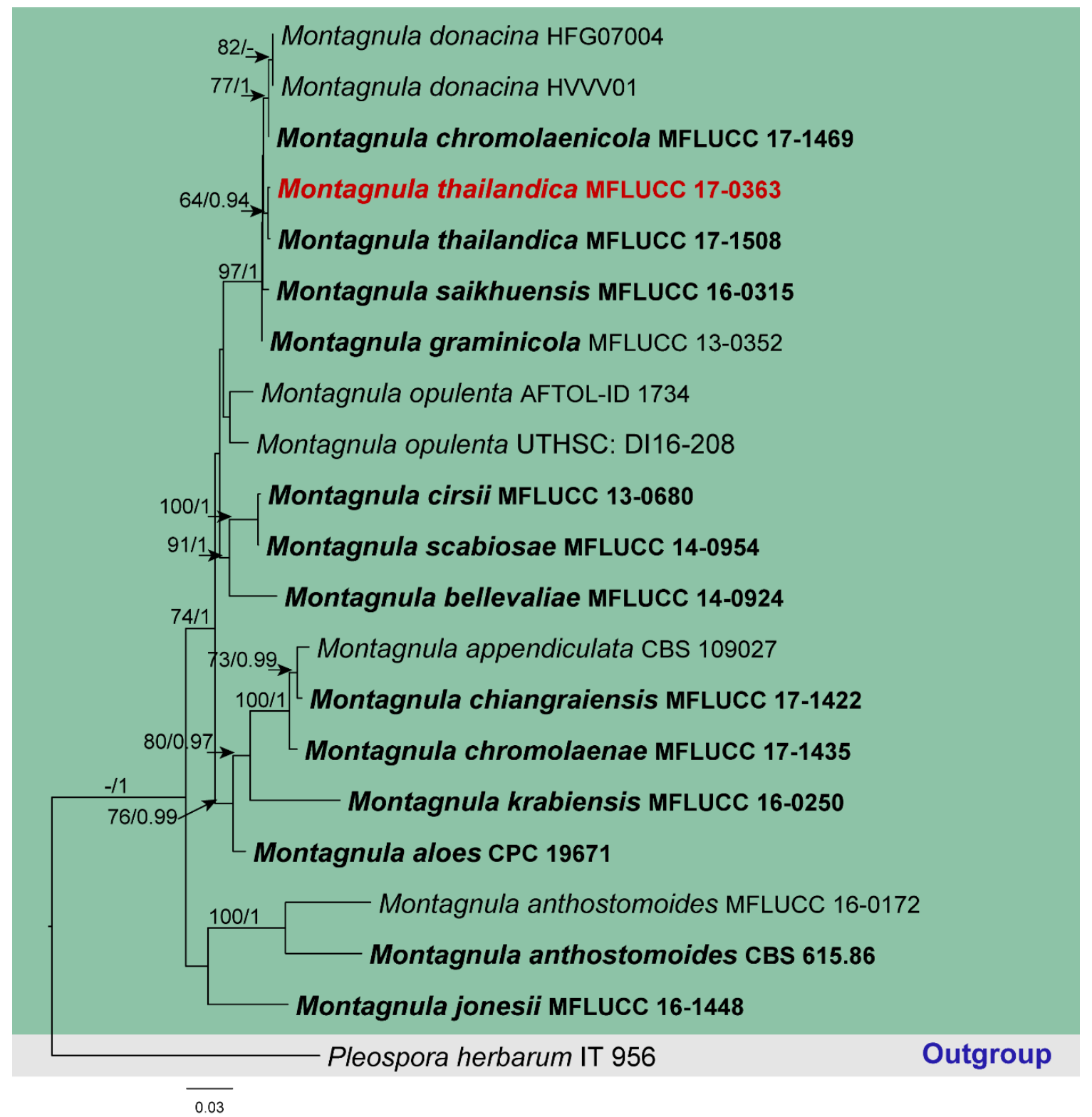

Figure 20 - RAxML tree of Montagnula based on a combined LSU, ITS, SSU and TEF1 sequence dataset. Twenty-one strains are included in the combined sequence analysis, which comprise 2802 characters with gaps. Tree topology of the ML analysis was similar to the BYPP. The best scoring RAxML tree with a final likelihood value of -12629.744665 is presented. The matrix had 924 distinct alignment patterns, with $34.10 \%$ of undetermined characters or gaps. Estimated base frequencies were as follows: $\mathrm{A}=0.244441, \mathrm{C}=0.248269, \mathrm{G}=0.272059, \mathrm{~T}=0.235231$; substitution rates: $\mathrm{AC}=1.311889, \mathrm{AG}=2.257389, \mathrm{AT}=1.482806, \mathrm{CG}=1.080343, \mathrm{CT}=$ 5.534655, GT $=1.000000$; gamma distribution shape parameter $\alpha=0.725183$. Bootstrap support values for ML equal to or greater than $60 \%$ and BYPP equal to or greater than 0.90 are defined as 
ML/BYPP above the nodes. Newly generated sequences are in red bold and type species are in bold. Pleospora herbarum (IT 956) is used as the outgroup taxon.
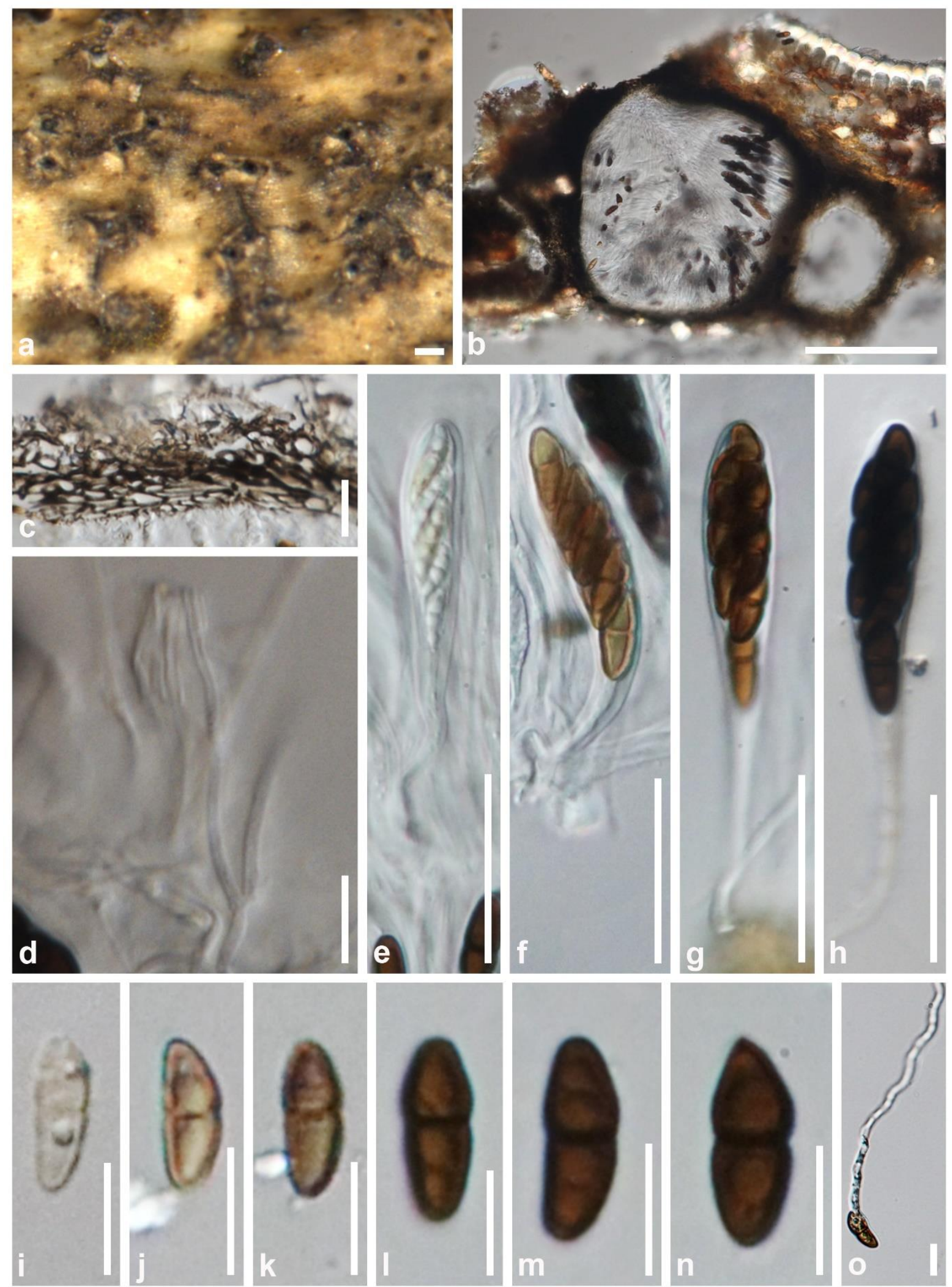

Figure 21 - Montagnula thailandica (MFLU 21-0191, new host record). a Habit of ascomata on substrate. b Vertical section through the ascoma. c Peridium. d. Pseudoparaphyses. e- $\mathrm{h}$ Asci. $\mathrm{i}-\mathrm{n}$ Ascospores. o Germinated spores. Scale bars: $\mathrm{a}=200 \mu \mathrm{m}, \mathrm{b}=100 \mu \mathrm{m}, \mathrm{c}, \mathrm{d}, \mathrm{i}-\mathrm{o}=10 \mu \mathrm{m}, \mathrm{f}-\mathrm{h}=30$ $\mu \mathrm{m}$. 
Pseudopithomyces palmicola Jun F. Li, Ariyaw. \& K.D. Hyde, in Ariyawansa et al., Fungal Divers. 75: 27-274 (2015)

Fig. 23

Index Fungorum number: IF551394

Saprobic on dried leaf of Hevea brasiliensis. Sexual morph: Undetermined. Asexual morph: Colonies effuse, dark brown to black. Mycelium superficial or partly immersed on the substrate, composed of septate, smooth, thin-walled, pale to brown hyphae. Conidiophores $6-12(-15) \times 2-4$ $\mu \mathrm{m}(\bar{x}=10.1 \times 3.2 \mu \mathrm{m}, \mathrm{n}=10)$, micronematous, mononemous, closely packed, hyaline, thinwalled, aseptate, smooth, branched. Conidiogenous cells 4.5-10.8 $\times 2.2-4 \mu \mathrm{m}(\bar{x}=6.8 \times 3.1 \mu \mathrm{m}, \mathrm{n}$ $=10)$, holoblastic, terminal, hyaline. Conidia (9-)12-24(-26) $\times 6-14(-16) \mu \mathrm{m}(\bar{x}=18.5 \times 11 \mu \mathrm{m}, \mathrm{n}$ $=30$ ), ellipsoidal to obclavate, muriform, brown to dark brown, round at ends, mostly 3 transverse septate, longitudinally 1-3-septate, slightly constricted at the septa, verrucose to echinulate. Appressoria solitary, hyaline, globose to sub globose, thick-walled.

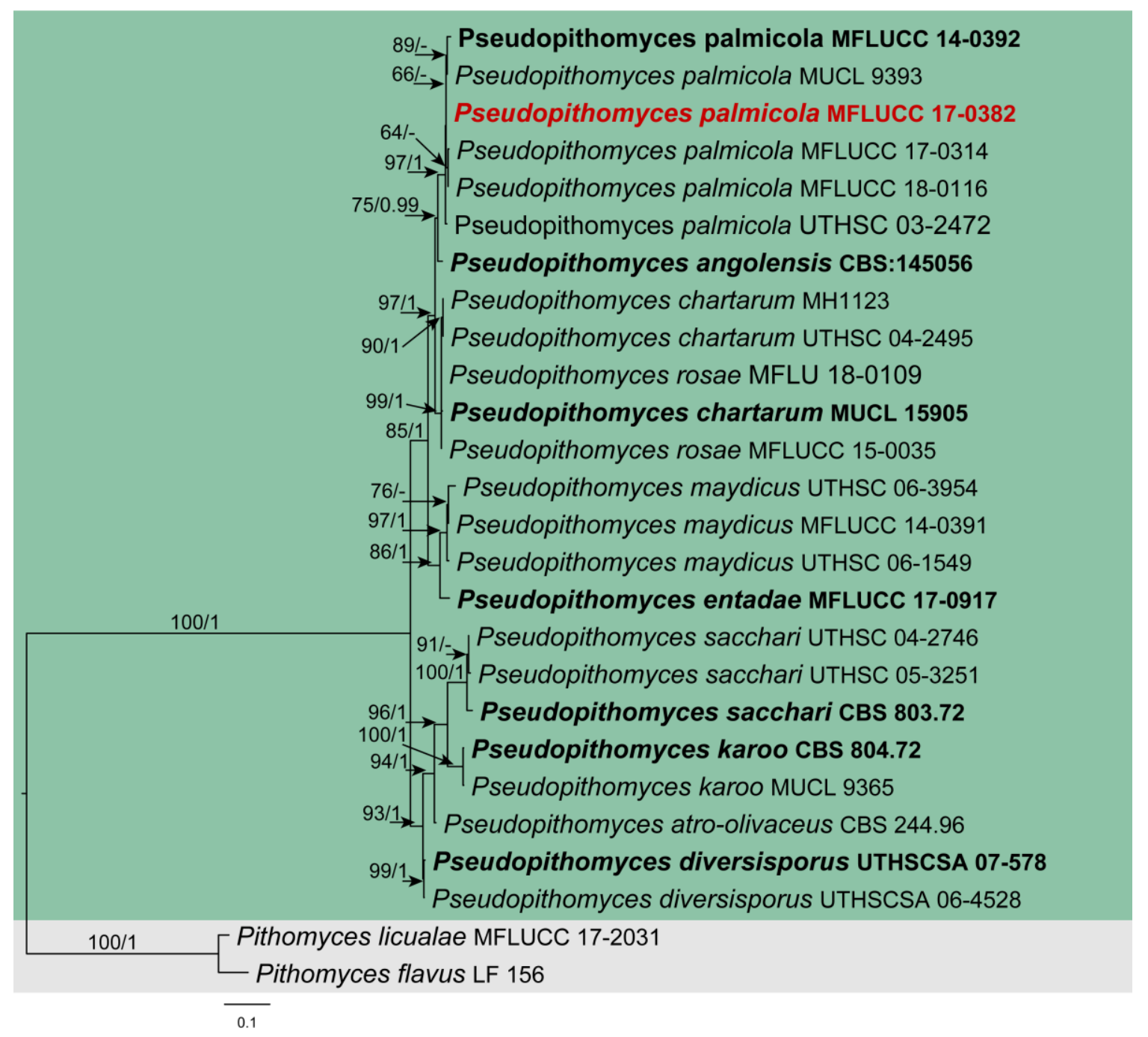

Figure 22 - RAxML tree of Pseudopithomyces based on a combined LSU, ITS, RPB2 and GPD sequence dataset. Twenty-six strains are included in the combined sequence analysis, which comprise 3145 characters with gaps. Tree topology of the ML analysis was similar to the BYPP. The best scoring RAxML tree with a final likelihood value of -11022.299869 is presented. The matrix had 804 distinct alignment patterns, with $33.48 \%$ of undetermined characters or gaps. Estimated base frequencies were as follows: $\mathrm{A}=0.240009, \mathrm{C}=0.264477, \mathrm{G}=0.272648, \mathrm{~T}=$ 0.222866; substitution rates: $\mathrm{AC}=1.431352, \mathrm{AG}=3.802855, \mathrm{AT}=1.142783, \mathrm{CG}=1.135958, \mathrm{CT}$ $=9.493994, \mathrm{GT}=1.000000$; gamma distribution shape parameter $\alpha=0.406456$. Bootstrap support values for ML equal to or greater than $60 \%$ and BYPP equal to or greater than 0.90 are defined as 
ML/BYPP above the nodes. Newly generated sequences are in red bold and type species are in bold. Pithomyces flavus (LF-156) and P. licualae (MFLUCC 17-2031) are used as outgroup taxa.
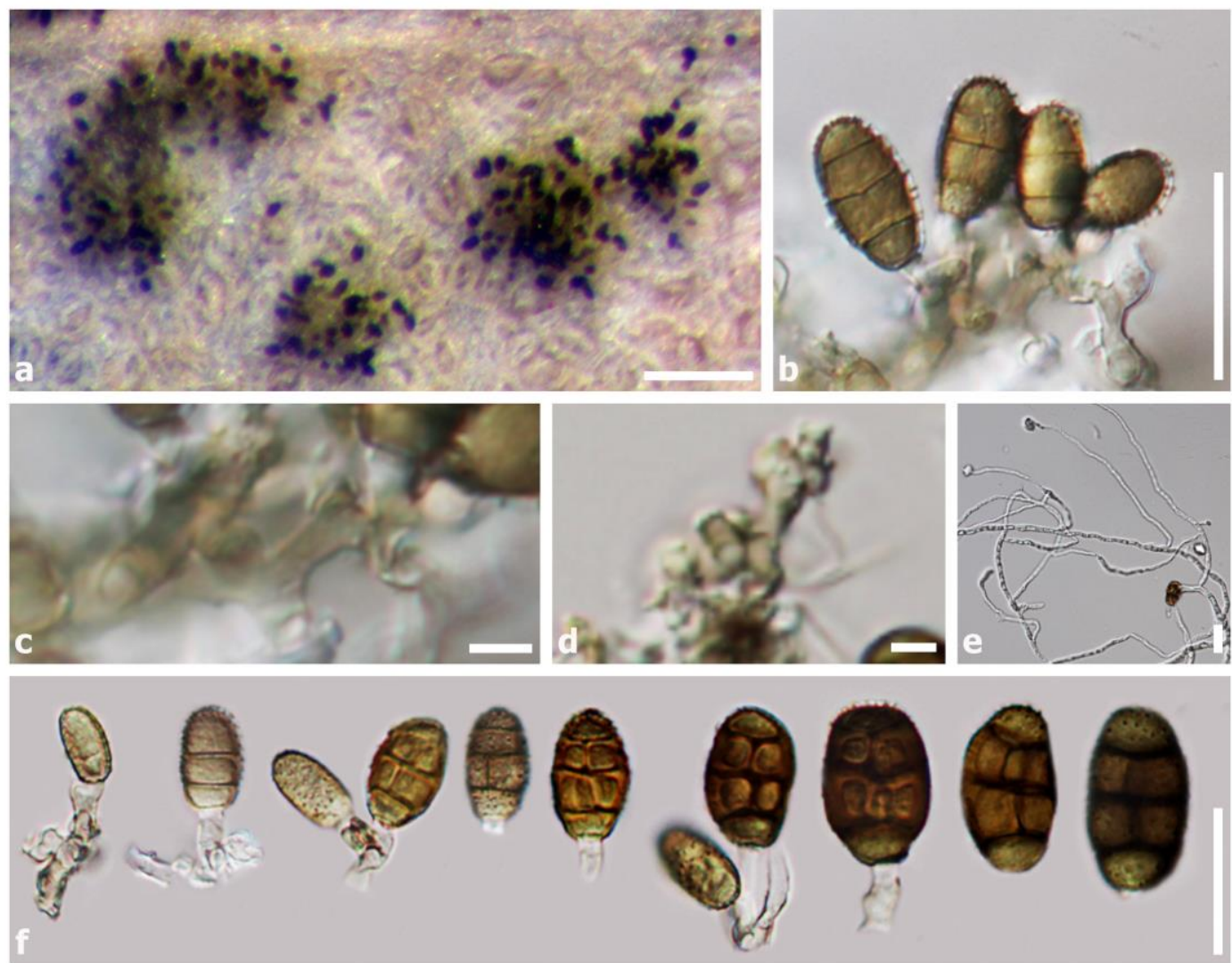

Figure 23 - Pseudopithomyces palmicola (MFLU 19-0222, new host record). a Colonies on host substrate. b, f Conidia attach to conidiogenous cells. c-d Dematiaceous hyphae. e Germinated spore. $\mathrm{f}$ Conidia. Scale bars: $\mathrm{a}=100 \mu \mathrm{m}, \mathrm{b}, \mathrm{f}=20 \mu \mathrm{m}$. $\mathrm{c}-\mathrm{d}=5 \mu \mathrm{m}$.

Culture characteristics - Conidia germinating on MEA within 24 hours at room temperature and germ tubes produced from every cell of conidium with developing appressoria. Colonies on MEA circular, mycelium slightly raised, effuse, cultures white at first, becoming creamy white from the centre and white at the margin from above, and creamy white in reverse.

Material examined - Thailand, Chiang Mai Province, Muang District, Mae Hia Agricultural Research, Demonstrative and Training Center, on dried leaf of Hevea brasiliensis (Euphorbiaceae), 22 September 2016, C. Senwanna, RBCM05 (MFLU 19-0222), living culture MFLUCC 17-0382 (new host record).

Host and distribution - Acoelorrhaphe wrightii (Thailand; Ariyawansa et al. 2015), unidentified grass (China; Hyde et al. 2017), Fragaria sp., Phaseolus vulgaris, Poa annua and Vitis vinifera (Italy; Liu et al. 2018a), Pandanus amaryllifolius (Thailand; Tibpromma et al. 2018), Chromolaena odorata (Thailand; Mapook et al. 2020), Hevea brasiliensis (Thailand; this study).

GenBank numbers - MFLUCC 17-0382: ITS = OL782143, LSU = OL782060.

Notes - In a BLASTn search, the closest match of the ITS and LSU sequences with $99.45 \%$ (MH388364) and 100\% (MH376738) similarity, respectively was Pseudopithomyces pandanicola. Pseudopithomyces was introduced by Ariyawansa et al. (2015) with P. chartarum (type species). The genus is characterized by brown to black colonies on the host and fusiform, verruculose dark conidia (Ariyawansa et al. 2015). In our phylogenetic analyses, MFLUCC 17-0382 strain clusters with $P$. palmicola (Fig. 22). The collection is similar to P. palmicola (Ariyawansa et al. 2015) (Table 2). We, therefore, name our collection as $P$. palmicola and this is the first report of this species on Hevea brasiliensis. 
Table 2 Synopsis of recorded Pseudopithomyces species.

\begin{tabular}{|c|c|c|c|c|}
\hline \multirow{2}{*}{$\begin{array}{l}\text { Pseudopithomyces } \\
\text { species }\end{array}$} & \multicolumn{3}{|c|}{ Size $(\mu \mathrm{m})$} & \multirow[t]{2}{*}{ Reference } \\
\hline & Conidiophore & Conidiogenous cell & Conidia & \\
\hline P. angolensis & $10-25 \times 2-3.5$ & $7-15 \times 2-3.5$ & $\begin{array}{l}(28-) 30-34(-37) \times(7-) 8(- \\
9) ; \text { brown appendage; } 3 \\
\text { transverse septa }\end{array}$ & Crous et al. 2018a \\
\hline P. atro-olivaceus & - & - & $\begin{array}{l}14-35 \times 7-10 ; 3-6 \\
\text { transverse septa }\end{array}$ & Ellis 1971 \\
\hline P. chartarum & $2-5 \times 1.5-2.5$ & - & $\begin{array}{l}18-29 \times 10-17 ; 3-4 \\
\text { transverse septa }\end{array}$ & $\begin{array}{l}\text { Ariyawansa et al. } \\
2015\end{array}$ \\
\hline P. diversisporus & $2-4.5 \times 2-2.5$ & - & $\begin{array}{l}20-38 \times 7-11 ;(1-) 2-3(-5) \\
\text { transverse septa }\end{array}$ & Crous et al. 2016 \\
\hline P. entadae & - & - & $\begin{array}{l}10-14 \times 6-9 ; 1-2 \\
\text { transverse septa and } 1 \\
\text { longitudinal septum }\end{array}$ & Jayasiri et al. 2019 \\
\hline P. karoo & - & - & $\begin{array}{l}17-30 \times 8-18 ; 2 \text { transverse } \\
\text { septa and } 1 \text { longitudinal } \\
\text { septum }\end{array}$ & Ellis 1976 \\
\hline P. maydicus & - & - & $\begin{array}{l}12-20 \times 6-12 ; \text { mostly } 2 \\
\text { transverse septa }\end{array}$ & Ellis 1971 \\
\hline P. palmicola & $3.6-6 \times 3.2-3.5$ & $3.5-5.5 \times 2.5-3.5$ & $\begin{array}{l}21.5-30.5 \times 10-16.5 ; \\
\text { mostly } 3 \text { transverse septa }\end{array}$ & $\begin{array}{l}\text { Ariyawansa et al. } \\
2015\end{array}$ \\
\hline P. palmicola & $6-12(-15) \times 2-4$ & $4.5-10.8 \times 2.2-4$ & $\begin{array}{l}(9-) 12-24(-26) \times 6-14(- \\
16) ; \text { mostly } 3 \text { transverse } \\
\text { septa and } 1-3 \text { longitudinal } \\
\text { septa }\end{array}$ & This study \\
\hline P. rosae & $7-9 \times 4-7$ & $3-5 \times 2-4$ & $\begin{array}{l}13-30 \times 9-20 ; \text { with } 3 \\
\text { transverse septa and } 1 \\
\text { longitudinal septum }\end{array}$ & $\begin{array}{l}\text { Wanasinghe et al. } \\
2018\end{array}$ \\
\hline P. sacchari & - & - & $\begin{array}{l}12-25 \times 5-15 ; 1-2 \\
\text { transverse septa }\end{array}$ & Ellis 1971 \\
\hline
\end{tabular}

Hermatomycetaceae Locq.

Hermatosphaeriaceae was established to accommodate the single genus Hermatomyces which has been commonly reported as saprobic on plants in terrestrial habitats (Hashimoto et al. 2017, Hongsanan et al. 2020a). The genus is characterized by sporodochia conidiomata, lenticular to cylindrical, muriform conidia and lack a known sexual morph (Doilom et al. 2017, Hashimoto et al. 2017). In this study, we follow the updated classification by Koukol et al. (2018), Phukamsakda et al. (2020) and Ren et al. (2021).

Hermatomyces sphaericus (Sacc.) S. Hughes, Mycological Papers 50: 100 (1953)

Fig. 25

Index Fungorum number: IF298410

Saprobic on dried branch of Hevea brasiliensis. Sexual morph: Undetermined. Asexual morph: Colonies on natural substrate dry, blackish brown, velvety, circular or oval, doughnutshaped, dull, consisting of a sterile mycelial outer zone and a round, glistening, abundantly sporulating center. Mycelium 2-3 $\mu \mathrm{m}$ wide, superficial, composed of a network of branched, septate, brown, thick-walled, smooth hyphae. Conidiophores $9-53 \times 2.5-3(\bar{x}=27 \times 3 \mu \mathrm{m}, \mathrm{n}=13)$, micronematous, straight or flexuous, pale to dark brown, smooth, unbranched, arising from prostrate hyphae at the center of circular colony. Conidiogenous cells holoblastic, monoblastic, integrated, terminal, cylindrical, subhyaline. Conidia (16-)18-27(-29.2) $\mu \mathrm{m}$ high, (12-)16-26 $\mu \mathrm{m}$ wide $(\bar{x}=23.7 \times 20.2 \mu \mathrm{m}, \mathrm{n}=31)$, broadly ellipsoidal, lenticular in front view, fattened and diskshaped in lateral view, with subhyaline peripheral cells surrounding central with blackish-brown cells, thick-walled, smooth.

Culture characteristics - Conidia germinating on MEA within 24 hours at room temperature and germ tubes produced from every cell of the conidium. Colonies on MEA circular, slightly 
raised, surface smooth with entire edge, whitish grey to grey at the surface with white margin and light brown from the centre of the colony in reverse with creamy-white margin.

Material examined - Thailand, Chiang Rai Province, Wiang Chiang Rung District, on dried branch of Hevea brasiliensis (Euphorbiaceae), 1 November 2016, C. Senwanna, RBCR07 (MFLU 19-0228), living culture MFLUCC 17-0373 (new host record).

Host and distribution - Wide host range, widely distributed in tropical and subtropical regions.

GenBank numbers - MFLUCC 17-0373: ITS = OL782144, LSU $=$ OL782061, $\mathrm{SSU}=$ OL780526, TEF1 = OL875103, RPB2 = OL828753.

Notes - In a BLASTn search of NCBI GenBank, the closest match of the ITS, LSU, SSU, TEF1 and RPB2 sequence of our strain with $99.4 \%, 100 \%, 99.9 \%, 100 \%$ and $99.9 \%$ similarity, respectively, was Hermatomyces sphaericus. In the present phylogenetic analysis, MFLUCC 170373 cluster with $H$. sphaericus (Fig. 24). Our collection is similar to H. sphaericus described by Hughes (1953) and Koukol et al. (2018). We, therefore, name our collection as H. sphaericus which is a new host record for Hevea brasiliensis in Thailand. It should be noted that H. sphaericus is a poorly supported group and is likely to represent a species complex. Thus, further work is needed on this group with more collections or more informative genes.

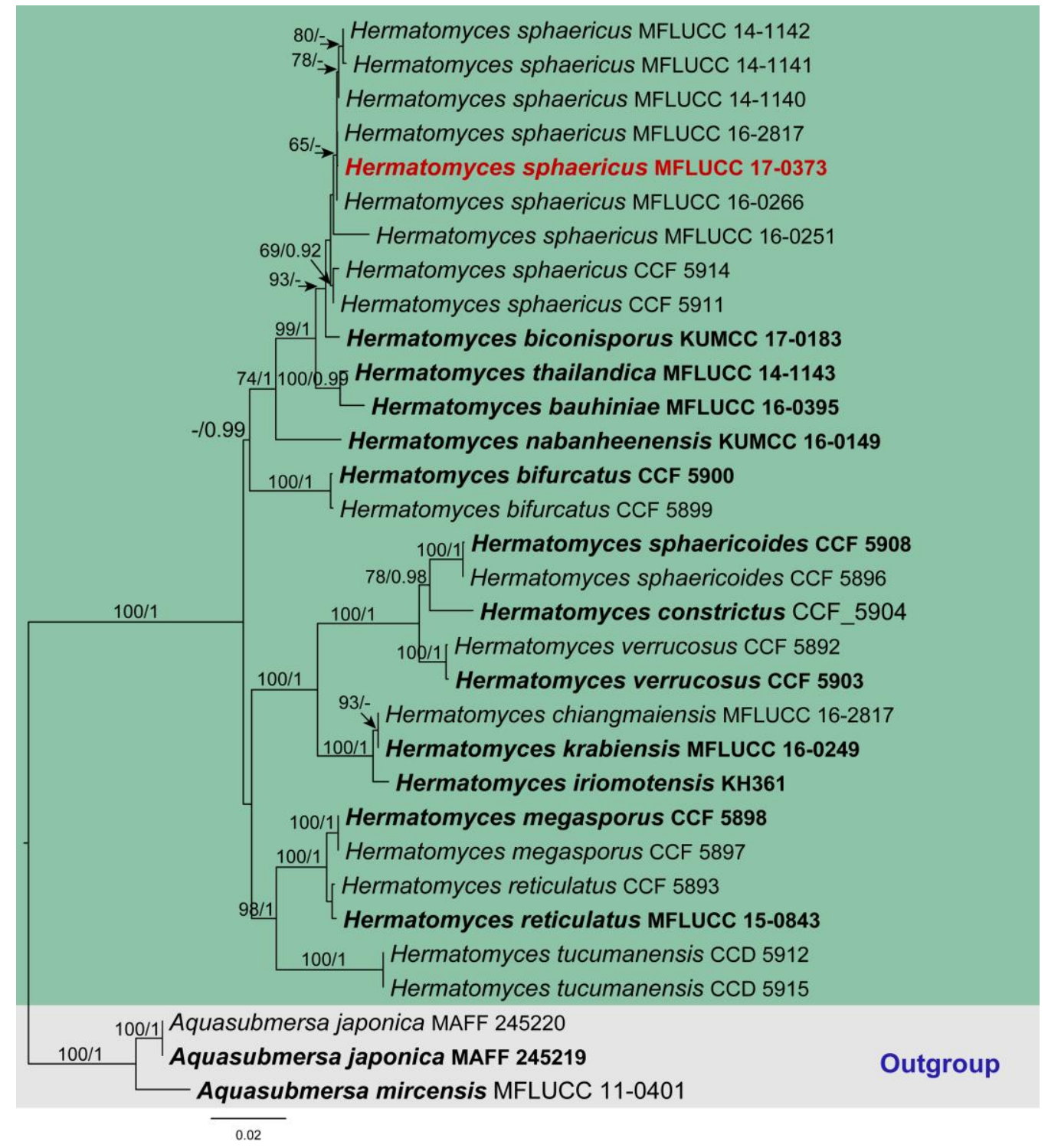

Figure 24 - RAxML tree of Hermatomyces based on a combined LSU, SSU, ITS, TEF1 and RPB2 sequence dataset. Thirty strains are included in the combined sequence analysis, which comprise 
4417 characters with gaps. Tree topology of the ML analysis was similar to the BYPP. The best scoring RAxML tree with a final likelihood value of -11357.352145 is presented. The matrix had 765 distinct alignment patterns, with $33.26 \%$ of undetermined characters or gaps. Estimated base frequencies were as follows: $\mathrm{A}=0.248169, \mathrm{C}=0.254390, \mathrm{G}=0.261434, \mathrm{~T}=0.236007$; substitution rates: $\mathrm{AC}=1.423292, \mathrm{AG}=5.030421, \mathrm{AT}=1.604814, \mathrm{CG}=0.958622, \mathrm{CT}=$ 14.391543, GT = 1.000000; gamma distribution shape parameter $\alpha=0.797709$. Bootstrap support values for ML equal to or greater than $60 \%$ and BYPP equal to or greater than 0.90 are defined as ML/BYPP above the nodes. Newly generated sequences are in red bold and type species are in bold. Aquasubmersa japonica (MAFF 245219 and MAFF 245220) and A. mircensis (MFLUCC 110401) are used as outgroup taxa.
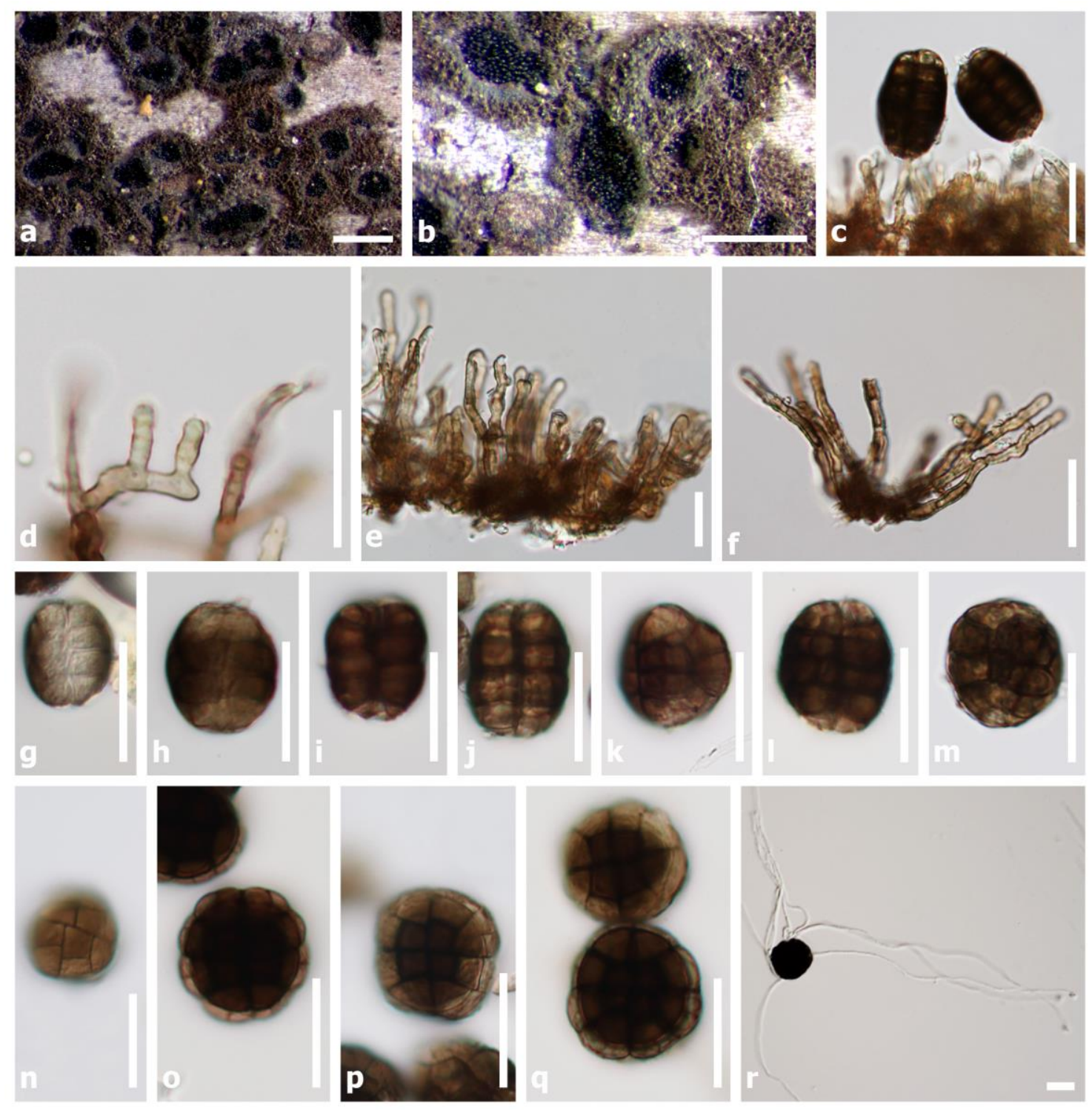

Figure 25 - Hermatomyces sphaericus (MFLU 19-0228, new host record). a-b Habit on substrate. c Conidia and conidiophores. $d-f$ Conidiophores. g- $q$ Conidia. $r$ Germinated spore. Scale bars: $a-b$ $=500 \mu \mathrm{m}, \mathrm{c}-\mathrm{r}=20 \mu \mathrm{m}$.

\section{Lophiostomataceae Sacc.}

There are 28 genera listed in Lophiostomataceae which are saprobes on herbaceous and woody plants in terrestrial and aquatic habitats (Thambugala et al. 2015, Hashimoto et al. 2017, Jayasiri et al. 2019, Hongsanan et al. 2020b, Mapook et al. 2020). In this study, a new host record for Vaginatispora amygdali is reported together with descriptions and illustrations. 


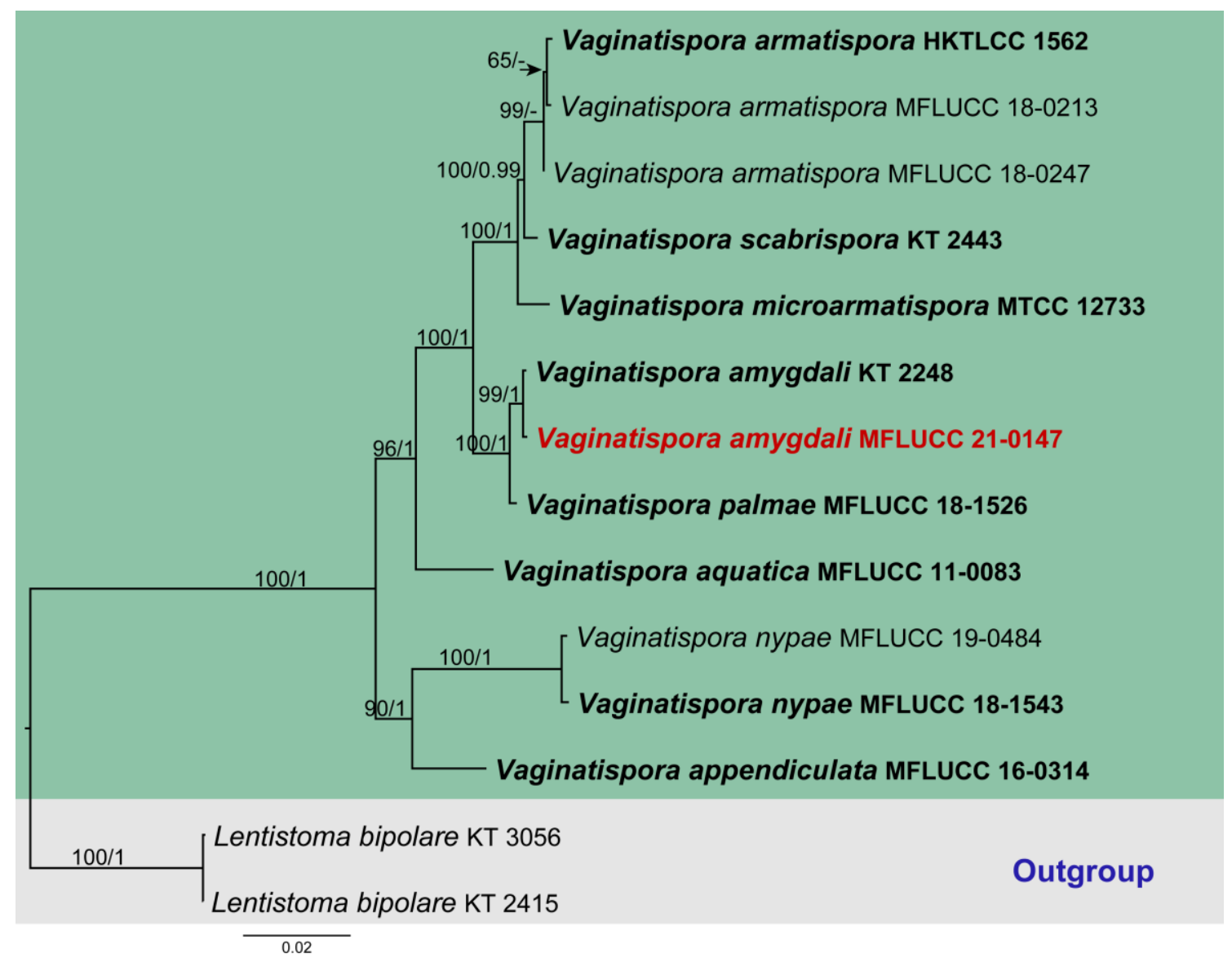

Figure 26 - RAxML tree of Vaginatispora based on a combined LSU, SSU, ITS, TEF1 and RPB2 sequence dataset. Fourteen strains are included in the combined sequence analysis, which comprise 4627 characters with gaps. Tree topology of the ML analysis was similar to the BYPP. The best scoring RAxML tree with a final likelihood value of -9807.737828 is presented. The matrix had 474 distinct alignment patterns, with $25.73 \%$ of undetermined characters or gaps. Estimated base frequencies were as follows: $\mathrm{A}=0.246544, \mathrm{C}=0.249060, \mathrm{G}=0.270437, \mathrm{~T}=0.233959$; substitution rates: $\mathrm{AC}=1.365166, \mathrm{AG}=2.333774, \mathrm{AT}=0.793336, \mathrm{CG}=1.076903, \mathrm{CT}=$ 7.127814, GT $=1.000000$; gamma distribution shape parameter $\alpha=0.621507$. Bootstrap support values for ML equal to or greater than $60 \%$ and BYPP equal to or greater than 0.90 are defined as ML/BYPP above the nodes. Newly generated sequences are in red bold and type species are in bold. Lentistoma bipolare (KT 2415 and KT 3056) are used as outgroup taxa.

Vaginatispora amygdali A. Hashim., K. Hiray. \& Kaz. Tanaka, in Hashimoto et al., Stud. Mycol. 90: 179 (2018) Fig. 27

Index Fungorum number: IF 823145

Saprobe on twig (attached on tree) of Hevea brasiliensis. Sexual morph: Ascomata 260-610 $\times 270-640 \mu \mathrm{m}$, scattered, immersed, globose to subglobose. Ostiolar crest-like, black, central. Peridium 12-42 $\mu \mathrm{m}(\bar{x}=27 \mu \mathrm{m}, \mathrm{n}=30)$ wide, composed of cells of textura angularis at the sides, outer layers dark brown to black, inner layers hyaline, thin-walled. Pseudoparaphyses 1.2-3.8 $\mu \mathrm{m}$ $(\bar{x}=2.7 \mu \mathrm{m}, \mathrm{n}=20)$ wide, hyaline, dense, septate, branched, filamentous. Asci (67-)70-105(-111) $\times 12-18(-20) \mu \mathrm{m}(\bar{x}=91 \times 16 \mu \mathrm{m}, \mathrm{n}=12), 8$-spored, bitunicate, fissitunicate, cylindric-clavate, short pedicellate, apically rounded. Ascospores $23-35(-39) \times(4-) 6-8.5(-10) \mu \mathrm{m}(\bar{x}=25 \times 7 \mu \mathrm{m}, \mathrm{n}$ $=80$ ), overlapping biseriate, hyaline, fusiform with obtuse ends, 1-septate, constricted at septum, smooth-walled, guttulate, surrounded by a narrow mucilaginous sheath and drawn out towards each end to form tapering appendages, $(3-) 5.5-9 \mu \mathrm{m}(\bar{x}=6.9 \mu \mathrm{m}, \mathrm{n}=80)$ long, with an internal chamber at both ends. Asexual morph: Undetermined. 
Culture characteristics - Ascospores germinating on MEA within 24 hours at room temperature and germ tubes produced from both ends. Colonies on PDA circular, mycelium slightly raised, effuse, cultures dark brown and light brown aerial mycelium at the margin.

Material examined - Thailand, Loei Province, Mueang District, on branch (attached on tree) of Hevea brasiliensis (Euphorbiaceae), 23 July 2019, C. Senwanna, RBLOEI07 (MFLU 21-0197), living culture MFLUCC 21-0147.

Host and distribution - Amygdalus persica (Japan; Hashimoto et al. 2017), Hevea brasiliensis (Thailand; this study).

GenBank numbers - MFLUCC 21-0147: ITS = OL782145, LSU = OL782062, TEF1 = OL875104.

Notes - Phylogenetic analyses show that the strain MFLUCC 21-0147 grouped with the type strain of Vaginatispora amygdali (KT 2248) with high bootstrap support (Fig. 26). In a BLASTn search, the closest match of the LSU sequence of our strains with $100 \%$ similarity was $V$. amygdali (KT 2248, LC312553) and V. appendiculata (MFLUCC 13-0835, KY264745), while the closest match to the ITS and TEF1 sequence with $100 \%$ similarity was $V$. amygdali (KT 2248, LC312582). Our collection is similar to the type strain, which was described from endocarp of Amygdalus persica in Japan (Hashimoto et al. 2017). We, therefore, name our collection as $V$. amygdali, which is a new record for Hevea brasiliensis in Thailand.

Neohendersoniaceae Giraldo \& Crous

Neohendersoniaceae was established by Giraldo et al. (2017) to accommodate Neohendersonia. According to Hongsanan et al. (2020b), there are five genera listed in this family viz. Brevicollum, Crassiparies, Medicopsis, Neohendersonia and Neomedicopsis. Members of the Neohendersoniaceae are saprobic in terrestrial habitats (Li et al. 2016, Giraldo et al. 2017, Tanaka et al. 2017, Hyde et al. 2018, Crous et al. 2019).

Brevicollum hyalosporum Kaz. Tanaka \& Toy. Sato, in Tanaka et al., Mycologia 109(4): 611 (2017)

Fig. 29

Index Fungorum number: IF821756

Descriptions and illustrations - See Hyde et al. (2018)

Material examined - Thailand, Chiang Mai Province, Mueang District, on twig (attached on tree) of Hevea brasiliensis (Euphorbiaceae), 1 July 2017, C. Senwanna, RBCM22 (MFLU 210185), living culture MFLUCC 18-0305, ibid., Chiang Mai Province, Mueang District, on twig (attached on tree) of Hevea brasiliensis (Euphorbiaceae), 1 July 2017, C. Senwanna, RBCM24 (MFLU 21-0186), living culture MFLUCC 18-0306.

Host and distribution - Syzygium samarangense (Japan; Tanaka et al. 2017), Hevea brasiliensis (Thailand; Hyde et al. 2018, this study).

GenBank numbers - MFLUCC 18-0305: LSU = OL782063; MFLUCC 18-0306: ITS = OL782146, LSU = OL782064.

Notes - Brevicollum was established to accommodate $B$. hyalosporum and $B$. versicolor (Tanaka et al. 2017). The genus is characterized by immersed, globose to depressed globose ascomata, clavate asci and broadly fusiform, 3-5-septate ascospores. In the present phylogenetic analysis, MFLUCC 18-0305 and MFLUCC 18-0306 cluster with B. hyalosporum (MAFF 243400, type species) and MFLUCC 14-0071 (collection from Hevea brasiliensis) with high bootstrap support (Fig. 28). We, therefore, name our collection as B. hyalosporum.

Crassiparies octosporarum Senwanna, Cheewangkoon \& K.D. Hyde, sp. nov.

Fig. 30

Index Fungorum number: IF559359

Etymology - The epithet "octosporarum" refers to the 8-spored asci.

Saprobe on twig (attached on tree) of Hevea brasiliensis. Sexual morph: Ascomata 180-400 $\mu \mathrm{m}$ high, 180-355 $\mu \mathrm{m}$ diam., scattered, sometimes in groups of 2-3, immersed globose to subglobose, with a central ostiole. Peridium 11-22 $\mu \mathrm{m}(\bar{x}=15 \mu \mathrm{m}, \mathrm{n}=20)$ wide, composed of cell 
of textura angularis, thick at the sides, thin at base, outer layers dark brown to black, inner layers hyaline, thin-walled. Pseudoparaphyses $1.3-3 \mu \mathrm{m}(\bar{x}=2 \mu \mathrm{m}, \mathrm{n}=20)$ wide, dense, hyaline, septate, branched, filamentous. Asci (55-)83-129(-134) $\times(13-) 17.5-26(-28) \mu \mathrm{m}(\bar{x}=111 \times 22 \mu \mathrm{m}, \mathrm{n}=$ 25), 8-spored, bitunicate, fissitunicate, cylindric-clavate or clavate, short pedicellate, apically rounded. Ascospores $(23-) 28-35(-40) \times 8-12(-14) \mu \mathrm{m}(\bar{x}=31 \times 10 \mu \mathrm{m}, \mathrm{n}=50)$, overlapping biseriate, hyaline, broadly fusiform, thick-walled, with a septum mostly submedian, 1-septate, constricted at septum, smooth-walled, guttulate, without a mucilaginous sheath. Asexual morph: Undetermined.
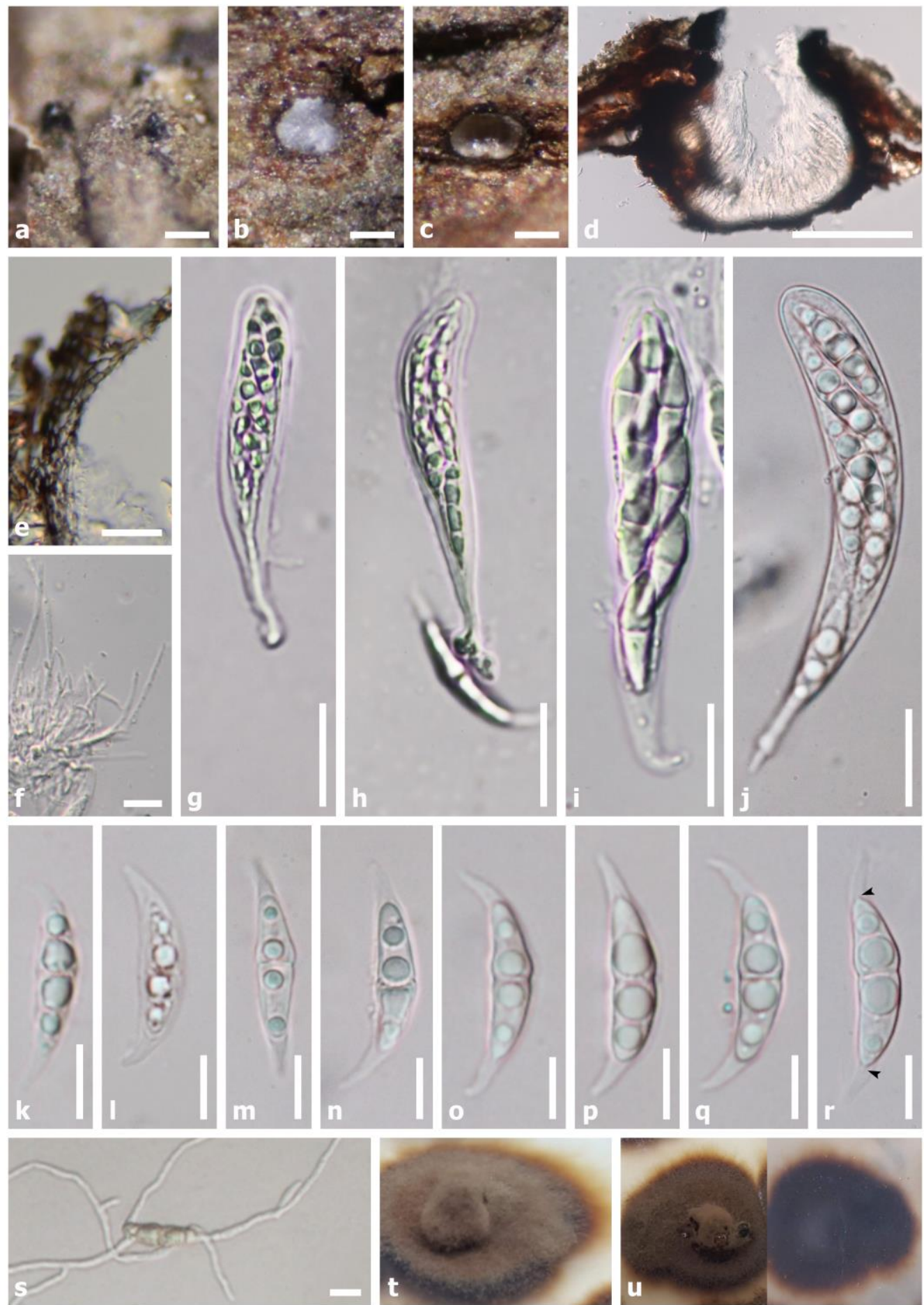

Figure 27 - Vaginatispora amygdali (MFLU 21-0197, new host record). a Habit of ascoma. b Transverse sections through ascomata. c Vertical section through ascoma. d Section through ascoma. e Peridium. f Pseudoparaphyses. g-j asci. $\mathrm{k}-\mathrm{q}$ Ascospores. $\mathrm{r}$ Arrowheads indicate an 
internal chamber at both ends of ascospore. $\mathrm{s}$ Germinated ascospore. $\mathrm{t}$, $\mathrm{u}$ Culture characteristic on PDA after 3 months. Scale bars: $\mathrm{a}-\mathrm{d}=200 \mu \mathrm{m}, \mathrm{e}-\mathrm{j}=20 \mu \mathrm{m}, \mathrm{k}-\mathrm{s}=20 \mu \mathrm{m}$.

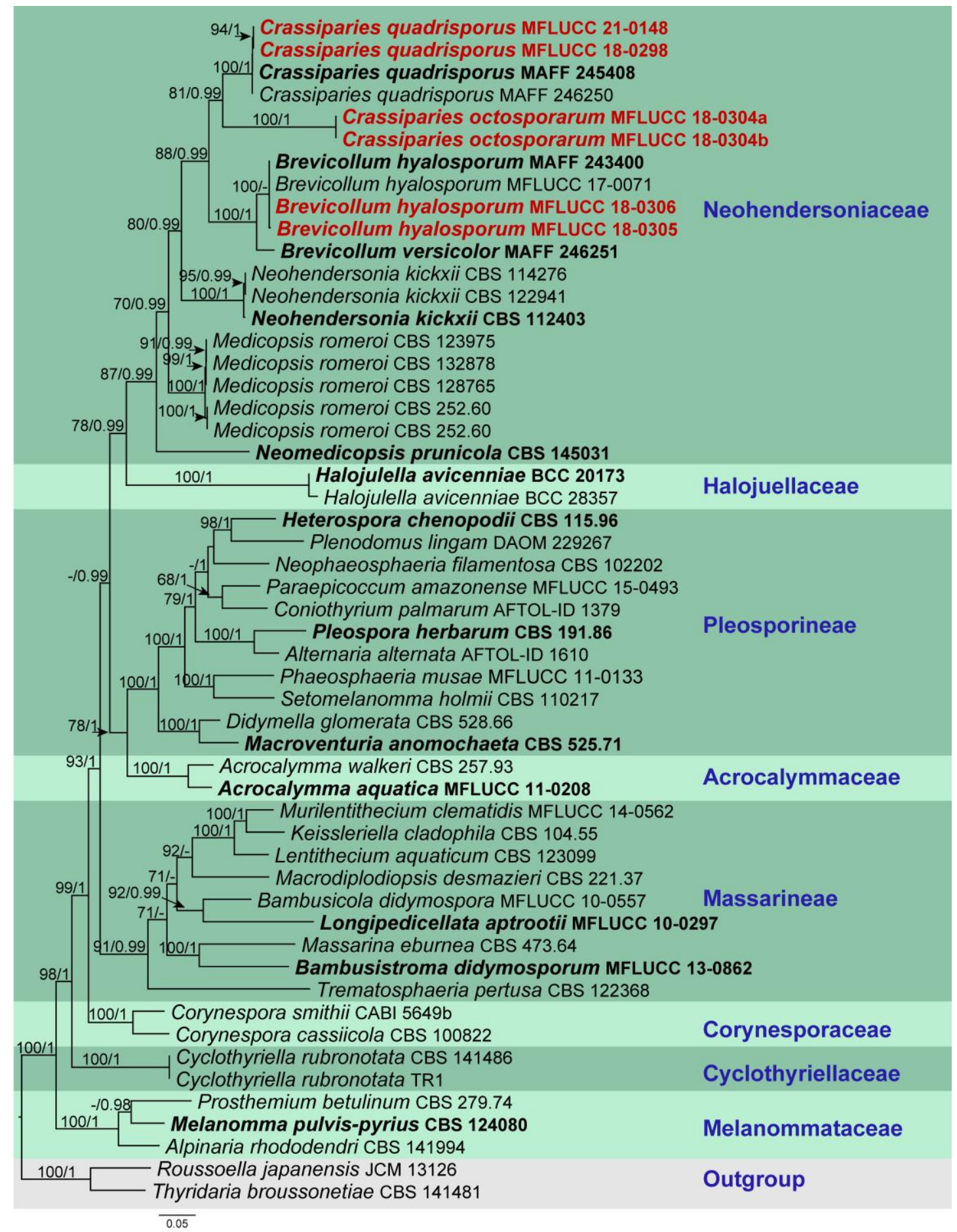

Figure 28 - RAxML tree of Neohendersoniaceae based on a combined LSU, SSU, ITS, TEF1 and RPB2 sequence dataset. Fifty-three strains are included in the combined sequence analysis, which comprise 5029 characters with gaps. Tree topology of the ML analysis was similar to the BYPP. The best scoring RAxML tree with a final likelihood value of -42571.938944 is presented. The matrix had 2169 distinct alignment patterns, with $33.08 \%$ of undetermined characters or gaps. Estimated base frequencies were as follows: $\mathrm{A}=0.244632, \mathrm{C}=0.248770, \mathrm{G}=0.268959$, $\mathrm{T}=0.237639$; substitution rates: $\mathrm{AC}=1.476624, \mathrm{AG}=3.617383, \mathrm{AT}=1.621981, \mathrm{CG}=1.194981$, $\mathrm{CT}=7.377308, \mathrm{GT}=1.000000$; gamma distribution shape parameter $\alpha=0.664131$. Bootstrap support values for ML equal to or greater than $60 \%$ and BYPP equal to or greater than 0.90 are 
defined as ML/BYPP above the nodes. Newly generated sequences are in red bold and type species are in bold. Roussoella japanensis (JCM 13126) and Thyridaria broussonetiae (CBS 141481) are used as outgroup taxa.
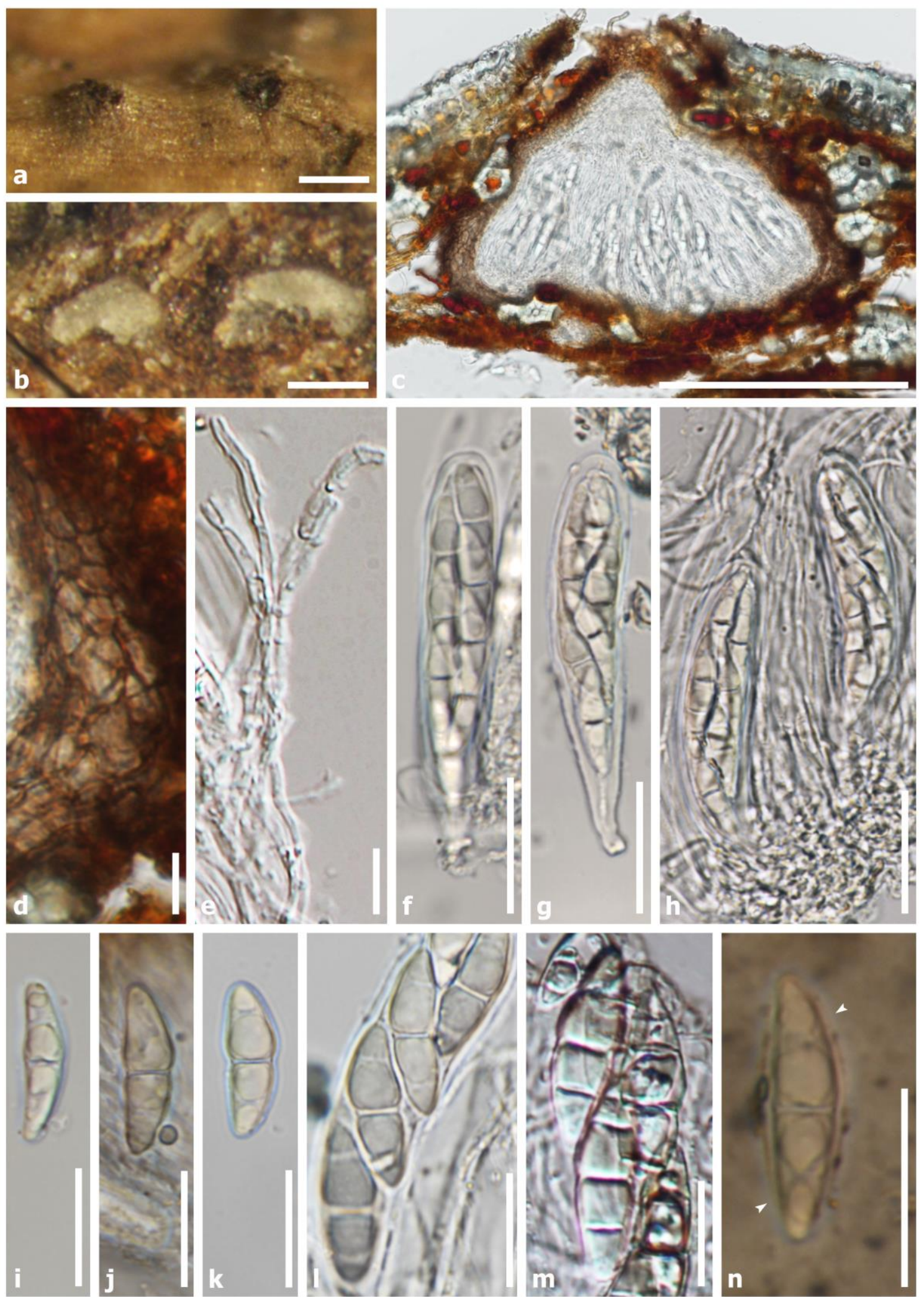

Figure 29 - Brevicollum hyalosporum (MFLU 21-0185). a Habit of ascoma. b, c Transverse sections through ascomata. $d$ Peridium. e Pseudoparaphyses. $\mathrm{f}-\mathrm{h}$ asci. $\mathrm{i}-\mathrm{m}$ Ascospores (mounted in 
double-distilled water). $\mathrm{n}$ Arrowheads indicate gelatinous sheath surrounding ascospores after treating with India ink. Scale bars: $\mathrm{a}-\mathrm{c}=200 \mu \mathrm{m}, \mathrm{d}-\mathrm{e}=10 \mu \mathrm{m}, \mathrm{f}-\mathrm{h}=30 \mu \mathrm{m}, \mathrm{i}-\mathrm{n}=20 \mu \mathrm{m}$.
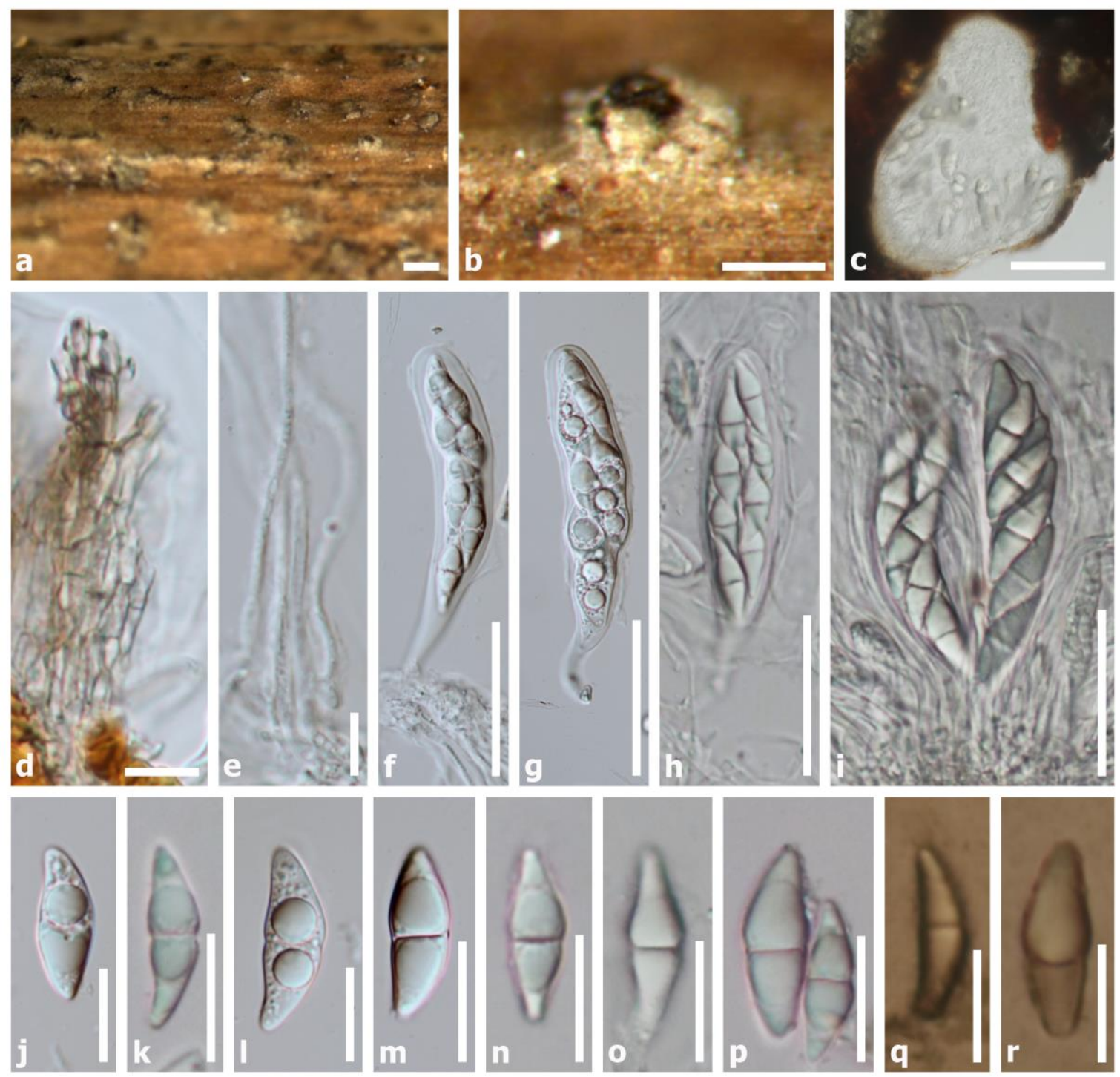

Figure 30 - Crassiparies octosporarum (MFLU 21-0188, holotype), a, b Habit of ascoma. $\mathrm{c}$ transverse sections through ascomata. d Peridium. e Pseudoparaphyses. $\mathrm{f}-\mathrm{i}$ Asci. $\mathrm{j}-\mathrm{p}$ Ascospores (mounted in double-distilled water). q, $\mathrm{r}$ Ascospores (stained in Indian ink). Scale bars: $\mathrm{a}=500 \mu \mathrm{m}$, $\mathrm{b}=200 \mu \mathrm{m}, \mathrm{c}=100 \mu \mathrm{m}, \mathrm{d}-\mathrm{e}=10 \mu \mathrm{m}, \mathrm{f}-\mathrm{i}=50 \mu \mathrm{m}, \mathrm{j}-\mathrm{r}=20 \mu \mathrm{m}$.

Culture characteristics - Ascospores germinating on MEA within 24 hours at room temperature and germ tubes produced from both ends. Colonies on MEA circular, slightly raised, with entire edge, grey at the surface with white margin and dark brown from the centre of the colony in reverse with brown aerial mycelium at the margin.

Material examined - Thailand, Chiang Mai Province, Mueang District, on twig (attached on tree) of Hevea brasiliensis (Euphorbiaceae), 1 July 2017, C. Senwanna, RBCM21 (MFLU 21-0188, holotype), ex-type living culture MFLUCC 18-0304a = MFLUCC 18-0304b.

Host and distribution - Hevea brasiliensis (Thailand; this study).

GenBank numbers - MFLUCC 18-0304a: ITS = OL782147, LSU = OL782065, TEF1 = OL875105; MFLUCC 18-0304b: LSU = OL782066.

Notes - In a BLASTn search, the closest match of the LSU and TEF1 sequence of Crassiparies octosporarum (MFLUCC 18-0304) was C. quadrisporus with $98.31 \%$ and $94.28 \%$ similarity to the strain MAFF 246250 (LC271241) and MAFF 245408 (LC271247) respectively. 
Crassiparies was introduced by Li et al. (2016) with C. quadrisporus as the type species based on molecular analyses. In our analysis, Crassiparies octosporarum forms a separate branch and clusters to C. quadrisporus (Fig. 28). Our collection fits well within the species concept of Crassiparies. Crassiparies octosporarum is introduced here as a new species and morphologically clearly differs from $C$. quadrisporus in having longer asci with 8 spores, while $C$. quadrisporus has 2-4-spored asci (Li et al. 2016, Tanaka et al. 2017).

Crassiparies quadrisporus M. Matsum., K. Hiray. \& Kaz. Tanaka, in Li et al., Fungal Divers. 78: 63 (2016)

Index Fungorum number: IF815295

Fig. 31

Saprobe on twig (attached on tree) of Hevea brasiliensis. Sexual morph: Ascomata 140-295 $\mu \mathrm{m}$ high, 150-400 $\mu \mathrm{m}$ diam., scattered, sometimes in groups of 2-4, immersed to semu-immersed, globose to subglobose, with a central ostiole. Peridium $7-19(-23) \mu \mathrm{m}$ wide $(\bar{x}=13.6 \mu \mathrm{m}, \mathrm{n}=25)$, thick at the sides, thin at base, outer layers dark brown to black, inner layers thin-walled, hyaline, composed of cells of textura angularis. Hamathecium comprising $1.2-3 \mu \mathrm{m}$ wide $(\bar{x}=1.8 \mu \mathrm{m}, \mathrm{n}=$ $25)$, dense, hyaline, septate, branched, filamentous pseudoparaphyses. Asci (71-)75-112(-118) $\times$ (13-)15-19(-20) $\mu \mathrm{m}(\bar{x}=97 \times 17 \mu \mathrm{m}, \mathrm{n}=35), 4$-spored, bitunicate, fissitunicate, cylindric-clavate or clavate, short pedicellate, apically rounded. Ascospores $(10-) 22-30(-32) \times 6-11(-12) \mu \mathrm{m}(\bar{x}=$ $26.5 \times 9.2 \mu \mathrm{m}, \mathrm{n}=50$ ), overlapping biseriate, hyaline, broadly fusiform, ends rounded, thickwalled, with a septum mostly submedian, 1-septate, minutely echinulate, guttulate, without mucilaginous sheath. Asexual morph: Undetermined.

Culture characteristics - Conidia germinating on MEA within 24 hours at room temperature and germ tubes produced from every cell of the conidium. Colonies on MEA irregular, with undulate edge, greenish brown to dark brown at the surface with white margin and brown from the centre of the colony in reverse with white margin.

Material examined - Thailand, Chiang Mai Province, Mueang District, twig (attached on tree) of Hevea brasiliensis (Euphorbiaceae), 22 September 2016, C. Senwanna, RBCM18 (MFLU 21-0189), living culture MFLUCC 18-0298; ibid, Mukdahan Province, Dong Luang District, Tambon Phang Dang, on twig (attached on tree) of Hevea brasiliensis (Euphorbiaceae), 24 July 2019, C. Senwanna, RBMUK02 (MFLU 21-0190), living culture MFLUCC 21-0148 (new host record).

Host and distribution - Acer sp. (Japan; Li et al. 2016), Machilus japonica (Japan; Tanaka et al. 2017), Hevea brasiliensis (Thailand; this study).

GenBank numbers - MFLUCC 18-0298: ITS = OL782148, LSU = OL782067, SSU = OL780527, TEF1 = OL875106; MFLUCC 21-0148: ITS $=$ OL780489, LSU $=$ OL782068, TEF1 $=$ OL875107.

Notes - Phylogenetic analyses show that the strain MFLUCC 18-0298 and MFLUCC 210148 grouped within the Crassiparies quadrisporus clade (Fig. 28). In a BLASTn search, the closest match of the LSU, ITS, SSU and TEF1 sequences with $100 \%$ similarity was $C$. quadrisporus (MAFF 245408). Our collection (MFLU 21-0189) is similar to the holotype of $C$. quadrisporus ( $\mathrm{Li}$ et al. 2016, Tanaka et al. 2017). We, therefore, identify our isolate as Crassiparies quadrisporus.

\section{Periconiaceae Nann.}

The sexual morph of Periconiaceae is characterized by scattered, immersed to erumpent, globose ascomata, oblong to cylindrical asci and broadly fusiform with 1-septate, hyaline ascospores, while the asexual morph is characterized by macronematous, mononematous conidiomata, forming spherical conidial heads, monoblastic to polyblastic, discrete and branched conidiogenous cells and globose to ellipsoidal, aseptate, catenate, brown, verruculose to echinulate conidia (Tanaka et al. 2015). Four genera are listed in this family, i.e., Bambusistroma, Flavomyces, Noosia and Periconia, which can be found as endophytes, saprobes, and plant pathogens (Crous et al. 2011, Adamčík et al. 2015, Tanaka et al. 2015, Hongsanan et al. 2020b). 

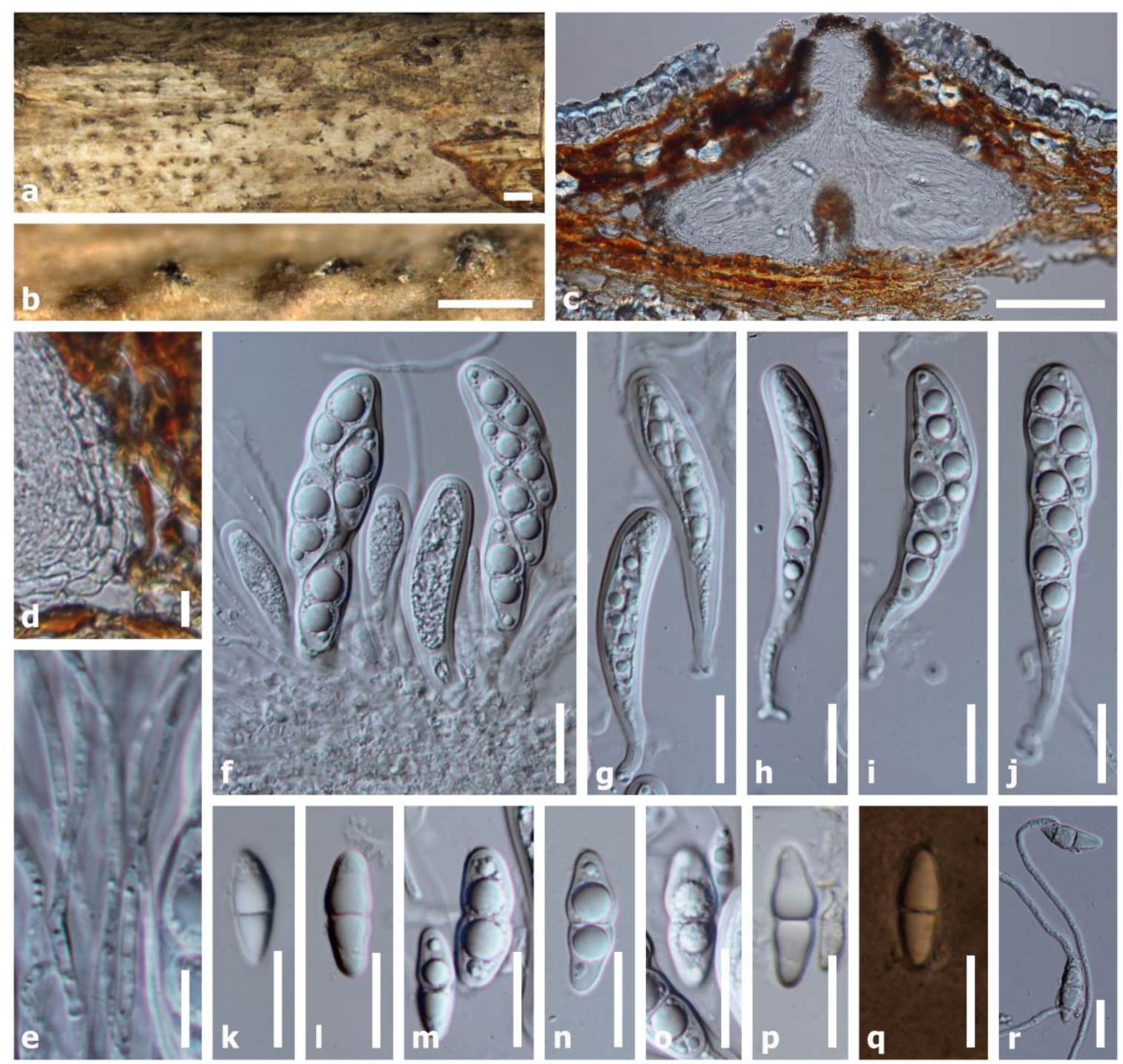

Figure 31 - Crassiparies quadrisporus (MFLU 21-0189, new host record): a, b Habit of ascoma. c Transverse section through ascoma. d Peridium. e Pseudoparaphyses. $f-j$ asci. $k-p$ Ascospores (mounted in double-distilled water). q Ascospores (stained in Indian ink). $r$ Germinated ascospore. Scale bars: $\mathrm{a}-\mathrm{b}=1000 \mu \mathrm{m}, \mathrm{c}=100 \mu \mathrm{m}, \mathrm{d}-\mathrm{e}=10 \mu \mathrm{m}, \mathrm{f}-\mathrm{r}=20 \mu \mathrm{m}$.

Periconia heveae J.A. Stev. \& Imle, Mycologia 37(5): 580 (1945)

Fig. 33

Index Fungorum number: IF 289148

Associated with spots on leaves of Hevea basiliensis. Leaf spots subcircular to circular, pale brown to brown on upper surface with dark brown margin surrounded by yellowish halo, light brown on lower surface. Sexual morph: Undetermined. Asexual morph: Conidiophores (251-) 263-320 (-450) × (16-) 18-23 $(-25) \mu \mathrm{m}(\bar{x}=298 \times 21 \mu \mathrm{m}, \mathrm{n}=13)$, mononematous, unbranched, erect, stout, straight or slightly flexuous, forming spherical heads at the apex, single, grayish brown to dark brown, mostly 2 -septate, smooth to minutely verruculose, thick-walled. Conidiogenous cells $8-15 \mu \mathrm{m}$ diam., monoblastic, discrete, terminal, globose to subglobose, brown, smooth or minute echinulate. Conidia (16-)22-37(-41) $\mu \mathrm{m}$ diam. $(\bar{x}=30.4 \mu \mathrm{m}, \mathrm{n}=45)$, solitary, in acropetal chains, globose, aseptate, light brown to dark brown, verrucose.

Culture characteristics - Conidia germinated on MEA within 12 hours and germ tube produced from the conidia. Colony circular, dense, slightly raised, surface smooth with undulate edge, velvety to woolly, slightly radiating; colony from above white to white greyish; from below: white to white greyish at the margin, light brown at the middle, and brown at the center; not producing pigmentation in agar. 
Material examined - Thailand, Phayao Province, Muang, leaf spots of Hevea brasiliensis (Euphorbiaceae), 3 January 2017, C. Senwanna, RBPY22 (MFLU 19-0248, reference specimen designated here), living culture MFLUCC 17-0341.

Host and distribution - Hevea benthamiana (Costa Rica; Spaulding 1961), H. brasiliensis (Brazil; Spaulding 1961, China; Zhuang 2001, Costa Rica; Spaulding 1961, Mexico; McGuire \& Crandall 1967, Thailand; this study), H. guianensis (Costa Rica; Spaulding 1961), H. spruceana (Costa Rica; Spaulding 1961).

GenBank numbers - MFLUCC 17-0341: ITS = OL780490, LSU = OL782069, SSU $=$ OL780528, TEF1 = OL875108.

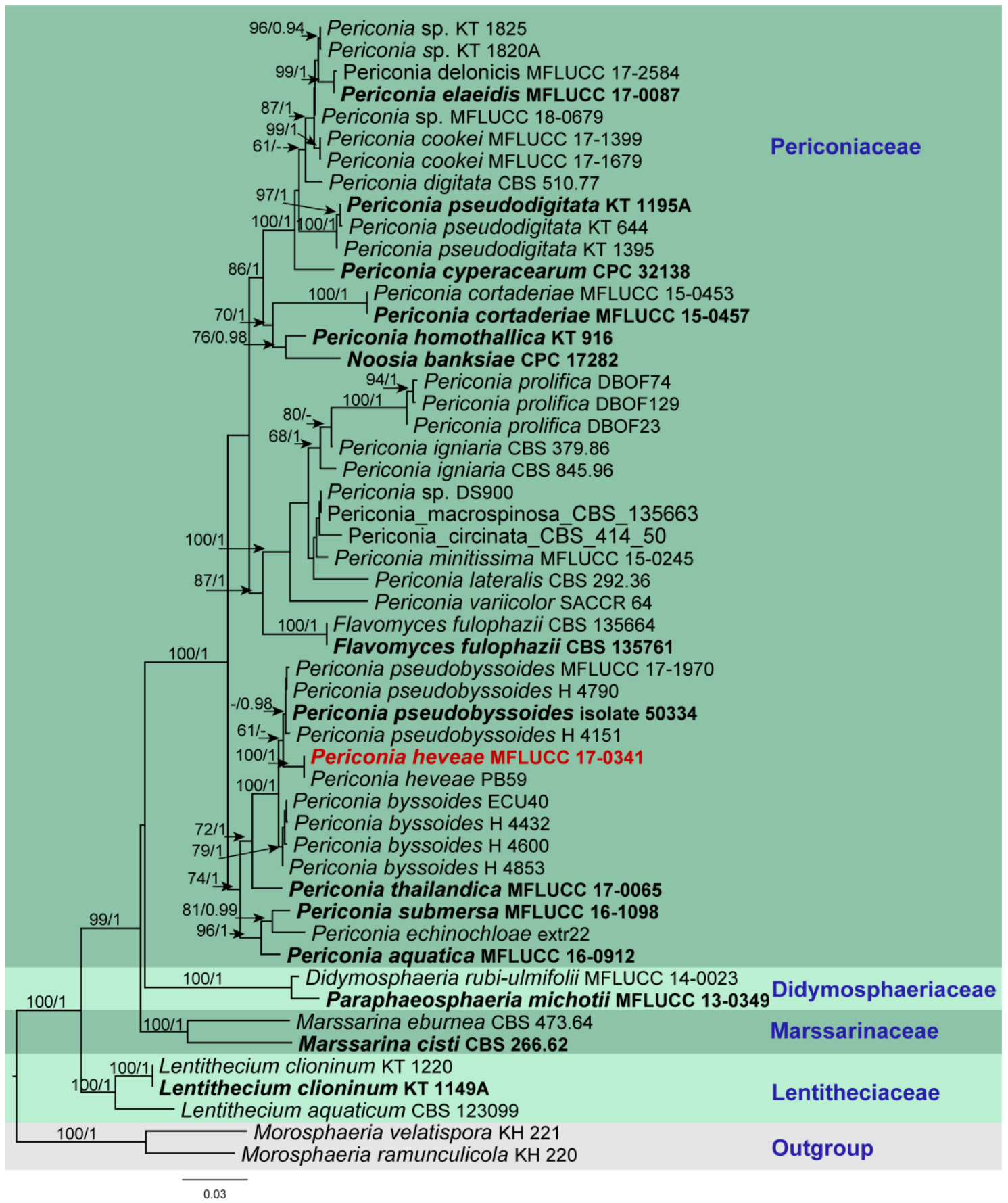

Figure 32 - RAxML tree of Periconia based on a combined LSU, ITS, SSU and TEF1 sequence dataset. Fifteen strains are included in the combined sequence analysis, which comprise 4458 characters with gaps. Tree topology of the ML analysis was similar to the BYPP. The best scoring RAxML tree with a final likelihood value of -14077.406498 is presented. The matrix had 889 
distinct alignment patterns, with $44.35 \%$ of undetermined characters or gaps. Estimated base frequencies were as follows: $\mathrm{A}=0.239377, \mathrm{C}=0.250332, \mathrm{G}=0.269372, \mathrm{~T}=0.240920$; substitution rates: $\mathrm{AC}=1.525550, \mathrm{AG}=2.537508, \mathrm{AT}=1.407167, \mathrm{CG}=1.273121, \mathrm{CT}=$ 9.595137, GT $=1.000000$; gamma distribution shape parameter $\alpha=0.500868$. Bootstrap support values for ML equal to or greater than $60 \%$ and BYPP equal to or greater than 0.90 are defined as ML/BYPP above the nodes. Newly generated sequences are in red bold and type species are in bold. Morosphaeria ramuculicola (KH 220) and M. velatispora (KH 221) are used as outgroup taxa.
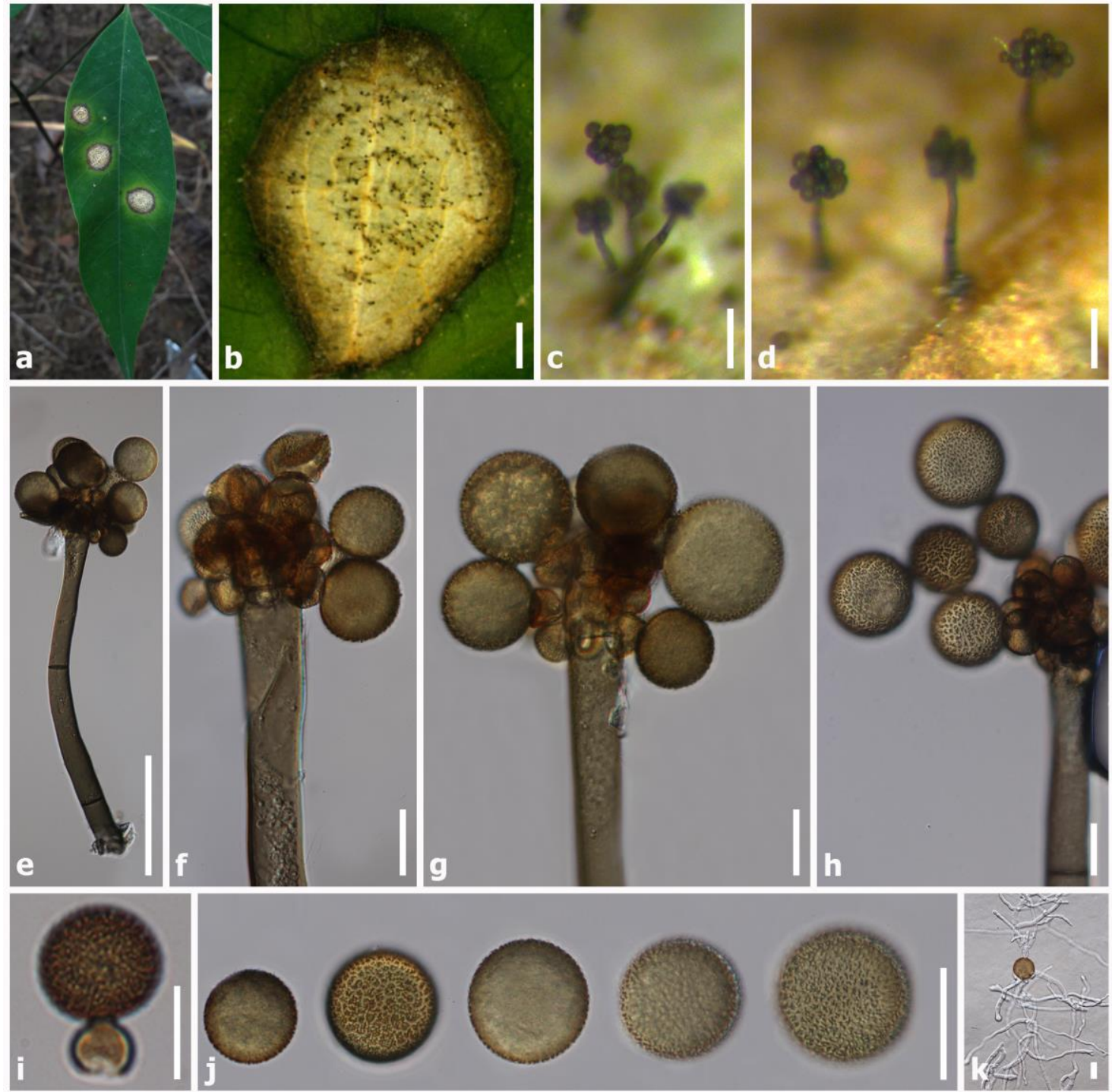

Figure 33 - Periconia heveae (MFLU 19-0248, reference specimen). a-b Leaf spots. b Close-up of lesion. $\mathrm{c}-\mathrm{d}$ Conidiophores and conidia on leaf spot. e Conidiophores with conidia. $\mathrm{f}-\mathrm{g}$ Conidiophores with conidiogenous cells and conidia. $\mathrm{h}$ Conidiophores with conidia in chains. i Conidiogenous cells and conidia. $\mathrm{j}$ Conidia. $\mathrm{k}$ Germinated spore. Scale bars: $\mathrm{b}=500 \mu \mathrm{m}, \mathrm{c}-\mathrm{d}=$ $100 \mu \mathrm{m}, \mathrm{e}=100 \mu \mathrm{m}, \mathrm{f}-\mathrm{i}=20 \mu \mathrm{m}, \mathrm{j}-\mathrm{k}=30 \mu \mathrm{m}$.

Notes - Periconia species have a cosmopolitan distribution occurring as pathogens, saprobes or endophytes on various substrates worldwide in terrestrial and marine habitats (Tanaka et al. 2015, Liu et al. 2017, Crous et al. 2018a, Hyde et al. 2018, Dayarathne et al. 2020, Phukamsakda et al. 2020). Periconia heveae was introduced by Stevenson \& Imle (1945) on Hevea spp. and morphology of our collection fits well with the description of this taxa. In the NCBI BLASTn search of ITS sequences, Periconia heveae most closely matches Periconia aquatica strain 
(MFLUCC 16-0912) with 93.41\% similarity. However, the sequence of Periconia heveae is not available in GenBank. Phylogenetic analyses of LSU, ITS, SSU and TEF1 sequence dataset show that Periconia heveae (MFLUCC 17-0341) forms a distinct lineage sister to P. pseudobyssoides (Fig. 32). They are different in conidial dimension ((16-)22-37(-41) $\mu \mathrm{m}$ diam. vs (12-)15-17(-20) $\mu \mathrm{m}$ diam., respectively) (Markovskaja \& Kačergius 2013). A comparison of ITS nucleotides shows that Periconia heveae differs from P. pseudobyssoides (BILAS 50334) in 20/576 bp (3.47\%). Periconia heveae was only reported from Hevea spp. and this probably specific on Hevea (Stevenson \& Imle 1945). We, therefore, name our collection as $P$. heveae and designate our strain as a reference specimen. In phylogenetic analysis (Fig. 32), Periconia heveae clusters with $P$. byssoides (PB59) was collected from Hevea brasiliensis in China. However, we could not compare the morphology with our strain. A comparison of ITS nucleotides shows that Periconia byssoides (PB59) 100\% similarity to Periconia heveae strain MFLUCC 17-0341. We, hence, name Periconia byssoides (strain PB59) as P. heveae.

\section{Phaeoseptaceae Boonmee, Thambug. \& K.D. Hyde}

Phaeoseptaceae was introduced by Hyde et al. (2018) to accommodate Phaeoseptum, Lignosphaeria and Neolophiostoma. Pem et al. (2019) treated treated Lignosphaeria in Dothideomycetes, genera incertae sedis based on molecular analyses. According to Hongsanan et al. (2020b), Phaeoseptum and Pleopunctum were accepted in Phaeoseptaceae. The members of this family are saprobes in terrestrial and aquatic habitats (Hyde et al. 2018, Liu et al. 2019, Dayarathne et al. 2020, Hongsanan et al. 2020b, Phukamsakda et al. 2020). In this study, we follow the updated classification by Boonmee et al. (2021) and Pleopunctum heveae is introduced based on morphological characters and molecular analyses.

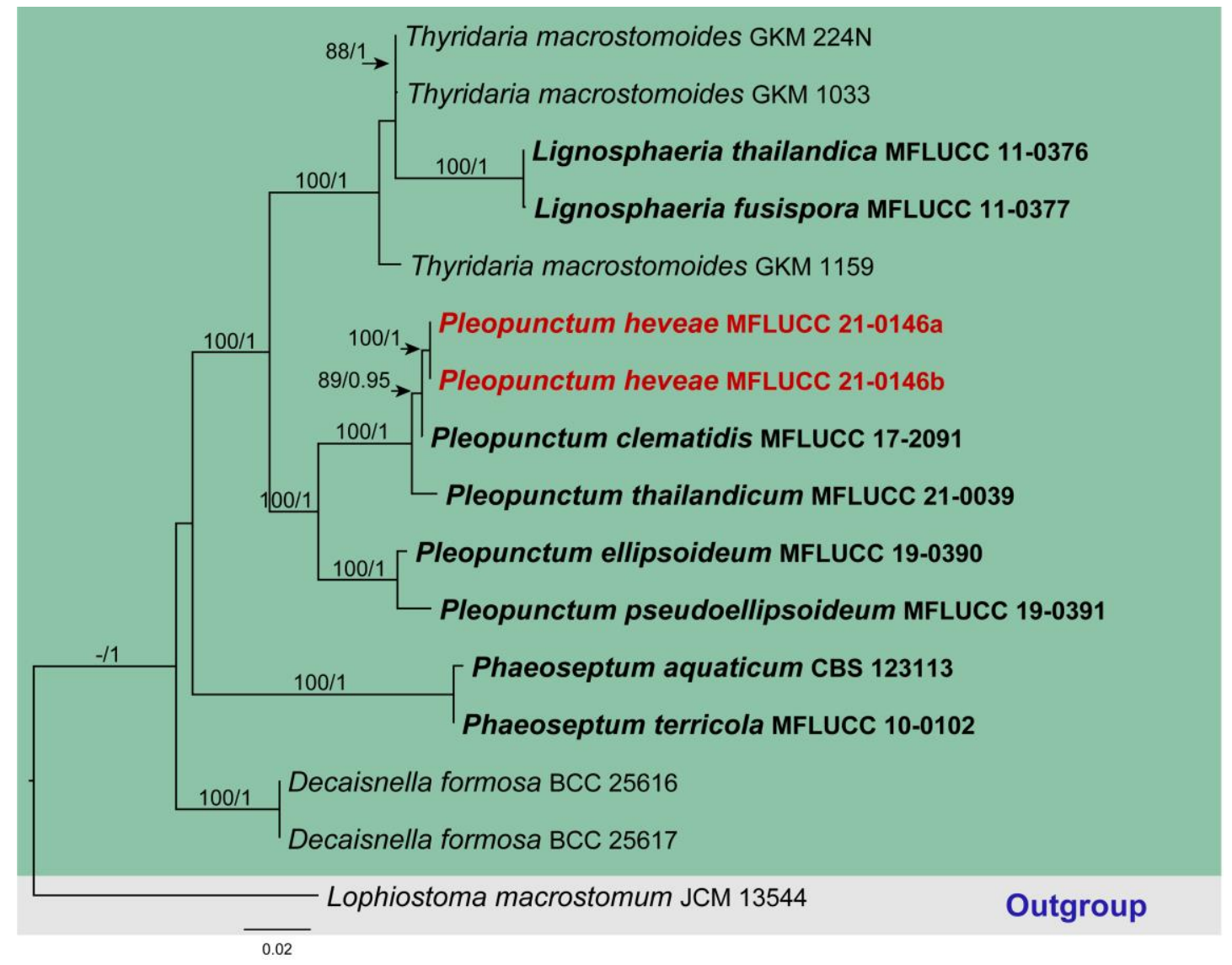

Figure 34 - RAxML tree of Pleopunctum based on a combined LSU, SSU, ITS and TEF1 sequence dataset. Sixteen strains are included in the combined sequence analysis, which comprise 3420 characters with gaps. Tree topology of the ML analysis was similar to the BYPP. The best scoring RAxML tree with a final likelihood value of -9029.635817 is presented. The matrix had 
529 distinct alignment patterns, with $43.57 \%$ of undetermined characters or gaps. Estimated base frequencies were as follows: $\mathrm{A}=0.237935, \mathrm{C}=0.258248, \mathrm{G}=0.279468, \mathrm{~T}=0.224349$; substitution rates: $\mathrm{AC}=1.281320, \mathrm{AG}=2.481340, \mathrm{AT}=1.270661, \mathrm{CG}=1.248672, \mathrm{CT}=$ 8.669740, GT $=1.000000$; gamma distribution shape parameter $\alpha=1.014728$. Bootstrap support values for ML equal to or greater than $60 \%$ and BYPP equal to or greater than 0.90 are defined as ML/BYPP above the nodes. Newly generated sequences are in red bold and type species are in bold. Lophiostoma macrostomum (JCM 13544) is used as the outgroup taxon.

Pleopunctum heveae Senwanna, Cheewangkoon \& K.D. Hyde, sp. nov.

Fig. 35

Index Fungorum number: IF559360

Etymology - Named after the host on which it occurs, Hevea brasiliensis
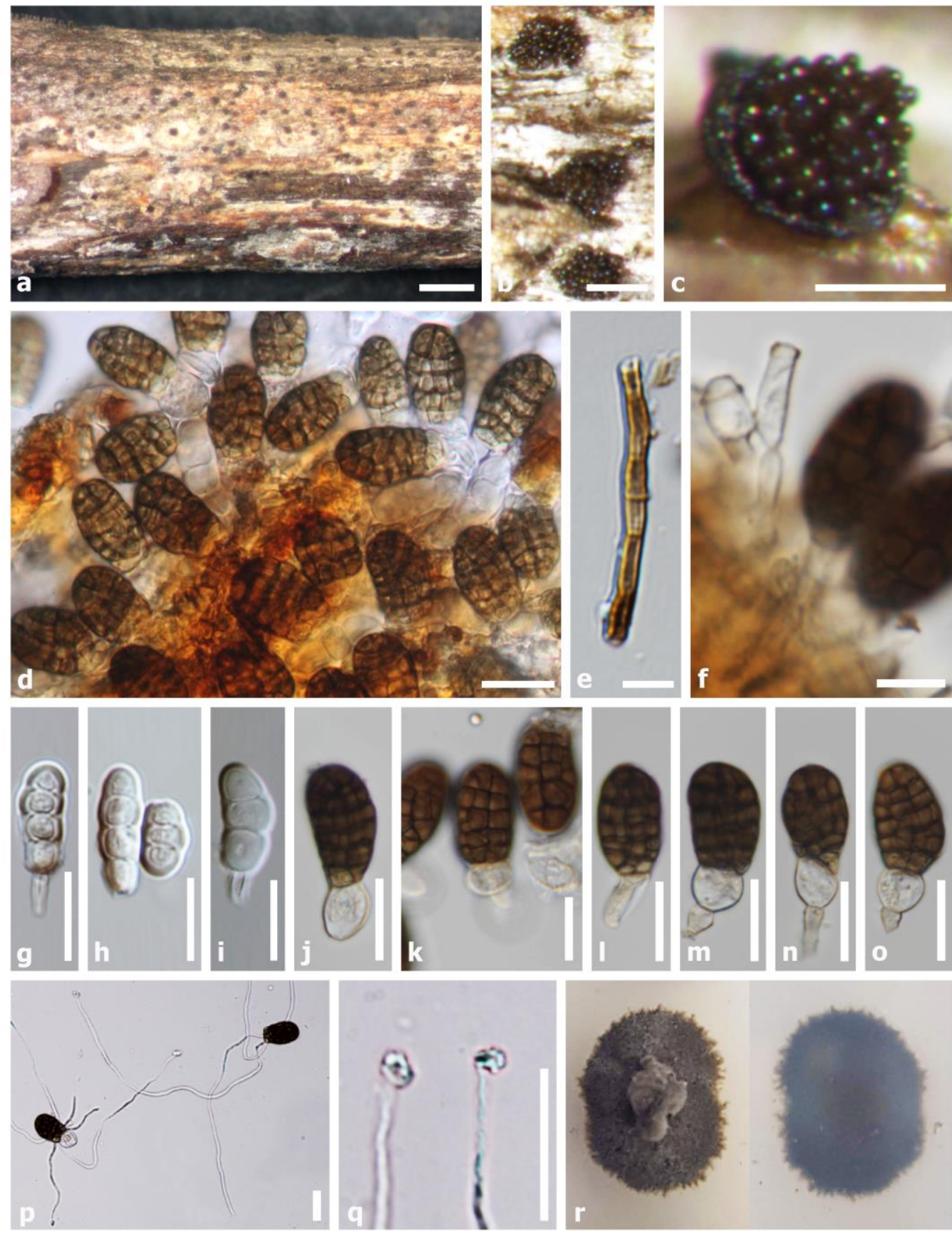

Figure 35 - Pleopunctum heveae (MFLU 21-0193, holotype). a-c Colonies on substrate. d Conidia on substrate. e Mycelium. f Conidiophores. g-i. Immature conidia. j-o Mature conidia. 
p Germinated spores. $q$ Appressoria. $r$ Culture on PDA. Scale bars: $\mathrm{a}=1000 \mu \mathrm{m}, \mathrm{b}=200 \mu \mathrm{m}, \mathrm{c}=$ $100 \mu \mathrm{m}, \mathrm{d}, \mathrm{g}-\mathrm{o}=20 \mu \mathrm{m}, \mathrm{e}, \mathrm{f}=10 \mu \mathrm{m}$.

Saprobic on dried twig of Hevea brasiliensis. Sexual morph: Undetermined. Asexual morph: Colonies on natural substrate sporodochial, superficial, dark brown, scattered, gregarious, punctiform. Mycelium 3.5-6 $\mu \mathrm{m}$ wide $(\overline{\mathrm{x}}=4.8 \mu \mathrm{m}, \mathrm{n}=10)$, immersed in the substratum, septate, subhyaline to light brown hyphae. Conidiophores $1.5-3.5 \mu \mathrm{m}$ wide $(\bar{x}=2.5 \mu \mathrm{m}, \mathrm{n}=15)$, macronematous, mononematous, cylindrical, branched, septate, hyaline. Conidiogenous cells (68.5-12(-15) $\times 3-5 \mu \mathrm{m}$ wide $(\bar{x}=10 \times 4 \mu \mathrm{m}, \mathrm{n}=15)$, monoblastic, terminal, integrated, hyaline. Conidia dimorphic, solitary, smooth-walled ; cylindrical conidia $(8.5-) 11-30(-33) \times(7.5-) 9-$ $12.5(-15) \mu \mathrm{m}$ wide $(\bar{x}=22 \times 10.7 \mu \mathrm{m}, \mathrm{n}=35)$, cylindrical to ellipsoidal, hyaline, rounded at apex, truncate at base, 2-3-transversely septate, constricted at the septa; lenticular conidia (28-)34.5$43.5(-45.5) \times 13-18(-23) \mu \mathrm{m}(\bar{x}=38.5 \times 16.3 \mu \mathrm{m}, \mathrm{n}=40)$, acrogenous, muriform, constricted at septa, oval to ellipsoidal, pale brown when immature, round at apex, truncate at base, often with a hyaline, elliptical to globose basal cell, $(4.5-) 8-13.5(-15) \mu \mathrm{m}$ high $\times(5-) 8-13.5 \mu \mathrm{m}$ wide $(\bar{x}=11 \times$ $11 \mu \mathrm{m}, \mathrm{n}=40)$. Appressoria solitary, hyaline, globose to subglobose, thick-walled.

Material examined - Thailand, Chiang Mai Province, Muang District, Mae Hia Agricultural Research, Demonstrative and Training Center, on dried twig of Hevea brasiliensis (Euphorbiaceae), 1 July 2017, C. Senwanna, RBCM12 (MFLU 21-0193, holotype), ex-type living culture MFLUCC 21-0146.

Host and distribution - Hevea brasiliensis (Thailand; this study).

GenBank numbers - MFLUCC 21-0146a: ITS = OL780491, LSU = OL782070, MFLUCC 21-0146b: ITS $=$ OL780492, LSU = OL782071.

Table 3 Synopsis of Pleopunctum species.

\begin{tabular}{|c|c|c|c|c|}
\hline Species & Conidia & Conidiogenous cell & Conidiophore & Mycelium \\
\hline $\begin{array}{l}\text { P. clematidis } \\
\text { (Phukamsakda et al. } \\
\text { 2020) }\end{array}$ & $\begin{array}{l}\text { Lenticular conidia: } \\
16-33 \times 15-23 \mu \mathrm{m} \\
\text { Cylindrical conidia: } 15-35 \times \\
6-11,2-3 \text {-septate } \\
\text { Hyaline basal cell: }-\end{array}$ & $3-8 \times 4-9 \mu \mathrm{m}$ & $\begin{array}{l}6.5-15.5 \times 2-5 \\
\mu \mathrm{m}\end{array}$ & $\begin{array}{l}3.5-4.5 \mu \mathrm{m} \\
\text { wide }\end{array}$ \\
\hline $\begin{array}{l}\text { P. heveae (This } \\
\text { study) }\end{array}$ & $\begin{array}{l}\text { Lenticular conidia: } \\
(28-) 34.5-43.5(-45.5) \times 13- \\
18(-23) \mu \mathrm{m} \\
\text { Cylindrical conidia: } 8(8.5- \\
) 11-30(-33) \times(7.5-) 9- \\
12.5(-15) \mu \mathrm{m}, 2-3 \text {-septate } \\
\text { Hyaline basal cell: }(4.5-) 8- \\
13.5(-15) \mu \mathrm{m} \times(5-) 8-13.5 \\
\mu \mathrm{m}\end{array}$ & $1.5-3.5 \mu \mathrm{m}$ wide & $\begin{array}{l}(6-) 8.5-12(-15) \\
\times 3-5 \mu \mathrm{m}\end{array}$ & $\begin{array}{l}3.5-6 \mu \mathrm{m} \\
\text { wide }\end{array}$ \\
\hline $\begin{array}{l}\text { P. ellipsoideum } \\
\text { (Liu et al. 2019) }\end{array}$ & $\begin{array}{l}\text { Lenticular conidia: } 39-51 \times \\
17-24 \mu \mathrm{m} \\
\text { Cylindrical conidia: }- \\
\text { Hyaline basal cell: } 8-20 \times \\
8.5-18.5 \mu \mathrm{m}\end{array}$ & - & $1.5-3.5 \mu \mathrm{m}$ wid & - \\
\hline $\begin{array}{l}P . \\
\text { pseudoellipsoideum } \\
\text { (Liu et al. 2019) }\end{array}$ & $\begin{array}{l}\text { Lenticular conidia: } 39-59 \times \\
19-28 \mu \mathrm{m} \\
\text { Cylindrical conidia: }- \\
\text { Hyaline basal cell: } 6.5-13.5 \\
\times 11-15.5 \mu \mathrm{m}\end{array}$ & - & $1.5-4.5 \mu \mathrm{m}$ wide & - \\
\hline $\begin{array}{l}\text { P. thailandicum } \\
\text { (Boonmee et al. } \\
\text { 2021) }\end{array}$ & $\begin{array}{l}\text { Lenticular conidia: } 29-38 \times \\
19-25 \mu \mathrm{m} \\
\text { Cylindrical conidia: }- \\
\text { Hyaline basal cell: } 8-20 \times \\
8.5-18.5 \mu \mathrm{m}\end{array}$ & - & $2.5-5 \mu \mathrm{m}$ wide & - \\
\hline
\end{tabular}


Notes - Pleopunctum is listed as the first hyphomycetous genus in Phaeoseptaceae and its sexual morph is still undetermined (Liu et al. 2019). In a BLASTn search on NCBI GenBank, the closest matches of LSU sequence of MFLUCC 21-0146a and MFLUCC 21-0146b is Lignosphaeria fusispora (MFLUCC 11-0377; KP 888646) with 93.74\% similarity, while the closest matches with the ITS sequence is $85.61 \%$ similar to Lignosphaeria fusispora (MFLUCC 11-0377; KP899140). Phylogenetically, Pleopunctum heveae clustered in the same clade with $P$. clematidis, $P$. ellipsoideum, P. pseudoellipsoideum and P. thailandicum with high statistical support and formed a sister clade to P. clematidis (Fig. 34). Pleopunctum heveae is similar to other species in the morphological characters of having sporodochial conidiomata, monoblastic conidiogenous cells and muriform conidia with a hyaline, elliptical to globose basal cell (Liu et al. 2019). However, $P$. clematidis and $P$. heveae differ from $P$. ellipsoideum, $P$. pseudoellipsoideum and $P$. thailandicum as they have dimorphic conidia on the natural substrate (Phukamsakda et al. 2020). Pleopunctum heveae differs from $P$. clematidis in its conidia size (Table 3 ).

\section{Torulaceae Corda}

Members of Torulaceae are saprobic in terrestrial and freshwater habitats (Su et al. 2018, Hongsanan et al. 2020b, Phukamsakda et al. 2020). Currently, there are six genera accepted in this family viz. Dendryphion, Neotorula, Rostriconidium, Rutola, Sporidesmioides and Torula (Hongsanan et al. 2020b).

Torula fici Crous, IMA Fungus 6 (1): 192 (2015)

Fig. 37

Index Fungorum number: IF816154

Saprobic on dried twigs of Hevea brasiliensis. Sexual morph: Undetermined. Asexual morph: Hyphomycetous. Colonies effuse on host, dark brown to black, powdery. Mycelium partly immersed to superfcial on the host surface, comprising septate, smooth, and pale brown to brown hyphae. Conidiophores $19-53 \times 2.5-4.5 \mu \mathrm{m}(\bar{x}=35.7 \times 3.8 \mu \mathrm{m}, \mathrm{n}=10)$, macronematous, mononematous, solitary, arising from hypha, erect, pale brown to brown, smooth, thick-walled, subglobose to oblong. Conidiogenous cells 5.8-11.5 $\times 3-4.5 \mu \mathrm{m}(\bar{x}=8.3 \times 3.8 \mu \mathrm{m}, \mathrm{n}=12)$, monoto polyblastic, doliiform to subglobose, dark brown to black, paler at apex, smooth, thick-walled. Conidia (8-)10-20 × 5-8 $\mu \mathrm{m}(\bar{x}=14.2 \times 6 \mu \mathrm{m}, \mathrm{n}=45)$, phragmosporous, catenate, acrogenous, branched, oblong, elongated, 1-4-septate, constricted with dark bands at the septa, brown to dark brown, verrucose, rounded and mostly dark brown at the apex, straight or slightly curved.

Culture characteristics - Conidia germinating on MEA within 24 hours at room temperature and germ tubes produced from one or both ends. Colonies on MEA circular, mycelium slightly raised, entire, cultures white at the surface and light brown from the centre of the colony in reverse with creamy-white at the margin.

Material examined - Thailand, Phayao Province, Muang District, on dried twig of Hevea brasiliensis (Euphorbiaceae), 2 October 2016, C. Senwanna, RBPY06 (MFLU 19-0237), living culture MFLUCC 17-0325; ibids, RBPY15a, living culture MFLUCC 17-0336; ibid., Chiang Mai province, Muang District, Mae Hia Agricultural Research, Demonstrative and Training Center, on dead twig of Hevea brasiliensis (Euphorbiaceae), 1 July 2017, C. Senwanna, RBCM14 (MFLU 210196), living culture MFLUCC 18-0686.

Host and distribution - Chromolaena odorata (Thailand; Li et al. 2017, Mapook et al. 2020), Ficus religiosa (Cuba; Crous et al. 2015a), Hevea brasiliensis (Thailand; this study), Magnolia grandifora (China; Jayasiri et al. 2019), Garcinia sp. (Thailand; Jayasiri et al. 2019), Pandanus sp. (Thailand; Hyde et al. 2018), submerged decaying wood (China; Su et al. 2018).

GenBank numbers - MFLUCC 17-0325: ITS = OL780493, LSU = OL782072, TEF1 $=$ OL875109; MFLUCC 17-0336: ITS = OL780494, LSU = OL782072, TEF1 = OL875110; MFLUCC 18-0686: ITS = OL780495. 


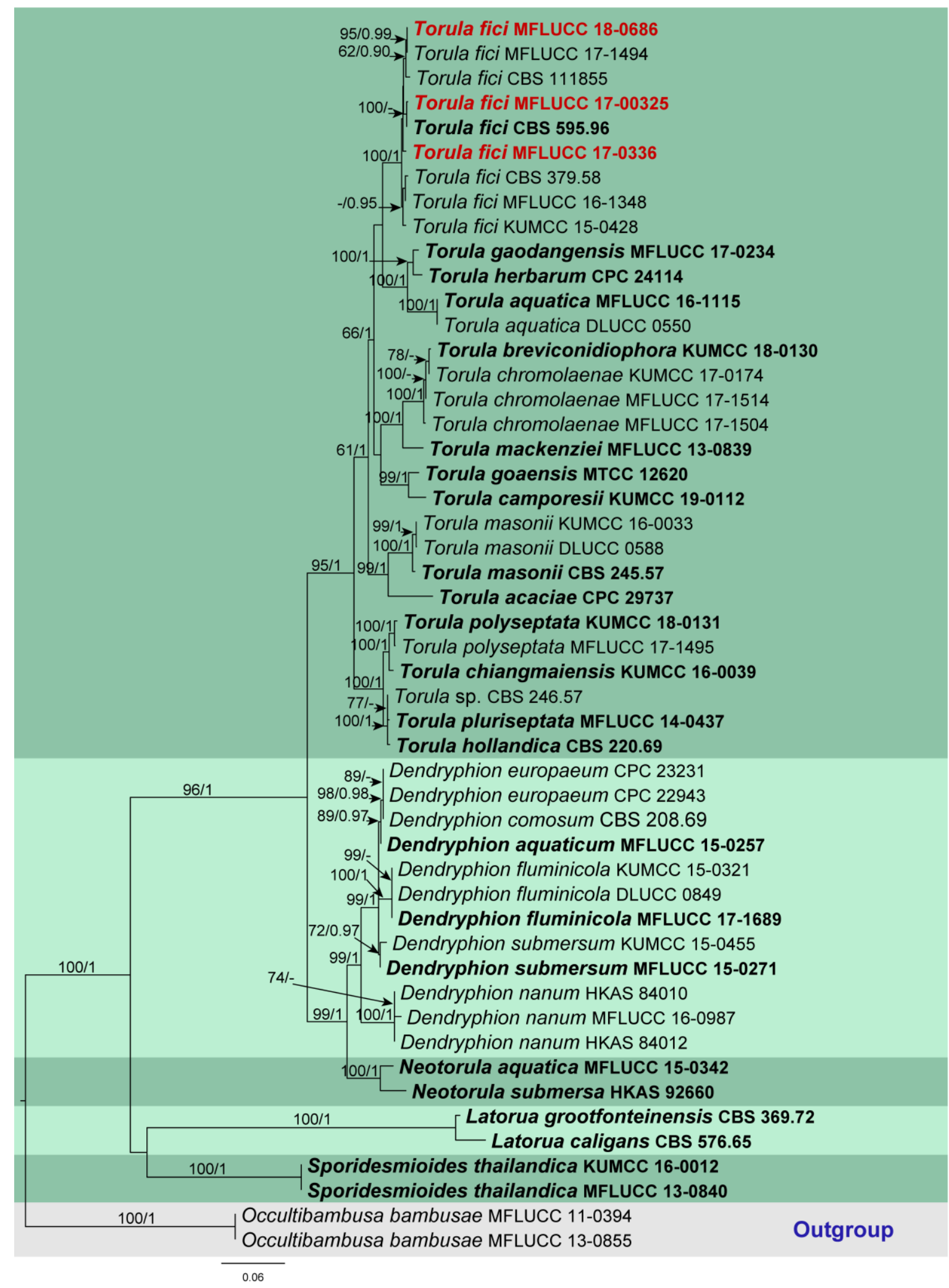

Figure 36 - RAxML tree of Torula based on a combined LSU, SSU, TEF1, RPB2 and ITS sequence dataset. Fifty strains are included in the combined sequence analysis, which comprise 4635 characters with gaps. Tree topology of the ML analysis was similar to the BYPP. The best scoring RAxML tree with a final likelihood value of -18924.957846 is presented. The matrix had 1338 distinct alignment patterns, with $42.51 \%$ of undetermined characters or gaps. Estimated base frequencies were as follows: $\mathrm{A}=0.245644, \mathrm{C}=0.259294, \mathrm{G}=0.271689, \mathrm{~T}=0.223374$; substitution rates: $\mathrm{AC}=2.016665, \mathrm{AG}=3.689714, \mathrm{AT}=1.530770, \mathrm{CG}=1.200166, \mathrm{CT}=$ 9.075026, GT $=1.000000$; gamma distribution shape parameter $\alpha=0.484975$. Bootstrap support 
values for ML equal to or greater than $60 \%$ and BYPP equal to or greater than 0.90 are defined as ML/BYPP above the nodes. Newly generated sequences are in red bold and type species are in bold. Occultibambusa bambusae (MFLUCC 11-0394 and MFLUCC 13-0855) are used as outgroup taxa.
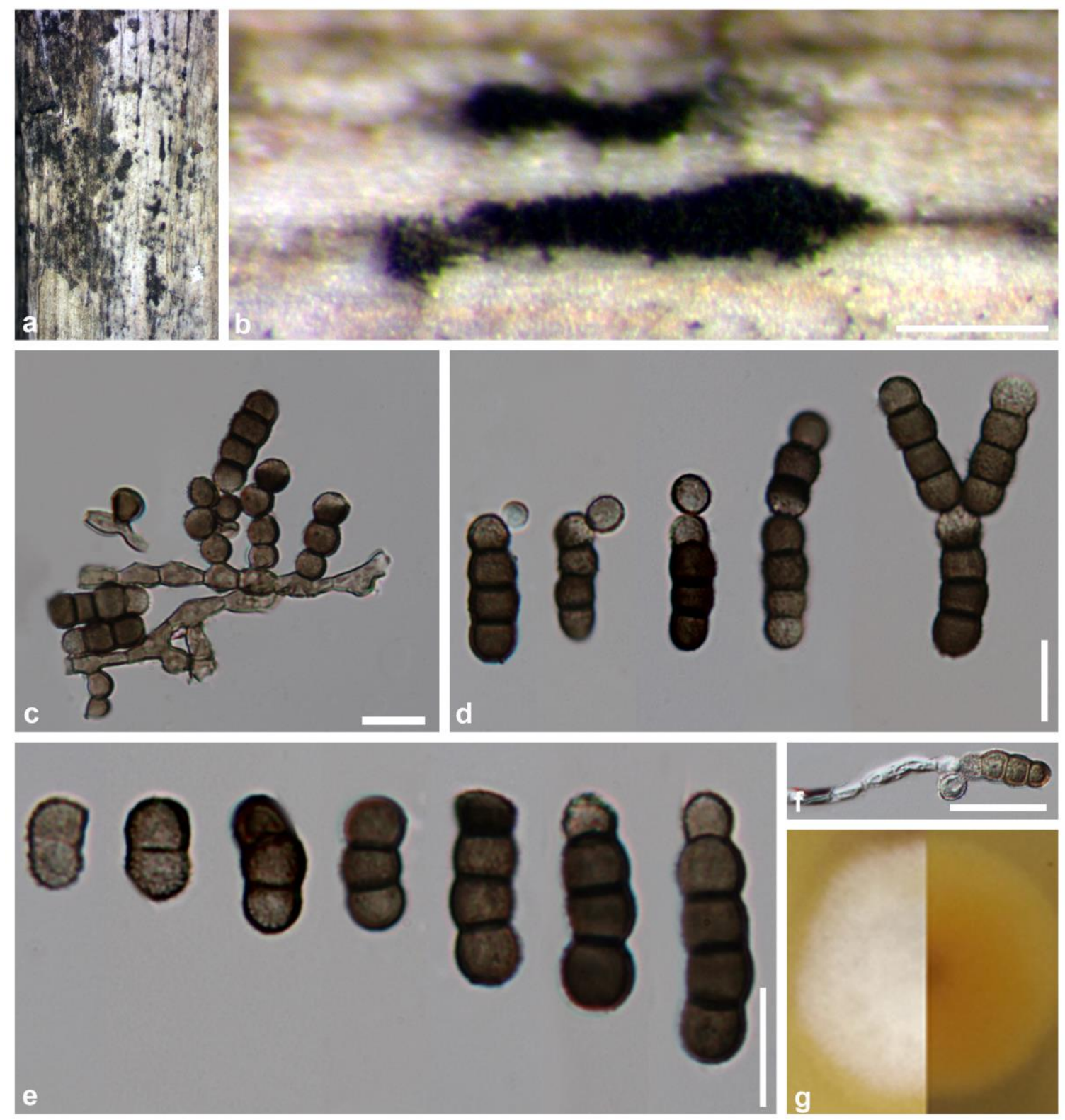

Figure 37 - Torula fici (MFLU 19-0237, new host record). a-b Habitat on host surface. c Conidia and conidiophores. d Catenulate conidia and the development of conidiogenous cells from the apical cell of conidium. e Conidia. $\mathrm{f}$ Germinated spore. Scale bars: $\mathrm{b}=500 \mu \mathrm{m}, \mathrm{c}-\mathrm{e}=10 \mu \mathrm{m}, \mathrm{f}=20$ $\mu \mathrm{m}$.

Notes - In a BLASTn search of NCBI GenBank, the closest match of the ITS, TEF1 and RPB2 sequence of our three strains with 93\% (MN507400), 95.87\% (MN507403) and 87.55\% (MN507404) similarity, respectively, were identical to Torula camporesii, while the closest match of the LSU and SSU sequence with 99.27\% (NG_059827) and 99.89\% (NG_063641) similarity, respectively, were identical to $T$. gaodangensis. Phylogenetic analysis shows that three strains MFLUCC 17-0325, MFLUCC 17-0336 and MFLUCC 18-0686 are grouped with Torula fici (Fig. 36). We, therefore, name our collections as Torula fici. The collection is a new host record for Hevea brasiliensis in Thailand. 


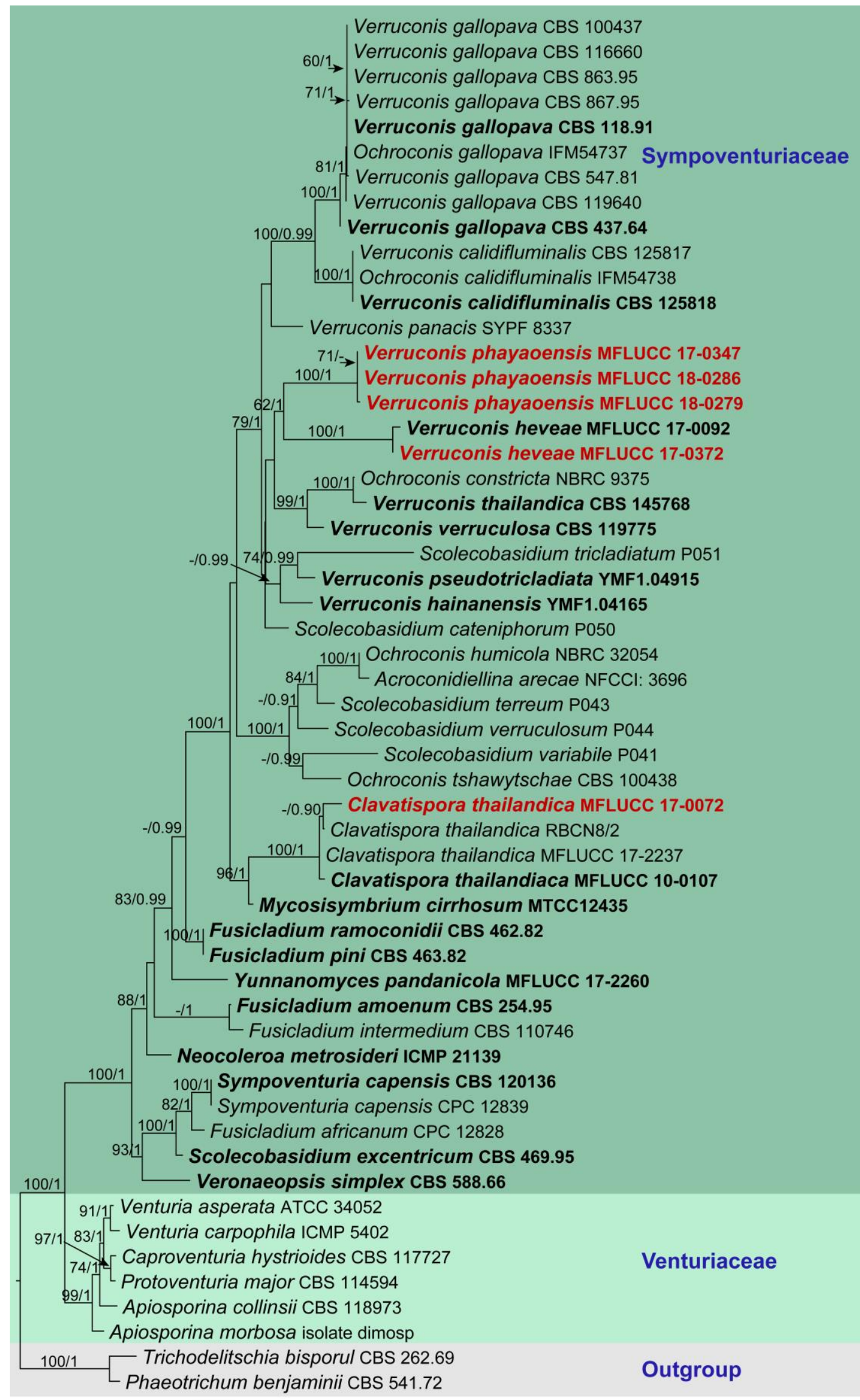

0.06

Figure 38 - RAxML tree of Sympoventuriaceae based on a combined LSU, SSU and ITS sequence dataset. Fifty-five strains are included in the combined sequence analysis, which comprise 3025 
characters with gaps. Tree topology of the ML analysis was similar to the BYPP. The best scoring RAxML tree with a final likelihood value of -17079.179295 is presented. The matrix had 1115 distinct alignment patterns, with $47.10 \%$ of undetermined characters or gaps. Estimated base frequencies were as follows: $\mathrm{A}=0.253338, \mathrm{C}=0.221785, \mathrm{G}=0.296212, \mathrm{~T}=0.228665$; substitution rates: $\mathrm{AC}=0.933707, \mathrm{AG}=1.846509, \mathrm{AT}=1.253993, \mathrm{CG}=0.962690, \mathrm{CT}=$ 4.086957, GT $=1.000000$; gamma distribution shape parameter $\alpha=0.636589$. Bootstrap support values for ML equal to or greater than $60 \%$ and BYPP equal to or greater than 0.90 are defined as ML/BYPP above the nodes. Newly generated sequences are in red bold and type species are in bold. Phaeotrichum benjaminii (CBS 541.72) and Trichodelitschia bisporul (CBS 262.69) are used as outgroup taxa.

Venturiales Y. Zhang ter, C.L. Schoch \& K.D. Hyde Sympoventuriaceae Y. Zhang ter, C.L. Schoch \& K.D. Hyde

There are 13 genera accepted in Sympoventuriaceae based on molecular analyses (Hongsanan et al. 2020a). Members of this family are plant pathogens, saprobes and opportunistic pathogens on animals and humans (Zhang et al. 2011, Samerpitak et al. 2014, Tibpromma et al. 2018, Huanraluek et al. 2019). In this study, we present a new species from Hevea brasiliensis, together with descriptions and illustrations. In addition, Clavatispora thailandica and Verruconis heveae are also reported.

Clavatispora thailandica Boonmee \& K.D. Hyde, in Boonmee et al., Phytotaxa 176(1): 96 (2014)

Index Fungorum number: IF 805924

Saprobic on dead branch of Hevea brasiliensis. Sexual morph: 64-143(-237) $\mu$ m diam. $\times 86-$ $129(-170) \mu \mathrm{m}$ high $(\bar{x}=138 \times 111 \mu \mathrm{m}, \mathrm{n}=7)$, superficial, scattered, solitary to gregarious, black, rounded above, held to the host surface by mycelium, with septate setae, easily removed from the host surface, with a central irregular ostiole. Peridium 13-32 $\mu \mathrm{m}$ thick, composed of cells of textura angularis, thick-walled, dark brown to black, becoming thin-walled and hyaline towards the inner region. Hamathecium comprising numerous, filamentous, hyaline, septate, branched pseudoparaphyses. Asci 62-95(-119) $\times(12-) 14-20 \mu \mathrm{m}(\bar{x}=81.6 \times 16.2 \mu \mathrm{m}, \mathrm{n}=27), 6-8$-spored, bitunicate, broadly obovoid or subclavate-oblong, short pedicellate, with an ocular chamber. Ascospores (16-)18-29(-37) $\times(5-) 7-10(-13) \mu \mathrm{m}(\bar{x}=24.5 \times 8.9 \mu \mathrm{m}, \mathrm{n}=44)$, biseriate, clavate, brown to dark brown, muriform, 3-5(-7)-transversely septate, longitudinally 1-3-septate, constricted at the septa, with conical and narrowly round ends, with granular appearance, smoothwalled. Asexual morph: Undetermined

Culture characteristics - Ascospores germinating on MEA within 24 hours at room temperature and germ tubes produced from spore cells. Colonies on MEA circular, mycelium slightly raised, entire, cultures creamy-white to pale yellow at the surface with greyish brown margin and olivaceous-brown from the centre of the colony in reverse with creamy-white margin.

Material examined - Thailand, Chiang Rai Province, Wiang Chiang Rung District, on branch of Hevea brasiliensis (Euphorbiaceae), 1 November 2016, C. Senwanna, RBCR013 (MFLU 171979), living culture MFLUCC 17-0072; CHINA, Yunnan, Xishuangbanna, on decaying branch of Hevea brasiliensis (Euphorbiaceae), January 2019, Phookamsak R., RBCN08 (MFLU 21-0187).

Host and distribution - Hevea brasiliensis (Thailand; Huanraluek et al. 2020, this study, China; this study), unidentified herbaceous plants (Thailand; Boonmee et al. 2014).

GenBank numbers - MFLUCC 17-0072: ITS = OL780496, LSU = OL782074, SSU $=$ OL780529, TEF1 = OL875111; MFLU 21-0187: ITS = OL780497, LSU = OL782075.

Notes - Clavatispora thailandica was introduced from dead stems of herbaceous plants by Boonmee et al. (2014) and is characterized by subclavate to broadly obovoid with short pedicellate asci, and clavate, muriform, brown to dark brown ascospores. In a BLASTn search of GenBank, the LSU sequence of MFLUCC 17-0072 and MFLU 21-0187 showed 99.76\% and 99.40\% similarity to Clavatispora thailandica (MFLU 10-0107; NG_058863), while the ITS sequence had $88.74 \%$ and 
89.35\% similarity to Ochroconis pandanicola (CPC 26317; NR_145399). The closest match of the SSU sequences of MFLUCC 17-0072 with 98.87\% (NG_062677) similarity was Helicoma vaccinii. In molecular phylogenetic analysis our isolate clusters with Clavatispora thailandica (Fig. 38). Our collection is similar to $C$. thailandica described by Boonmee et al. (2014) and the collection from $H$. brasiliensis by Huanraleuk et al. (2020). We, therefore, name our collection as C. thailandica.
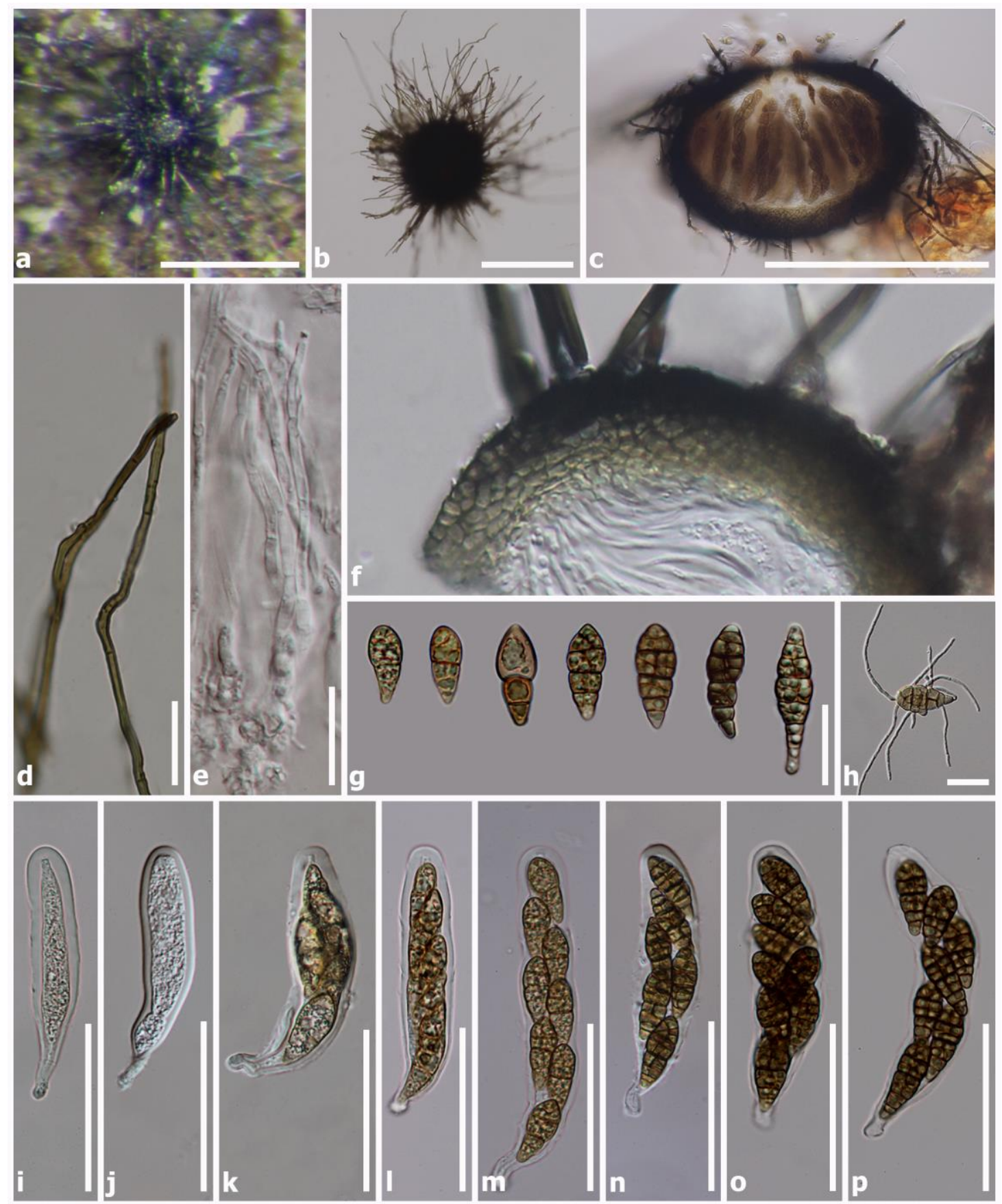

Figure 39 - Clavatispora thailandica (MFLU 17-1979). a Ascomata on host substrate. b Squash mount. c Section through ascoma. d Setae. e Pseudoparaphyses. f Peridium. g Ascospores. $\mathrm{h}$ Germinated spore. $\mathrm{i}-\mathrm{p}$ Asci. Scale bars: $\mathrm{a}-\mathrm{c}=200 \mu \mathrm{m}, \mathrm{d}-\mathrm{h}=20 \mu \mathrm{m}, \mathrm{i}-\mathrm{p}=50 \mu \mathrm{m}$.

Verruconis heveae Huanrluek, Senwanna, Jayawardena \& K.D. Hyde, in Huanraluek et al., Phytotaxa 403(1): 50 (2019)

Fig. 40

Index Fungorum number: IF555289 
Saprobic or parasitic on the dried latex on petioles of Hevea brasiliensis. Sexual morph: Undetermined. Asexual morph: Hyphomycetes. Colonies black, hairy, velvety. Mycelium superficial, brown to dark brown, composed of septate, branched, brown to dark brown, smooth hyphae. Conidiophores (45-)62-100(-133) $\times 3-4.5 \mu \mathrm{m}(\bar{x}=80 \times 3.7 \mu \mathrm{m}, \mathrm{n}=15)$, micronematous, mononematous, in groups, develop in fascicles, erect, flexuous, brown to dark brown, septate, branched, smooth-walled. Conidiogenous cells holoblastic, integrated, terminal becoming intercalary, nodose, with inner wall layers of the conidiogenous cell continuous with the conidial wall. Conidia (3-)6-18(-20) $\times(2-) 3-5(\bar{x}=11.5 \times 4 \mu \mathrm{m}, \mathrm{n}=56)$, solitary, ellipsoidal to oblong, pale brown to dark brown, aseptate when immature, 1-3-septate at maturity, constricted and darkened at septa, smooth-walled, basal hilum distinct.
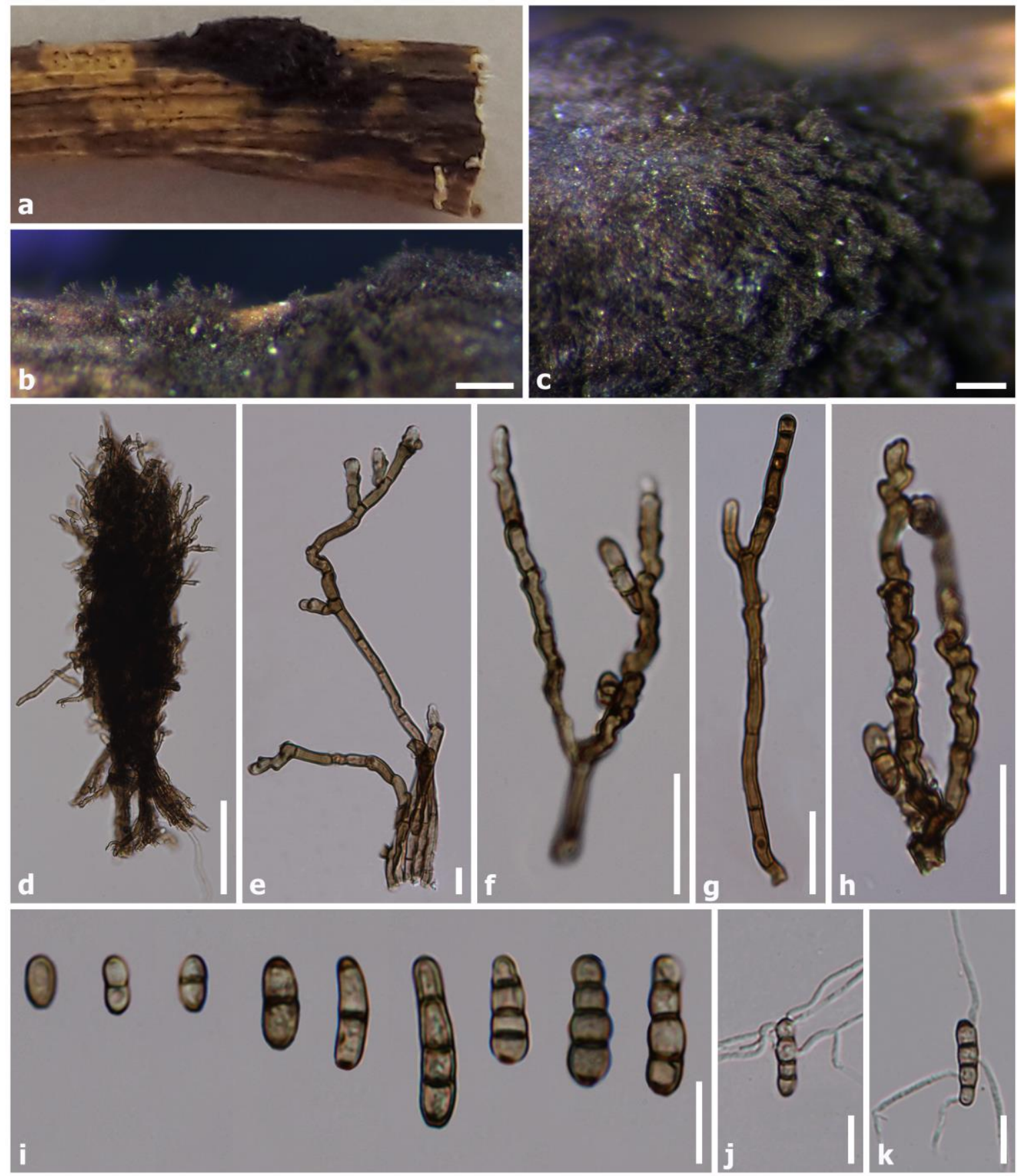

Figure 40 - Verruconis heveae (MFLU 19-0227). a-c Habit on substrate. d-h Conidiophores. i Conidia. j-k Germinated spores. Scale bars: $\mathrm{b}-\mathrm{c}=200 \mu \mathrm{m}, \mathrm{d}=50 \mu \mathrm{m}, \mathrm{e}-\mathrm{h}=20 \mu \mathrm{m}, \mathrm{i}-\mathrm{k}=10 \mu \mathrm{m}$. 
Culture characteristics - Conidia germinating on MEA within 24 hours at room temperature and germ tubes produced from spore cells. Colonies on MEA circular, mycelium slightly raised, slightly effuse, olivaceous-grey with dark brown to black margin and dark olivaceous-grey to black in reverse.

Material examined - Thailand, Chiang Rai Province, Wiang Chiang Rung District, on the dried latex on petioles of Hevea brasiliensis (Euphorbiaceae), 1 November 2016, C. Senwanna, RBCR06 (MFLU 19-0227), living culture MFLUCC 17-0372.

Host and distribution - Hevea brasiliensis (Thailand; Huanraluek et al. 2019, this study).

GenBank numbers - MFLUCC 17-0372: LSU = OL782076, SSU = OL780530.

Notes - Verruconis species are saprobes and pathogens in plants, humans, and animals (Samerpitak et al. 2014). In a BLASTn search, the closest match of the LSU sequences with 93.41\% similarity was Verruconis gallopava (CBS 437.64; KF282656), while the closest match of the SSU sequences with $99.80 \%$ similarity was Pseudocryptoclypeus yakushimensis (HHUF 30503, NG_061073). Phylogenetic analyses of LSU, SSU and ITS sequence dataset show that MFLUCC 17-0372 grouped with Verruconis heveae (MFLUCC 17-0092) (Fig. 38). Verruconis heveae was introduced on Hevea brasiliensis by Huanraleuk et al. (2019). The morphology of our collection is similar to Verruconis heveae described by Huanraleuk et al. (2019), however, they are differed in size of conidia and conidiophores (Table 4).

Verruconis phayaoensis Senwanna, Cheewangkoon \& K.D. Hyde, sp. nov.

Fig. 41

Index Fungorum number: IF559361

Etymology - The epithet "phayaoensis" refers to Phayao Province in Thailand where the fungus was found.

Saprobic or parasitic on the dried latex on petioles of Hevea brasiliensis. Sexual morph: Undetermined. Asexual morph: Hyphomycetes. Colonies black, hairy, velvety. Mycelium superficial, brown to dark brown, composed of septate, branched, brown to dark brown, smooth hyphae. Conidiophores (57-)63-93(-100) ×2-3.7 $\mu \mathrm{m}(\bar{x}=79 \times 2.7 \mu \mathrm{m}, \mathrm{n}=14)$, micronematous, mononematous, in groups, developed in fascicles, erect, brown to dark brown, septate, branched, smooth-walled. Conidiogenous cells holoblastic, integrated, nodose, with inner wall layers of the conidiogenous cell continuous with the conidial wall. Conidia $6-10.5 \times 3-5.5(\bar{x}=8.5 \times 4.4 \mu \mathrm{m}, \mathrm{n}$ = 56), solitary, ellipoidal to oblong, pale brown to dark brown, aseptate when immature, 1-3septate at maturity, constricted and darkened at septa, smooth-walled, basal hilum indistinct. Appressoria hyaline, globose to subglobose, thick-walled, $3.5-5 \mu \mathrm{m}$ wide $(\bar{x}=4.4 \mu \mathrm{m}, \mathrm{n}=5)$.

Culture characteristics - Conidia germinating on MEA within 24 hours at room temperature and germ tubes produced from spore cells with developing appressoria structure. Colonies on MEA circular, mycelium, raised, fluffy, olivaceous-brown and dark olivaceous-brown to black in reverse.

Material examined - Thailand, Phayao Province, Mueang District, on the dried latex on bark of Hevea brasiliensis (Euphorbiaceae), 3 January 2017, C. Senwanna, RBPY29 (MFLU 21-0198, holotype), ex-type living culture MFLUCC 17-0347; ibid, Phayao Province, Chiang Kam District, on the dried latex on bark of Hevea brasiliensis (Euphorbiaceae), 26 July 2017, C. Senwanna, RBPY52 (MFLU 21-0199), living culture MFLUCC 18-0279; ibid, Phayao Province, Chiang Kam District, on the dried latex on twig of Hevea brasiliensis (Euphorbiaceae), 26 July 2017, C. Senwanna, RBPY55 (MFLU 21-0205), living culture MFLUCC 18-0286.

Host and distribution - Hevea brasiliensis (Thailand; this study).

GenBank numbers - MFLUCC 17-0347: ITS = OL780498, LSU = OL782077, SSU = OL780531; MFLUCC 18-0279: ITS = OL780498, LSU = OL782078; MFLUCC 18-0286: LSU = OL782079.

Notes - In a BLASTn search, the closest match of the LSU sequence for MFLUCC 17-0347 and MFLUCC 18-0279 is V. gallopava (CBS 437.64; KF282656) with 94.26\% similarity, while the closest match to the ITS sequence was with $V$. calidifluminalis (IFM 54738, NR_145332) with 98.90\% similarity. The closest match of the SSU sequence for MFLUCC 17-0347 is $V$. pseudotricladiata (YMF 1.04915; NG_070120) with $95.12 \%$ and $89.25 \%$ similarity, respectively. 
In our analyses, Verruconis phayaoensis (MFLUCC 17-0347 and MFLUCC 18-0279) forms a distinct lineage sister to $V$. heveae and is closely related to Ochroconis constricta (NBRC9375) and V. verruculosa (CBS119775) (Fig. 38). Verruconis phayaoensis is similar to V. verruculosa in conidial size but differs in size of conidiophores and number of septa (Table 4). Verruconis heveae and $V$. phayaoensis were collected from Para rubber. However, these species can be distinguished based on their conidiophores, conidial characters and phylogenetic analyses (Table 4, Fig. 38). Therefore, $V$. phayaoensis is introduced as a new species.

Table 4 Morphology and synopsis of recorded Verruconis species.

\begin{tabular}{|c|c|c|c|c|}
\hline \multirow[t]{2}{*}{ Verruconis species } & \multirow[t]{2}{*}{ Conidial morphology } & \multicolumn{2}{|r|}{ Size $(\mu \mathrm{m})$} & \multirow[t]{2}{*}{ Host } \\
\hline & & conidiophore & Conidia; septa in conidia & \\
\hline $\begin{array}{l}\text { V. calidifluminalis } \\
\text { (Samerpitak et al. } \\
\text { 2014) }\end{array}$ & $\begin{array}{l}\text { cylindrical to clavate, pale to } \\
\text { medium brown, with or without } \\
\text { constrictions at the septa }\end{array}$ & - & $9.5-20.5 \times 2.5-5.0 ; 1$ septate & $\begin{array}{l}\text { water of a } \\
\text { hot stream }\end{array}$ \\
\hline $\begin{array}{l}\text { V. gallopava } \\
\text { (Samerpitak et al. } \\
\text { 2014) }\end{array}$ & $\begin{array}{l}\text { clavate, subhyaline to pale } \\
\text { brown, apical cell wider than } \\
\text { basal cell, constricted at the } \\
\text { septum }\end{array}$ & - & $11-18 \times 2.5-4.5 ; 1$ septate & $\begin{array}{l}\text { brain } \\
\text { abscess of } \\
\text { Meleagris } \\
\text { gallopavo }\end{array}$ \\
\hline $\begin{array}{l}\text { V. hainanensis (Qiao } \\
\text { et al. 2019) }\end{array}$ & $\begin{array}{l}\text { fusiform, rostrate at the apical } \\
\text { cell, dark at the septa, slightly } \\
\text { constricted at the median } \\
\text { septum, bicolored, with brown } \\
\text { middle cells, and subhyaline end } \\
\text { cells, with an inconspicuous } \\
\text { basal frill. }\end{array}$ & $25 \mu \mathrm{m}$ long & $23-30.2 \times 3.6-5.7 ; 3$ septate & $\begin{array}{l}\text { submerged } \\
\text { leaves in a } \\
\text { stream }\end{array}$ \\
\hline $\begin{array}{l}\text { V. heveae } \\
\text { (Huanraluek et al. } \\
\text { 2019) }\end{array}$ & $\begin{array}{l}\text { ellipsoidal to oblong, pale brown } \\
\text { to dark brown, rounded at apex, } \\
\text { sub-acute at base, constricted } \\
\text { and darkened at septa, basal } \\
\text { hilum indistinct }\end{array}$ & $21-92 \times 1-4$ & $\begin{array}{l}6-14 \times 3-6 ; 1 \text {-septate when } \\
\text { immature, } 2-3 \text {-septate at } \\
\text { maturity }\end{array}$ & $\begin{array}{l}\text { on dried } \\
\text { latex of } \\
\text { Hevea } \\
\text { brasiliensis }\end{array}$ \\
\hline $\begin{array}{l}\text { V. heveae (This } \\
\text { study) }\end{array}$ & $\begin{array}{l}\text { ellipsoidal to oblong, pale brown } \\
\text { to dark brown, constricted and } \\
\text { darkened at septa, smooth- } \\
\text { walled, basal hilum distinct }\end{array}$ & $\begin{array}{l}(45-) 62- \\
100(-133) \times \\
3-4.5\end{array}$ & $\begin{array}{l}(3-) 6-18(-20) \times(2-) 3-5 ; 1- \\
\text { septate when immature, } 1-3- \\
\text { septate at maturity }\end{array}$ & $\begin{array}{l}\text { on dried } \\
\text { latex of } \\
\text { Hevea } \\
\text { brasiliensis }\end{array}$ \\
\hline $\begin{array}{l}\text { V. phayaoensis (This } \\
\text { study) }\end{array}$ & $\begin{array}{l}\text { ellipsoidal to oblong, pale brown } \\
\text { to dark brown, constricted and } \\
\text { darkened at septa, smooth- } \\
\text { walled, basal hilum distinct }\end{array}$ & $\begin{array}{l}(57-) 63-93(- \\
100) \times 2-3.7\end{array}$ & $\begin{array}{l}6-10.5 \times 3-5.5 ; 1 \text {-septate } \\
\text { when immature, } 1-3 \text {-septate } \\
\text { at maturity }\end{array}$ & $\begin{array}{l}\text { on dried } \\
\text { latex of } \\
\text { Hevea } \\
\text { brasiliensis }\end{array}$ \\
\hline $\begin{array}{l}\text { V. pseudotricladiata } \\
\text { (Qiao et al. 2019) }\end{array}$ & $\begin{array}{l}\text { Staurosporic, subhyaline to pale } \\
\text { brown, smooth to verruculose, } \\
\text { unbranched or branched: i) } \\
\text { unbranched conidia (main axis) } \\
\text { cylindrical-clavate, slightly } \\
\text { constricted at the septa, ii) } \\
\text { branched conidia staurosporic, } \\
\text { Y-, or T-shaped, cylindrical- } \\
\text { clavate to clavate, very pale } \\
\text { brown }\end{array}$ & $\begin{array}{l}6.5-27.2 \times \\
2.1-3.5\end{array}$ & $\begin{array}{l}\text { i) unbranched conidia: } 16-20 \\
\times 3.3-4.7 ; 2-4 \text { septate } \\
\text { ii) branched conidia: } 15.6- \\
20.6 \times 3.8-5.7,1-3 \text {-septate, } \\
\text { mostly } 2 \text {-septate }\end{array}$ & $\begin{array}{l}\text { submerged } \\
\text { leaves in a } \\
\text { stream }\end{array}$ \\
\hline $\begin{array}{l}\text { V. thailandica } \\
\text { (Hernández-Restrepo } \\
\text { et al. 2020) }\end{array}$ & $\begin{array}{l}\text { broadly ellipsoidal with a } \\
\text { protuberant hilum, brown, } \\
\text { verrucose, constricted at the } \\
\text { septum, thick-walled, sometimes } \\
\text { with a wing-like gelatinous } \\
\text { brown sheath, released by } \\
\text { rhexolytic secession }\end{array}$ & $\begin{array}{l}(3.6-) 4.1- \\
7.1(-9) \\
\times(1.3-) 2(- \\
2.3) ; 0-1- \\
\text { septate }\end{array}$ & $\begin{array}{l}(5-) 5.8(-7) \times \\
(2.2-) 2.6(-3.1) ; 1 \text { septate }\end{array}$ & soil \\
\hline $\begin{array}{l}\text { V. verruculosa } \\
\text { (Samerpitak et al. } \\
\text { 2014) }\end{array}$ & $\begin{array}{l}\text { oblong with rounded ends, pale } \\
\text { brown to olivaceous-brown, } \\
\text { constricted at the } \\
\text { septum }\end{array}$ & $5-45 \times 2-3$ & $\begin{array}{l}(6-) 7.5(-9) \times(3.5-) 4(-5) ; 1 \\
\text { septate }\end{array}$ & $\begin{array}{l}\text { grassland } \\
\text { soil }\end{array}$ \\
\hline
\end{tabular}



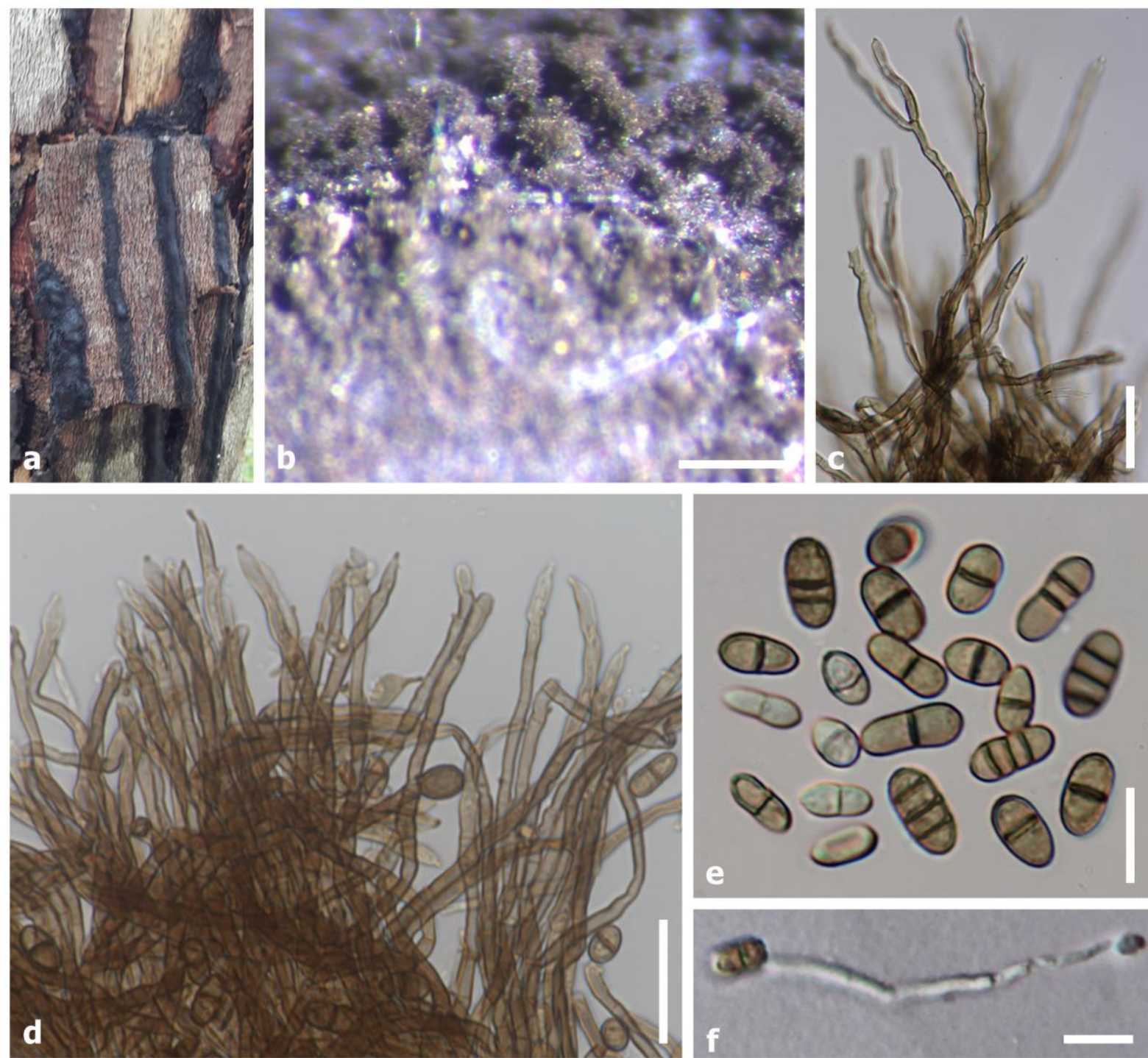

Figure 41 - Verruconis phayaoensis (MFLU 21-0198, holotype). a-b Habit on substrate. $\mathrm{c}-\mathrm{d}$ Conidiophores. e Conidia. f Germinated spore. Scale bars: $\mathrm{b}=200 \mu \mathrm{m}, \mathrm{c}-\mathrm{d}=20 \mu \mathrm{m}, \mathrm{e}-\mathrm{f}=10$ $\mu \mathrm{m}$.

Class Sordariomycetes O.E. Erikss. \& Winka Diaporthales Nannf.

\section{Coryneaceae Corda}

Coryneaceae is characterized by erumpent stromata, perithecial ascomata arranged in valsoid configuration and hyaline or brown, irregularly fasciculate, ellipsoid, fusoid or elongate, uni- or multiseptate ascospores (Jiang et al. 2018, Senanayake et al. 2017, 2018). The asexual morph comprises acervular conidiomata and hyaline to dark brown, curved, broadly fusiform to cylindrical or clavate with distoseptate conidia (Sutton 1980, Jiang et al. 2018, Senanayake et al. 2017, 2018, Senwanna et al. 2018a). The family comprises only single genus, Coryneum which are saprobes on decaying wood or plant pathogens causing Coryneum-blight, cankers and dieback in economically plant hosts as well as forest trees (Strouts 1972, Gadgil \& Dick 2007, Senanayake et al. 2017, 2018, Jiang et al. 2018, Senwanna et al. 2018a, Hyde et al. 2020b).

Coryneum heveanum Senwanna, Cheewangkoon \& K.D. Hyde, in Senwanna et al., MycoKeys 43: $81(2018)$

Fig. 43

Index Fungorum number: IF555338

Descriptions and illustrations Senwanna et al. (2018) 
Material examined - Thailand, Krabi Province, on branches (attached on tree) of Hevea brasiliensis, 30 August 2017, C. Senwanna, RBKB01 (MFLU 21-0204), living culture MFLUCC 18-0310, MFLUCC 18-0311.

Host and distribution - Hevea brasiliensis (Thailand; Senwanna et al. 2018a, this study).

GenBank numbers - MFLUCC 18-0310: ITS = OL780500, LSU = OL782080; MFLUCC 180311, TEF1 = OL944425: ITS = OL780501, LSU = OL782081, TEF1 = OL944426.

Notes - Coryneum heveanum was collected from Hevea brasiliensis in Chiang Rai, Thailand (Senwanna et al. 2018a). In this study, MFLUCC 18-0310 and MFLUCC 18-0311 are phylogenetically related to $C$. heveanum (MFLUCC 17-0369) with high bootstrap support (Fig. 42). The morphology of our collection (MFLU 21-0204) is similar to the holotype (Senwanna et al. 2018) in having acervular conidiomata, hyaline to dark brown, fusiform or clavate with distoseptate conidia. We, therefore, identify our strain as $C$. heveanum based on phylogenetic analyses and morphology.

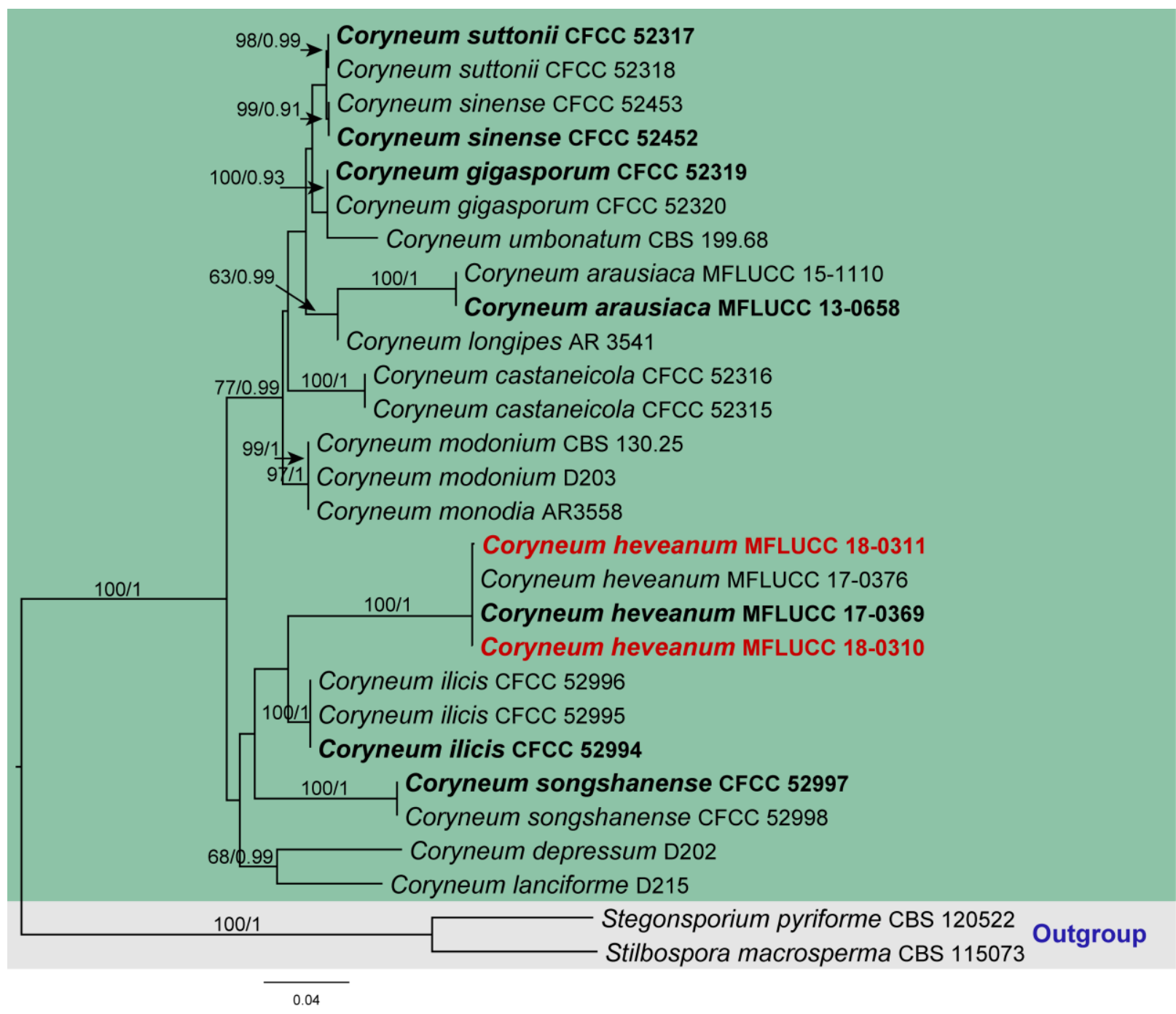

Figure 42 - RAxML tree of Coryneum based on a combined LSU, ITS and TEF1 sequence dataset. Twenty-eight strains are included in the combined sequence analysis, which comprise 2506 characters with gaps. Tree topology of the ML analysis was similar to the BYPP. The best scoring RAxML tree with a final likelihood value of -9299.960163 is presented. The matrix had 762 distinct alignment patterns, with $24.06 \%$ of undetermined characters or gaps. Estimated base frequencies were as follows: $\mathrm{A}=0.232474, \mathrm{C}=0.274010, \mathrm{G}=0.280437, \mathrm{~T}=0.213078$; substitution rates: $\mathrm{AC}=1.708719, \mathrm{AG}=1.793689, \mathrm{AT}=1.631050, \mathrm{CG}=1.135433, \mathrm{CT}=$ $5.841390, \mathrm{GT}=1.000000$; gamma distribution shape parameter $\alpha=0.689346$. Bootstrap support values for ML equal to or greater than $60 \%$ and BYPP equal to or greater than 0.90 are defined as 
ML/BYPP above the nodes. Newly generated sequences are in red and type species are in bold. Stegonsporium pyriforme (CBS 120522) and Stilbospora macrosperma (CBS 115073) are used as outgroup taxa.
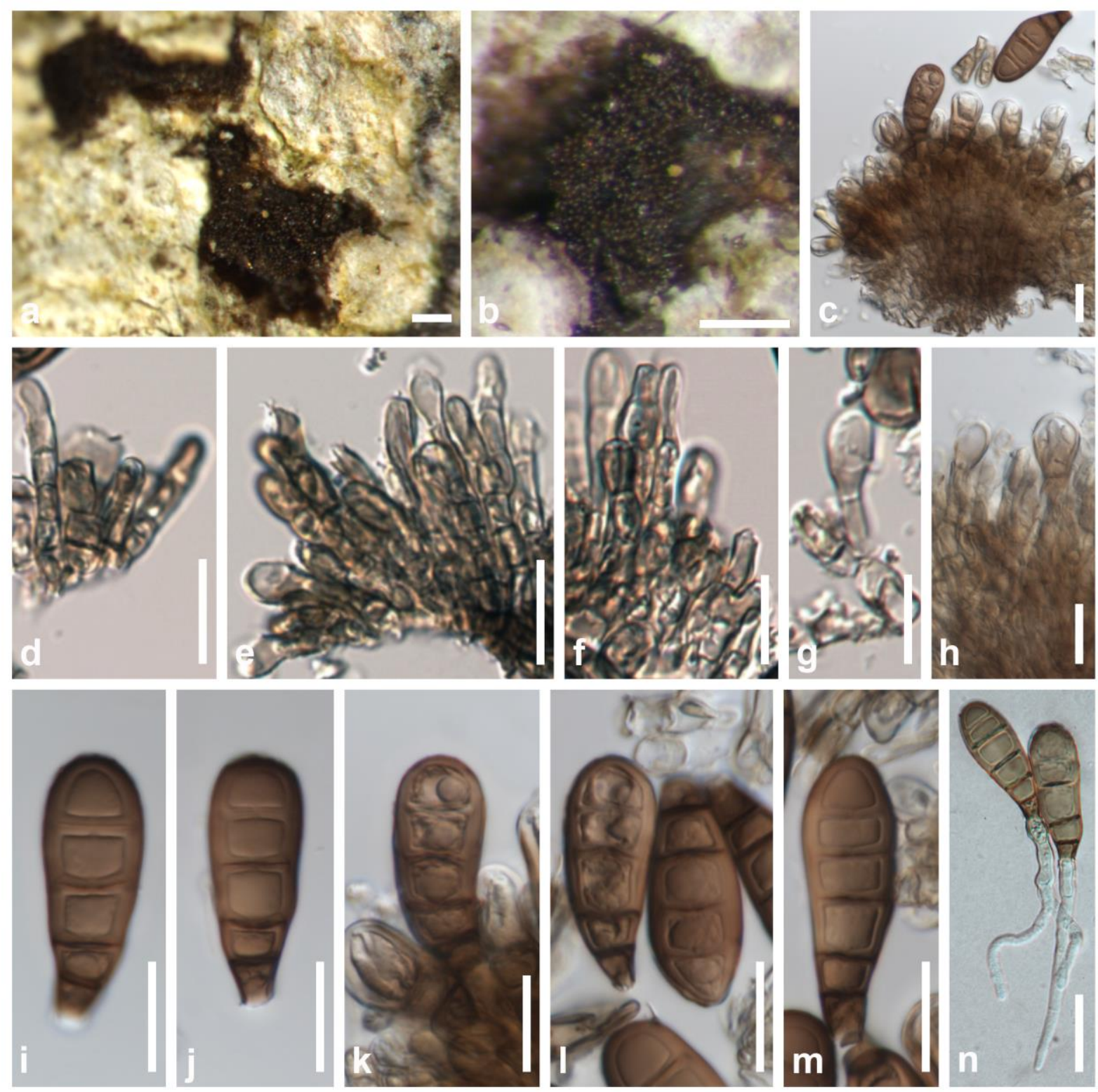

Figure 43 - Coryneum heveanum (MFLU 21-0204). a-b Conidiomata on host surface. c Acervulus. $\mathrm{d}-\mathrm{h}$ Conidiophores and conidiogeneous cells with conidia. $\mathrm{i}-\mathrm{m}$ Conidia. $\mathrm{n}$ Germinated spores. Scale bars: $\mathrm{a}-\mathrm{b}=200 \mu \mathrm{m}, \mathrm{c}-\mathrm{n}=20 \mu \mathrm{m}$.

\section{Cytosporaceae Fr.}

Hyde et al. (2020b) listed six genera under Cytosporaceae viz. Cryptascoma, Cytospora, Pachytrype, Paravalsa, Waydora and Xenotypa. In this study, Cytospora diopuiensis, C. heveae and $C$. thailandica were reported on Hevea brasiliensis. Members of Cytospora are important plant pathogens associated with canker and dieback disease on various host plants worldwide, saprobe and endophytes (Fan et al. 2020, Jiang et al. 2020, Shang et al. 2020).

Cytospora diopuiensis Q.J. Shang, J.K. Liu \& K.D. Hyde, in Shang et al., Mycosphere 11(1): 202 (2020)

Index Fungorum number: IF 555502

Figs 45, 46 
Associated with twigs and dead branches of Hevea brasiliensis, distinct, subcircular to circular surrounded by dark brown margin on host surface. Sexual morph: Stromata solitary to gregarious, semi-immersed in host tissue, erumpent, with 3-8 locules arranged circularly or subcircular with dark brown to black margin, becoming raised by the ostiolar canal, with ostiolar neck. Ascomata (90-)140-480 $\mu \mathrm{m}$ high, 135-380 $\mu \mathrm{m}$ diam. $(\bar{x}=220 \times 229 \mu \mathrm{m}, \mathrm{n}=23)$, perithecial, immersed in a stroma, dark brown to black, globose to subglobose, glabrous, individual ostiole with the neck. Ostiole 100-380 $\mu \mathrm{m}$ high, cylindrical, sulcate, at the same level as the disc, occasionally area below disc a lighter entostroma. Peridium 20-40(-47) $\mu \mathrm{m}$ wide, composed of several layers of brown to dark brown cells of textura angularis mixed with textura prismatica, becoming hyaline at the inner regions. Paraphyses absent. Asci $(24.5-) 26-31.5(-35) \times(4-) 5-6 \mu \mathrm{m}$ $(\bar{x}=29.2 \times 5.3 \mu \mathrm{m}, \mathrm{n}=23), 8$-spored, unitunicate, clavate, sessile, apically rounded to truncate, with a J-, refractive apical ring. Ascospores (4.5-)6-8(-9) $\times(1.3-) 1.5-2.6 \mu \mathrm{m}(\bar{x}=7.3 \times 2 \mu \mathrm{m}, \mathrm{n}=$ 62), overlapping 1-2-seriate, hyaline, elongate-allantoid, aseptate, smooth-walled. Asexual morph: Conidiomata 370-560 $\mu \mathrm{m}$ high, 170-360 $\mu \mathrm{m}$ diam., semi-immersed in host tissue, solitary, scattered, erumpent, with 7-10 locules arranged circularly or subcircular with dark brown to black margin, with ostiolar neck. Ostioles 120-200 $\mu \mathrm{m}$ high., at the same level as the disc surface. Peridium 8-12(-18) $\mu \mathrm{m}$ wide, composed of several layers of brown to dark brown, thick-walled cells of textura angularis, becoming hyaline, thin-walled cells of textura angularis. Conidiophores branched, reduced to conidiogenous cells. Conidiogenous cells $(3-) 4.5-8(-10) \times 1.2-1.7(-2) \mu \mathrm{m}(\bar{x}$ $=6.7 \times 1.5 \mu \mathrm{m}, \mathrm{n}=35)$, blastic, enteroblastic, phialidic, hyaline, smooth-walled. Conidia 3-3.7(-4) $\times 1-1.8 \mu \mathrm{m}(\bar{x}=3.5 \times 1.4 \mu \mathrm{m}, \mathrm{n}=60)$, elongate-allantoid, hyaline, aseptate, smooth-walled.

Culture characteristic - Ascospores germinating on MEA within 24 hours at room temperature $\left(25-30{ }^{\circ} \mathrm{C}\right)$ and germ tube was produced from the ends of the ascospores. Initially aerial mycelium white, circular, after 15 days become whitish grey, velvety, raise, dense mycelium, lacking aerial mycelium. Colony from single ascospores: initially aerial mycelium white, circular, velvety with sparse aspects, after 10 days become to whitish grey from the center, white at the edge, slight raise, dense, after 20 days of incubation, colonies become iron grey, no asexual morph produced on culture.

Material examined - Thailand, Phayao Province, Muang District, on twigs of Hevea brasiliensis (Euphorbiaceae), 2 October 2016, C. Senwanna, RBPY07 (MFLU 19-0238), living culture MFLUCC 17-0326; ibid, Sukhothai Province, Srisatchanalai District, on dead branch of Hevea brasiliensis (Euphorbiaceae), 2 January 2017, N. Huanraluek, RBSK05 (MFLU 19-0255).

Host and distribution - Hevea brasiliensis (Thailand; this study), undetermined wood (Thailand; Shang et al. 2020).

GenBank numbers - MFLUCC 17-0326: ITS $=$ OL780502, LSU $=$ OL782082, $\mathrm{SSU}=$ OL780532, TEF1 = OL944427; MFLU 19-0255a: ITS = OL780503, LSU = OL782083; MFLU 190255b: ITS $=$ OL780504.

Notes - In a BLASTn search, the closest matches of ITS sequence of MFLUCC 17-0326, MFLU 19-0255a and MFLU 19-0255b are Cytospora diopuiensis with 99.80\%, 100\% and 99.79\% similarity to strain MFLUCC 18-1419 (MK912137), while the closest match of the LSU sequence of our strains with $99.50 \%$ similarity, were identical to C. thailandica (MFLU 17-0709 and MFLUCC 17-0262). Phylogenetic analysis shows that strains MFLUCC 17-0326, MFLU 19-0255a and MFLU 19-0255b grouped with $C$. diopuiensis (Fig. 44). The sexual morph of Cytospora diopuiensis was introduced by Shang et al. (2020) for isolates from dead wood of unidentified host in Thailand. Morphological characters of our collection (MFLU 19-0238, Fig. 45) are similar to the holotype of $C$. diopuiensis (MFLU 18-0390). However, the ascospores of $C$. diopulensis in this study are narrower than those reported by Shang et al. (2020) and the paraphyses were not found. In this study, isolate of the asexual morph of C. diopuiensis (MFLU 19-0255) was observed directly on dead branch of Hevea brasiliensis (Fig. 46) and the morphology could not be compared as the current studies were reported only its sexual morph (Shang et al. 2020). Therefore, we consider the new collection as host record and new record of the asexual morph of $C$. diopuiensis based on the phylogenetic evidence. 


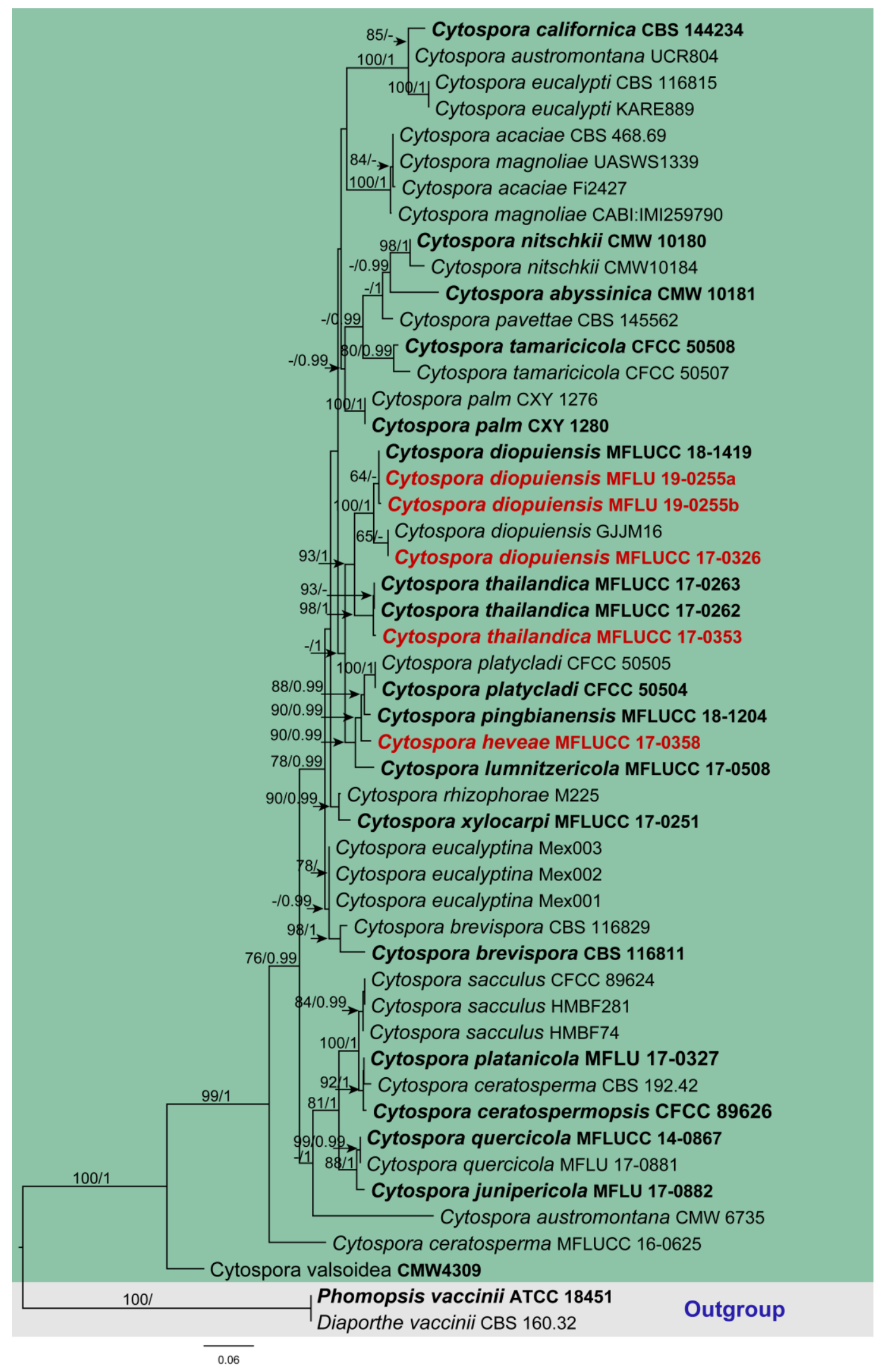

Figure 44 - RAxML tree of Cytospora based on a combined ITS, LSU, ACT and TEF1 sequence dataset. Fifty strains are included in the combined sequence analysis, which comprise 2323 characters with gaps. Tree topology of the ML analysis was similar to the BYPP. The best scoring RAxML tree with a final likelihood value of -10048.719308 is presented. The matrix had 820 distinct alignment patterns, with $50.24 \%$ of undetermined characters or gaps. Estimated base frequencies were as follows: $\mathrm{A}=0.236415, \mathrm{C}=0.266617, \mathrm{G}=0.257777, \mathrm{~T}=0.239191$; 
substitution rates: $\mathrm{AC}=1.856562, \mathrm{AG}=3.049365, \mathrm{AT}=1.676404, \mathrm{CG}=1.079642, \mathrm{CT}=$ 7.045005, GT $=1.000000$; gamma distribution shape parameter $\alpha=0.456988$. Bootstrap support values for ML equal to or greater than $60 \%$ and BYPP equal to or greater than 0.90 are defined as ML/BYPP above the nodes. Newly generated sequences are in red bold and type species are in bold. Diaporthe vaccinii (CBS 160.32) and Phomopsis vaccinii (ATCC 18451) are used as outgroup taxa.
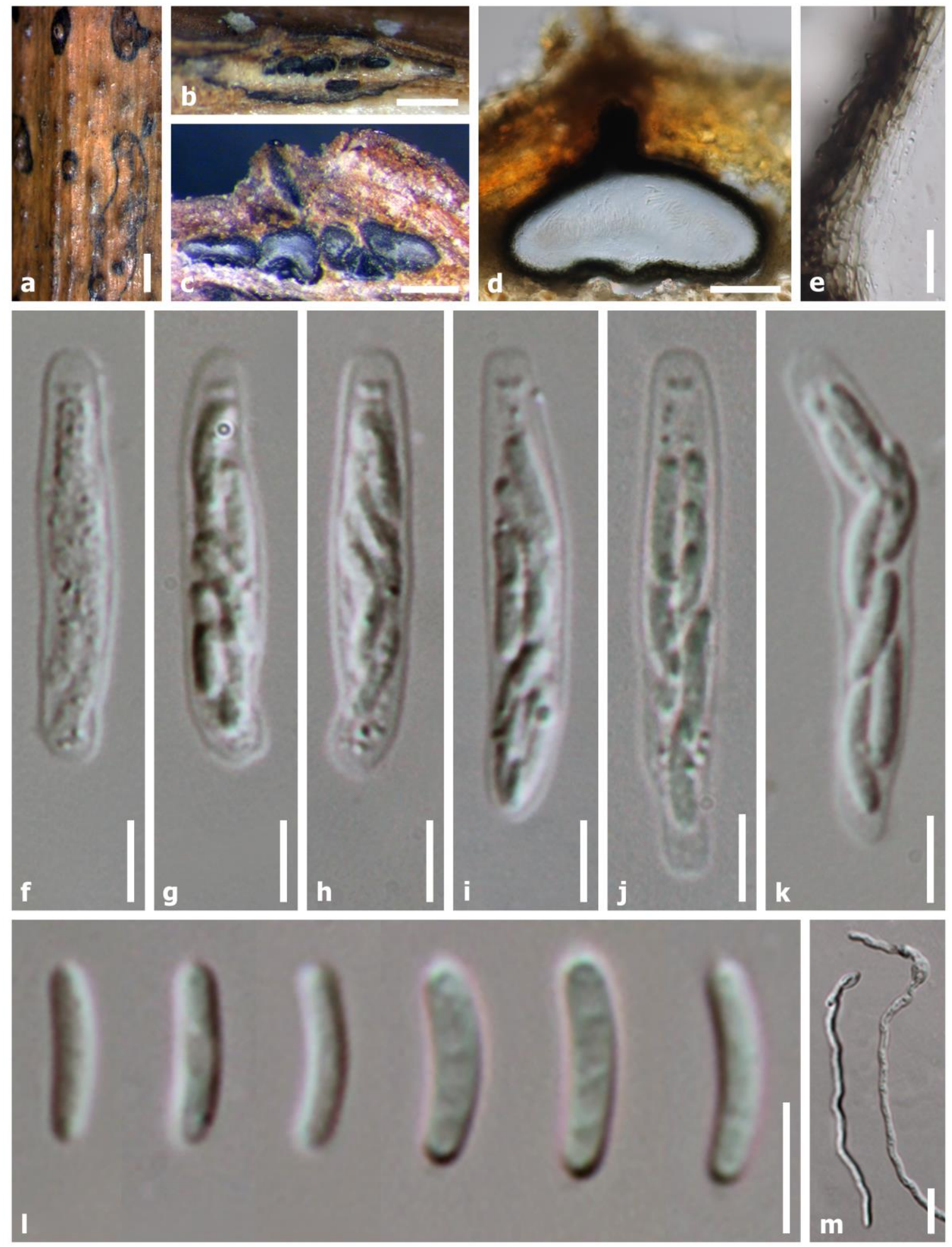

Figure 45 - Sexual morph of Cytospora diopuiensis (MFLU 19-0238, new host record). a Habit of ascomata in bark. b Vertical section through ascomata. c Longitudinal sections through ascomata. 
$\mathrm{d}$ Section through the ascoma. e Peridium. $\mathrm{f}-\mathrm{j}$ Asci. k. Ascospores. 1 Germinated spores. Scale bars: $\mathrm{a}=1000 \mu \mathrm{m}, \mathrm{b}=500 \mu \mathrm{m}, \mathrm{c}=200 \mu \mathrm{m}, \mathrm{d}=100 \mu \mathrm{m} . \mathrm{e}, \mathrm{m}=20 \mu \mathrm{m}, \mathrm{f}-1=5 \mu \mathrm{m}$.
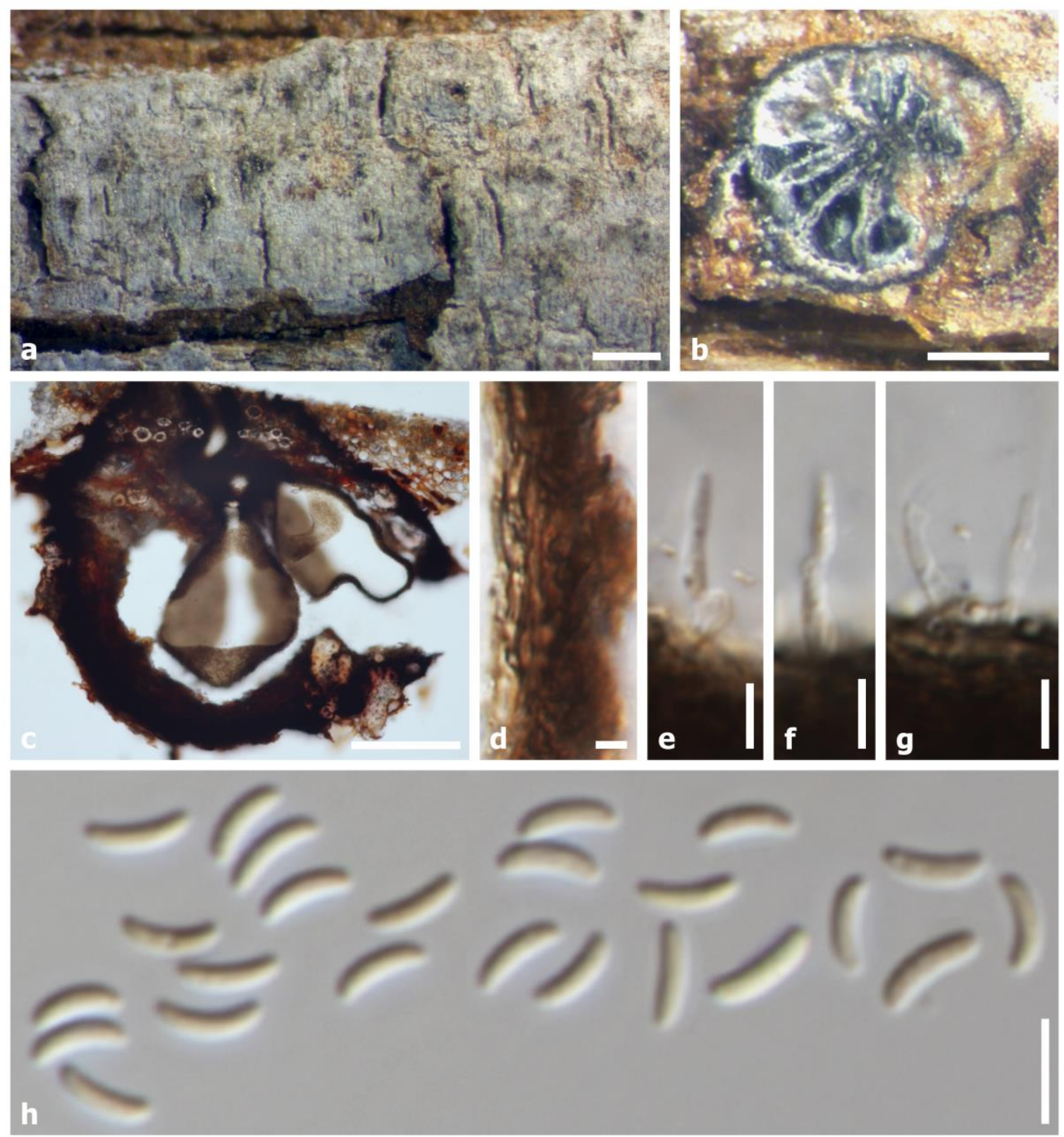

Figure 46 - Asexual morph of Cytospora diopuiensis (MFLU 19-0255, new host record). a Habit in bark. $b$ Vertical section through conidiomata. c Section through the conidiomata. $d$ Peridium. e-g conidiophores. $\mathrm{h}$ Conidia. Scale bars: $\mathrm{a}-\mathrm{b}=500 \mu \mathrm{m}, \mathrm{c}=200 \mu \mathrm{m}, \mathrm{d}-\mathrm{h}=5 \mu \mathrm{m}$.

Cytospora heveae Senwanna, Cheewangkoon \& K.D. Hyde, sp. nov.

Fig. 47

Index Fungorum number: IF559362

Etymology - named after the host genus Hevea, from which this species was isolated.

Associated with canker on seedling stem of Hevea brasiliensis. Sexual morph: Undetermined. Asexual morph: Conidiomata 370-1000 × 200-480 $\mu \mathrm{m}$ diam., semi-immersed in host tissue, solitary, scattered, erumpent, with 7-10 locules arranged circularly or elliptically with independent walls, with ostiolar neck. Ostioles 75-95 $\mu \mathrm{m}$ diam., at the same level as the disc surface. Peridium 8-12(-18) $\mu \mathrm{m}$ wide, composed of several layers of brown to dark brown, thick-walled cells of textura angularis, becoming hyaline, thin-walled cells of textura angularis. Conidiophores branched, reduced to conidiogenous cells. Conidiogenous cells $(3-) 4.5-8(-10) \times 1.2-1.7(-2) \mu \mathrm{m}(\bar{x}$ 
$=6.7 \times 1.5 \mu \mathrm{m}, \mathrm{n}=35)$, blastic, enteroblastic, phialidic, hyaline, smooth-walled. Conidia 3-3.7(-4) $\times 1-1.8 \mu \mathrm{m}(\bar{x}=3.5 \times 1.4 \mu \mathrm{m}, \mathrm{n}=60)$, elongate-allantoid, hyaline to light yellow, aseptate, smoothwalled.
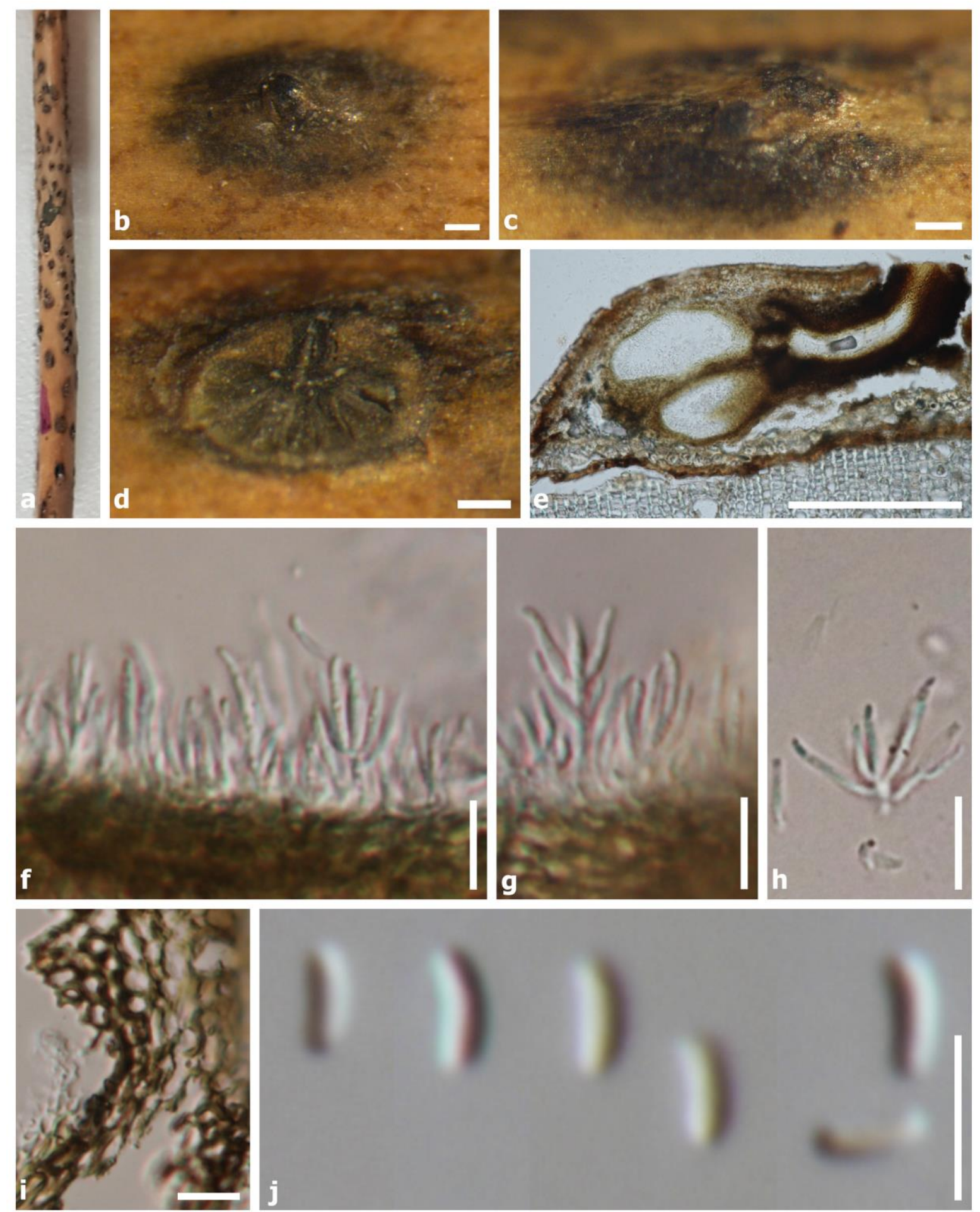

Figure 47 - Cytospora heveae (MFLU 21-0203, holotype). a Habit in bark. b-c Surface of ascomata. d Vertical section through conidiomata. e Longitudinal sections through conidiomata. $\mathrm{f}-\mathrm{h}$ Conidiophores. i Peridium. j Conidia. Scale bars: $\mathrm{a}-\mathrm{e}=200 \mu \mathrm{m}, \mathrm{f}-\mathrm{i}=10 \mu \mathrm{m}, \mathrm{j}=5 \mu \mathrm{m}$.

Culture characteristics - Conidia germinating on MEA within 24 hours at room temperature $\left(25-30^{\circ} \mathrm{C}\right)$ and germ tubes produced from the ends of the conidia. producing dense mycelium, 
margin rough, white, after 10 days become whitish grey, slightly raise, dense mycelium, lacking aerial mycelium.

Material examined - Thailand, Phayao Province, Mueang District, canker on seedling stem of Hevea brasiliensis (Euphorbiaceae), 29 January 2017, C. Senwanna, RBPY40 (MFLU 21-0203, holotype), ex-type living culture MFLUCC 17-0358.

Host and distribution - Hevea brasiliensis (Thailand; this study).

GenBank numbers - MFLUCC 17-0358: ITS $=$ OL780505, SSU $=$ OL780534, TEF1 = OL944428.

Notes - In the NCBI BLASTn search, Cytospora heveae has the closest match to $C$. pingbianensis (MFLUCC 18-1204; MK912135) with 98.72\% similarity, the closest match of LSU sequence is similar to $C$. thailandica (MFLU 17-0709; MH253455 and MFLUCC 17-0262; MH253455) with 99.63\% similarity, while the closest match of the ACT and TEF sequence of our strain with 97.63\% (MH933552) and 94.13\% (MH933516) similarity, respectively, are identical to C. platycladi (CFCC 50504). Phylogenetic analyses of the combined ITS, LSU, ACT and TEF1 sequence dataset show that $C$. heveae forms a distinct lineage closely related to C. lumnitzukicola, C. platycladi and C. pingblanensis (Fig. 44). Cytospora heveae differs from C. lumnitzukicola and C. platycladi in conidiogenous cells $(3-10 \times 1.2-2$ vs $5-12 \times 1-1.5$ vs $8-14 \times 0.6-1.6 \mu \mathrm{m})$ and conidia $(3-4 \times 1-1.8$ vs $4-5.5 \times 1-1.5$ vs $3.7-4.5 \times 1-1.5 \mu \mathrm{m})$ dimensions (Norphanphoun et al. 2018, Fan et al. 2020). However, we could not compare the morphological characteristics of our strain with $C$. pingblanensis as it is only known as sexual morph species (Shang et al. 2020). Cytospora heveae is introduced as a new species based on morphological characters and phylogenetic evidence.

Cytospora thailandica Norph., T.C. Wen \& K.D. Hyde, in Norphanphoun et al., MycoKeys 38: 106 (2018)

Index Fungorum number: IF554779

Fig. 48

Associated with canker on twigs of Hevea brasiliensis. Sexual morph: Stromata immersed in bark. Ascomata 350-1780 × 430-950 $\mu \mathrm{m}$ diam., semi-immersed in host tissue, scattered, erumpent, uni- or multi-loculate, with ostiolar neck. Ostiole 60-152 $\mu \mathrm{m}$ diam., numerous, dark brown to black, at the same level as the disc, occasionally area below disc a lighter entostroma. Peridium (12-)16-25(-31) $\mu \mathrm{m}$ wide, composed of several layers of brown to dark brown, thick-walled cells of textura angularis, becoming hyaline, thin-walled cells of textura angularis. Paraphyses cylindrical, aseptate, hyaline. Asci (20-)22-30(-34.5) × (3.6-)4.2-5.4(-5.8) $\mu \mathrm{m}(\bar{x}=26.8 \times 4.7 \mu \mathrm{m}$, $\mathrm{n}=35), 8$-spored, unitunicate, clavate to elongate obovoid, sessile, apically rounded to truncate, with a J-, refractive apical ring. Ascospores $(3.5-) 4-8.7(-10) \times(0.8-) 1-1.9(-2.4) \mu \mathrm{m}(\bar{x}=6.8 \times 7.5$ $\mu \mathrm{m}, \mathrm{n}=85)$, biseriate, elongate-allantoid, aseptate, hyaline or light yellow, smooth-walled. Asexual morph: Undetermined.

Culture characteristics - Ascospores germinating on MEA within 24 hours at room temperature $\left(25-30{ }^{\circ} \mathrm{C}\right)$ and germ tube produced from the ends of the ascospores. Initially aerial mycelium white, circular, after 15 days become whitish grey, velvety, raise, dense mycelium, lacking aerial mycelium.

Material examined - Thailand, Phayao Province, Mueang District, on twigs of Hevea brasiliensis (Euphorbiaceae), 29 January 2017, C. Senwanna, RBPY35 (MFLU 21-0200), MFLUCC 17-0353 (new host record).

Host and distribution - Hevea brasiliensis (Thailand; this study), Xylocarpus moluccensis (Thailand; Norphanphoun et al. 2018).

GenBank numbers - MFLUCC 17-0353: ITS $=$ OL780506, LSU $=$ OL782084, SSU $=$ OL780533, TEF1 = OL944429.

Notes - Phylogenetic analysis show that strain MFLUCC 17-0353 grouped with Cytospora thailandica (Fig. 44). In a BLASTn search of NCBI GenBank, the closest match of the ITS, LSU, and ACT sequence of our strain with 99.81\% (MG975776 and MG975777), 100\% (MH253456 and MH253455) and 98.65\% (MH253459) similarity, respectively, were identical to Cytospora 
thailandica. However, the asci and ascospores of our strain is longer than reported by Norphanphoun et al. (2018). We, therefore, name our collection as Cytospora thailandica. The collection is a new host record for Hevea brasiliensis in Thailand.
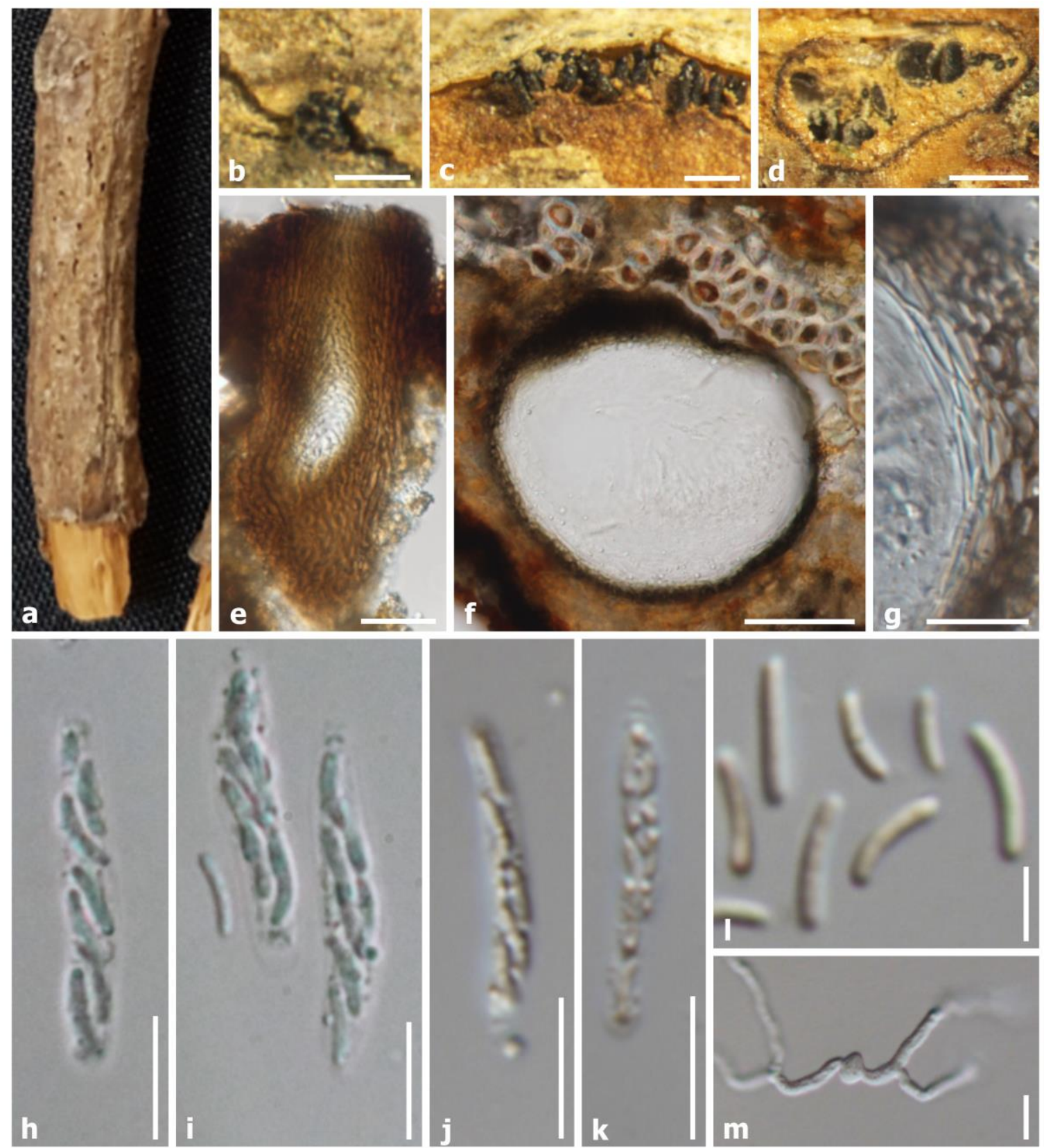

Figure 48 - Cytospora thailandica (MFLU 21-0200, new host record). a Habit of ascomata in bark. b-c Surface of ascomata. d Vertic al section through ascomata. e Ostiolar neck. f Section through the ascoma. g Peridium. $\mathrm{h}-\mathrm{k}$ Asci. 1 . Ascospores. $\mathrm{m}$ Germinated spore. Scale bars: $\mathrm{a}=1000 \mu \mathrm{m}$, $\mathrm{b}-\mathrm{d}=500 \mu \mathrm{m}, \mathrm{e}, \mathrm{g}=20 \mu \mathrm{m}, \mathrm{f}=50 \mu \mathrm{m} . \mathrm{h}-\mathrm{k}=10 \mu \mathrm{m}, \mathrm{l}-\mathrm{m}=5 \mu \mathrm{m}$.

Diaporthaceae Höhn. ex Wehm.

Members of Diaporthaceae are plant pathogens, saprobes, and endophytes on a broad range of plants in terrestrial and aquatic habitats worldwide (Dissanayake et al. 2017b, Senanayake et al. 2018, Dayarathne et al. 2020, Phukamsakda et al. 2020). Fifteen genera are accepted by Hyde et al. (2020b). In this study, a new species, Diaporthe heveicola, and a new record of D. rosae are introduced on Hevea brasiliensis based on morphology and molecular data, together with descriptions and illustrations. 


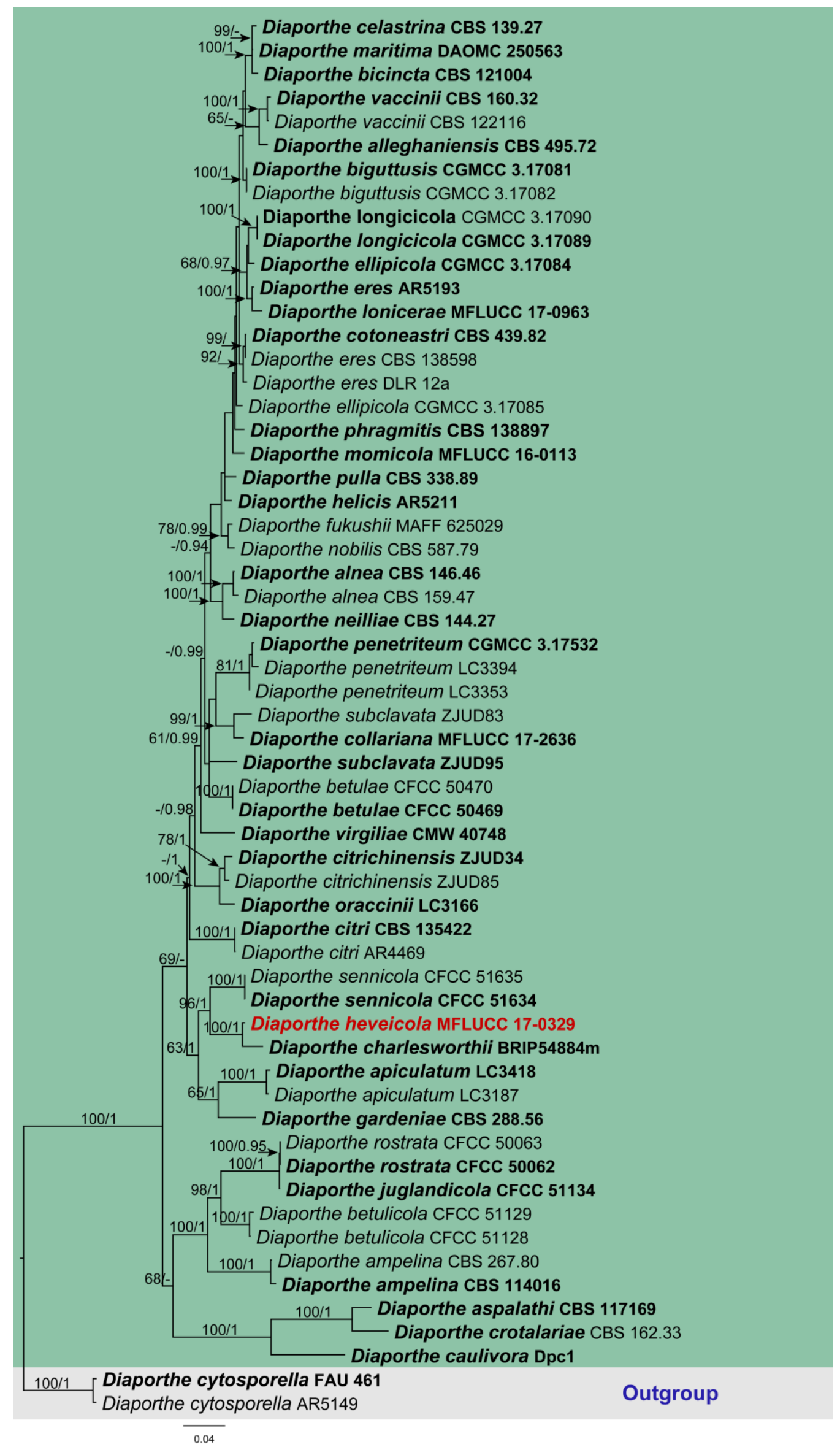

Figure 49 - RAxML tree of selected members of Diaporthe (I) based on a combined ITS, TEF1 and TUB2 sequence dataset. Fifty-nine strains are included in the combined sequence analysis, 
which comprise 1754 characters with gaps. Tree topology of the ML analysis was similar to the BYPP. The best scoring RAxML tree with a final likelihood value of -19229.929462 is presented. The matrix had 798 distinct alignment patterns, with $23.43 \%$ of undetermined characters or gaps. Estimated base frequencies were as follows: $\mathrm{A}=0.223034, \mathrm{C}=0.322803, \mathrm{G}=0.228233, \mathrm{~T}=$ 0.225930; substitution rates: $\mathrm{AC}=1.555611, \mathrm{AG}=4.299339, \mathrm{AT}=1.646087, \mathrm{CG}=1.117010, \mathrm{CT}$ $=6.414037, \mathrm{GT}=1.000000$; gamma distribution shape parameter $\alpha=0.862258$. Bootstrap support values for ML equal to or greater than $60 \%$ and BYPP equal to or greater than 0.90 are defined as ML/BYPP above the nodes. Newly generated sequences are in red bold and type species are in bold. Diaporthe cytosporella (AR5149 and FAU 461) are used as outgroup taxa.

Diaporthe heveicola Senwanna, Cheewangkoon \& K.D. Hyde, sp. nov.

Fig. 50

Index Fungorum number: IF559363

Etymology - Named after the host genus on which it occurs, Hevea.

Saprobe on branch (attached on tree) of Hevea brasiliensis. Sexual morph: Ascomata 190 $460 \mu \mathrm{m}$ diam., $180-480 \mu \mathrm{m}$ high, perithecial, solitary to aggregated, immersed, obpyriform to globose, dark brown to black, papillate, ostiolate. Peridium $12-31 \mu \mathrm{m}$ wide $(\bar{x}=21 \mu \mathrm{m}, \mathrm{n}=20$ ), composed of 2-3 layers of thin-walled cells of textura globosa mixed with textura angularis, brown to dark brown, becoming hyaline at inner regions, composed of thin-walled cells of Textura prismatica. Paraphyses 5-8 $\mu \mathrm{m}$ wide, septate, constricted at septa, broad filiform, tapering above asci. Asci (36-)45-59(-63) $\times(6-) 7-9.5(-10) \mu \mathrm{m}(\bar{x}=51.6 \times 8.4 \mu \mathrm{m}, \mathrm{n}=29), 8$-spored, unitunicate, elongate to clavate, sessile, thin-walled, with a refractive, J-, apical ring. Ascospores (9-)10-14 $\times$ (2.5-)3-4.5 $\mu \mathrm{m}(\bar{x}=11.5 \times 3.5 \mu \mathrm{m}, \mathrm{n}=52)$, elliptical to fusiform, hyaline, uniseptate, constricted at septum, often 2-4-guttulate, with larger guttules at center and smaller ones at the ends. Asexual morph: Undetermined.

Culture characteristics - Ascospores germinating on MEA within 24 hours at room temperature $\left(25-30^{\circ} \mathrm{C}\right)$ and germ tube was produced from the ends of the ascospores. Colonies from ascospores and conidia germinating on MEA reaching $3 \mathrm{~cm}$ after 2 days at room temperature, initially aerial mycelium white, circular, cottony to fluffy with sparse aspects, colony from above white to white greyish; from below: white to white greyish, slight raise, fluffy, dense, undulate.

Material examined - Thailand, Phayao Province, Muang District, on branch (attached on tree) of Hevea brasiliensis (Euphorbiaceae), 2 October 2016, C. Senwanna, RBPY10 (MFLU 19-0240, holotype), ex-type living culture MFLUCC 17-0329.

Host and distribution - Hevea brasiliensis (Thailand; this study).

GenBank numbers - MFLUCC 17-0329: ITS = OL780507, TEF1 = OL944430, TUB2 = OL840999.

Note - In a BLASTn search, the closest match to the ITS sequence with $97 \%$ similarity was Diaporthe hongkongensis (CBS 115448), while the closest match of the TEF1 and TUB2 sequences with $98 \%$ and $99 \%$ similarity was D. charlesworthii (BRIP 54884m). Phylogenetic analyses of a combined ITS, TEF1 and TUB2 show that Diaporthe heveicola (MFLUCC 17-0329) forms a distinct lineage sister to D. charlesworthii (BRIP 54884m) with high support (Fig. 49). In a comparison of ITS, TEF1 and TUB2 nucleotides, D. heveicola differs from $D$. charlesworthii in 28/576 bp, 4/461 bp and 3/510 bp, respectively. However, we could not compare the morphological characteristics of those species; D. heveicola (MFLUCC 17-0329) is found as sexual morph in nature and we could not obtain its asexual morph in culture, while $D$. charlesworthii was found as asexual morphs in culture (Thompson et al. 2015). Diaporthe heveae have been reported on Hevea brasiliensis; however, our collection differs from $D$. heveae in size of asci (36-63 × 6-10 vs 40-45 $\times 6-8 \mu \mathrm{m})$ and ascospores $(9-14 \times 2.5-4.5$ vs $10-15 \times 4 \mu \mathrm{m})$ (Saccardo 1913). Therefore, $D$. heveicola is described here as a new species based on phylogeny.

Diaporthe rosae Samarakoon \& K.D. Hyde, in Wanasinghe et al., Fungal Divers. 89: 1-236 (2018) Fig. 52

Index Fungorum number: IF554072 
Saprobe on dead branch (attached on tree) of Hevea brasiliensis. Sexual morph: Undetermined. Asexual morph: Conidiomata 45-160 $\mu \mathrm{m}$ diam., 30-120 $\mu \mathrm{m}$ high, pycnidial, globose to subglobose, immersed, dense, with a single locule. Conidiomata wall $13-25 \mu \mathrm{m}$ wide $(\bar{x}$ $=20 \mu \mathrm{m}, \mathrm{n}=10$ ), composed of thick-walled cells of textura angularis, brown to dark brown, becoming hyaline at inner regions, composed of thin-walled cells of textura angularis. Conidiophores arising all around the cavity of the conidioma, reduced to conidiogenous cells. Conidiogenous cells (5-)6-10(-15) $\times(1.5-) 2-3.5(-3.7) \mu \mathrm{m}(\bar{x}=8 \times 3.1 \mu \mathrm{m}, \mathrm{n}=33)$ aseptate, ampulliform or cylindrical, straight, densely aggregated, hyaline. Alpha conidia (4-)5.5-7.5(-8) $\times$ (2-)2.3-3(-3.2) $\mu \mathrm{m}(\bar{x}=6.5 \times 2.7 \mu \mathrm{m}, \mathrm{n}=90)$, oval to fusiform, hyaline, aseptate, conspicuously biguttulate. Beta conidia not found.
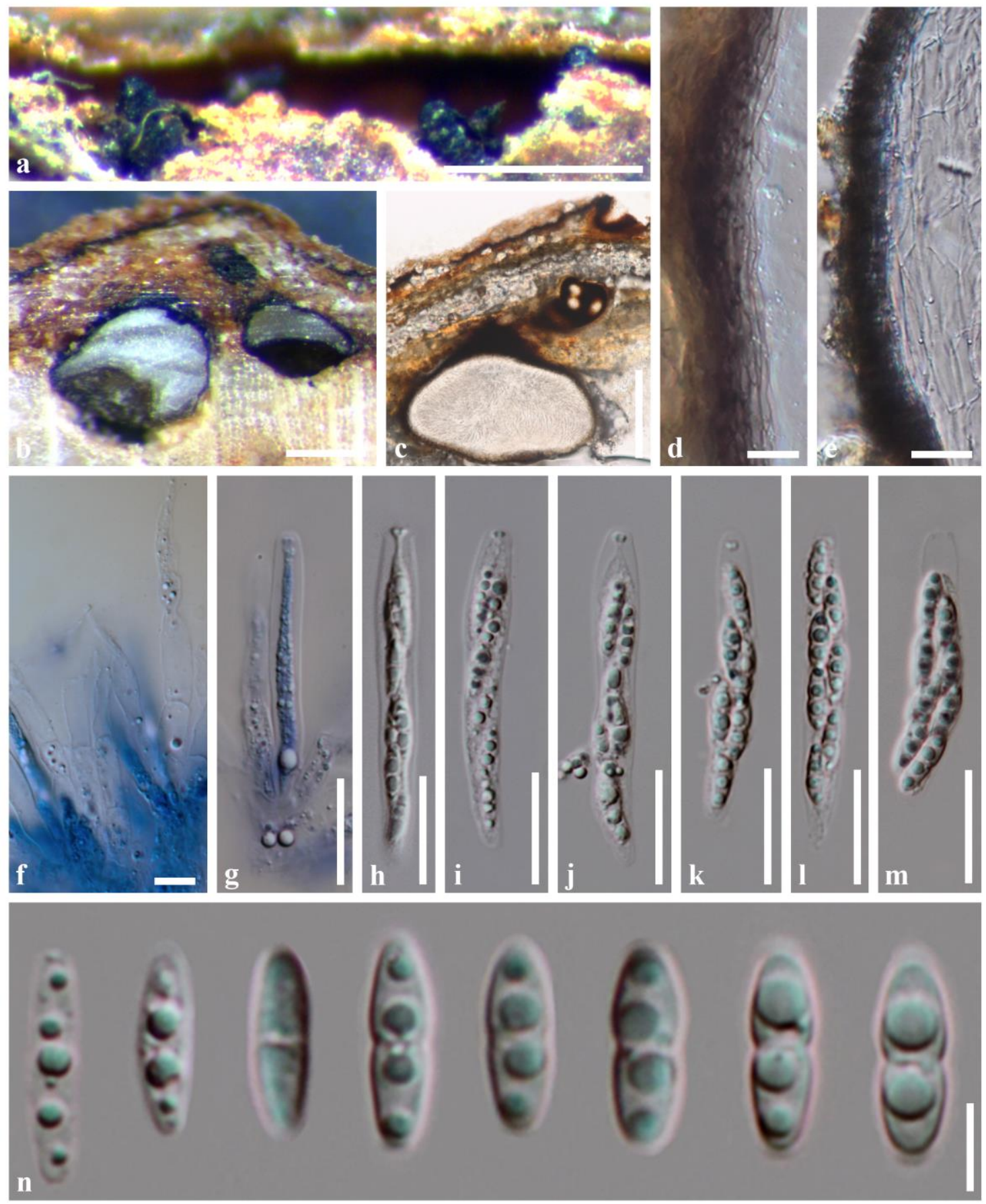

Figure 50 - Diaporthe heveicola (MFLU 19-0240, holotype). a-b Habitat on host surface. b Longitudinal sections through ascomata. c Section through the ascoma. d-e Peridium. f Paraphyses (mounted in Lactophenol cotton blue). g-m Asci; g. asci mounted in Lactophenol 
cotton blue, h asci mounted in Melzer's reagent, $\mathrm{i}-\mathrm{m}$. asci mounted in $\mathrm{ddH}_{2} \mathrm{O}$. n Ascospore. Scale bars: $\mathrm{a}=500 \mu \mathrm{m}, \mathrm{b}-\mathrm{c}=200 \mu \mathrm{m}, \mathrm{d}, \mathrm{e}, \mathrm{h}-\mathrm{m}=20 \mu \mathrm{m}, \mathrm{f}=10 \mu \mathrm{m}, \mathrm{n}=5 \mu \mathrm{m}$.

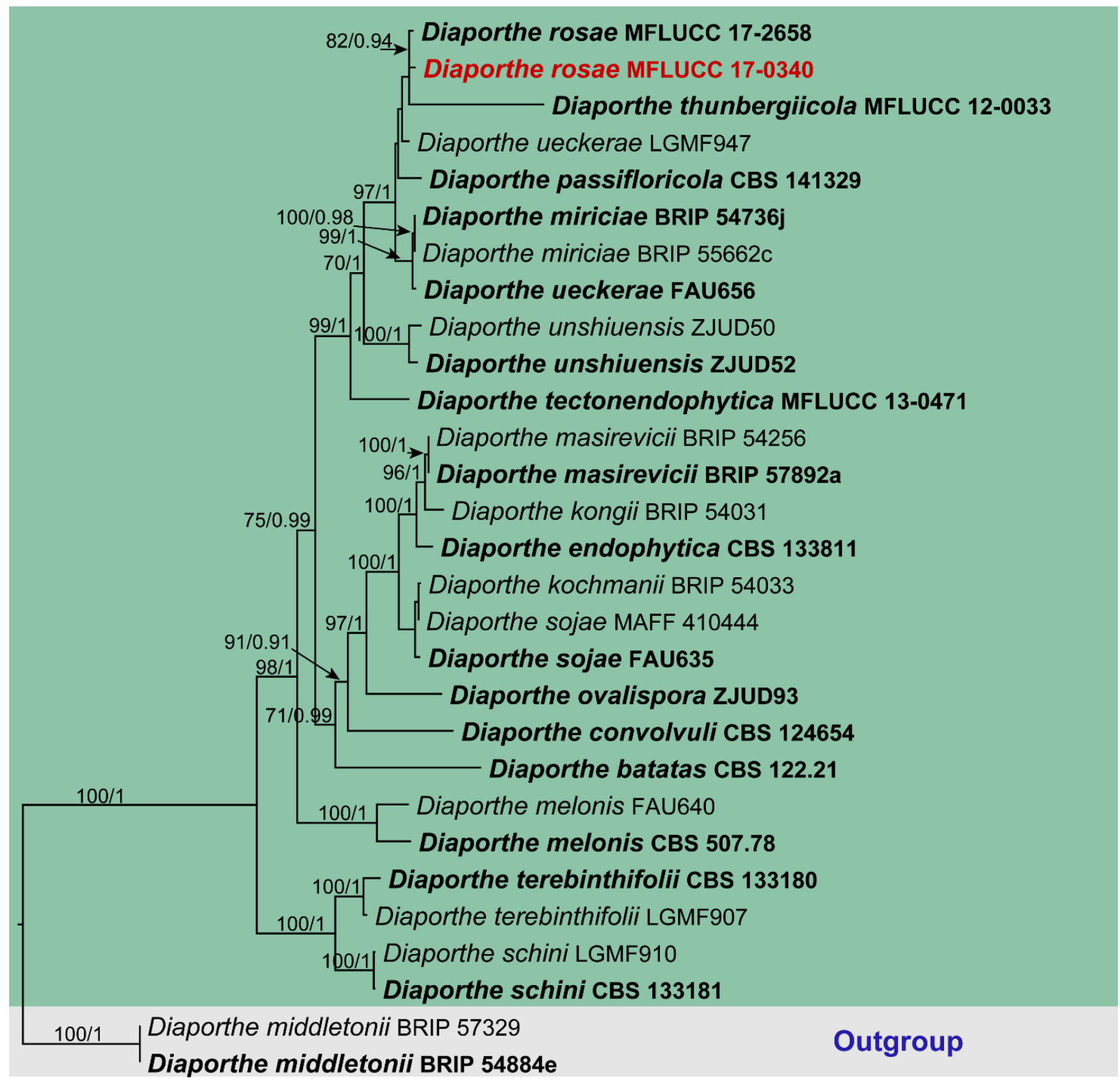

0.03

Figure 51 - RAxML tree of selected members of Diaporthe (II) based on a combined ITS, TEF1 and BT sequence dataset. Twenty-nine strains are included in the combined sequence analysis, which comprise 1688 characters with gaps. Tree topology of the ML analysis was similar to the BYPP. The best scoring RAxML tree with a final likelihood value of -6627.827469 is presented. The matrix had 564 distinct alignment patterns, with $18.47 \%$ of undetermined characters or gaps. Estimated base frequencies were as follows: $\mathrm{A}=0.220652, \mathrm{C}=0.314490, \mathrm{G}=0.236062, \mathrm{~T}=$ 0.228796; substitution rates: $\mathrm{AC}=1.749158, \mathrm{AG}=5.679014, \mathrm{AT}=1.685358, \mathrm{CG}=1.424435, \mathrm{CT}$ $=6.823319, \mathrm{GT}=1.000000$; gamma distribution shape parameter $\alpha=0.787298$. Bootstrap support values for ML equal to or greater than $60 \%$ and BYPP equal to or greater than 0.90 are defined as ML/BYPP above the nodes. Newly generated sequences are in red bold and type species are in bold. Diaporthe middletonii (BRIP 54884e and BRIP 57329) are used as outgroup taxa. 

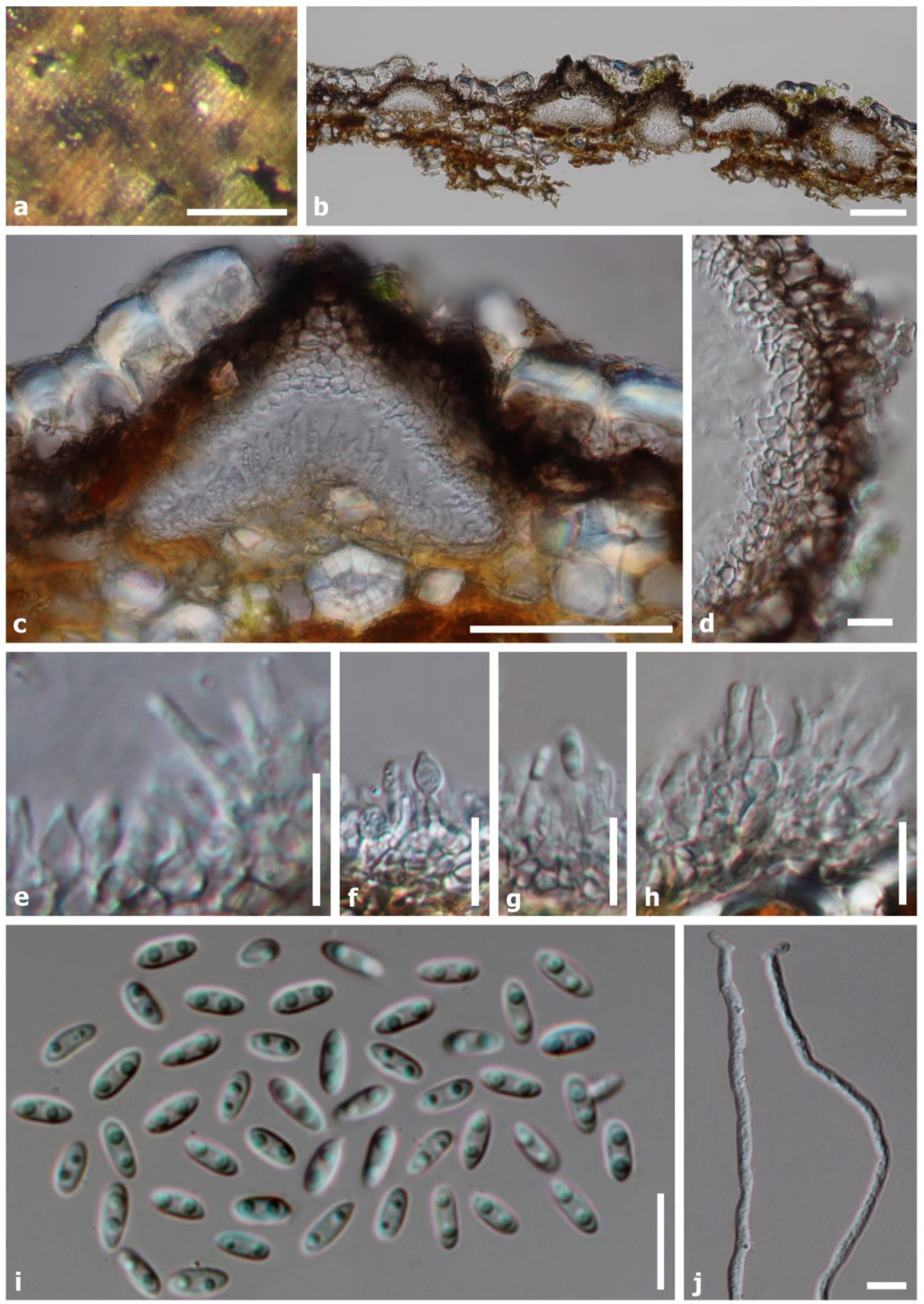

Figure 52 - Diaporthe rosae (MFLU 19-0247, new host record). a Habit on host substrate. $\mathrm{b}-\mathrm{c}$ Section through the conidiomata. d Peridium. e- $\mathrm{h}$ Conidiophores and conidiogenous cells. i Conidia. j Germinated spores. Scale bars: $a=200 \mu \mathrm{m}, b-c=100 \mu \mathrm{m}, \mathrm{d}-\mathrm{j}=10 \mu \mathrm{m}$.

Culture characteristics - Ascospores germinating on MEA within 24 hours at room temperature $\left(25-30^{\circ} \mathrm{C}\right)$ and germ tubes produced from the ends of the ascospores. Colonies initially 
aerial mycelium white, circular, cottony to fluffy with sparse aspects, colony from above white to white greyish; from below: white to white greyish, slight raise, fluffy, dense, undulate.

Material examined - Thailand, Phayao Province, Mueang District, on dead branch (attached on tree) of Hevea brasiliensis (Euphorbiaceae), 5 December 2016, C. Senwanna, RBPY021 (MFLU 19-0247), living culture MFLUCC 17-0340 (new host record).

Host and distribution - Rosa sp. (California; French 1989, Thailand; Perera et al. 2018, Wanasinghe et al. 2018), Magnolia champaca (Thailand; Perera et al. 2018), Senna siamea Thailand (Perera et al. 2018), Hevea brasiliensis (Thailand; this study).

GenBank numbers - MFLUCC 17-0340: ITS = OL780508.

Notes - A phylogenetic analysis shows that the strain MFLUCC 17-0340 clusters to Diaporthe rosae (MFLUCC 17-2658) and D. thunbergiicola (MFLUCC 12-0033) (Fig. 51). In a BLASTn search, the closest match of the ITS sequence of strain MFLUCC 18-0304 was Diaporthe rosae with $99.65 \%$ similarity to the strain MFLUCC 17-2658 (MG828894). Morphological characters of conidiophores, conidiogenous cells and conidial dimensions from our collection (MFLU 19-0247) are similar to the holotype of Diaporthe rosae which was collected from dead pedicel of Rosa sp. in Thailand (Wanasinghe et al. 2018). We, therefore, name our collection as Diaporthe rosae which is a new host record for Hevea brasiliensis in Thailand.

\section{Hypocreales Lindau}

Nectriaceae Tul. \& C. Tul.

Nectriaceae comprises numerous plant and human pathogens (Lombard et al. 2015). The family is characterized by lightly to brightly coloured, uniloculate ascomata, and synnematous, sporodochial or pycnidial conidiomata with phialidic conidiogenesis (Lombard et al. 2015). The two collections in this study are considered to be Albonectria rigidiuscula and Nectria pseudotrichia based on phylogeny and morphological comparison.

Albonectria rigidiuscula (Berk. \& Broome) Rossman \& Samuels, in Rossman et al., Stud. Mycol. 42: 105 (1999)

Index Fungorum number: IF 460215

Saprobic on branches of Hevea brasiliensis. Sexual morph: Ascomata 275-640 $\mu \mathrm{m}$ diam., 250-590 $\mu \mathrm{m}$ high, solitary or gregarious, superficial, globose to subglobose, pale yellow, with or without a small, pointed papilla, ascomata surface with concolorous wart. Peridium 43-89 $\mu \mathrm{m}$ thick $(\bar{x}=64 \mu \mathrm{m}, \mathrm{n}=15)$, comprising several layers, hyaline to pale yellow cells of textura angularis. Paraphyses 109-117 $\times 16-19 \mu \mathrm{m}$, hyaline, septate, constricted at septum. Asci (47-)55$114(-118.5) \times(8.5-) 10-18 \mu \mathrm{m}(\bar{x}=81.5 \times 13 \mu \mathrm{m}, \mathrm{n}=33), 4$-spored, unitunicate, hyaline, clavate to cylindrical, with a short pedicellate, apical ring. Ascospores $(16-) 18-25(-28) \times(4-) 5-9(-12) \mu \mathrm{m}$ ( $\bar{x}=21.5 \times 7.4 \mu \mathrm{m}, \mathrm{n}=42$ ), fusiform to narrowly ellipsoidal-ovoid with rounded ends, straight to rarely curved, hyaline, 3-4-septate, smooth-walled. Asexual morph: Undetermined.

Culture characteristics - Ascospores germinating on MEA within 24 hours and germtube produced from one or both ends of the ascospores. Colonies on PDA reaching 2-3 cm diam. after 5 days at $25-30{ }^{\circ} \mathrm{C}$, colonies circular, mycelium slightly raised, effuse, cultures white at first, becoming creamy white from the centre with white margin from above and creamy white in reverse.

Material examined - Thailand, Phayao Province, Mae Ka Subdistrict, Mueang District, on branch of Hevea brasiliensis (Euphorbiaceae), 2 October 2016, C. Senwanna, RBPY09 (MFLU 181383), living culture MFLUCC 17-0328 (new host record).

Host and distribution - Wide host range, widely distributed in tropical and subtropical regions.

GenBank numbers - MFLUCC 17-0328: ITS $=$ OL780509, LSU $=$ OL782090, TUB2 $=$ OL840997. 


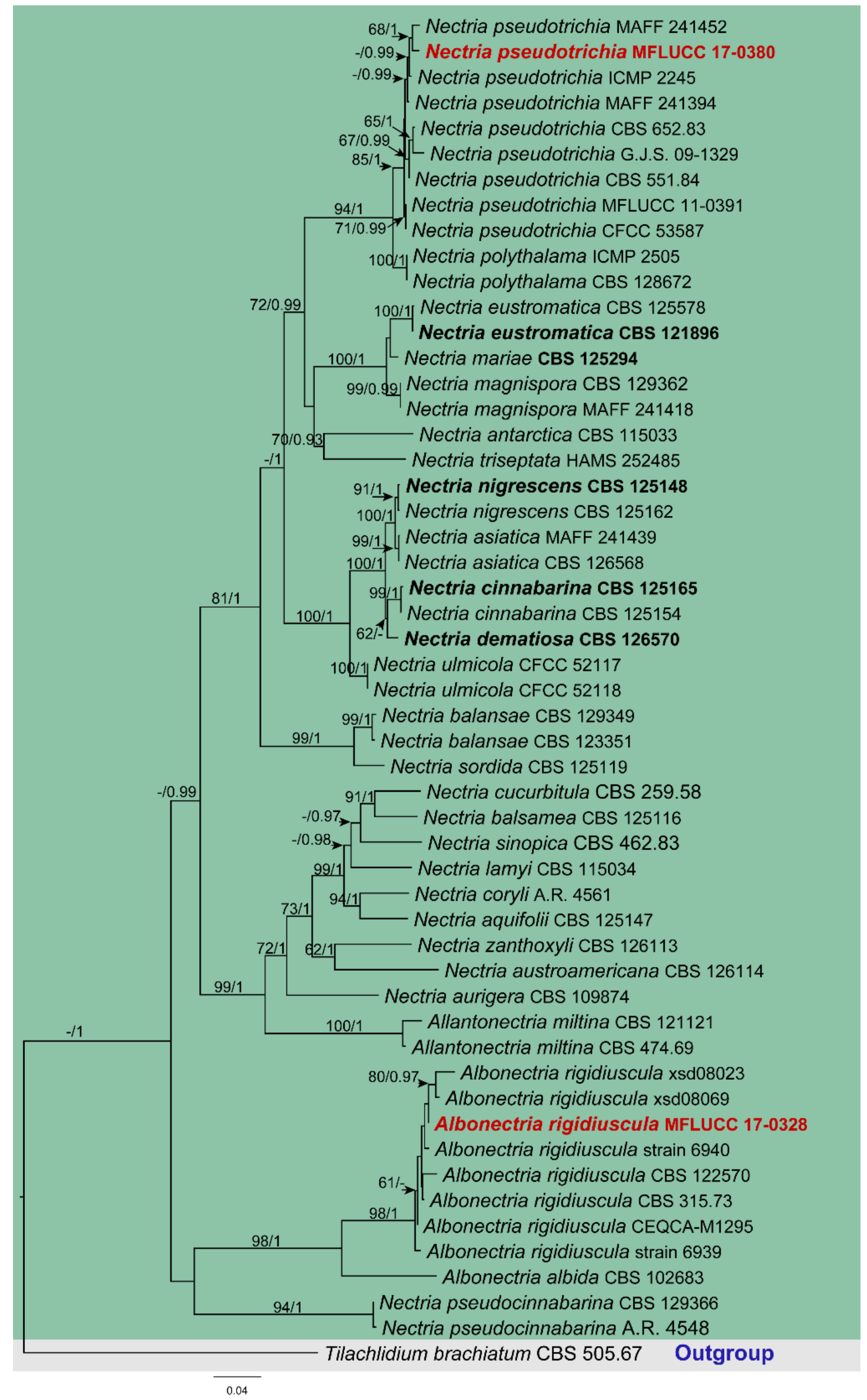

Figure 53 - RAxML tree of Nectria based on a combined ITS, LSU, RPB1 and TUB1 sequence dataset. Twenty-nine strains are included in the combined sequence analysis, which comprise 1720 
characters with gaps. Tree topology of the ML analysis was similar to the BYPP. The best scoring RAxML tree with a final likelihood value of -19229.929462 is presented. The matrix had 1060 distinct alignment patterns, with $23.91 \%$ of undetermined characters or gaps. Estimated base frequencies were as follows: $\mathrm{A}=0.236620, \mathrm{C}=0.257172, \mathrm{G}=0.275135, \mathrm{~T}=0.231073$; substitution rates: $\mathrm{AC}=1.133952, \mathrm{AG}=3.018968, \mathrm{AT}=1.454018, \mathrm{CG}=0.937166, \mathrm{CT}=$ $6.245900, \mathrm{GT}=1.000000$; gamma distribution shape parameter $\alpha=0.859225$. Bootstrap support values for ML equal to or greater than $60 \%$ and BYPP equal to or greater than 0.90 are defined as ML/BYPP above the nodes. Newly generated sequences are in red bold and type species are in bold. Tilachlidium brachiatum (CBS 505.67) is used as the outgroup taxon.
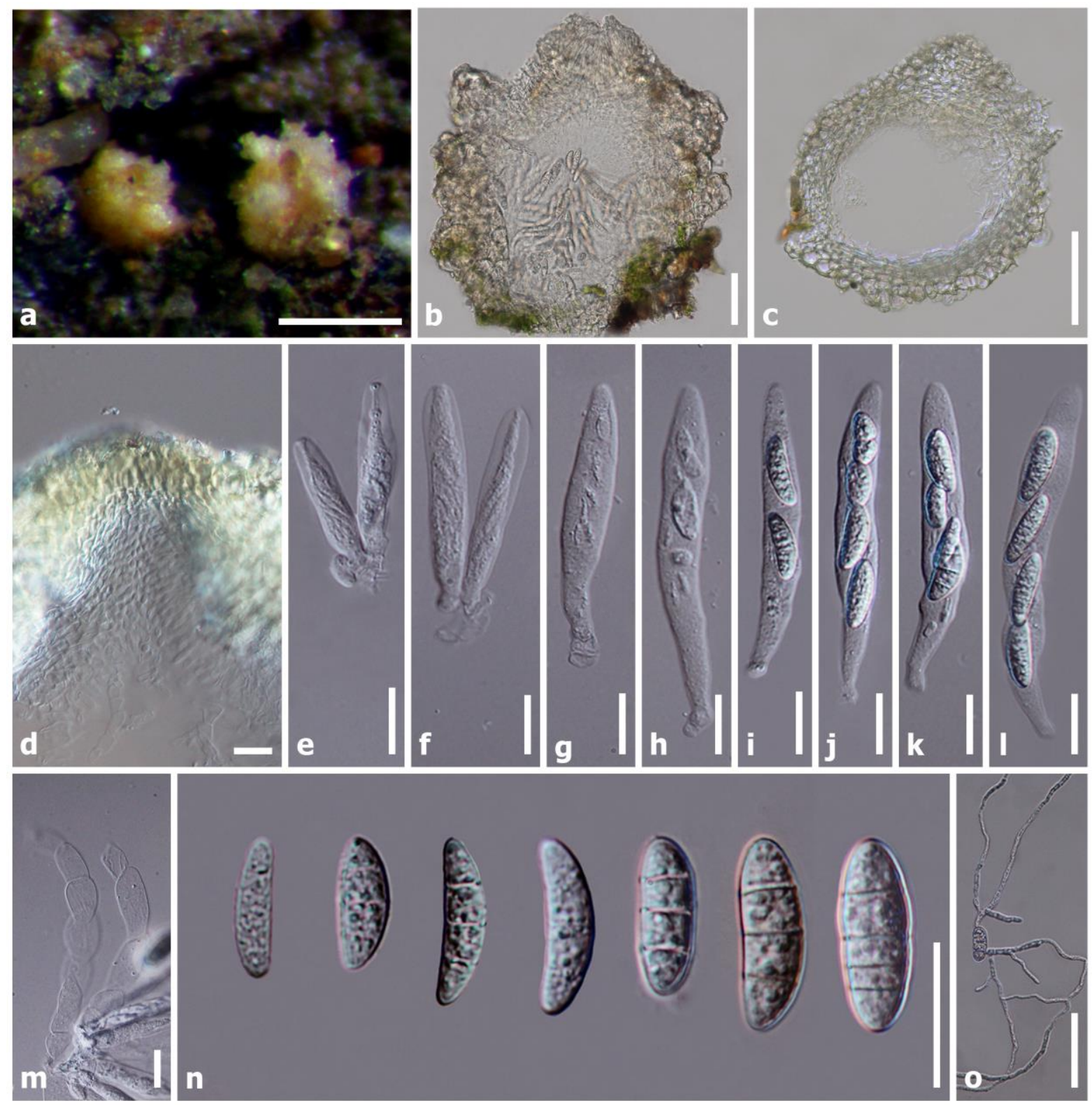

Figure 54 - Albonectria rigidiuscula (MFLU 18-1383, new host record). a-b Ascomata on host substrate. c Section through the ascoma. c Peridium. d Ostiole in section with periphyses. e-1 Asci. m Paraphyses. n Ascospores. o Germinated spore. Scale bars: $a-b=200 \mu \mathrm{m}, \mathrm{c}=50 \mu \mathrm{m}$, $\mathrm{d}-1=20 \mu \mathrm{m}, \mathrm{m}=10 \mu \mathrm{m}, \mathrm{n}=30 \mu \mathrm{m}$.

Notes - In a BLASTn search, the closest match of the ITS sequence is Fusarium continuum (NRRL 66286; NR_159818) and F. babinda (CBS 397.96; MH862578) with 90\% similarity, while the closest match to the LSU sequence was with F. sublunatum (CBS 189.34; MH866966) with 
97.66\% similarity. In the present study, phylogenetic analysis shows that our strain MFLUCC 170328 grouped within Albonectria rigidiuscula (Fig. 53). Albonectria was introduced by Rossman et al. (1999) to accommodate species with white to pale yellow ascomata. Moreover, Albonectria was listed as sexual morphs connected with Fusarium (Wijayawardene et al. 2012). Our collection is similar to A. rigidiuscula described in Rossman et al. (1999) and Guu et al. (2007). We, therefore, name our collection as A. rigidiuscula which is a new host record for Hevea brasiliensis in Thailand.

Nectria pseudotrichia Berk. \& M.A. Curtis, J. Acad. Nat. Sci. Philadelphia 2, 2: 289. 1853

Fig. 55

Index Fungorum number: IF 460215

Saprobic on dead branches of Hevea brasiliensis. Sexual morph: Undetermined. Asexual morph: Colonies effuse. Mycelium partly immersed on the substrate, composed of septate, branched, brown, hyphae. Conidiophores macronematous, synnematous, orange, septate, branched. Synnemata scattered, superficial, solitary, rarely gregarious, humate or coniform, erect or nodding, rigid, orange or reddish brown, branched in top half, hyaline at the tip, velvety, smooth, composed of compactly arranged conidiophores, $1.5-2.5 \mathrm{~mm}$ long, $135-220 \mu \mathrm{m}$ wide at the base, 50-140 $\mu \mathrm{m}$ wide in the middle, 40-70 $\mu \mathrm{m}$ wide at the tip, fertile only apically. Conidiogenous cells (11-)13$19(-28) \times(1.5-) 2-3.5 \mu \mathrm{m}(\bar{x}=15.8 \times 2.4 \mu \mathrm{m}, \mathrm{n}=21)$, enteroblastic, phialidic, integrated or discrete, cylindrical, hyaline, smooth. Conidial mass globose or slightly tapering toward tip, light orange or creamy-white in color. Conidia (3.5-)4-6(-8) $\times 2-3(-3.5) \mu \mathrm{m}(\bar{x}=5.1 \times 2.8 \mu \mathrm{m}, \mathrm{n}=$ 54) $\mu \mathrm{m}$, cylindrical, straight, aseptate, hyaline, smooth-walled.
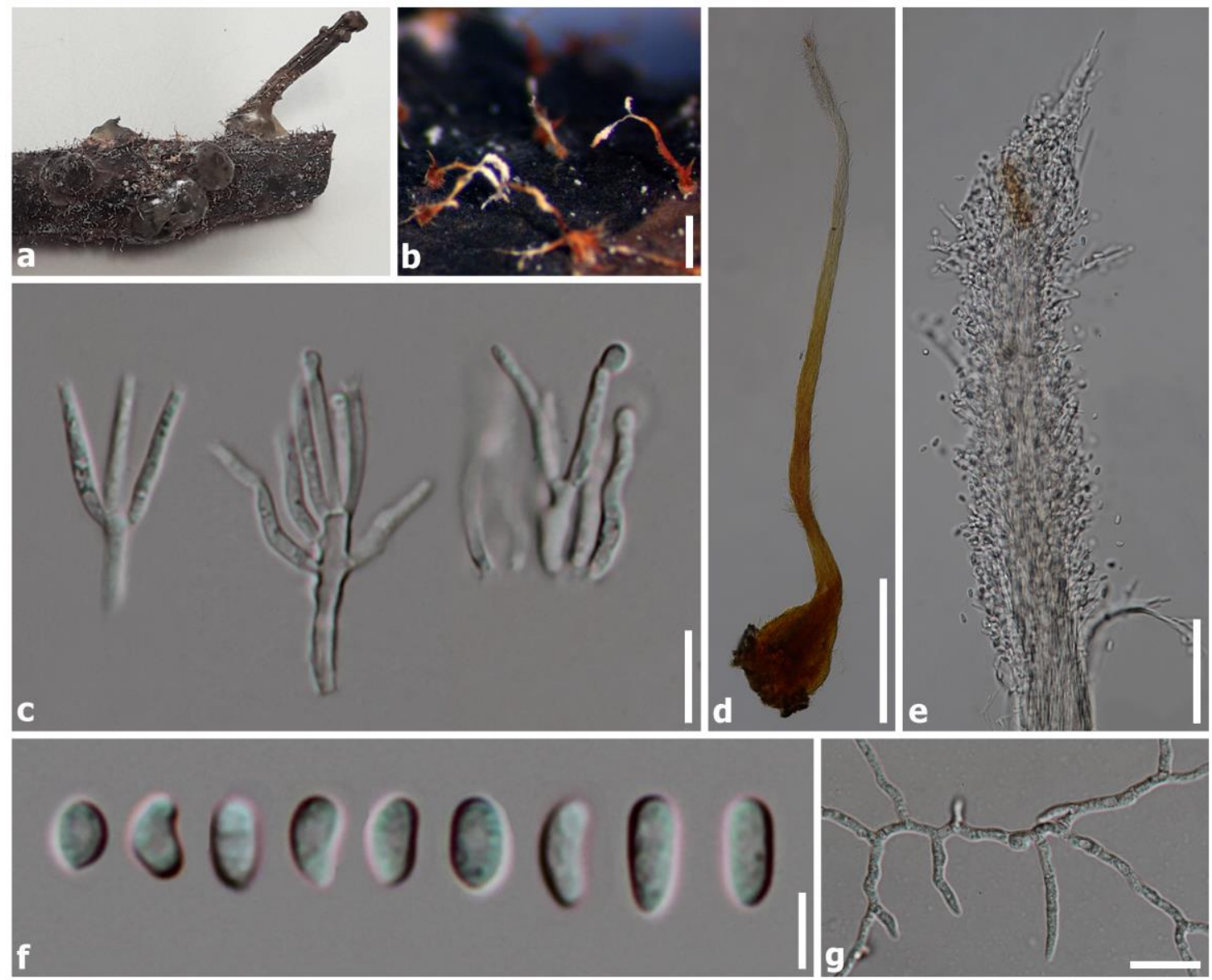

Figure 55 - Nectria pseudotrichia (MFLUCC 19-0220). a-b Synnemata on host surface. c Conidiogenous cells and conidiophores. d Synnemata. e Apex of synnemata. $f$ Conidia. 
g Germinated spore. Scale bars: $\mathrm{b}=500 \mu \mathrm{m}, \mathrm{c}=10 \mu \mathrm{m}, \mathrm{d}=500 \mu \mathrm{m}, \mathrm{e}=50 \mu \mathrm{m}, \mathrm{f}=5 \mu \mathrm{m}, \mathrm{g}=15$ $\mu \mathrm{m}$.

Culture characteristics - Conidia germinating on MEA within 24 hours and germ tube produced from both ends. Colonies on MEA, colonies circular, mycelium slightly raised, effuse, cultures white at first, becoming creamy white from the center, and creamy white in reverse.

Host and distribution - Wide host range and widely distributed in tropical and subtropical regions.

Material examined - Thailand, Chiang Mai Province, Mueang District, on dead branch of Hevea brasiliensis (Euphorbiaceae), 22 September 2016, C. Senwanna, RBCM03 (MFLU 190220), living culture MFLUCC 17-0380.

GenBank numbers - MFLUCC 17-0380: ITS = OL780510, LSU = OL782089, TUB2 $=$ OL840998, RPB1 = OL944405.

Notes - In a BLASTn search, the closest match to the LSU sequences with $97.90 \%$ similarity was Nectria dematiosa (CBS 126570; MH875619), while the closest match to the ITS sequence was $N$. polythalama (CBS 129240; NR_160251) with 98.16\% similarity. A phylogenetic analysis based on combined dataset of ITS, LSU, RPB1 and TUB sequence data show that strain MFLUCC 17-0380 groups with Nectria pseudotrichia (Fig. 53). Nectria pseudotrichia is common tropical species with a synnematous anamorph (Hirooka et al. 2012).

Coronophorales Nannf. (= Melanosporales N. Zhang \& M. Blackw.)

Nitschkiaceae (Fitzp.) Nannf.

Nitchkiaceae is characterized by erumpent, black, carbonaceous or coriaceous to membranaceous, rough, tuberculate, smooth or with short spines ascomata and 4- to multi-spored, clavate asci with hyaline, fusiform or allantoid ascospores (Fitzpatrick 1923, Mugambi \& Huhndorf 2010, Hyde et al. 2020b, Huang et al. 2021). Members of this family are saprobes on decaying bark and wood in terrestrial and aquatic habitats with worldwide distribution (Mugambi \& Huhndorf 2010, Vasilyeva et al. 2010).

Fracchiaea heveae Senwanna, Cheewangkoon \& K.D. Hyde, sp. nov.

Fig. 57

Index Fungorum number: IF559364

Etymology - named after the host genus Hevea, from which this species was isolated.

Saprobe on branch of Hevea brasiliensis. Sexual morph: Ascomata 115-350 $\mu \mathrm{m}$ high, 120 $385 \mu \mathrm{m}$ diam., superficial or erumpent through bark of host, single or clusters of 2-20 ascomata, globose, black, coriaceous, ornamented with pointed spines 18-25 $\mu \mathrm{m}$ long. Ostioles scarcely prominent, hyaline periphysate. Peridium 25-79 $\mu \mathrm{m}$ wide, outer layers dark brown to black, inner layers thin-walled, hyaline, composed of cells of textura angularis. Paraphyses not seen. Asci (6065-130(-137) $\times(9-) 14-22(-27) \mu \mathrm{m}(\bar{x}=100 \times 19 \mu \mathrm{m}, \mathrm{n}=27)$, with numerous ascospores, unitunicate, thin-walled, clavate to cylindrical, short pedicellate, apically rounded. Ascospores $(9-) 12-19(-21) \times 2-4 \mu \mathrm{m}(\bar{x}=15.7 \times 3.3 \mu \mathrm{m}, \mathrm{n}=75)$, crowded, hyaline, lunate or cylindrical with acute ends, slightly curved, aseptate, smooth-walled, mostly with small guttules. Asexual morph: Undetermined.

Host and distribution - Hevea brasiliensis (Thailand; this study)

Material examined - Thailand, Chiang Rai Province, Wiang Chiang Rung District, on branch of Hevea brasiliensis (Euphorbiaceae), 1 November 2016, C. Senwanna, RBCR15 (MFLU 17-0214, holotype).

GenBank numbers - MFLU 17-0214a: ITS $=$ OL780511, LSU $=$ OL782086, SSU $=$ OL780535; MFLU 17-0214b: ITS = OL780512, LSU = OL782086, SSU = OL780536.

Notes - In a BLASTn search of GenBank, the closest match of the LSU sequence of MFLU 17-0214 is Coronophora myricoides (IFRD 9201; KX856174) with 85.27\% similarity. The present study using morphology and phylogenetic analyses, places Fracchiaea heveae in Nitschkiaceae. Fracchiaea is typified by Fracchiaea heterogenea and there are 33 epithets in Index Fungorum 
(2021). The genus is characterized by perithecia, coriaceous-carbonaceous, turbinate, superficial ascomata, clavate and polysporous asci with allantoid, slightly curve ascospores (Fitzpatrick 1924, Mugambi \& Huhndorf 2010, Vasilyeva et al. 2010). Phylogenetic analyses of LSU, TEF and RPB2 sequence data (Fig. 56), indicate that Fracchiaea heveae can be distinguished from other species within the genus Fracchiaea and is close to F. brooneiana and F. lunata. However, Fracchiaea heveae differs from those species in the shape of ascospores and ascospores dimensions (Petch 1917, Talde 1970, Vasilyeva et al. 2010).

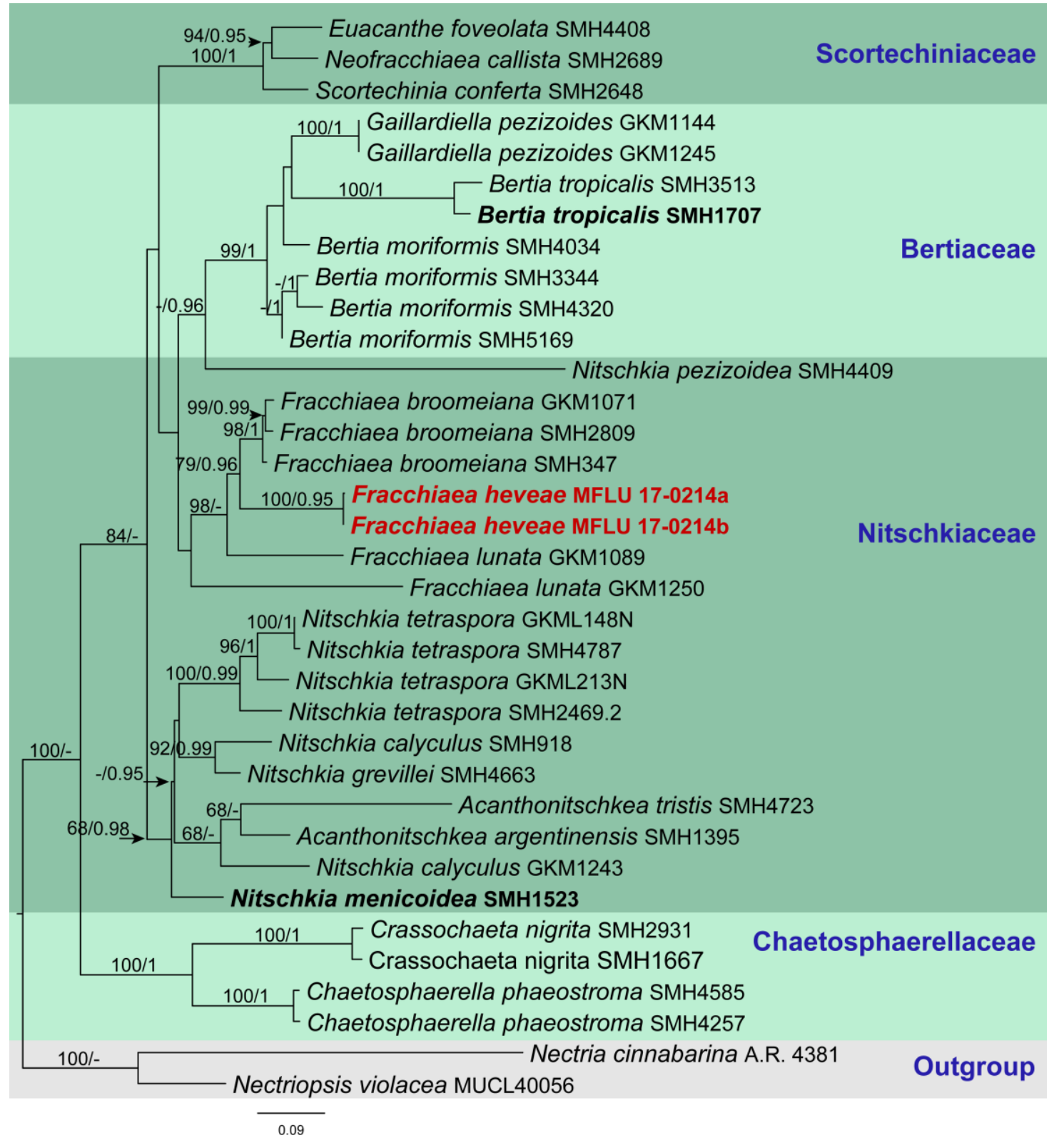

Figure 56 - RAxML tree of Fracchiaea based on a combined LSU, TEF and RPB2 sequence dataset. Thirty-five strains are included in the combined sequence analysis, which comprise 2945 characters with gaps. Tree topology of the ML analysis was similar to the BYPP. The best scoring RAxML tree with a final likelihood value of -20484.619200 is presented. The matrix had 1380 distinct alignment patterns, with $52.38 \%$ of undetermined characters or gaps. Estimated base frequencies were as follows: $\mathrm{A}=0.224476, \mathrm{C}=0.286277, \mathrm{G}=0.309625, \mathrm{~T}=0.179622$; substitution rates: $\mathrm{AC}=1.188678, \mathrm{AG}=2.970846, \mathrm{AT}=1.415215, \mathrm{CG}=1.431534, \mathrm{CT}=$ 7.251219, $\mathrm{GT}=1.000000$; gamma distribution shape parameter $\alpha=0.806399$. Bootstrap support values for ML equal to or greater than $60 \%$ and BYPP equal to or greater than 0.90 are defined as ML/BYPP above the nodes. Newly generated sequences are in red bold and type species are in 
bold. Nectria cinnabarina (A.R. 4381) and Nectriopsis violacea (MUCL 40056) are used as outgroup taxa.
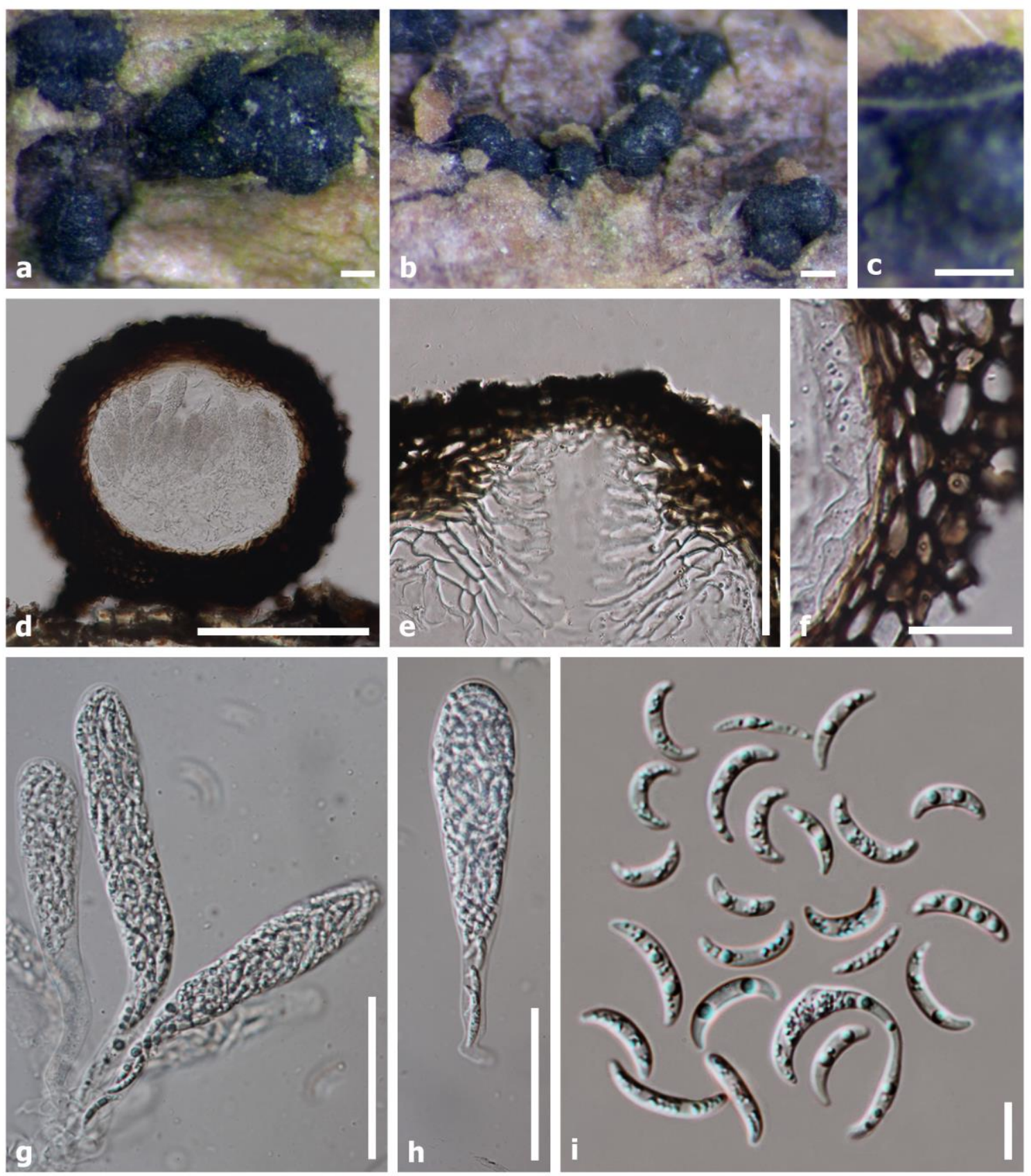

Figure 57 - Fracchiaea heveae (MFLU 17-0214, holotype). a-b Habit on substrate. c Section through the ascoma. d Ostiole in section with periphyses. e Peridium. f, g Asci. h Ascospores. Scale bars: $\mathrm{a}-\mathrm{d}=200 \mu \mathrm{m}, \mathrm{e}=100 \mu \mathrm{m}, \mathrm{f}=30 \mu \mathrm{m}, \mathrm{g}, \mathrm{h}=50 \mu \mathrm{m}, \mathrm{i}=10 \mu \mathrm{m}$.

\section{Sporidesmiales Crous}

Sporidesmiaceae Fr.

Spridesmiaceae is monotypic family which includes a single genus Sporidesmium (Crous et al. 2018b, Hyde et al. 2020b). Sporidesmium species are saprobic on wood in terrestrial and aquatic habitats or mycoparasites of fungi (Hyde et al. 2020b).

Sporidesmium tropicale M.B. Ellis, Mycol. Pap. 70 : 58 (1958)

Fig. 59

Index Fungorum number: IF 306326 
Saprobic on dried twigs of Hevea brasiliensis. Sexual morph: Undetermined. Asexual morph: Hyphomycetous. Colonies effuse, olivaceous or black. Mycelium party immersed or party superficial on the substrate. Conidiophores $(71-) 110-260(-290) \times 4-6.5 \mu \mathrm{m}(\bar{x}=177 \times 5.7 \mu \mathrm{m}, \mathrm{n}$ $=21$, macronematous, mononematous, erect, unbranched, septate, straight, cylindrical, brown to dark brown, smooth. Conidiogenous cells holoblastic, polyblastic, integrated, determinate, terminal, brown. Conidia (39-)51-100(-133) $\times 11-15(-17) \mu \mathrm{m}(\bar{x}=79.4 \times 14.1 \mu \mathrm{m}, \mathrm{n}=21)$, dry, acrogenous, solitary, obclavate, tapering gradually toward the apex, brown to dark brown, rounded at the apex, truncate at the base, 6-13-septate, basal cell cut off by a dark brown septum, smoothwalled.

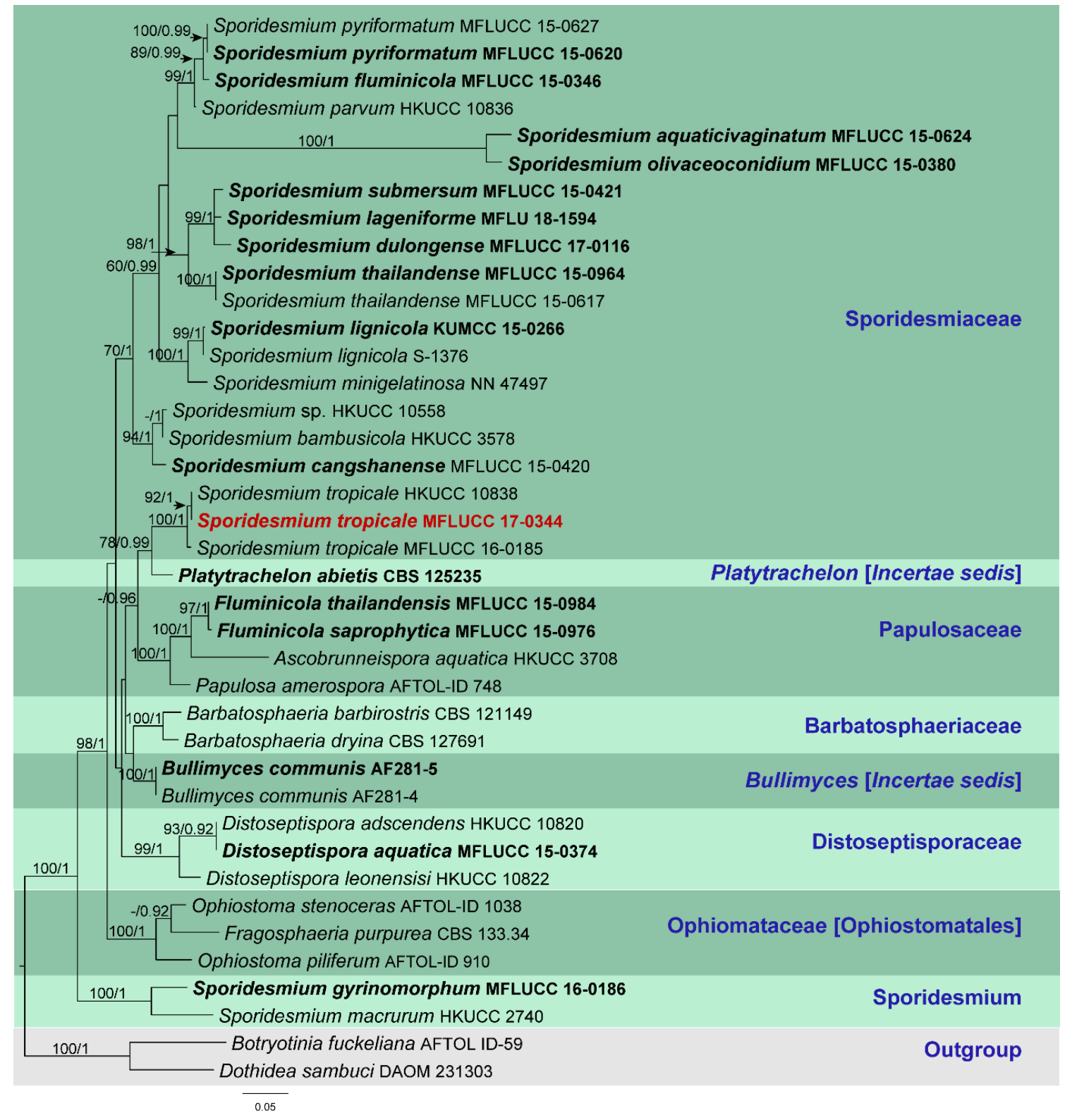

Figure 58 - RAxML tree of Sporidesmium based on a combined LSU, SSU, ITS and TEF1 sequence dataset. Thirty-nine strains are included in the combined sequence analysis, which comprise 3734 characters with gaps. Tree topology of the ML analysis was similar to the BYPP. The best scoring RAxML tree with a final likelihood value of -17079.179295 is presented. The matrix had 1384 distinct alignment patterns, with $50.74 \%$ of undetermined characters or gaps. Estimated base frequencies were as follows: $\mathrm{A}=0.246422, \mathrm{C}=0.250697, \mathrm{G}=0.280180, \mathrm{~T}=$ 0.222701; substitution rates: $\mathrm{AC}=1.069496, \mathrm{AG}=2.093524, \mathrm{AT}=1.590610, \mathrm{CG}=1.012377, \mathrm{CT}$ $=6.424773, \mathrm{GT}=1.000000$; gamma distribution shape parameter $\alpha=0.458862$. Bootstrap support 
values for ML equal to or greater than $60 \%$ and BYPP equal to or greater than 0.90 are defined as ML/BYPP above the nodes. Newly generated sequences are in red bold and type species are in bold. Botryotinia fuckeliana (AFTOL-ID 59) and Dothidea sambuci (DAOM231303) are used as outgroup taxa.

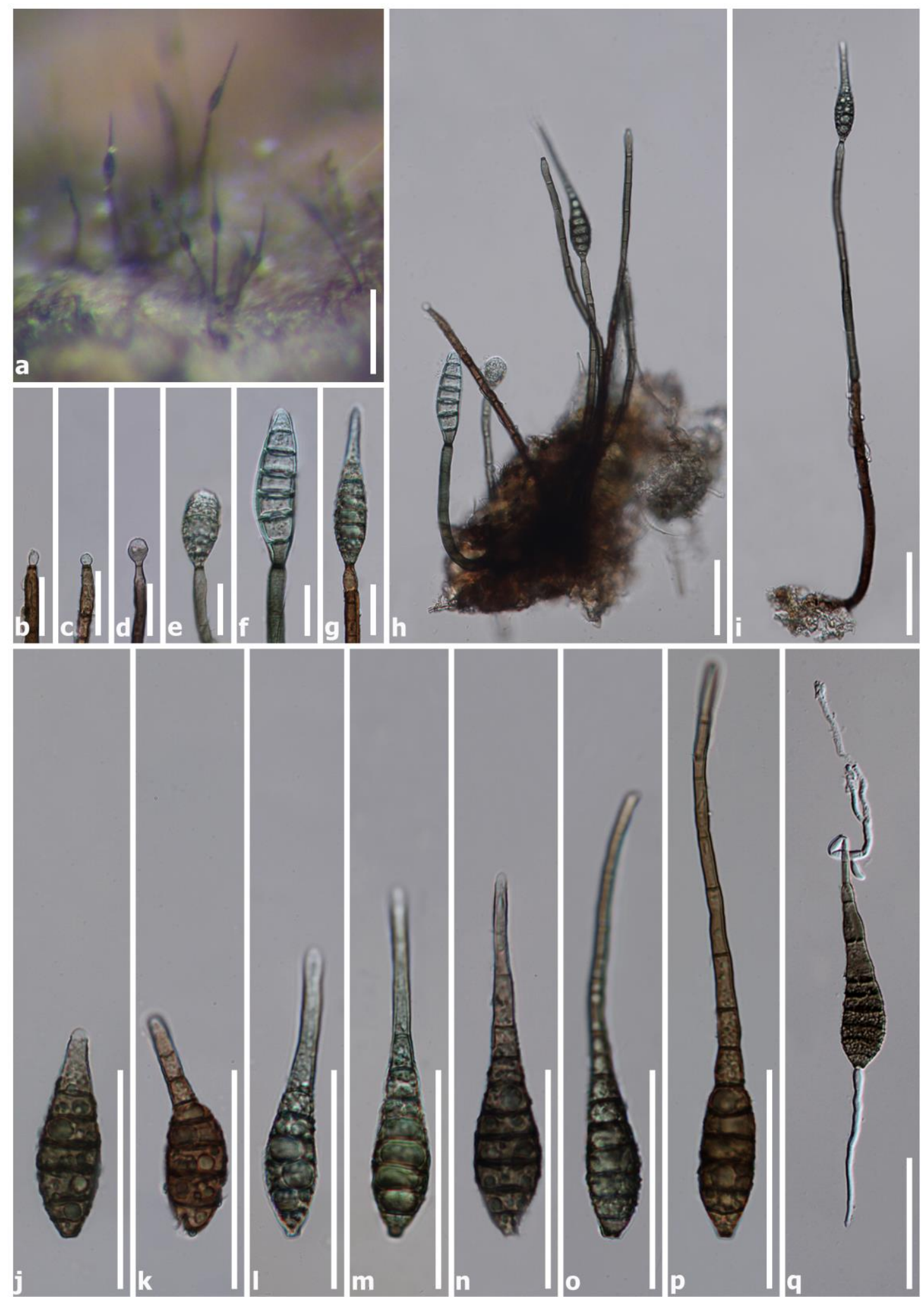

Figure 59 - Sporidesmium tropicale (MFLU 17-1984, new host record). a Colonies on twigs. $\mathrm{b}-\mathrm{g}$ Conidium developing on the apex of conidiophores. $\mathrm{h}-\mathrm{i}$ Conidiophores with conidia. $\mathrm{j}-\mathrm{p}$ Conidia. $\mathrm{q}$ Germinated spore. Scale bars: $\mathrm{a}=100 \mu \mathrm{m}, \mathrm{b}-\mathrm{g}=20 \mu \mathrm{m}, \mathrm{h}-\mathrm{q}=50 \mu \mathrm{m}$. 
Culture characteristics - Conidia germinating on MEA within 24 hours at room temperature and germ tubes produced from one or both ends. Colonies on MEA circular, mycelium raised, entire, cultures olivaceous-grey at the surface and dark olivaceous-grey to black from the center of the colony in reverse.

Material examined - Thailand, Phayao Province, Muang District, on dried twigs of Hevea brasiliensis (Euphorbiaceae), 3 January 2017, C. Senwanna, RBPY25 (MFLU 17-1984), living cultures MFLUCC 17-0344.

Host and distribution - Wide host range and widely distributed in temperate, tropical and subtropical regions.

GenBank numbers - MFLUCC 17-0344: ITS = OL780513, LSU = OL782088, TEF1 = OL875112.

Notes - In a BLASTn search, the LSU sequence of RBPY25 showed $100 \%$ similarity to Sporidesmium tropicale (HKUCC 10838; DQ408560), while the ITS sequence had 98.38\% similarity to S. tropicale (MFLUCC:16-0185; MF077551). In the present phylogenetic analysis, RBPY25 cluster with Sporidesmium tropicale with 100\% ML and 0.99 BYPP bootstrap support (Fig. 58). The morphology of our collection is slightly varied in morphological characters from those in Ellis (1972). This may be due to distribution and morphological variability within the species. We, therefore, name our collection as Sporidesmium tropicale which is a new host record for Hevea brasiliensis in Thailand.

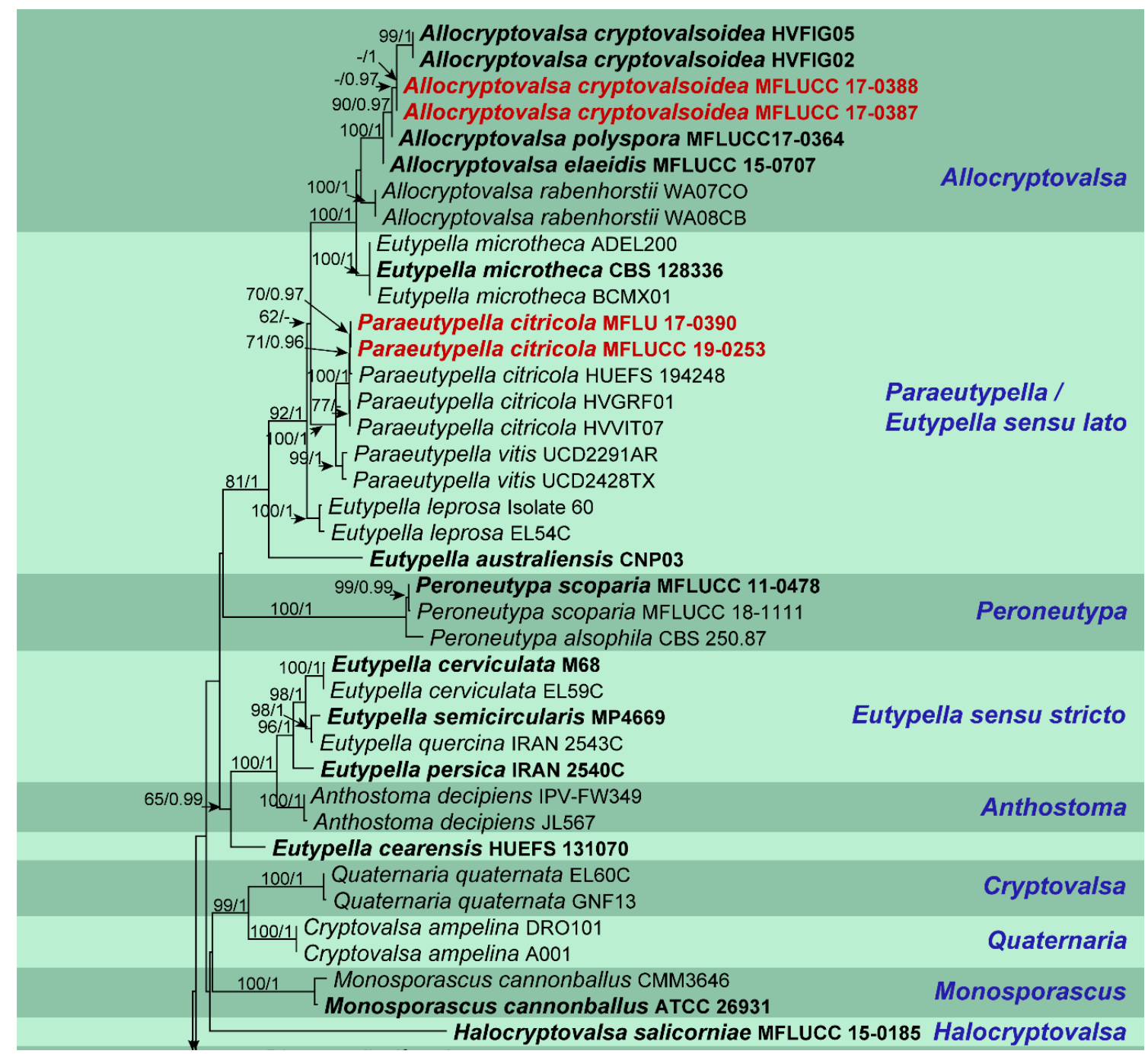

Figure 60 - RAxML tree of Diatrypaceae based on a combined ITS and TUB2 sequence dataset. 73 strains are included in the combined sequence analysis, which comprise 1615 characters with gaps. Tree topology of the ML analysis was similar to the BYPP. The best scoring RAxML tree 
with a final likelihood value of -14833.221963 is presented. The matrix had 1101 distinct alignment patterns, with $50.60 \%$ of undetermined characters or gaps. Estimated base frequencies were as follows: $\mathrm{A}=0.231120, \mathrm{C}=0.263007, \mathrm{G}=0.232197, \mathrm{~T}=0.273676$; substitution rates: $\mathrm{AC}=$ 0.987957, $\mathrm{AG}=2.999746, \mathrm{AT}=1.222521, \mathrm{CG}=0.823710, \mathrm{CT}=3.903183, \mathrm{GT}=1.000000$; gamma distribution shape parameter $\alpha=0.928682$. Bootstrap support values for ML equal to or greater than $60 \%$ and BYPP equal to or greater than 0.90 are defined as ML/BYPP above the nodes. Newly generated sequences are in red bold and type species are in bold. Kretzschmaria deusta (CBS 826.72) and Xylaria hypoxylon (CBS 122620) are used as outgroup taxa.

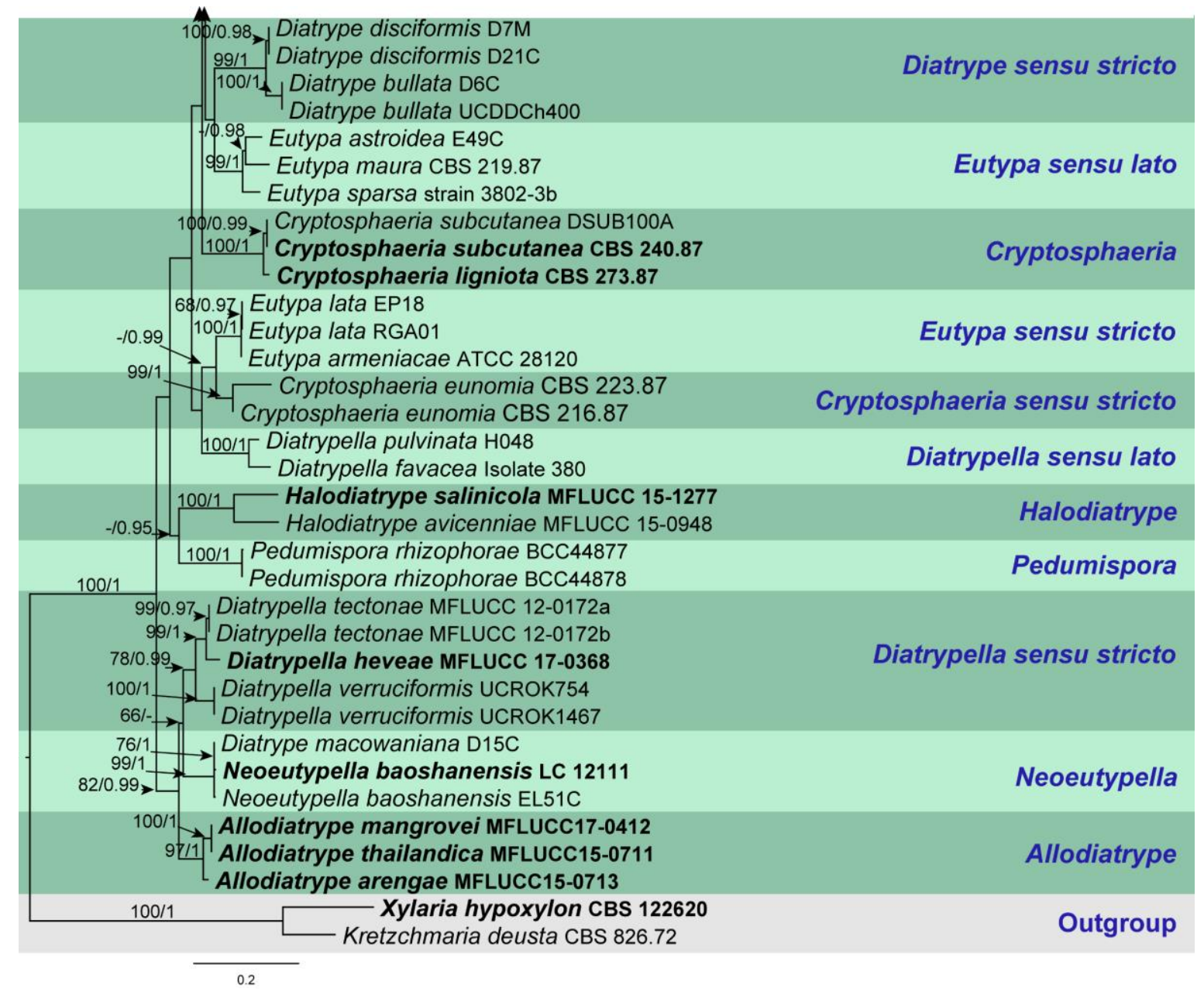

Figure 60 - Continued.

Xylariales Nannf.

Diatrypaceae Nitschke

The members of Diatrypaceae are characterized by perithecial ascomata, immersed to erumpent in the host substrates, cylindric-clavate to clavate or spindle-shaped asci and allantoid ascospores (Trouillas et al. 2011, Mehrabi et al. 2015, de Almeida et al. 2016, Senwanna et al. 2017, Phookamsak et al. 2019, Dayarathne et al. 2020, Konta et al. 2020). The family are saprobes, pathogens and endophytes on various plant hosts in terrestrial and aquatic habitats (Trouillas et al. 2011, Mehrabi et al. 2016, Dayarathne et al. 2020, Hyde et al. 2020b). In this study, Allocryptovalsa cryptovalsoidea and Paraeutypella citricola are reported as new host records on Hevea brasiliensis in Thailand.

Allocryptovalsa cryptovalsoidea (Trouillas, W.M. Pitt \& Gubler), in Senwanna et al., Mycosphere 8 (10): 1840 (2017)

Fig. 61

Index Fungorum number: IF553863 


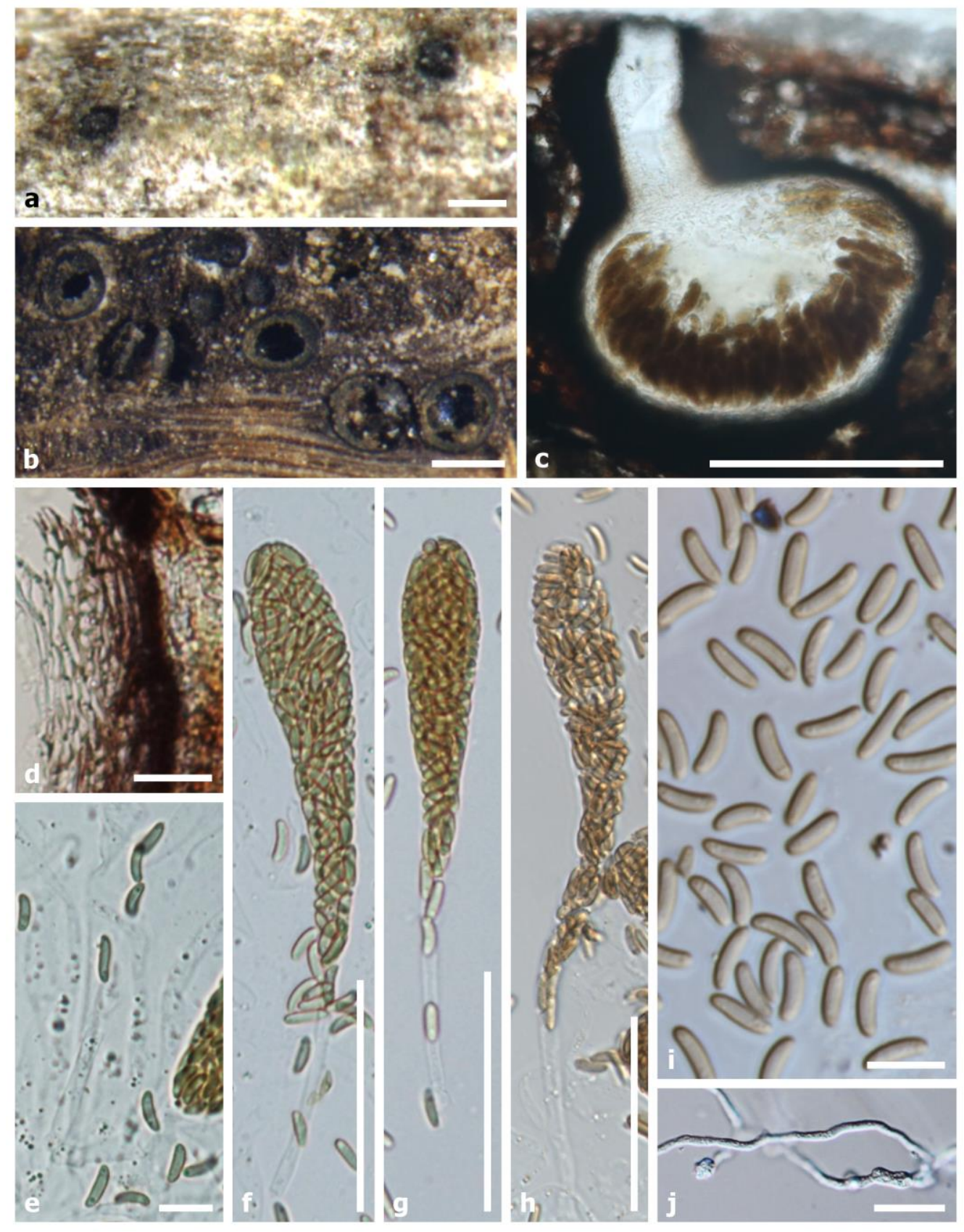

Figure 61 - Allocryptovalsa cryptovalsoidea (MFLU 19-0254, new host record). a Habit of ascostromata on substrate. b Transverse sections through ascostroma. c Section through the ascoma. d Peridium. e Paraphyses. $\mathrm{f}-\mathrm{h}$ Asci. i Ascospores. $\mathrm{j}$ Germinated ascospores. Scale bars: $\mathrm{a}=$ $200 \mu \mathrm{m}, \mathrm{b}=500 \mu \mathrm{m}, \mathrm{c}=300 \mu \mathrm{m} \mathrm{d}=20 \mu \mathrm{m}, \mathrm{e}, \mathrm{i}, \mathrm{j}=10 \mu \mathrm{m}, \mathrm{f}-\mathrm{h}=50 \mu \mathrm{m}$.

Saprobic on dead twig of Hevea brasiliensis. Sexual morph: Ascostromata solitary, 1-3loculate, immersed. Ascomata (including ostiole) 300-500 $\mu \mathrm{m}$ diam., 440-610 $\mu \mathrm{m}$ high, perithecial, dark brown to black, solitary, or gregarious, immersed in substrate, globose to subglobose, dark brown to black, ostiolate. Ostiolar canal 130-217 $\mu \mathrm{m}$ wide, central, not prominent, cylindrical, straight, dark brown to black, with periphysate. Peridium $24-48 \mu \mathrm{m}$ wide, composed of two type layers, outer layer comprising several layers of thick-walled, dark brown to black cells of textura angularis, inner layer comprising 3-5 layers of thin-walled, hyaline cells of textura angularis. Paraphyses 4-8.5 $\mu \mathrm{m}$ wide, dense, hyaline, septate, unbranched, slightly constricted at the septa, filamentous. Asci (including stalks) $(95-) 102-154(-177) \times 14-19(-23) \mu \mathrm{m}$ $(\bar{x}=131.5 \times 17.8 \mu \mathrm{m}, \mathrm{n}=20)$, spore-bearing part length [p. sp.] $(57-) 67-104(-125) \mu \mathrm{m}(\bar{x}=87$ $\mu \mathrm{m}, \mathrm{n}=25)$, polysporous, unitunicate, thin-walled, clavate, long pedicellate, apically rounded, with 
a refractive, J-, subapical ring. Ascospores 7-11 $\times 2-3.5 \mu \mathrm{m}(\bar{x}=8.8 \times 2.5 \mu \mathrm{m}, \mathrm{n}=60)$, crowded, pale yellowish to pale brown at maturity, oblong to allantoid, aseptate, slightly curved, smoothwalled, with small guttules. Asexual morph: Undetermined. Appressoria hyaline, globose to sub globose, thick-walled.

Culture characteristics - Ascospores germinating on MEA within 24 hours at room temperature and germ tubes produced from one or both ends with developing appressoria structure. Colonies on MEA medium dense, irregular, flat or effuse, slightly raised, fluffy, cultures white at the surface and creamy-white at the in reverse.

Material examined - Thailand, Sukhothai Province, Si Satchanalai District, on dead twig of Hevea brasiliensis (Euphorbiaceae), 2 January 2017, N. Huanraluek, RBSK04 (MFLU 19-0254), living culture, MFLUCC 17-0387 = MFLUCC 17-0388.

Host and distribution - Ficus carica (New South Wales; Trouillas et al. 2011), Hevea brasiliensis (Thailand; this study)

GenBank numbers - MFLUCC 17-0387: ITS = OL780514 MFLUCC 17-0388: ITS = OL780515.

Notes - In a BLASTn search of GenBank, the closest match of the ITS sequence of MFLUCC 17-0387 and MFLUCC 17-0388 is Allocryptovalsa polyspora (MFLU 17-1218) with 99.59\% similarity. Phylogenetic analyses of ITS and BT sequence dataset show that our strains form a sister lineage to Allocryptovalsa cryptovalsoidea (Fig. 60). Allocryptovalsa cryptovalsoidea differs from A. polyspora in size of asci and ascospores (Table 5). The morphology of our strain is similar to Allocryptovalsa cryptovalsoidea described by Trouillas et al. (2011). We, therefore, name our collection as A. cryptovalsoidea which is a new host record for Hevea brasiliensis in Thailand.

Table 5 Synopsis of Allocryptovalsa species discussed in this study.

\begin{tabular}{|l|l|l|l|l|l|}
\hline Species name & $\begin{array}{l}\text { Asci length/ } \\
([\mathbf{p} . \mathbf{s p} .])(\boldsymbol{\mu m})\end{array}$ & Asci width $(\boldsymbol{\mu m})$ & $\begin{array}{l}\text { Ascospores } \\
\text { length }(\boldsymbol{\mu m})\end{array}$ & $\begin{array}{l}\text { Ascospore } \\
\text { width }(\boldsymbol{\mu m})\end{array}$ & Reference \\
\hline $\begin{array}{l}\text { Allocryptovalsa } \\
\text { polyspora } \\
\text { (polysporous) }\end{array}$ & $\begin{array}{l}(33.5-) 70-120-177) / \\
(41-) 54-74(-101)\end{array}$ & $(4-) 13-19(-21)$ & $(4-) 7-12(-14)$ & $2-4$ & This study \\
\hline $\begin{array}{l}\text { Allocryptovalsa } \\
\text { cryptovalsoidea } \\
\text { 三 Eutypella } \\
\text { cryptovalsoidea } \\
\text { (polysporous) }\end{array}$ & $-/ 65-120$ & $15-20$ & $8-12(-13.5)$ & $2-3$ & $\begin{array}{l}\text { Trouillas et al. } \\
2011\end{array}$ \\
\hline $\begin{array}{l}\text { Allocryptovalsa } \\
\text { cryptovalsoidea } \\
\text { (polysporous) }\end{array}$ & $(95-) 102-154(-177) /$ & $14-19(-23)$ & $7-11$ & $2-3.5$ & This study \\
\hline $\begin{array}{l}\text { Allocryptovalsa } \\
\text { rabenhorstii } \\
\text { (polysporous) }\end{array}$ & $-/(55-) 70-90(-95)$ & $(15-) 18-22(-27)$ & $(10-) 13.5-15$ & $(3-) 4-5(-6)$ & $\begin{array}{l}\text { Trouillas et al. } \\
(-17.5)\end{array}$ \\
\hline
\end{tabular}

Paraeutypella vitis (Schwein.) L.S. Dissan., J.C. Kang \& K.D. Hyde, in Dissanayake, Wijayawardene, Dayarathne, Samarakoon \& Dai, Biodiversity Data Journal 9: e63864, 16 (2021)

Index Fungorum number: IF 228646

Fig. 62

Saprobic on dead branch of Hevea brasiliensis. Sexual morph: Ascostromata immersed to semi-immersed, becoming raised to erumpent through the host tissue, visible as black, solitary to gregarious. Ascomata (including ostiole) 425-670 $\mu \mathrm{m}$ high, 250-500 $\mu \mathrm{m}$ diam., perithecial, black, clustered, immersed to semi-immersed in ascostroma, ovoid to subglobose, 2-4 locules in ascostroma, glabrous, ostioles not prominent. Ostiolar canal 150-260 $\mu \mathrm{m}$ high, 85-150 $\mu \mathrm{m}$ diam., cylindrical, sulcate, periphysate. Peridium 19-45 $\mu \mathrm{m}$ wide, composed of two layers, outer layer comprising several layers of thick-walled, dark brown to black cells of textura angularis, inner layer comprising thin-walled, hyaline cells of textura prismatica. Paraphyses $2.6-7.5 \mu \mathrm{m}$ wide. $(\bar{x}$ $=4.5, \mathrm{n}=32$ ), dense, hyaline, septate, unbranched, filamentous, embedded in hyaline gelatinous 
matrix. Asci (including stalks) $(62-) 70-95(-103) \times 6-9(-11) \mu \mathrm{m}(\bar{x}=80.3 \times 8.3 \mu \mathrm{m}, \mathrm{n}=20)$, spore-bearing part length [p. sp.] (25.5-)32-43(-48) $\mu \mathrm{m}(\bar{x}=36.3 \mu \mathrm{m}, \mathrm{n}=20)$, 8-spored, unitunicate, thin-walled, clavate to cylindric-clavate, long pedicellate, apically rounded to truncate with indistinct, J-, subapical ring. Ascospores $(6-) 8-11(-13) \times 2-3 \mu \mathrm{m}(\bar{x}=10 \times 2.5 \mu \mathrm{m}, \mathrm{n}=45)$, crowded, initially hyaline, becoming pale yellowish to pale brown at maturity, oblong to allantoid, aseptate, slightly curved, smooth-walled, mostly with small guttules. Asexual morph: Undetermined. Appressoria hyaline, globose to sub globose, thick-walled.

Culture characteristics - Ascospores germinated on MEA within 24 hours and germ tube produced from one end of the ascospore with developing appressoria. Colonies on MEA medium dense, irregular, flat or effuse, slightly raised, cottony, white, margin rough, not produced pigmentation on MEA media.

Material examined - Thailand, Sukhothai Province, Si Satchanalai District, on dead branch of Hevea brasiliensis (Euphorbiaceae), 2 Janaury 2017, N. Huanraluek, RBSK003 (MFLU 17-0390), living culture MFLUCC 19-0253 (new host record).

Host and distribution - Wide host range and widely distributed in temperate, tropical and subtropical regions.

GenBank numbers - MFLUCC 19-0253: ITS = OL780516, TUB2 = OL875097; MFLU 170390: ITS $=$ OL780517.

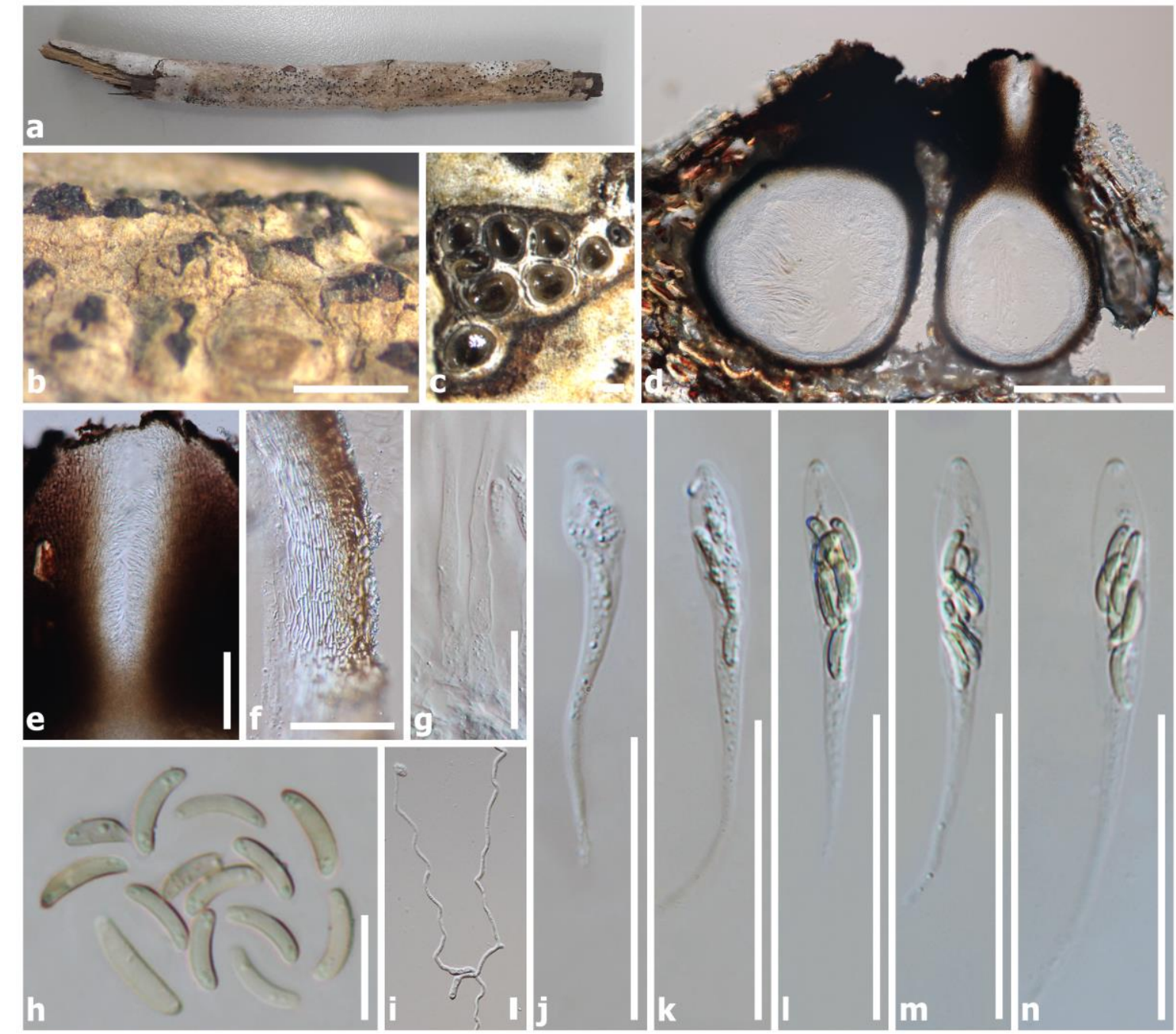

Figure 62 - Paraeutypella citricola (MFLU 17-0390, new host record). a-b Ascostromata on substrate. d Vertical section through ascostroma. e Ostiole with short periphyses. f Peridium. g Paraphyses. h Ascospores. i Germinated ascospores. $\mathrm{j}-\mathrm{n}$ Asci. Scale bars: $\mathrm{b}=1000 \mu \mathrm{m}, \mathrm{c}=200$ $\mu \mathrm{m}, \mathrm{d}=100 \mu \mathrm{m}, \mathrm{e}, \mathrm{f}=30 \mu \mathrm{m} \mathrm{g}=10 \mu \mathrm{m}, \mathrm{h}-\mathrm{i}=5 \mu \mathrm{m}, \mathrm{j}-\mathrm{n}=20 \mu \mathrm{m}$. 
Notes - Phylogenetic analyses show that the strain MFLU 17-0390 and MFLUCC 19-0253 grouped within the Paraeutypella citricola clade (Fig. 60). In a BLASTn search, the closest match of the ITS sequences with 89.91\% (MN308410) similarity was to Allocryptovalsa elaeidis (MFLUCC 15-0707). Our collection (MFLU 17-0390) is similar to Paraeutypella citricola in having 8-spored asci and in the size of spore-bearing part length (p. sp.) and ascospores (de Almeida et al. 2016, Dissanayake et al. 2021). We, therefore, name our collection as Paraeutypella citricola which is a new host record for Hevea brasiliensis in Thailand.

\section{Checklist of fungi associated with Para rubber}

This checklist of fungi associated with Hevea brasiliensis is based on U.S. National Fungus Collections Fungus-Host Database (Farr and Rossman 2021) together with published articles in journals and books. The checklist includes fungal species names, information on substrate and locality from where fungi have been recorded on Para rubber. The current names are used according to Index Fungorum (2020).

\section{List of fungi associated with Para rubber (Hevea brasiliensis)}

\section{Phylum: Ascomycota}

Acanthohelicospora aurea (Corda) Rossman \& W.C. Allen, in Rossman et al., IMA Fungus 7(1): 2 (2016) al. 2010)

On leaf and branch litter of $H$. brasiliensis: Thailand as Helicosporium aureum (Seephueak et

Acanthonitschkea argentinensis Speg., Anal. Mus. nac. B. Aires, Ser. 3 17(10): 116 (1908)

On stems of $H$. brasiliensis: Ghana (Hughes 1953)

Acanthonitschkea pulchella (Sacc.) Nannf., Svensk bot. Tidskr. 69(3): 320 (1975)

On stems of H. brasiliensis: Ghana, Malaysia as Neotrotteria pulchella (Nannfeldt 1975, Singh 1980)

Acarocybe deightonii M.B. Ellis, Mycol. Pap. 76: 4 (1960)

On leaf and branch litter of H. brasiliensis: Thailand (Seephueak et al. 2010)

Acarocybe formosa (Bat. \& J.L. Bezerra) M.B. Ellis, Mycol. Pap. 82: 50 (1961)

On branch litter of $H$. brasiliensis: Thailand (Seephueak et al. 2011)

Acarocybe hansfordii Syd., Ann. mycol. 35(3/4): 285 (1937)

On branch litter of $H$. brasiliensis: Thailand (Seephueak et al. 2011)

\section{Acarocybe sp.}

On leaf and branch litter of $H$. brasiliensis: Thailand (Seephueak et al. 2010, 2011)

Acremoniula brevis M.B. Ellis ex S. Hughes, N.Z. J1 Bot. 17(2): 165 (1979)

On branch litter of H. brasiliensis: Thailand as Endophragmia brevis (Seephueak et al. 2011)

Acremonium alternatum Link, Mag. Gesell. naturf. Freunde, Berlin 3(1-2): 15 (1809)

On leaf litter of $H$. brasiliensis: Thailand (Seephueak et al. 2010)

Acremonium fusidioides (Nicot) W. Gams, Cephalosporium-artige Schimmelpilze (Stuttgart): 70 (1971)

On leaf and branch litter of H. brasiliensis: Thailand (Seephueak et al. 2010, 2011) 
Acremonium byssoides W. Gams \& T.M. Lim, in Gams, Trans. Br. Mycol. Soc. 64(3): 391 (1975) A hyperparasite of the fungus Oidium heveae on H. brasiliensis: Malaysia (Gam 1975)

Acremonium murorum (Corda) W. Gams, Cephalosporium-artige Schimmelpilze (Stuttgart): 84 (1971)

On leaf and branch litter of H. brasiliensis: Thailand (Seephueak et al. 2010, 2011)

Acremonium polychromum (J.F.H. Beyma) W. Gams, Cephalosporium-artige Schimmelpilze (Stuttgart): 81 (1971)

On bark of H. brasiliensis: Indonesia (Perdomo et al. 2011)

\section{Acremonium sp.}

On leaf and branch litter of H. brasiliensis: Thailand (Seephueak et al. 2010, 2011)

Acrodictys sacchari M.B. Ellis, Mycol. Pap. 125: 6 (1971)

On leaf litter of $H$. brasiliensis: Thailand (Seephueak et al. 2010)

\section{Acrodictys sp.}

On branch litter of $H$. brasiliensis: Thailand (Seephueak et al. 2011)

Acrophialophora fusispora (S.B. Saksena) Samson, in Samson \& Tariq Mahmood, Acta bot. neerl. 19(6): 805 (1970)

On branch litter of $H$. brasiliensis: Thailand (Seephueak et al. 2011)

Acrostaurus turneri Deighton \& Piroz., Mycol. Pap. 128: 94 (1972)

On leaf and branch litter of H. brasiliensis: Thailand (Seephueak et al. 2010)

Actinocladium rhodosporum Ehrenb., Jb. Gewächsk. 1(2): 52 (1819)

On branch litter of $H$. brasiliensis: Thailand (Seephueak et al. 2011)

Akanthomyces lecanii (Zimm.) Spatafora, Kepler \& B. Shrestha, in Kepler et al., IMA Fungus 8(2): 343 (2017)

On H. brasiliensis: Haiti as Torrubiella confragosa (Benjamin \& Slot 1969)

Albonectria rigidiuscula (Berk. \& Broome) Rossman \& Samuels, in Rossman, Samuels, Rogerson \& Lowen 1999

Associated with die back disease of $H$. brasiliensis: Democratic Republic of the Congo, Malaysia, as Calonectria rigidiuscula (Spaulding 1961, Singh 1980), on branch of H. brasiliensis: Thailand (this study)

Allocryptovalsa cryptovalsoidea (Trouillas, W.M. Pitt \& Gubler) Senwanna, Phookamsak \& K.D. Hyde in Senwanna et al., Mycosphere 8(10): 1840 (2017)

On dead twig of $H$. brasiliensis: Thailand (this study)

Allocryptovalsa polyspora Senwanna, Phookamsak \& K.D. Hyde, in Senwanna et al., Mycosphere 8(10): 1840 (2017)

On branch of $H$. brasiliensis: Thailand (Senwanna et al. 2017)

Alternaria alternata (Fr.) Keissl., Beih. bot. Zbl., Abt. 2 29: 434 (1912)

Associated with leaf blight and black leaf spot of $H$. brasiliensis: China; endophytic on living leaves and sapwoods of H. brasiliensis: Peru (Gazis \& Chaverri 2010, Cai et al. 2015) 
Alternaria heveae E.G. Simmons, Mycotaxon 50: 262 (1994)

Associated with black leaf spot on seedling of H. brasiliensis: China, Mexico (Martin 1947, Cai et al. 2014)

Alternaria radicina Meier, Drechsler \& E.D. Eddy, Phytopathology 12: 157 (1922)

On leaf litter of H. brasiliensis: Thailand (Seephueak et al. 2010)

\section{Alternaria sp.}

Associated with leaf Spot of H. brasiliensis: Brazil, Mexico, Sri Lanka (McGuire et al. 1967, Mendes et al. 1998, Jayasinghe 1999a)

\section{Alternaria spp.}

Associated with rubber tree seeds harvested of H. brasiliensis: Brazil (Theodoro \& Batista 2014)

\section{Alternaria yunnanensis}

Associated with leaf spots of $H$. brasiliensis: China (Cai et al. 2019)

\section{Amerosporium sp.}

On leaf litter of $H$. brasiliensis: Thailand (Seephueak et al. 2010)

\section{Ampelomyces quisqualis}

A hyperparasite of powdery mildews on H. brasiliensis: Myanmar (Thaung 2008)

\section{Ampullifera sp.}

On H. brasiliensis: Malaysia (Turner 1971)

Annellophora dendrographii M.B. Ellis, Mycol. Pap. 103: 36 (1965)

On branch litter of H. brasiliensis: Thailand (Seephueak et al. 2011)

Annellophora solani (Syd.) S. Hughes, Trans. Br. Mycol. Soc. 34(4): 544 (1952) [1951]

On leaf litter of $H$. brasiliensis: Thailand (Seephueak et al. 2010)

Annulohypoxylon moriforme (Henn.) Y.M. Ju, J.D. Rogers \& H.M. Hsieh, Mycologia 97(4): 859 (2005)

On bark of H. brasiliensis: Viet Nam as Hypoxylon heveae (Anonymous 1968)

\section{Annulohypoxylon sp.}

Endophytic on living leaves of H. brasiliensis: Peru (Gazis \& Chaverri 2010)

Annulohypoxylon stygium (Lév.) Y.M. Ju, J.D. Rogers \& H.M. Hsieh, Mycologia 97(4): 861 (2005)

On H. brasiliensis: Ghana as Hypoxylon stygium (Hughes 1953)

\section{Anthina sp.}

On branch litter of H. brasiliensis: Thailand (Seephueak et al. 2011)

Anthostomella formosa Kirschst., Verh. bot. Ver. Prov. Brandenb. 66: 29 (1923)

On branch litter of $H$. brasiliensis: Thailand (Seephueak et al. 2011)

Anthostomella heveae Saccas, J. Agric. Trop. Bot. Appl. 1: 182 (1954)

On dead branches of $H$. brasiliensis: French Equatorial Africa (Anonymous 1963) 


\section{Astrosphaeriella sp.}

On branch litter of $H$. brasiliensis: Thailand (Seephueak et al. 2011)

Apiosporium atrum Massee, Bull. Misc. Inf., Kew (3): 104 (1913)

On dead branches of $H$. brasiliensis: Malaysia (Weir 1926, Singh 1980)

Aposphaeria heveae Petch, Ann. R. bot. Gdns Peradeniya 6(3): 234 (1917)

On roots of $H$. brasiliensis: Sri Lanka (Petch 1917)

\section{Aposphaeria sp.}

On H. brasiliensis: Haiti (Benjamin \& Slot 1969)

Aplosporella heveae Saccas [as 'Aplosporella'], J. Agric. Trop. Bot. Appl. 1: 201 (1954)

On dead branches of $H$. brasiliensis: French Equatorial Africa (Anonymous 1963)

Aquaticheirospora lignicola Kodsueb \& W.H. Ho, in Kodsueb et al., Bot. J. Linn. Soc. 155(2): 286 (2007)

On leaf litter of $H$. brasiliensis: Thailand (Seephueak et al. 2010)

Arthrinium muelleri M.B. Ellis, More Dematiaceous Hyphomycetes (Kew): 477 (1976)

On branch litter of $H$. brasiliensis: Thailand (Seephueak et al. 2011)

Arthrobotryum atrocephalum (Ellis) Sacc., Syll. fung. (Abellini) 4: 630 (1886)

On leaf and branch litter of H. brasiliensis: Thailand (Seephueak et al. 2010, 2011)

\section{Arthrinium sp.}

Endophytic on living sapwood of H. brasiliensis: Peru (Gazis \& Chaverri 2010)

\section{Aschersonia sp.}

On leaves of H. brasiliensis: Malaysia, Papua New Guinea (Turner 1966, Shaw 1984)

Ascochyta heveae Petch, Ann. R. bot. Gdns Peradeniya 6(3): 236 (1917)

Associated with leaf spot of $\mathrm{H}$. brasiliensis: China, Democratic Republic of the Congo, Costa

Rica, Ghana, India, Malay Peninsula, Sri Lanka (Thompson \& Johnston 1953, Spaulding 1961,

McGuire \& Crandall 1967, Turner 1971, Zhuang 2001)

Ascochyta heveana Saccas, Agronomía trop. 8(2): 182 (1953) 1961)

Associated with leaf spot of $H$. brasiliensis: Democratic Republic of the Congo (Spaulding

\section{Ascochyta sp.}

On leaves of H. brasiliensis: Brazil (Mendes et al. 1998)

Aspergillus niger Tiegh., Annls Sci. Nat., Bot., sér. 5 8: 240 (1867)

Associated with leaf spot of $H$. brasiliensis: India (Ariharan et al. 2016)

\section{Aspergillus sp.}

Associated with transparent spots on unsmoked sheet or biscuit rubber of $H$. brasiliensis:

Brazil, on leaf litter of $H$. brasiliensis: Thailand (Weir 1926, Seephueak et al. 2010)

\section{Aspergillus spp.}

Associated with rubber tree seeds harvested of $H$. brasiliensis: Brazil (Theodoro \& Batista 
Asteroma coryli (Fuckel) B. Sutton, The Coelomycetes (Kew): 496 (1980)

On branch litter of $H$. brasiliensis: Thailand (Seephueak et al. 2011)

\section{Asteromella sp.}

On H. brasiliensis: Myanmar (Thaung 2008)

\section{Astrosphaeriella sp.}

On leaf litter of $H$. brasiliensis: Thailand (Seephueak et al. 2010)

\section{Aureobasidium sp.}

On branch litter of $H$. brasiliensis: Thailand (Seephueak et al. 2011)

Bactrodesmium betulicola M.B. Ellis, Mycol. Pap. 72 : 13 (1959)

On leaf and branch litter of H. brasiliensis: Thailand (Seephueak et al. 2010, 2011)

Bactrodesmium longisporum M.B. Ellis, More Dematiaceous Hyphomycetes (Kew): 68 (1976)

On leaf litter of $H$. brasiliensis: Thailand (Seephueak et al. 2010)

Bactrodesmium pallidum M.B. Ellis, Mycol. Pap. 72: 11 (1959)

On leaf and branch litter of H. brasiliensis: Thailand (Seephueak et al. 2010, 2011)

\section{Bactrodesmium sp.}

On leaf and branch litter of H. brasiliensis: Thailand (Seephueak et al. 2010, 2011)

Bactrodesmium spilomeum (Berk. \& Broome) E.W. Mason \& S. Hughes, in Hughes, Can. J. Bot. 31(5): 616 (1953)

On leaf and branch litter of H. brasiliensis: Thailand (Seephueak et al. 2010, 2011)

\section{Bactrodesmium rahmii}

On decaying log of H. brasiliensis: Thailand (Seephueak et al. 2011)

Bagnisiella examinans (Berk.) Arx \& E. Müll. 1975

On of H. brasiliensis: Myanmar as Auerswaldia examinans (Thaung 2008)

Balladyna vanderystii (Hansf.) Arx, in Müller \& von Arx, Beitr. Kryptfl. Schweiz 11(no. 2): 186 (1962)

On leaf litter of $H$. brasiliensis: Thailand as Balladynopsis vanderystii (Seephueak et al. 2010)

Beltrania rhombica Penz., Nuovo G. bot. ital. 14(2): 72 (1882)

On leaf litter of $H$. brasiliensis: Thailand (Seephueak et al. 2010)

Beltrania santapaui Piroz. \& S.D. Patil, Can. J. Bot. 48(3): 570 (1970)

On leaf litter of H. brasiliensis: Thailand (Seephueak et al. 2010)

Beltraniella pirozynskii P.M. Kirk, Trans. Br. Mycol. Soc. $77(3)$ : 457 (1981)

On branch litter of $H$. brasiliensis: Thailand (Seephueak et al. 2011)

Beltraniella portoricensis (F. Stevens) Piroz. \& S.D. Patil, Can. J. Bot. 48(3): 575 (1970)

On leaf and branch litter of H. brasiliensis: Thailand as Ellisiopsis gallesiae (Seephueak et 
al. 2010)

Berkeleyomyces basicola (Berk. \& Broome) W.J. Nel, Z.W. de Beer, T.A. Duong \& M.J. Wingf., in Nel et al., Pl. Path. 67(4): 877 (2017)

On leaf litter of H. brasiliensis: Thailand as Chalara elegans (Seephueak et al. 2010)

Berkleasmium concinnum (Berk.) S. Hughes, Can. J. Bot. 36: 740 (1958)

On branch litter of $H$. brasiliensis: Thailand (Seephueak et al. 2011)

Berkleasmium minutissimum (Peck) R.T. Moore, Mycologia 51(5): 736 (1961) [1959]

On leaf and branch litter of H. brasiliensis: Thailand (Seephueak et al. 2010, 2011)

Bipolaris cactivora (Petr.) Alcorn, Mycotaxon 17: 67 (1983)

On branch litter of H. brasiliensis: Thailand (Seephueak et al. 2011)

Bidenticula cannae Deighton, Trans. Br. Mycol. Soc. 59(3): 425 (1972)

On leaf and branch litter of H. brasiliensis: Thailand (Seephueak et al. 2010, 2011)

Bipolaris cynodontis (Marignoni) Shoemaker, Can. J. Bot. 37(5): 883 (1959)

On leaves of $H$. brasiliensis: Thailand (Worapattamasri et al. 2009)

Bipolaris heveae (Petch) Arx, Beih. Nova Hedwigia 87: 288 (1987)

= Drechslera heveae (Petch) M.B. Ellis, Dematiaceous Hyphomycetes (Kew): 451 (1971) -

= Helminthosporium heveae Petch, Ann. R. bot. Gdns Peradeniya 3(1): 8 (1906)

Associated with leaf spot, bird's eye leaf spot especially in young nursery plants of $H$. brasiliensis: Andaman Islands, Brazil, Cambodia, China, Costa Rica, Cote d'Ivoire, Democratic Republic of the Congo, Dominican Republic, Florida, Ghana, Guinea, Guatemala, Haiti, Honduras, India, Indonesia, Malay Peninsula, Malaysia, Myanmar, Mexico, Nicaragua, Nigeria, Panama, Papua New Guinea, Philippines, Sri Lanka, Thailand, Viet Nam (Spaulding 1961, Zhuang 2001, Thaung 2008, Manamgoda et al. 2014)

\section{Bipolaris sp.}

On branch litter of $H$. brasiliensis: Thailand (Seephueak et al. 2011)

Biscogniauxia capnodes (Berk.) Y.M. Ju \& J.D. Rogers, in Ju et al., Mycotaxon 66: 23 (1998)

On H. brasiliensis: Ghana as Nummularia maxima (Hughes 1953), Haiti as Hypoxylon nummularium var. pseudopachyloma (Benjamin \& Slot 1969)

Biscogniauxia mediterranea (De Not.) Kuntze, Revis. gen. pl. (Leipzig) 2: 398 (1891)

On H. brasiliensis: Malaysia as Nummularia repandoides (Singh 1980)

\section{Biscogniauxia sp.}

Endophytic on living sapwood of H. brasiliensis: Peru (Gazis \& Chaverri 2010)

Bispora antennata (Pers.) E.W. Mason, in Hughes, Can. J. Bot. 31(5): 582 (1953)

On leaf and branch litter of H. brasiliensis: Thailand (Seephueak et al. 2010, 2011)

Boerlagiomyces grandisporus S.J. Stanley \& K.D. Hyde, Mycol. Res. 101(5): 635 (1997)

On branch litter of $H$. brasiliensis: Thailand (Seephueak et al. 2011)

Botryodiplodia acerina Ellis \& Everh., Proc. Acad. Nat. Sci. Philad. 45: 161 (1893)

On leaf litter of H. brasiliensis: Thailand (Seephueak et al. 2010) 


\section{Botryodiplodia sp.}

On decaying rubber log and branch of $H$. brasiliensis: Brazil, Papua New Guinea, Thailand (Shaw 1984, Mendes et al. 1998, Seephueak et al. 2011)

Botryosphaeria plicatula (Berk. \& Broome) S. Ahmad, Monogr. Biol. Soc. Pakistan 8: 11 (1979) [1978]

On H. brasiliensis: Ghana as Phaeobotryosphaeria plicatula (Hughes 1953)

\section{Botryosphaeria sp.}

On branch litter of $H$. brasiliensis: Thailand (Seephueak et al. 2011)

Botryotinia fuckeliana (de Bary) Whetzel, Mycologia 37(6): 679 (1945)

On H. brasiliensis: Japan (Kobayashi 2007)

Botryotrichum piluliferum Sacc. \& Marchal, in Marchal, Bull. Soc. R. Bot. Belg. 24(1): 66 (1885)

On leaf litter of H. brasiliensis: Thailand (Seephueak et al. 2010)

\section{Botryotrichum sp.}

On leaf and branch litter of H. brasiliensis: Thailand (Seephueak et al. 2010, 2011)

Brachiosphaera tropicalis Nawawi, in Descals et al., Trans. Br. Mycol. Soc. 67(2): 213 (1976)

On branch litter of $H$. brasiliensis: Thailand (Seephueak et al. 2011)

Brachydesmiella biseptata G. Arnaud ex S. Hughes, Can. J. Bot. 39: 1095 (1961)

On leaf and branch litter of H. brasiliensis: Thailand (Seephueak et al. 2010, 2011)

Brachyhelicoon xylogenum G. Arnaud, Bull. Trimest. Soc. Mycol. Fr. 68: 209 (1952)

On branch litter of $H$. brasiliensis: Thailand (Seephueak et al. 2011)

Brachysporiella gayana Bat., in Batista \& Vital, Bol. Secr. Agric. (Pernambuco) 19(1-2): 109 (1952)

On branch litter of $H$. brasiliensis: Thailand (Seephueak et al. 2011)

Brachysporiella laxa H.J. Huds. ex M.B. Ellis, Mycol. Pap. 125: 7 (1971)

On branch litter of $H$. brasiliensis: Thailand (Seephueak et al. 2011)

Brachysporium britannicum S. Hughes, Naturalist: 48 (1951)

On branch litter of $H$. brasiliensis: Thailand (Seephueak et al. 2011)

\section{Brachysporium sp.}

On branch litter of $H$. brasiliensis: Thailand (Seephueak et al. 2011)

Brachysporium dingleyae S. Hughes, N.Z. Jl Bot. 3: 27 (1965)

On branch litter of $H$. brasiliensis: Thailand (Seephueak et al. 2011)

Brevicollum hyalosporum Kaz. Tanaka \& Toy. Sato, in Tanaka et al., Mycologia 109(4): 611 (2017)

On branches of $H$. brasiliensis: Thailand (Hyde et al. 2018, this study)

Broomella acuta Shoemaker \& E. Müll., Can. J. Bot. 41: 1239 (1963)

On leaf litter of $H$. brasiliensis: Thailand (Seephueak et al. 2010) 
Calonectria kyotensis Terash., Trans. Mycol. Soc. Japan 8(3): 124 (1968)

On H. brasiliensis: China as Cylindrocladium floridanum, Malaysia (Liu 1977, Crous 2002)

Calonectria reteaudii (Bugnic.) C. Booth, Mycol. Pap. 104: 41 (1966)

Associated with leaf spot of $H$. brasiliensis as Cylindrocladium quinqueseptatum: China, Malaysia, Sri Lanka (Crous 2002, Jayasinghe et al. 2009)

Calonectria morganii Crous, Alfenas \& M.J. Wingf., Mycol. Res. 97(6): 706 (1993)

On leaf and branch litter of $H$. brasiliensis: Thailand as Cylindrocladium scoparium (Seephueak et al. 2010, 2011)

Calostilbe striispora (Ellis \& Everh.) Seaver, Mycologia 20(4): 248 (1928)

Associated with bark rot disease of $H$. brasiliensis: Ghana, The Republic of Trinidad and Tobago (Spaulding 1961)

Camarosporidiella elongata (Fr.) Wanas., Wijayaw. \& K.D. Hyde, in Wanasinghe et al. Stud. Mycol. 87: 230 (2017)

On leaf litter of H. brasiliensis: Thailand as Cucurbitaria elongata (Seephueak et al. 2010)

Camarosporium rosae Grove, British Stem- and Leaf-Fungi (Coelomycetes) (Cambridge) 2: 362 (1937)

On leaf litter of $H$. brasiliensis: Thailand (Seephueak et al. 2010)

Camarosporium salicinum Sacc., M. Rousseau \& E. Bommer, Atti Inst. Veneto Sci. lett., ed Arti, Sér. 6 2: no. 13 (1884)

On leaf litter of $H$. brasiliensis: Thailand (Seephueak et al. 2010)

Camillea punctulata (Berk. \& Ravenel) Læssøe, J.D. Rogers \& Whalley, Mycol. Res. 93(2): 143 (1989)

On H. brasiliensis: Malaysia as Nummularia punctulata (Singh 1980)

Camposporium antennatum Harkn., Bull. Calif. Acad. Sci. 1(no. 1): 37 (1884)

On leaf litter of $H$. brasiliensis: Thailand (Seephueak et al. 2010)

Camposporium cambrense S. Hughes, Mycol. Pap. 36: 11 (1951)

On leaf litter of $H$. brasiliensis: Thailand (Seephueak et al. 2010)

Camposporium laundonii M.B. Ellis, More Dematiaceous Hyphomycetes (Kew): 197 (1976)

On leaf litter of $H$. brasiliensis: Thailand (Seephueak et al. 2010)

Camposporium antennatum Harkn., Bull. Calif. Acad. Sci. 1(no. 1): 37 (1884)

On branch litter of $H$. brasiliensis: Thailand (Seephueak et al. 2011)

Camposporium cambrense S. Hughes, Mycol. Pap. 36: 11 (1951)

On branch litter of $H$. brasiliensis: Thailand (Seephueak et al. 2011)

\section{Camposporium sp.}

On leaf and branch litter of H. brasiliensis: Thailand (Seephueak et al. 2010, 2011)

Canalisporium exiguum Goh \& K.D. Hyde, in Goh et al., Can. J. Bot. 76(1): 145 (1998)

On leaf litter of $H$. brasiliensis: Thailand (Seephueak et al. 2010) 
Canalisporium pallidum Goh, W.H. Ho \& K.D. Hyde, in Goh et al., Can. J. Bot. 76(1): 148 (1998)

On leaf litter of $H$. brasiliensis: Thailand (Seephueak et al. 2010)

\section{Capnodium sp.}

On H. brasiliensis: Thailand (Giatgong 1980)

Cephaliophora irregularis Thaxt., Bot. Gaz. 35: 158 (1903)

On branch litter of $H$. brasiliensis: Thailand (Seephueak et al. 2011)

\section{Cephalosporium sp.}

On H. brasiliensis: Brazil, Malaysia (Mendes et al. 1998, Thompson \& Johnston 1953)

Ceratocystis fimbriata Ellis \& Halst., Bull. New York Agricultural Experimental Station 76: 14 (1890)

= Ceratostomella fimbriata (Ellis \& Halst.) J.A. Elliott, Phytopathology 13: 56 (1923)

= Endoconidiophora fimbriata (Ellis \& Halst.) R.W. Davidson, J. Agric. Res., Washington 50: 800 (1935)

Associated with canker disease on bark and mouldy rot on tapping panels of $H$. brasiliensis: Brazil, Brunei Darussalam, Cambodia, Costa Rica, Ghana, Indonesia, Malay Peninsula, Malaysia, Mexico, Myanmar, Papua New Guinea, Thailand (Spaulding 1961, McGuire \& Crandall 1967, Giatgong 1980, Valdetaro et al. 2015)

Ceratosporella deviata Subram., Proc. Indian Acad. Sci., Pl. Sci. 46: 327 (1957)

On branch litter of $H$. brasiliensis: Thailand (Seephueak et al. 2011)

Ceratosporella novae-zelandiae S. Hughes, N.Z. J1 Bot. 9(2): 352 (1971)

On branch litter of H. brasiliensis: Thailand (Seephueak et al. 2011)

Ceratosporium fuscescens Schwein., Trans. Am. phil. Soc., New Series 4(2): 300 (1832) [1834]

On branch litter of $H$. brasiliensis: Thailand (Seephueak et al. 2011)

Ceratosporium productum Petch, Ann. R. bot. Gdns Peradeniya 3(1): 9 (1906)

On dead branches of H. brasiliensis: Sri Lanka (Ellis 1971)

Ceratophorum uncinatum (Peck \& Clinton) Sacc., Syll. fung. (Abellini) 4: 396 (1886)

On leaf litter of H. brasiliensis: Thailand (Seephueak et al. 2010)

\section{Ceratostomella sp.}

On H. brasiliensis: Nigeria (West 1938)

Cercospora achyranthina Thirum. \& Chupp, Mycologia 40(3): 352 (1948)

On branch litter of H. brasiliensis: Thailand (Seephueak et al. 2011)

Cercospora apii Fresen., Beitr. Mykol. 3: 91 (1863)

On leaf litter of $H$. brasiliensis: Thailand (Seephueak et al. 2010)

Cercospora canescens Ellis \& G. Martin, Am. Nat. 16(12): 1003 (1882)

On branch litter of $H$. brasiliensis: Thailand (Seephueak et al. 2011)

Cercospora dioscoreae-pyrifoliae J.M. Yen, Bull. Trimest. Soc. Mycol. Fr. 84: 6 (1968)

Associated with leaf spots diseases of $H$. brasiliensis: Thailand (this study) 


\section{Cercospora sp.}

2010)

On H. brasiliensis: Malay Peninsula, Thailand (Thompson \& Johnston 1953, Seephueak et al.

\section{Cercospora spp.} 2014)

Associated with rubber tree seeds harvested of H. brasiliensis: Brazil (Theodoro \& Batista

Ceriospora polygonacearum (Petr.) Piroz. \& Morgan-Jones, Trans. Br. Mycol. Soc. 51(2): 189 (1968)

On branch litter of $H$. brasiliensis: Thailand (Seephueak et al. 2011)

\section{Chaetochalara sp.}

On leaf litter of H. brasiliensis: Thailand (Seephueak et al. 2010)

Chaetoconidium arachnoideum Zukal, Verh. zool.-bot. Ges. Wien 37: 45 (1887)

On branch litter of $H$. brasiliensis: Thailand (Seephueak et al. 2011)

Chaetomium globosum Kunze, Mykologische Hefte (Leipzig) 1: 16 (1817)

Associated with black root disease on rubber tree seedlings of $H$. brasiliensis: China (Jiang et al. 2019)

\section{Chaetomium sp.}

On H. brasiliensis: China, Thailand on leaf and branch litter (Seephueak et al. 2010, 2011, Jiang et al. 2019)

\section{Chaetomium spp.} 2014)

Associated with rubber tree seeds harvested of $H$. brasiliensis: Brazil (Theodoro \& Batista

\section{Chaetopsina sp.}

On leaf litter of H. brasiliensis: Thailand (Seephueak et al. 2010)

Chaetopsis grisea (Ehrenb.) Sacc., Michelia 2(no. 8): 640 (1882)

On branch litter of $H$. brasiliensis: Thailand (Seephueak et al. 2011)

Chaetothyrium annonicola Hansf., Mycol. Pap. 15: 149 (1946)

On H. brasiliensis: Malaysia as Phaeochaetia annonicola (Turner 1971)

Chaetothyrium javanicum (Zimm.) Boedijn, Bull. Jard. Bot. Buitenz, 3 Sér. 11(2): 225 (1931)

On H. brasiliensis: Malaysia as Phaeosaccardinula javanica and Limacinula javanica (Thompson \& Johnston 1953, Singh 1980)

Chaetothyrina tenuissima (Petch) Arx, in Müller \& von Arx 1962

On shoot and leaves of $H$. brasiliensis as Chaetopeltopsis tenuissima: Brazil, India, Malay Peninsula (Spaulding 1961)

Associated with black mildew on $H$. brasiliensis as Asterina tenuissima: India, Malaysia; on stems and fruit of H. brasiliensis: Sri Lanka (Willis 1906, Spaulding 1961)

Chalara cylindrosperma (Corda) S. Hughes, Can. J. Bot. 36: 747 (1958)

On leaf litter of $H$. brasiliensis: Thailand (Seephueak et al. 2010) 
Chalara urceolata Nag Raj \& W.B. Kendr., in Nag Raj \& Hughes, N.Z. J1 Bot. 12: 120 (1974)

On branch litter of $H$. brasiliensis: Thailand (Seephueak et al. 2011)

\section{Chalara sp.}

On leaf and branch litter of H. brasiliensis: Thailand (Seephueak et al. 2010, 2011)

\section{Chalaropsis sp.}

On branch litter of $H$. brasiliensis: Thailand (Seephueak et al. 2011)

Chryseidea africana Onofri, in Onofri et al., Mycotaxon 13(2): 333 (1981)

On leaf litter of H. brasiliensis: Thailand (Seephueak et al. 2010)

Chuppia sarcinifera Deighton, in Deighton \& Pirozynski, Mycol. Pap. 101: 32 (1965)

On leaf litter of $H$. brasiliensis: Thailand (Seephueak et al. 2010)

Circinotrichum maculiforme Nees, Syst. Pilze (Würzburg): 19 (1816) [1816-17]

On leaf litter of $H$. brasiliensis: Thailand (Seephueak et al. 2010)

Circinotrichum poonense Piroz. \& S.D. Patil, Can. J. Bot. 48(3): 576 (1970)

On leaf and branch litter of H. brasiliensis: Thailand (Seephueak et al. 2010, 2011)

Cirrenalia nigrospora Somrith., Chatmala \& E.B.G. Jones, Nova Hedwigia 75(3-4): 479 (2002)

On fallen pod and seed of H. brasiliensis: Thailand (Somrithipol et al. 2002)

Cladophialophora chaetospira (Grove) Crous \& Arzanlou, in Crous et al., Stud. Mycol. 58: 187 (2007)

On leaf litter of $H$. brasiliensis: Thailand as Heteroconium chaetospira (Seephueak et al. 2010)

Cladosporium acaciicola M.B. Ellis, More Dematiaceous Hyphomycetes (Kew): 342 (1976)

On leaf litter of H. brasiliensis: Thailand (Seephueak et al. 2010)

Cladosporium balladynae Deighton, Mycol. Pap. 118: 32 (1969)

On leaf litter of $H$. brasiliensis: Thailand (Seephueak et al. 2010)

Cladosporium cladosporioides (Fresen.) G.A. de Vries, Contrib. Knowledge of the Genus Cladosporium Link ex Fries: 57 (1952)

Endophytic on living leaves and sapwoods of H. brasiliensis: Peru (Gazis \& Chaverri 2010)

Cladosporium gallicola B. Sutton, Mycol. Pap. 132: 37 (1973)

On leaf and branch litter of H. brasiliensis: Thailand (Seephueak et al. 2010, 2011)

Cladosporium nigrellum Ellis \& Everh., Proc. Acad. Nat. Sci. Philad. 45: 463 (1894) [1893]

On leaf litter of $H$. brasiliensis: Thailand (Seephueak et al. 2010)

Cladosporium oxysporum Berk. \& M.A. Curtis, in Berkeley, J. Linn. Soc., Bot. 10(no. 46): 362 (1868) [1869]

On leaves of $H$. brasiliensis: Malaysia, Myanmar, Papua New Guinea, Thailand (Williams \& Liu 1976, Thaung 2006, Shaw 1984, Seepheuk et al. 2010)

Cladosporium orchidacearum Cooke \& Massee [as 'orchidearum'], Grevillea 16(no. 79): 80 (1888) 
On leaf litter of H. brasiliensis: Thailand (Seephueak et al. 2010)

Cladosporium tenuissimum Cooke, Grevillea 6(no. 40): 140 (1878)

On leaf and branch litter of H. brasiliensis: Thailand (Seephueak et al. 2010, 2011)

Cladosporium uredinicola Speg., Anal. Mus. nac. Hist. Nat. B. Aires 23: 122 (1912)

On leaf litter of H. brasiliensis: Thailand (Seephueak et al. 2010)

\section{Cladosporium sp.}

On leaves and branch of H. brasiliensis: Malaysia, Thailand (Liu 1977, Seepheuk et al. 2010)

Clasterosporium cocoicola M.B. Ellis, in Shaw \& Ellis, Mycol. Pap. 72 : 71 (1959)

On branch litter of $H$. brasiliensis: Thailand (Seephueak et al. 2011)

Clasterosporium flagellatum (Syd. \& P. Syd.) M.B. Ellis, Mycol. Pap. 70 : 5 (1958)

On branch litter of $H$. brasiliensis: Thailand (Seephueak et al. 2011)

Claussenomyces atrovirens (Pers.) Korf \& Abawi, Can. J. Bot. 49(11): 1882 (1971)

On branch litter of $H$. brasiliensis: Thailand (Seephueak et al. 2011)

Claussenomyces prasinulus (P. Karst.) Korf \& Abawi, Can. J. Bot. 49: 1882 (1971)

On leaf litter of $H$. brasiliensis: Thailand (Seephueak et al. 2010)

Clavariopsis aquatica De Wild., Ann. Soc. Belge Microscop. 19: 201 (1895)

On leaf and branch litter of H. brasiliensis: Thailand (Seephueak et al. 2010)

Clavariopsis brachycladia Tubaki, Bull. Natn. Sci. Mus., Tokyo, N.S. 3: 255 (1957)

On branch litter of $H$. brasiliensis: Thailand (Seephueak et al. 2011)

Clavatispora thailandica Boonmee \& K.D. Hyde, in Boonmee, Bhat, Maharachchikumbura \& Hyde, Phytotaxa 176(1): 96 (2014)

On dead twig of $H$. brasiliensis: Thailand (Huanraluek et al. 2020, this study)

Clavatospora filiformis Nawawi, Trans. Br. Mycol. Soc. 61(2): 390 (1973)

On branch litter of $H$. brasiliensis: Thailand as Nawawia filiformis (Seephueak et al. 2011)

Clonostachys rosea (Link) Schroers, Samuels, Seifert \& W. Gams, Mycologia 91(2): 369 (1999)

On $H$. brasiliensis as Gliocladium roseum: Malaysia, Thailand (Seephueak et al. 2010, Williams \& Liu 1976)

Cochliobolus bicolor A.R. Paul \& Parbery 1966

Associated with leaf spot of H. brasiliensis: China as Bipolaris bicolor (Liang et al. 2019)

Cochliobolus heveicola Tsukib. \& W.H. Chung, Mycoscience 46(1): 20 (2005)

Associated with bird 's eye leaf spot of $H$. brasiliensis: Thailand (Worapattamasri et al. 2009,

Manamgoda et al. 2011)

Cochliobolus geniculatus R.R. Nelson 1964

On leaves of $H$. brasiliensis: Malay Peninsula, Thailand as Curvularia geniculate (Thompson \& Johnston 1953, Worapattamasri et al. 2009, Seephueak et al. 2010)

Cochliobolus setariae (S. Ito \& Kurib.) Drechsler ex Dastur 1942 
Associated with leaf spot of H. brasiliensis: China as Bipolaris setariae (Liu et al. 2016b)

\section{Cochliobolus sp.}

On leaves of H. brasiliensis: Myanmar, Peru (Thaung 2008, Manamgoda et al. 2011)

Codinaea assamica (Agnihothr.) S. Hughes \& W.B. Kendr., N.Z. J1 Bot. 6: 334 (1968)

On leaf and branch litter of H. brasiliensis: Thailand (Seephueak et al. 2011)

\section{Codinaea sp.}

On leaf and branch litter of H. brasiliensis: Thailand (Seephueak et al. 2010, 2011)

Corallomycetella repens (Berk. \& Broome) Rossman \& Samuels, in Rossman et al., Stud. Mycol. 42: 113 (1999)

On H. brasiliensis: Malaysia, Myanmar as Nectria mauritiicola (Williams \& Liu 1976, Thaung 2007)

Endophytic on living leaves and sapwood on H. brasiliensis: Peru (Gazis \& Chaverri 2010)

Colletotrichum acutatum J.H. Simmonds, Queensland J. agric. Anim. Sci. 25: 178A (1968)

Associated with leaf diseases, anthracnose of $H$. brasiliensis: India, Indonesia, Sri Lanka Brown \& Soepena 1994, Saha et al. 2002)

Colletotrichum annellatum Damm, P.F. Cannon \& Crous, in Damm, Cannon, Woudenberg, Johnston, Weir, Tan, Shivas \& Crous, Stud. Mycol. 73: 6 (2012)

On leaves of H. brasiliensis: Colombia (Damm et al. 2012a)

Colletotrichum australisinense X.B. Liu, Sci. Rep. 8 (10435): 5 (2018)

Associated with leaf diseases of $H$. brasiliensis: China (Liu et al. 2018b)

Colletotrichum bannaense X.B. Liu, Sci. Rep. 8(10435): 2 (2018)

Associated with leaf diseases of $H$. brasiliensis: China (Liu et al. 2018b)

Colletotrichum brachytrichum Delacr., Bull. Soc. Mycol. Fr. 21: 192 (1905)

On H. brasiliensis: Malaysia (Turner 1971)

Colletotrichum citri F. Huang, L. Cai, K.D. Hyde \& Hong Y. Li, in Huang et al., Fungal Divers. 61(1): 69 (2013)

Associated with leaf diseases of H. brasiliensis: Sri Lanka (Hunupolagama et al. 2017)

Colletotrichum coccodes (Wallr.) S. Hughes, Can. J. Bot. 36: 754 (1958)

= Gloeosporium alborubrum Petch, Ann. R. bot. Gdns Peradeniya 3(1): 8 (1906)

On leaves of young plants and also leaves developing toward the latter part of the refoliation season and dieback of green stems and shoots of $H$. brasiliensis: China, Dominican Republic, Malay Peninsula, Myanmar, Sri Lanka, Thailand (Petch 1906, Thompson \& Johnston 1953, Ciferri 1961, Tai 1979, Giatgong 1980, Liyanage 1985, Thaung 2008)

Colletotrichum coffeanum F. Noack, Z. PflKrankh. 11: 202 (1901)

On H. brasiliensis: Nigeria (West 1938)

Colletotrichum corchori Ikata \& I. Tanaka [as 'corchorum'], Ann. phytopath. Soc. Japan 10: 148 (1940)

On H. brasiliensis: Malaysia (Singh 1980) 
Colletotrichum crassipes (Speg.) Arx, Verh. K. ned. Akad. Wet., tweede sect. 51(3): 77 (1957)

On leaves of H. brasiliensis: Malaysia, Myanmar (Williams \& Liu 1976, Thaung 2008)

Colletotrichum dematium (Pers.) Grove, J. Bot., Lond. 56: 341 (1918) 2010)

On leaves of H. brasiliensis: Malaysia, Thailand (Williams \& Liu 1976, Seephueak et al.

Colletotrichum derridis Hoof, Ann. Phytopath. Soc. Japan 13(3-4): 8 (1949)

On leaves of $H$. brasiliensis: Malaysia (Johnston 1960)

Colletotrichum falcatum Went, Archiv, voor de Java Suekerrind 1: 265 (1893)

On H. brasiliensis: Fiji as Glomerella tucumanensis (Dingley et al. 1981)

Colletotrichum ficus Koord., Bot. Unters. Java 13: 19 (1907)

On H. brasiliensis: Malay Peninsula (Thompson \& Johnston 1953)

Colletotrichum fructi (F. Stevens \& J.G. Hall) Sacc. [as 'fructus'], in Saccardo \& Trotter, Syll. fung. (Abellini) 22(2): 1201 (1913)

On leaf litter of H. brasiliensis: Thailand as Volutella fructi (Seephueak et al. 2010)

Colletotrichum fructicola Prihast., L. Cai \& K.D. Hyde, in Prihastuti et al., Fungal Divers. 39: 96 (2009)

On leaves of $H$. brasiliensis: China (Liu et al. 2018b)

Colletotrichum gloeosporioides (Penz.) Penz. \& Sacc., Atti Inst. Veneto Sci. lett., ed Arti, Sér. 62 : 670 (1884)

= Glomerella cingulata (Stoneman) Spauld. \& H. Schrenk, in Schrenk \& Spaulding, Science, N.Y. 17: 751 (1903)

Associated with leaf spot, anthracnose diseases of $H$. brasiliensis: Brazil, Brunei Darussalam, Cambodia, China, Democratic Republic of the Congo, Costa Rica, Fiji, Florida, India, Indonesia, Japan, Malaysia, Mexico on seedling, Myanmar, Nigeria, Papua New Guinea, Peru, Philippines, Sierra Leone, Sri Lanka, Thailand, Uganda (Martin 1947, Spaulding 1961, Litzenberger et al. 1962, Mendes et al. 1998, Jayasinghe 1999b, Zhuang 2001, Saha et al. 2002, Thuang 2008, Seephueak et al. 2010)

Colletotrichum heveae Petch, Ann. R. bot. Gdns Peradeniya 3(1): 8 (1906)

Associated with anthracnose diseases on leaves of H. brasiliensis: Brazil, China, Democratic Republic of the Congo, Cote d'Ivoire, Dominican Republic, India, Malay Peninsula, Malaysia, Sri Lanka, Thailand (Thompson \& Johnston 1953, Resplandy et al. 1954, Ciferri 1961, Spaulding 1961, Tai 1979, Giatgong 1980)

Colletotrichum karsti You L. Yang, Zuo Y. Liu, K.D. Hyde \& L. Cai [as 'karstii'], in Yang et al., Cryptog. Mycol. 32(3): 241 (2011)

Associated with anthracnose diseases on leaves of H. brasiliensis: China (Cai et al. 2016)

Colletotrichum laticiphilum Damm, P.F. Cannon \& Crous, in Damm, Cannon, Woudenberg, \& Crous, Stud. Mycol. 73: 74 (2012)

Associated with leaf diseases of $H$. brasiliensis: China, Colombia, India, Sri Lanka (Damm et al. 2012b, Braganca et al. 2016, Jayawardena et al. 2016, Hunupolagama et al. 2017, Shi et al. 2019)

Colletotrichum ledongense X.B. Liu, Sci. Rep. 8(10435): 6 (2018) 
Associated with leaf diseases of $H$. brasiliensis: China (Liu et al. 2018b)

Colletotrichum nymphaeae (Pass.) Aa, Net. J. Plant Pathol. Supplement 1 84(3): 110 (1978)

Associated with leaf diseases of H. brasiliensis: Sri Lanka (Hunupolagama et al. 2017)

Colletotrichum siamense Prihast., L. Cai \& K.D. Hyde, in Prihastuti et al., Fungal Divers. 39: 98 (2009)

Associated with leaf diseases of $H$. brasiliensis: China (Liu et al. 2018b)

Colletotrichum simmondsii R.G. Shivas \& Y.P. Tan, Fungal Divers. 39: 119 (2009)

Associated with leaf diseases of H. brasiliensis: India, Sri Lanka (Hunupolagama et al. 2017)

\section{Colletotrichum sp.}

On H. brasiliensis: Australia, Brazil, Cambodia, China, Cote d'Ivoire, Fiji, Haiti, Malay Peninsula, Malaysia (Thompson \& Johnston 1953, Litzenberger et al. 1962, Benjamin \& Slot 1969, Williams \& Liu 1976, Dingley et al. 1981, Nandris 1987, Mendes et al. 1998)

Colletotrichum truncatum (Schwein.) Andrus \& W.D. Moore, Phytopathology 25: 121 (1935)

On H. brasiliensis: Malaysia (Thompson \& Johnston 1953)

Colletotrichum wanningense X.R. Cao, H.Y. Che \& D.Q. Luo, in Cao et al., Plant Dis. 103(1): 120 (2018)

Associated with anthracnose diseases of H. brasiliensis: China (Cao et al. 2019)

\section{Conioscypha sp.}

On leaf litter of H. brasiliensis: Thailand (Seephueak et al. 2010)

Coniothyrium heveae Saccas, Agronomía trop. 8(2): 195 (1953) 1961)

Associated with leaf spot of H. brasiliensis: Democratic Republic of the Congo (Spaulding

Cookeina garethjonesii Ekanayaka, Q. Zhao \& K.D. Hyde, in Ekanayaka, Hyde \& Zhao, Mycosphere 7(9): 1403 (2016)

Associated with H. brasiliensis: Thailand (Surawut et al. 2021)

Cookeina sulcipes (Berk.) Kuntze, Revis. gen. pl. (Leipzig) 2: 849 (1891)

On branch litter of H. brasiliensis: Thailand (Seephueak et al. 2011, Surawut et al. 2021)

Cookeina tricholoma (Mont.) Kuntze, Revis. gen. pl. (Leipzig) 2: 849 (1891)

Associated with H. brasiliensis: Thailand (Surawut et al. 2021)

Corallomycetella elegans (Berk. \& M.A. Curtis) C.S. Herrera \& P. Chaverri, Mycosystema 32(3): 533 (2013)

On H. brasiliensis: Brazil, Cote d'Ivoire, Liberia (Herrera et al. 2013)

Corallomycetella repens (Berk. \& Broome) Rossman \& Samuels, in Rossman et al., Stud. Mycol. 42: 113 (1999)

= Sphaerostilbe repens Berk. \& Broome, J. Linn. Soc., Bot. 14(no. 74): 114 (1873) [1875] (Corallomycetella repens)

Associated with root rot disease of $H$. brasiliensis: China, Democratic Republic of the Congo, Cote d'Ivoire, Fiji, Ghana, India, Indonesia, Malay Peninsula, Malaysia, Papua New Guinea, Sri 
Lanka (Thompson \& Johnston 1953, Spaulding 1961, Dingley et al. 1981, Nandris et al. 1987, Shaw 1984)

Cordana pauciseptata Preuss, Linnaea 24: 129 (1851)

On branch litter of $H$. brasiliensis: Thailand (Seephueak et al. 2011)

Cordana terrestris (Timonin) Hern.-Restr., Gené \& Guarro, in Hernández-Restrepo et al., Mycologia 106(4): 729 (2014)

On branch litter of $H$. brasiliensis: Thailand as Pseudobotrytis terrestris (Seephueak et al. 2011)

Cordella clarkii M.B. Ellis, More Dematiaceous Hyphomycetes (Kew): 478 (1976)

On branch litter of $H$. brasiliensis: Thailand (Seephueak et al. 2011)

Corynespora cassiicola (Berk. \& M.A. Curtis) C.T. Wei, Mycol. Pap. 34 : 5 (1950)

Associated with leaf spots and leaf fall of $H$. brasiliensis: Brazil, China, Florida, Ghana, Malaysia, Papua New Guinea, Sierra Leone, Nigeria, Indonesia, Brazil, Sri Lanka, Thailand, Cameroon (Mendes et al. 1998, Jacob 2006, Jinji et al. 2007; Seephueak et al. 2010, Hieu et al. 2014; Sumabat et al. 2018, this study)

Corynespora proliferata Loer., Persoonia 8(2): 220 (1975)

On branch litter of $H$. brasiliensis: Thailand (Seephueak et al. 2011)

Corynespora trichiliae M.B. Ellis, Mycol. Pap. 76: 23 (1960)

On leaf and branch litter of H. brasiliensis: Thailand (Seephueak et al. 2010)

\section{Corynespora sp.}

On leaf litter of $H$. brasiliensis: Thailand (Seephueak et al. 2010)

Corynesporopsis quercicola (Borowska) P.M. Kirk, Trans. Br. Mycol. Soc. 77(2): 284 (1981)

On branch litter of $H$. brasiliensis: Thailand (Seephueak et al. 2011)

Coryneum elevatum (Riess) B. Sutton, Mycol. Pap. 138: 31 (1975)

On leaf litter of H. brasiliensis: Thailand (Seephueak et al. 2010)

Coryneum heveanum Senwanna, Cheewangkoon \& K.D. Hyde, in Senwanna et al., MycoKeys 43: $81(2018)$

Associated with canker disease on twigs of H. brasiliensis: Thailand (Senwanna et al. 2018a, this study)

\section{Coryneum sp.}

On leaf litter of H. brasiliensis: Thailand (Seephueak et al. 2010)

Cosmospora butyri (J.F.H. Beyma) Gräfenhan, Seifert \& Schroers, in Gräfenhan, Schroers, Nirenberg \& Seifert, Stud. Mycol. 68: 96 (2011)

On leaf litter of H. brasiliensis: Thailand as Acremonium butyri (Seephueak et al. 2010)

Crassiparies octosporarum Senwanna, Cheewangkoon \& K.D. Hyde

On twigs of $H$. brasiliensis: Thailand (this study)

Crassiparies quadrisporus M. Matsum., K. Hiray. \& Kaz. Tanaka, in Li et al., Fungal Divers. 78: 63 (2016) 
On twigs of $H$. brasiliensis: Thailand (this study)

Cryptocoryneum condensatum (Wallr.) E.W. Mason \& S. Hughes ex S. Hughes, Can. J. Bot. 36: 758 (1958)

On branch litter of $H$. brasiliensis: Thailand (Seephueak et al. 2011)

Curvularia australiensis (Bugnic. ex M.B. Ellis) Manamgoda, L. Cai \& K.D. Hyde, in Manamgoda et al., Fungal Divers. 56(1): 140 (2012)

On branch litter of $H$. brasiliensis: Thailand as Bipolaris australiensis (Seephueak et al. 2011)

Cryptospora heveae Saccas, J. Agric. Trop. Bot. Appl. 1: 186 (1954)

On dead branches of $H$. brasiliensis: French Equatorial Africa (Anonymous 1963)

Cryptovalsa microspora Sacc., Bulletino dell'orto Botanico della R. Universitá di Napoli 6: 46 (1921)

On H. brasiliensis: Malaysia (Singh 1980)

Curvularia affinis Boedijn, Bull. Jard. Bot. Buitenz, 3 Sér. 13(1): 130 (1933)

On leaf and branch litter of H. brasiliensis: Thailand (Seephueak et al. 2010, 2011)

Curvularia clavata B.L. Jain, Trans. Br. Mycol. Soc. 45(4): 542 (1962)

On leaves of $H$. brasiliensis: Thailand (Worapattamasri et al. 2009)

Curvularia deightonii M.B. Ellis, Mycol. Pap. 106: 3 (1966)

On leaf and branch litter of H. brasiliensis: Thailand (Seephueak et al. 2010, 2011)

Curvularia fallax Boedijn, Bull. Jard. Bot. Buitenz, 3 Sér. 13(1): 129 (1933)

On leaves of $H$. brasiliensis: Thailand (Worapattamasri et al. 2009)

Curvularia lunata (Wakker) Boedijn 1933

On leaves of $H$. brasiliensis: Nigeria, Malaysia as Cochliobolus lunatus, Thailand (Williams \& Liu 1976, Seephuek et al. 2010)

Curvularia neoindica Manamgoda, Rossman \& K.D. Hyde, in Manamgoda et al., Stud. Mycol. 79: 280 (2014)

On branch litter of H. brasiliensis: Thailand as Bipolaris indica (Seephueak et al. 2011)

Curvularia pallescens Boedijn, Bull. Jard. bot. Buitenz, 3 Sér. 13(1): 127 (1933)

= Cochliobolus pallescens (Tsuda \& Ueyama) Sivan, Mycol. Pap. 158: 118 (1987)

On leaves of $H$. brasiliensis: Sri Lanka, Thailand (Jayasinghe 1999, Worapattamasri et al. 2009, Managoda et al. 2011)

Curvularia penniseti (Mitra) Boedijn, Bull. Jard. Bot. Buitenz, 3 Sér. 13(1): 128 (1933)

On leaf litter of H. brasiliensis: Thailand (Seephueak et al. 2010)

Curvularia ravenelii (M.A. Curtis ex Berk.) Manamgoda, L. Cai \& K.D. Hyde, in Manamgoda et al., Fungal Divers. 56(1): 142 (2012)

On branch litter of $H$. brasiliensis: Thailand as Bipolaris ravenelii (Seephueak et al. 2011)

Curvularia richardiae Alcorn, Trans. Br. Mycol. Soc. 56(1): 155 (1971)

On leaf litter of $H$. brasiliensis: Thailand (Seephueak et al. 2010) 
Curvularia senegalensis (Speg.) Subram., J. Indian Bot. Soc. 35(4): 467 (1956)

On leaf litter of $H$. brasiliensis: Thailand (Seephueak et al. 2010)

Curvularia uncinata Bugnic., Monogr. Cantharelloid Fungi 57: 72 (1950)

On leaf litter of $H$. brasiliensis: Thailand (Seephueak et al. 2010)

\section{Curvularia sp.}

On branches of $H$. brasiliensis: Myanmar, Thailand (Seepheuk et al. 2010, Thaung 2008)

\section{Curvularia spp.}

Associated with rubber tree seeds harvested of $H$. brasiliensis: Brazil (Theodoro \& Batista 2014)

Cyathicula cyathoidea (Bull.) Thüm., Fungi austr. exsicc. 11-13: no. 1115 (1874)

On branch litter of $H$. brasiliensis: Thailand as Cylindrocolla urticae (Seephueak et al. 2011)

Cylindrocladium parvum P.J. Anderson, Bull. Mass. agric. Experimental Station 183: 37 (1919)

On leaf litter of $H$. brasiliensis: Thailand (Seephueak et al. 2010)

\section{Cylindocladium sp.}

On leaf and branch litter of H. brasiliensis: Thailand (Seephueak et al. 2010, 2011)

Cylindrocarpon aquaticum (Sv. Nilsson) Marvanová \& Descals, Trans. Br. Mycol. Soc. 89(4): 501 (1987)

On leaf litter of $H$. brasiliensis: Thailand as Bacillispora aquatica (Seephueak et al. 2010)

Cylindrocarpon didymum (Harting) Wollenw., Fusaria autographica delineata 2: no. 650 (1924)

On leaf litter of $H$. brasiliensis: Thailand (Seephueak et al. 2010)

Cylindrotrichum oligospermum (Corda) Bonord., Handb. Allgem. Mykol. (Stuttgart): 88 (1851)

On branch litter of $H$. brasiliensis: Thailand (Seephueak et al. 2011)

\section{Cylindrotrichum sp.}

On branch litter of $H$. brasiliensis: Thailand (Seephueak et al. 2011)

Cytospora diopuiensis Q.J. Shang, J.K. Liu \& K.D. Hyde, in Shang et al., Mycosphere 11(1): 202 (2020)

On twig and dead branch of $H$. brasiliensis: Thailand (this study)

Cytospora heveae Senwanna, Cheewangkoon \& K.D. Hyde

Associated with canker disease on seedling stem of $H$. brasiliensis (this study)

Cytospora thailandica Norph., T.C. Wen \& K.D. Hyde, in Norphanphoun, Raspé, Jeewon, Wen \& Hyde, MycoKeys 38: 106 (2018)

Associated with canker disease on twig of $H$. brasiliensis (this study)

\section{Cytosporina sp.}

On leaf litter of $H$. brasiliensis: Thailand (Seephueak et al. 2010)

Dactylaria acanthacearum (Cooke) de Hoog \& Arx [as 'acanthearum'], Kavaka 1: 58 (1974) [1973] 
On leaf and branch litter of $H$. brasiliensis: Thailand as Scolecobasidium acanthacearum (Seephueak et al. 2010)

Dactylaria obtriangularia Matsush., Icon. microfung. Matsush. lect. (Kobe): 51 (1975)

On leaf litter of H. brasiliensis: Thailand (Seephueak et al. 2010)

Dactylaria parvispora (Preuss) de Hoog \& Arx, Kavaka 1: 58 (1974) [1973] 2010)

On leaf litter of $H$. brasiliensis: Thailand as Pleurophragmium simplex (Seephueak et al.

Dactylaria purpurella (Sacc.) Sacc., Michelia 2(no. 6): 20 (1880)

On branch litter of $H$. brasiliensis: Thailand (Seephueak et al. 2011)

Dactylaria sp.

On leaf and branch litter of H. brasiliensis: Thailand (Seephueak et al. 2010, 2011)

Dactylella ellipsospora (Preuss) Grove, in Saccardo, Syll. fung. (Abellini) 4: 194 (1886)

On branch litter of H. brasiliensis: Thailand (Seephueak et al. 2011)

Dactylella sp.

On branch litter of $H$. brasiliensis: Thailand (Seephueak et al. 2011)

Dactylellina ellipsospora (Preuss) M. Scholler, Hagedorn \& A. Rubner, Sydowia 51(1): 110 (1999) On leaf litter of $H$. brasiliensis: Thailand as Dactylella ellipsospora (Seephueak et al. 2010)

Daldinia caldariorum Henn., Verh. bot. Ver. Prov. Brandenb. 40: 158 (1898) [1899]

On H. brasiliensis: Cameroon, Central African Republic, Chad, Democratic Republic of the Congo, Republic of the, Gabon (Stadler et al. 2014)

Daldinia concentrica (Bolton) Ces. \& De Not., Comm. Soc. crittog. Ital. 1(fasc. 4): 197 (1863)

Associated with mottled rot on bark or wood of $H$. brasiliensis: Brazil, India, Malaysia, Sri Lanka (Spaulding 1961)

Daldinia eschscholtzii (Ehrenb.: Fr.) Rehm, Annls EMycol. 2(2): 175. (1904)

On H. brasilensis: Ghana, Singapore, Thailand on branch litter (Hughes 1952, Seephueak et al. 2011, Stadler et al. 2014, Surawut et al. 2021)

Dendrospora erecta Ingold, Trans. Br. Mycol. Soc. 26(3-4): 107 (1943)

On leaf litter of $H$. brasiliensis: Thailand (Seephueak et al. 2010)

Dendryphion comosum Wallr., Fl. Crypt. Germ. (Norimbergae) 2: 300 (1833)

On branch litter of $H$. brasiliensis: Thailand (Seephueak et al. 2011)

Devriesia staurophora (W.B. Kendr.) Seifert \& N.L. Nick., in Seifert et al., Can. J. Bot. 82(7): 919 (2004)

On leaf litter of $H$. brasiliensis: Thailand as Cladosporium staurophorum (Seephueak et al. 2010)

Diaporthe heveae Petch, Ann. R. bot. Gdns Peradeniya 3(1): 3 (1906)

On branches and leaves of H. brasiliensis: Brazil, Honduras, India, Srilanka (Petch 1906, McGuire \& Crandall 1967, Gomes et al. 2013) 
Diaporthe heveicola Senwanna, Cheewangkoon \& K.D. Hyde

On dead branches of $H$. brasiliensis: Thailand (this study)

Diaporthe rosae Samarakoon \& K.D. Hyde, in Wanasinghe et al., Fungal Divers. 89: 1-236. [185] (2018)

On dead branches of $H$. brasiliensis: Thailand (this study)

Diatrypella heveae Senwanna, Phookamsak \& K.D. Hyde, in Senwanna et al., Mycosphere 8(10): 1846 (2017)

On dead twig of H. brasiliensis: Thailand (Senwanna et al. 2017)

Dichomera prunicola Ellis \& Dearn., in Ellis \& Everhart, Fungi Columb.: no. 2021 (1905)

On leaf litter of H. brasiliensis: Thailand as Codinaea assamica (Seephueak et al. 2010)

Dicyma biophila (Cif.) Arx, Gen. Fungi Sporul. Cult., Edn 3 (Vaduz): 316 (1981)

On branch litter of H. brasiliensis: Thailand as Hansfordia biophila (Seephueak et al. 2011)

Dicyma nebularis (Cooke \& Ellis) Arx, Gen. Fungi Sporul. Cult., Edn 3 (Vaduz): 316 (1981)

On branch litter of $H$. brasiliensis: Thailand as Hansfordia nebularis (Seephueak et al. 2011)

Dicyma ovalispora (S. Hughes) Arx, Gen. Fungi Sporul. Cult., Edn 3 (Vaduz): 316 (1981) 2011)

On branch litter of $H$. brasiliensis: Thailand as Hansfordia ovalispora (Seephueak et al.

\section{Dictyoarthrinium sp.}

On branch litter of $H$. brasiliensis: Thailand (Seephueak et al. 2011)

Dictyochaeta assamica (Agnihothr.) Aramb., Cabello \& Mengasc., Darwiniana 28: 297 (1988) [1987]

On leaf litter of H. brasiliensis: Thailand as Codinaea assamica (Seephueak et al. 2010)

Dictyochaeta fertilis (S. Hughes \& W.B. Kendr.) Hol.-Jech., Folia geobot. phytotax. 19(4): 426 (1984)

On leaf litter of $H$. brasiliensis: Thailand as Codinaea fertilis (Seephueak et al. 2010)

Dictyochaeta hughesii (M.B. Ellis) Whitton, McKenzie \& K.D. Hyde, Fungal Divers. 4: 140 (2000)

On leaf litter of H. brasiliensis: Thailand as Codinaea hughesii (Seephueak et al. 2010)

Dictyocheirospora gigantica (Goh \& K.D. Hyde) M.J. D'souza, Boonmee \& K.D. Hyde, in Boonmee et al., Fungal Divers. 80: 469 (2016)

On branch litter of $H$. brasiliensis: Thailand as Dictyosporium giganticum (Seephueak et al. 2011)

Dictyocheirospora heptaspora (Garov.) M.J. D'souza, Boonmee \& K.D. Hyde, in Boonmee et al., Fungal Divers. 80: 469 (2016)

On leaf and branch litter of $H$. brasiliensis: Thailand as Dictyosporium heptasporum (Seephueak et al. 2010, 2011)

Dictyosporium manglietiae Kodsueb \& McKenzie, in Kodsueb et al., Cryptog. Mycol. 27(2): 113 (2006)

On leaf and branch litter of $H$. brasiliensis: Thailand (Seephueak et al. 2010, 2011) 


\section{Dictyosporium sp.}

On leaf and branch litter of $H$. brasiliensis: Thailand (Seephueak et al. 2010, 2011)

Dicyma ovalispora (S. Hughes) Arx, Gen. Fungi Sporul. Cult., Edn 3 (Vaduz): 316 (1981)

On leaf litter of H. brasiliensis: Thailand as Hansfordia ovalispora (Seephueak et al. 2010)

Didymella heveana Saccas, Agronomía trop. 8: 229 (1953) 1961)

Associated with leaf spot $H$. brasiliensis: Democratic Republic of the Congo (Spaulding

Didymella oligospora Sacc., Bulletino dell'orto Botanico della R. Universitá di Napoli 6: 44 (1921) In dead branch of $H$. brasiliensis: Malaysia, Singapore (Singh 1980, Petrak 1930)

\section{Didymella sp.}

On seedling of $H$. brasiliensis: Mexico (Martin 1947)

\section{Didymosphaeria sp.}

On H. brasiliensis: Malaysia (Turner 1971)

Diplocladiella scalaroides G. Arnaud ex M.B. Ellis, More Dematiaceous Hyphomycetes (Kew): 229 (1976)

On leaf and branch litter of H. brasiliensis: Thailand (Seephueak et al. 2010)

Diplococcium asperum Piroz., Mycol. Pap. 129: 14 (1972)

On leaf and branch litter of H. brasiliensis: Thailand (Seephueak et al. 2010, 2011)

Diplococcium clarkii M.B. Ellis, More Dematiaceous Hyphomycetes (Kew): 391 (1976)

On branch litter of $H$. brasiliensis: Thailand (Seephueak et al. 2011)

Diplococcium lawrencei B. Sutton, Mycol. Pap. 132: 49 (1973)

On branch litter of $H$. brasiliensis: Thailand (Seephueak et al. 2011)

\section{Diplococcium sp.}

On leaf and branch litter of H. brasiliensis: Thailand (Seephueak et al. 2010)

Diplococcium spicatum Grove, J. Bot., Lond. 23: 167 (1885)

On leaf and branch litter of H. brasiliensis: Thailand (Seephueak et al. 2010, 2011)

Diplodia rapax Massee, Bull. Misc. Inf., Kew: 3 (1910)

On living branches, roots and trunks of H. brasiliensis: Cuba, Singapore (Massee 1910, Arnold 1986)

Diplodia melaena Lév., Annls Sci. Nat., Bot., sér. 3 5: 292 (1846)

On leaf litter of $H$. brasiliensis: Thailand (Seephueak et al. 2010)

\section{Diplodia sp.}

On H. brasiliensis: Brazil, China, Mexico, Thailand (McGuire \& Crandall 1967, Giatgong 1980, Mendes et al. 1998, Zhuang 2001)

Diplodia zeae Van der Byl, (1916)

On leaf litter of $H$. brasiliensis: Thailand (Seephueak et al. 2010) 
Diplodia zebrina Petch, Ann. R. bot. Gdns Peradeniya 3(1): 6 (1906)

On dead fruit of $H$. brasiliensis: SriLanka (Petch 1906)

\section{Diplodina sp.}

On leaf litter of $H$. brasiliensis: Thailand (Seephueak et al. 2010)

Discosia artocreas (Tode) Fr., Summa veg. Scand., Sectio Post. (Stockholm): 423 (1849)

On leaf and branch litter of H. brasiliensis: Thailand (Seephueak et al. 2010, 2011)

\section{Dothidotthia sp.}

On leaf and branch litter of H. brasiliensis: Thailand (Seephueak et al. 2010, 2011)

\section{Dothiorella sp.}

On leaf and branch litter of $H$. brasiliensis: Thailand (Seephueak et al. 2010, 2011)

Drechslera ellisii Danquah, Trans. Br. Mycol. Soc. 64(3): 545 (1975)

On branch litter of H. brasiliensis: Thailand as Bipolaris ellisii (Seephueak et al. 2011)

\section{Drechslera sp.}

On H. brasiliensis: Brazil (Mendes et al. 1998)

Drepanopeziza brunnea (Ellis \& Everh.) Rossman \& W.C. Allen, in Rossman et al., Mycotaxon 132(4): 952 (2017)

On H. brasiliensis: Malaysia as Gloeosporium brunneum (Singh 1980)

Dyfrolomyces sinensis Samarak., Tennakoon \& K.D. Hyde, in Hyde et al., Mycosphere 9(2): 354 (2018)

On branch of $H$. brasiliensis: Thailand (this study)

Ellisembia bambusae (M.B. Ellis) W.P. Wu, in Wu \& Zhuang, Fungal Divers. Res. Ser. 15: 109 (2005)

On leaf litter of H. brasiliensis: Thailand as Sporidesmium bambusae (Seephueak et al. 2010)

Ellisembia bambusicola (M.B. Ellis) J. Mena \& G. Delgado, in Mena-Portales et al., Boln Soc. Micol. Madrid 25: 266 (2000)

On branch litter of $H$. brasiliensis: Thailand as Sporidesmium bambusaicola (Seephueak et al. 2011)

Ellisembia dioscoreae (M.B. Ellis) Subram., Proc. Indian Natn Sci. Acad., Part B. Biol. Sci. 58(4): 183 (1992)

On leaf and branch litter of $H$. brasiliensis: Thailand as Sporidesmium dioscoreae (Seephueak et al. 2010, 2011)

Ellisembia leptospora (Sacc. \& Roum.) W.P. Wu, in Wu \& Zhuang, Fungal Divers. Res. Ser. 15: 140 (2005)

On leaf and branch litter of $H$. brasiliensis: Thailand as Sporidesmium leptosporum (Seephueak et al. 2010, 2011)

Ellisembia paravaginata McKenzie, Mycotaxon 56: 16 (1995)

On branch litter of $H$. brasiliensis: Thailand (Seephueak et al. 2011)

Ellisembia repentioriunda Goh \& K.D. Hyde, Fungal Divers. 3: 75 (1999) 
On branch litter of $H$. brasiliensis: Thailand (Seephueak et al. 2011)

\section{Ellisiopsis sp.}

On leaf and branch litter of $H$. brasiliensis: Thailand (Seephueak et al. 2010)

Ellisembia vaginata McKenzie, Mycotaxon 56: 19 (1995)

On leaf and branch litter of H. brasiliensis: Thailand (Seephueak et al. 2010, 2011)

Elsinoe heveae Bitanc. \& Jenkins, Archos Inst. biol., S. Paulo 23: 50 (1956)

On leaves, petioles and shoots of $H$. brasiliensis: Brazil as Sphaceloma heveae (Anonymous 1963, Mendes et al. 1998)

Endomelanconiopsis endophytica E.I. Rojas \& Samuels, in Rojas et al., Mycologia 100(5): 770 (2008)

Endophytic on living sapwood of H. brasiliensis: Peru (Gazis \& Chaverri 2010)

Endomelanconiopsis microspora (Verkley \& Aa) E.I. Rojas \& Samuels, in Rojas et al., Mycologia 100(5): 772 (2008)

Endophytic on living leaves and sapwood of H. brasiliensis: Peru (Gazis \& Chaverri 2010)

\section{Endophragmia sp.}

On leaf and branch litter of H. brasiliensis: Thailand (Seephueak et al. 2010, 2011)

Endophragmiella bisbyi B. Sutton ex P.M. Kirk, Index Fungorum 421: 1 (2019)

On leaf and branch litter of $H$. brasiliensis: Thailand as Endophragmia bisbyi (Seephueak et al. 2010, 2011)

Endophragmiella boewei J.L. Crane ex S. Hughes, N.Z. J1 Bot. 17(2): 147 (1979)

On branch litter of $H$. brasiliensis: Thailand as Endophragmia boewei (Seephueak et al. 2011)

Endophragmiella cesatii (Mont.) S. Hughes, N.Z. J1 Bot. 17(2): 148 (1979)

On leaf and branch litter of $H$. brasiliensis: Thailand as Endophragmia cesatii (Seephueak et al. 2010)

Endophragmiella lignicola S. Hughes, N.Z. J1 Bot. 17(2): 151 (1979)

On branch litter of $H$. brasiliensis: Thailand as Endophragmia boewei (Seephueak et al. 2011)

Endophragmiella pinicola M.B. Ellis ex P.M. Kirk, Index Fungorum 421: 1 (2019)

On branch litter of $H$. brasiliensis: Thailand as Endophragmia pinicola (Seephueak et al. 2011)

\section{Endophragmiella sp.}

On branch litter of $H$. brasiliensis: Thailand (Seephueak et al. 2011)

Endophragmiella theobromae M.B. Ellis, More Dematiaceous Hyphomycetes (Kew): 144 (1976)

On leaf litter of H. brasiliensis: Thailand (Seephueak et al. 2010)

Ephelis borealis Ellis \& Everh., J. Mycol. 1(7): 86 (1885)

On leaf litter of $H$. brasiliensis: Thailand (Seephueak et al. 2010) 
Eriomyces heveae Huanraluek, Thambugala \& K.D. Hyde, in Hyde et al., Fungal Divers. 100: 147 (2020)

On dead twigs of H. brasiliensis: Thailand (Hyde et al. 2020b)

Erysiphe quercicola S. Takam. \& U. Braun, in Takamatsu et al., Mycol. Res. 111(7): 819 (2007)

Associated with powdery mildew diseases of $H$. brasiliensis: Brazil, China, Japan, Malaysia,

Sri Lanka, Thailand, Viet Nam (Liyanage et al. 2016, Tam et al. 2016, Nguyen et al. 2018, Takamatsu et al. 2018, Wu et al. 2019)

\section{Eupenicillium sp.}

On leaf and branch litter of H. brasiliensis: Thailand (Seephueak et al. 2010, 2011)

Eutypa caulivora Massee, Bull. Misc. Inf., Kew: 251 (1910)

On trunk of H. brasiliensis: Malaysia, Singapore (Massee 1910, Singh 1980)

Eutypa erumpens Massee, Bull. Misc. Inf., Kew: 134 (1898)

On H. brasiliensis: Ghana (Dade 1940)

Eutypa heveana Saccas, J. Agric. Trop. Bot. Appl. 1: 194 (1954)

On dead branches of $H$. brasiliensis: French Equatorial Africa Cote d'Ivoire (Anonymous 1963, Rappaz 1987)

Eutypa ludibunda Sacc., Michelia 1(no. 1): 15 (1877)

On stems and branches, dead limbs of H. brasiliensis as Eutypa ludibunda var. heveana: Brazil, Singapore, Malaysia (Chipp 1920, Weir 1923, Petrak 1930, Singh 1980)

Eutypella heveae H.S. Yates, Philipp. J. Sci., C, Bot. 13(6): 378 (1918)

On dead branches of H. brasiliensis: Cote d'Ivoire, Philippines (Saccardo 1928, Teodoro 1937, Rappaz 1987)

Excipularia narsapurensis Subram., J. Indian Bot. Soc. 35(1): 56 (1956)

On branch litter of $H$. brasiliensis: Thailand (Seephueak et al. 2010)

Exosporium monanthotaxis Piroz., Mycol. Pap. 129: 47 (1972)

On branch litter of $H$. brasiliensis: Thailand (Seephueak et al. 2010)

Exserohilum rostratum (Drechsler) K.J. Leonard \& Suggs, Mycologia 66(2): 290 (1974)

Associated with leaf spot of $H$. brasiliensis: China (Liu et al. 2016a)

Fenestella heveana Saccas, J. Agric. Trop. Bot. Appl. 1: 198 (1954)

On dead branches of $H$. brasiliensis: French Equatorial Africa (Anonymous 1963)

Fimetariella rabenhorstii (Niessl) N. Lundq., Bot. Notiser 117: 239 (1964)

Endophytic on living leaves of H. brasiliensis: Peru (Gazis \& Chaverri 2010)

Flabellospora amphibia (I.P. Price \& P.H.B. Talbot) Descals, in Descals \& Webster, Trans. Br. mycol. Soc. 78(3): 414 (1982)

On branch litter of $H$. brasiliensis: Thailand as Tetracrium amphibium (Seephueak et al. 2010)

Fracchiaea heveae Senwanna, Cheewangkoon \& K.D. Hyde

On branch of $H$. brasiliensis: Thailand (this study) 
Fracchiaea hystricula (Berk. \& Broome) Petch, Ann. R. Bot. Gdns Peradeniya 5(4): 290 (1912)

On H. brasiliensis: Ghana, Malaysia (Hughes 1953, Williams \& Liu 1976)

\section{Fraseriella sp.}

On leaf litter of H. brasiliensis: Thailand (Seephueak et al. 2010)

\section{Fulvia sp.}

On leaf litter of H. brasiliensis: Thailand (Seephueak et al. 2010)

Fusariella kansensis (Ellis \& Barthol.) M.B. Ellis, More Dematiaceous Hyphomycetes (Kew): 459 (1976)

On branch litter of $H$. brasiliensis: Thailand (Seephueak et al. 2011)

Fusariella sarniensis M.B. Ellis, More Dematiaceous Hyphomycetes (Kew): 460 (1976)

On branch litter of $H$. brasiliensis: Thailand (Seephueak et al. 2011)

\section{Fusariella sp.}

On branch litter of $H$. brasiliensis: Thailand (Seephueak et al. 2011)

Fusarium bugnicourtii Brayford, Trans. Br. Mycol. Soc. 89(3): 350 (1987)

Associated with borer-damaged and dieback of H. brasiliensis: Malaysia (Brayford 1987, Aoki et al. 2018)

Fusarium heveae Vincens, Bull. Soc. Path. vég. Fr. 2: 19 (1915)

On leaves of H. brasiliensis: Brazil (Saccardo 1931)

Fusarium fujikuroi Nirenberg, Mitt. Biol. BundAnst. Ld- u. Forstw. 169: 32 (1976)

On leaf litter of $H$. brasiliensis: Thailand as Fusarium moniliforme (Seephueak et al. 2010)

Fusarium incarnatum (Desm.) Sacc., Syll. Fung. (Abellini) 4: 712 (1886)

On H. brasiliensis as Fusarium semitectum: Malaysia, Thailand (Williams \& Liu 1976, Seephueak et al. 2010)

Fusarium oxysporum Schltdl., Fl. Berol. (Berlin) 2: 139 (1824) 2014)

Associated with stem rot of H. brasiliensis: China, Malaysia (Williams \& Liu 1976, Li et al.

On leaf litter of $H$. brasiliensis: Thailand (Seephueak et al. 2010)

Fusarium polyphialidicum Marasas, P.E. Nelson, Toussoun \& P.S. van Wyk, Mycologia 78(4): 678 (1986)

Endophytic on living leaves of H. brasiliensis: Peru (Gazis \& Chaverri 2010)

\section{Fusarium sp.}

On H. brasiliensis: Brazil, China, Costa Rica, Malay Peninsula, Malaysia, Mexico, Papua New Guinea, Thailand (Thompson \& Johnston 1953, McGuire Jr. \& Crandall 1967, Shaw 1984, Mendes et al. 1998, Zhuang 2001, Seephueak et al. 2010, Na et al. 2018)

\section{Fusarium spp.}

Associated with rubber tree seeds harvested of $H$. brasiliensis: Brazil, Sri Lanka (Jayasinghe 1999a, Theodoro \& Batista 2014) 
Fusarium tuaranense T. Aoki, Kasson, S. Freeman, Geiser \& O'Donnell, in Aoki et al., Mycologia 111(6): 926 (2019)

From a beetle-damaged on $H$. brasiliensis, associated with dieback and canker diseases: Malaysia (Aoki et al. 2019)

Fusarium tumidum Sherb., Phytopathology 18: 148 (1928)

On H. brasiliensis: Malaysia (Williams \& Liu 1976)

Fusicladium orchidis (E.A. Ellis \& M.B. Ellis) K. Schub. \& U. Braun, Sydowia 56(2): 314 (2004)

On leaf land branch itter of $H$. brasiliensis: Thailand as Cladosporium orchidis (Seephueak et al. 2010, 2011)

Fusicladium britannicum (M.B. Ellis) U. Braun \& K. Schub., Mycotaxon 103: 211 (2008) 2011)

On branch litter of H. brasiliensis: Thailand as Cladosporium britannicum (Seephueak et al.

\section{Fusicladium sp.}

On leaf and branch litter of H. brasiliensis: Thailand (Seephueak et al. 2010, 2011)

\section{Fusicoccum sp.}

On H. brasiliensis: Sri Lanka (Jayasinghe 1999a, b)

Fusicolla aquaeductuum (Radlk. \& Rabenh.) Gräfenhan, Seifert \& Schroers, in Gräfenhan et al., Stud. Mycol. 68: 100 (2011) 2011)

On branch litter of $H$. brasiliensis: Thailand as Fusarium aquaeductuum (Seephueak et al.

Gaeumannomyces graminis (Sacc.) Arx \& D.L. Olivier, Trans. Br. Mycol. Soc. 35(1): 32 (1952)

On leaf and branch litter of H. brasiliensis: Thailand (Seephueak et al. 2010, 2011)

Geniculifera cystosporia (Dudd.) Rifai, Mycotaxon 2(2): 215 (1975)

On leaf litter of $H$. brasiliensis: Thailand (Seephueak et al. 2010)

Gliomastix cerealis (P. Karst.) C.H. Dickinson, Mycol. Pap. 115: 19 (1968)

On branch litter of H. brasiliensis: Thailand as Acremonium cereale (Seephueak et al. 2011)

Gliomastix musicola (Speg.) C.H. Dickinson, Mycol. Pap. 115: 8 (1968)

On branch litter of $H$. brasiliensis: Thailand (Seephueak et al. 2011)

Gloeosporium heveae Petch, Ann. R. bot. Gdns Peradeniya 3(1): 8 (1906)

On leaves of seedling and associated with dieback disease of $\mathrm{H}$. brasiliensis: Cote d'Ivoire, Malaysia, Sri Lanka (Petch 1906, Saccardo 1913, Resplandy et al. 1954, Singh 1980)

\section{Gloeosporium sp.}

On H. brasiliensis: Cote d'Ivoire, Fiji, Mexico (Nandris et al. 1987, Dingley et al. 1981, Alvarez 1976)

Gloniopsis leucaenae Jayasiri, E.B.G. Jones \& K.D. Hyde, Mycosphere 10 (1): 16 (2019)

On branch of $H$. brasiliensis: Thailand (this study)

Gnomonia amoena (Nees \& T. Nees) Fuckel, Jb. nassau. Ver. Naturk. 23-24: 120 (1870) [186970] 
On leaf litter of H. brasiliensis: Thailand (Seephueak et al. 2010)

\section{Goidanichiella sp.}

On branch litter of H. brasiliensis: Thailand as Acremonium cereale (Seephueak et al. 2011)

Graphium rhodophaeum Sacc. \& Trotter, in Bresadola \& Saccardo, Bull. Soc. R. Bot. Belg. 38(2): 166 (1899)

On H. brasiliensis: Ghana (Hughes 1952)

Guignardia heveae Syd. \& P. Syd., Annls Mycol. 14(5): 360 (1916)

On leaves of $H$. brasiliensis: Dominican Republic, Malay Peninsula, Malaysia, Myanmar, Peru as endophytic on living sapwood of H. brasiliensis, Philippines, Sri Lanka (Ciferri 1929, Teodoro 1937, Thompson \& Johnston 1953, Thaung 2008, Gazis \& Chaverri 2010)

Guignardia heveicola Cif., Quad. Ist. Bot. Univ. Pavia 19: 224 (1961)

On leaves of H. brasiliensis: Dominican Republic (Ciferri 1961)

Gyrothrix circinata (Berk. \& M.A. Curtis) S. Hughes, Can. J. Bot. 36: 771 (1958)

On leaf and branch litter of $H$. brasiliensis: Thailand (Seephueak et al. 2010)

Gyrothrix podosperma (Corda) Rabenh., Deutschl. Krypt.-Fl. (Leipzig) 1: 72 (1844)

On leaf and branch litter of H. brasiliensis: Thailand (Seephueak et al. 2010)

Hansfordia pulvinata (Berk. \& M.A. Curtis) S. Hughes, Can. J. Bot. 36: 771 (1958)

On leaf litter of H. brasiliensis: Thailand (Seephueak et al. 2010)

Haplariopsis fagicola Oudem., Ned. kruidk. Archf, 3 sér. 2(4): 902 (1903)

On leaf litter of $H$. brasiliensis: Thailand (Seephueak et al. 2010)

\section{Harknessia sp.}

On leaf litter of $H$. brasiliensis: Thailand (Seephueak et al. 2010)

\section{Harpographium sp.}

On leaf litter of $H$. brasiliensis: Thailand (Seephueak et al. 2010)

\section{Harposporium sp.}

On leaf litter of H. brasiliensis: Thailand (Seephueak et al. 2010)

Haplographium mangiferae Deighton, in Cejp \& Deighton, Mycol. Pap. 117: 8 (1969)

On leaf litter of H. brasiliensis: Thailand (Seephueak et al. 2010)

\section{Helicomyces sp.} 2011)

On branch litter of $H$. brasiliensis: Thailand as Hansfordia ovalispora (Seephueak et al.

Helicomyces roseus Link, Mag. Gesell. naturf. Freunde, Berlin 3(1-2): 21 (1809)

On branch litter of $H$. brasiliensis: Thailand (Seephueak et al. 2011)

Helicorhoidion botryoideum (Cooke) S. Hughes, Can. J. Bot. 36: 773 (1958)

On leaf litter of $H$. brasiliensis: Thailand (Seephueak et al. 2010) 
Helminthosporium phyllantheum Sacc. [as 'Helmisporium'], Atti Accad. Sci. Ven.-Trent.-Istr. 10: 91 (1917)

On leaf and branch litter of $H$. brasiliensis: Thailand as Exosporium phyllantheum (Seephueak et al. 2010)

\section{Helminthosporium sp.}

On H. brasiliensis: Cote d'Ivoire, Fiji, Thailand on leaf litter (Dingley et al. 1981, Nandris et al. 1987, Seephueak et al. 2010)

\section{Helminthosporium spp.}

Associated with rubber tree seeds harvested of H. brasiliensis: Brazil (Theodoro \& Batista 2014)

Helminthosporium velutinum Link [as 'Helmisporium'], Mag. Gesell. Naturf. Freunde, Berlin 3(1-2): 10 (1809)

On branch litter of $H$. brasiliensis: Thailand (Seephueak et al. 2011)

Hendersonia celtifolia Cooke, Nuovo G. bot. ital. 10: 22 (1878)

On leaf litter of H. brasiliensis: Thailand (Seephueak et al. 2010)

Hendersonia heveae Petch, Ann. R. bot. Gdns Peradeniya 7(4): 313 (1922)

On stems and fruits of $H$. brasiliensis: Sri Lanka (Petrak 1930, Saccardo 1972)

\section{Hendersonula sp.}

On leaf litter of H. brasiliensis: Thailand (Seephueak et al. 2010)

Henicospora coronata B. Sutton \& P.M. Kirk, in Kirk \& Sutton, Trans. Br. Mycol. Soc. 75(2): 249 (1980)

On leaf and branch litter of H. brasiliensis: Thailand (Seephueak et al. 2010, 2011)

Hermatomyces sphaericus (Sacc.) S. Hughes, Mycol. Pap. 50: 100 (1953)

On dried branch of $H$. brasiliensis: Thailand (this study)

Herpotrichia diffusa (Cooke) Ellis \& Everh., N. Amer. Pyren. (Newfield): 158 (1892)

On twig of H. brasiliensis: Ghana as Neopeckia diffusa (Hughes 1953)

\section{Heteroconium sp.}

On leaf litter of H. brasiliensis: Thailand (Seephueak et al. 2010)

Heteropatella alpina (Ellis \& Everh.) W.B. Cooke, Mycologia 31(1): 48 (1939)

On leaf litter of $H$. brasiliensis: Thailand (Seephueak et al. 2010)

Hirudinaria macrospora Ces., in Rabenhorst, Klotzschii Herb. Viv. Mycol., Edn Nov, Ser. Sec., Cent. 3: no. 269 (1856)

On branch litter of $H$. brasiliensis: Thailand (Seephueak et al. 2011)

\section{Hormiactis alba Preuss, Linnaea 24: 128 (1851)}

On leaf litter of H. brasiliensis: Thailand (Seephueak et al. 2010)

Hormiactis candida Höhn., Centbl. Bakt. ParasitKde, Abt. II 60: 20 (1923) [1924]

On leaf litter of $H$. brasiliensis: Thailand (Seephueak et al. 2010) 


\section{Hormiactis sp.}

On branch litter of $H$. brasiliensis: Thailand (Seephueak et al. 2011)

\section{Hyalotiella sp.}

On leaf litter of H. brasiliensis: Thailand (Seephueak et al. 2010)

Hymenoscyphus tetracladius Abdullah, Descals \& J. Webster, Trans. Br. Mycol. Soc. 77(3): 477 (1981)

On branch litter of $H$. brasiliensis: Thailand as Articulospora tetracladia (Seephueak et al. 2011)

Hyphodiscosia jaipurensis Lodha \& K.R.C. Reddy, Trans. Br. Mycol. Soc. 62(2): 421 (1974)

On branch litter of $H$. brasiliensis: Thailand (Seephueak et al. 2011)

Hypocrea splendens W. Phillips \& Plowr., Grevillea 13(no. 67): 79 (1885)

On branch litter of $H$. brasiliensis: Thailand (Seephueak et al. 2011)

Hypoxylon deustum (Hoffm.) Grev., Scott. Crypt. fl. (Edinburgh) 6: 324 (1828)

On H. brasiliensis: China, Fiji (Tai 1979, Dingley et al. 1981)

Hypoxylon lenormandii Berk. \& M.A. Curtis [as 'lenormandi'], in Berkeley, J. Linn. Soc., Bot. 10(no. 46): 385 (1868) [1869]

On dead branch of H. brasiliensis: Malaysia as Hypoxylon oodes (Singh 1980)

Hypoxylon notatum Berk. \& M.A. Curtis, in Berkeley, Grevillea 4(no. 30): 50 (1875)

On H. brasiliensis: India (Pande 2008)

Hypoxylon placentiforme Berk. \& M.A. Curtis, in Berkeley, J. Linn. Soc., Bot. 10(no. 46): 383 (1868) [1869]

On H. brasiliensis: Ghana (Hughes 1953)

Hypoxylon rubiginosum (Pers.) Fr., Summa veg. Scand., Sectio Post. (Stockholm): 384 (1849)

On H. brasiliensis: Brunei Darussalam, Dominican Republic, Ghana, Haiti (Hughes 1953, Ciferri 1961, Benjamin \& Slot 1969, Peregrine \& Ahmad1982)

Hypoxylon sp.

On leaf and branch litter of H. brasiliensis: Thailand (Seephueak et al. 2010, 2011)

Hypoxylon suborbiculare Welw. \& Curr., Trans. Linn. Soc. London 26(1): 281 (1868) [1870]

On H. brasiliensis: Ghana (Dade 1940)

Hysterium heveanum Sacc., Bulletino dell'orto Botanico della R. Universitá di Napoli 6: 53 (1921) On decaying branches of H. brasiliensis: Singapore, Malaysia (Petrak 1930, Singhe 1980)

Hysterostegiella dumeti (Sacc. \& Speg.) B. Hein, Nova Hedwigia 38: 690 (1983)

On branch litter of H. brasiliensis: Thailand as Stegopeziza dumeti (Seephueak et al. 2011)

Idriella lunata P.E. Nelson \& S. Wilh., Mycologia 48(4): 550 (1956)

On leaf and branch litter of $H$. brasiliensis: Thailand (Seephueak et al. 2010)

\section{Idriella sp.}

On leaf litter of H. brasiliensis: Thailand (Seephueak et al. 2010) 
Irenopsis vincensii Pinho \& O.L. Pereira, in Pinho et al., Trop. Plant Pathol. 39(1): 90 (2014)

= Irenopsis heveae Hansf., Beih. Sydowia 2: 207 (1961)

= Meliola heveae Vincens, Bull. Soc. Path. vég. Fr. 2: 26 (1915)

Associated with black mildew on leaves of $H$. brasiliensis: Brazil, Peru, Amazon Rainforest (Vincens 1915, Hansford 1961, Pinho et al. 2014)

Jackrogersella cohaerens (Pers.) L. Wendt, Kuhnert \& M. Stadler, in Wendt et al., Mycol. Progr. 17 (1-2): 141 (2017)

On leaf litter of $H$. brasiliensis: Thailand as Hypoxylon cohaerens (Seephueak et al. 2010)

Kirschsteiniothelia atra (Corda) D. Hawksw., in Wijayawardene et al., Fungal Divers. 69: 37 (2014)

On leaf litter of $H$. brasiliensis: Thailand as Dendryphiopsis atra (Seephueak et al. 2010)

\section{Kirschsteiniothelia sp.}

On leaves of H. brasiliensis: Thailand (Seephueak et al. 2010)

\section{Kramasamuha sp.}

On leaf litter of $H$. brasiliensis: Thailand (Seephueak et al. 2010)

Kretzschmaria cetrarioides (Welw. \& Curr.) Sacc., Syll. fung. (Abellini) 2: XXIX (1883)

On H. brasiliensis: Ghana, Malaysia as Kretzschmaria botrites (Dade 1940, Singh 1980)

Kretzschmaria micropus (Fr.) Sacc., Syll. fung. (Abellini) 1: 389 (1882)

On H. brasiliensis: Ghana (Dade 1940)

Kretzschmaria zonata (Lév.) P.M.D. Martin, Jl S. Afr. Bot. 42(1): 75 (1976)

= Ustulina zonata (Lév.) Sacc., Syll. fung. (Abellini) 1: 352 (1882)

On H. brasiliensis: Ghana, Malay Peninsula, Mexico, Myanmar on root tissue, Nigeria, Sierra Leone, Thailand (Deighton 1936, West 1938, Dade 1940, Thompson \& Johnston 1953, Alvarez 1976, Giatgong 1980, Thaung 2007)

Lasiodiplodia chinensis Z.P. Dou \& Y. Zhang ter, in Dou et al., Mycosphere 8(2): 528 (2017)

On branches of $H$. brasiliensis: China (Dou et al. 2017)

Lasiodiplodia pseudotheobromae A.J.L. Phillips, A. Alves \& Crous, Fungal Divers. 28: 8 (2008)

Associated with canker diseases, on asymptomatic and symptomatic leaves, stems and twigs of $H$. brasiliensis: China, Thailand, on seed cover of $H$. brasiliensis (Trakunyingcharoen et al. 2015a, Wu et al. 2019, this study)

Lasiodiplodia theobromae (Pat.) Griffon \& Maubl., Bulletin de la Société Mycologique de France 25: 57 (1909)

= Botryodiplodia elasticae Petch, Ann. R. bot. Gdns Peradeniya 3(1): 7 (1906)

= Botryodiplodia theobromae Pat., in Patouillard \& Lagerheim, Bull. Soc. Mycol. Fr. 8(3): $136(1892)$

= Chaetodiplodia grisea Petch, Ann. R. Bot. Gdns Peradeniya 3(1): 6 (1906)

= Diplodia theobromae (Pat.) W. Nowell, Diseases of Crop Plants in the Lesser Antilles: 158 (1923)

= Physalospora rhodina Berk. \& M.A. Curtis, Grevillea 17(no. 84): 92 (1889)

Associated with canker and dieback diseases on stem, twigs and branches, dead seedling, dried petiole, root rot diseases of seedling and endophytic fungi on $H$. brasiliensis: Brazil, China, Democratic Republic of the Congo, Costa Rica, Fiji, Haiti, Ghana, Honduras, India, Indonesia, 
Malay Peninsula, Malaysia, Mexico, Myanmar, Nigeria, Papua New Guinea, Philippines, Sri Lanka, Thailand, Uganda (Petch 1906, West 1938, Thompson \& Johnston 1953, Benjamin \& Slot 1969, Turner 1971, Firman 1972, Williams \& Liu 1976, Mathur 1979, Giatgong 1980, Shaw 1984, Mendes et al. 1998, Seephueak et al. 2010, 2011, Ghazali 2013, Picos-Muñoz et al. 2015, this study)

Lateriramulosa uniinflata Matsush., Microfungi of the Solomon Islands and Papua-New Guinea (Osaka): 34 (1971)

On leaf and branch litter of H. brasiliensis: Thailand (Seephueak et al. 2010, 2011)

Lauriomyces sakaeratensis Somrith., Kosol \& E.B.G. Jones, Nova Hedwigia 82(1-2): 210 (2006) On branch litter of H. brasiliensis: Thailand (Seephueak et al. 2011)

Lembosia glonioidea Sacc., Bulletino dell'orto Botanico della R. Universitá di Napoli 6: 53 (1921) On H. brasiliensis: Malaysia (Singh 1980)

Lemonniera terrestris Tubaki, J. Hattori bot. Lab. 20: 165 (1958)

On branch litter of $H$. brasiliensis: Thailand as Lemonniera brachycladian (Seephueak et al. 2011)

Leptodiscella africana (Papendorf) Papendorf, Trans. Br. Mycol. Soc. 53(1): 146 (1969)

On leaf and branch litter of H. brasiliensis: Thailand (Seephueak et al. 2010, 2011)

Leptosphaeria blumeri E. Müll., Sydowia 4(1-6): 275 (1950)

On branch litter of $H$. brasiliensis: Thailand (Seephueak et al. 2011)

Leptosphaeria cercocarpi Syd. \& P. Syd., Ann. Mycol. 5(4): 339 (1907)

On branch litter of $H$. brasiliensis: Thailand (Seephueak et al. 2011)

Leptosphaeria darkeri Shoemaker, Can. J. Bot. 62(12): 2699 (1985) [1984]

On branch litter of $H$. brasiliensis: Thailand (Seephueak et al. 2011)

Leptosphaeria doliolum (Pers.) Ces. \& De Not., Comm. Soc. crittog. Ital. 1(fasc. 4): 234 (1863) 2011)

On branch litter of $H$. brasiliensis: Thailand as Leptosphaeria conoidea (Seephueak et al.

Leptosphaeria heveae Saccas, Agronomía Trop. 8: 244 (1953)

Associated with leaf spot of $H$. brasiliensis: Democratic Republic of the Congo (Spaulding 1961, Anonymous 1963)

Leptosphaeria millefolii (Fuckel) Sacc., Syll. Fung. (Abellini) 2: 45 (1883)

On branch litter of $H$. brasiliensis: Thailand (Seephueak et al. 2011)

Leptosphaeria russellii Shoemaker, Can. J. Bot. 62(12): 2711 (1985) [1984]

On branch litter of $H$. brasiliensis: Thailand (Seephueak et al. 2011)

Leptosphaerulina trifolii (Rostr.) Petr., Sydowia 13(1-6): 76 (1959)

On H. brasiliensis: Malaysia as Pseudoplea trifolii (Williams \& Liu 1976)

Libertella heveae (Petch) B. Sutton, The Coelomycetes (Kew): 221 (1980)

In crack of branches of $H$. brasiliensis: Sri Lanka as Phlyctema heveae (Saccardo 1931) 


\section{Linocarpon sp.}

On leaf and branch litter of H. brasiliensis: Thailand (Seephueak et al. 2010, 2011)

Linodochium hyalinum (Lib.) Höhn., Sber. Akad. Wiss. Wien, Math.-naturw. Kl., Abt. 1 118: 1239 (1909)

On branch litter of $H$. brasiliensis: Thailand (Seephueak et al. 2011)

\section{Linospora sp.}

On leaf and branch litter of H. brasiliensis: Thailand (Seephueak et al. 2010, 2011)

Lophiostoma semiliberum (Desm.) Ces. \& De Not., Comm. Soc. crittog. Ital. 1(fasc. 4): 220 (1863)

On leaf litter of $H$. brasiliensis: Thailand (Seephueak et al. 2010)

Lophiostoma viridarium Cooke, Trans. Bot. Soc. Edinb. 9: 328 (1868)

On leaf litter of H. brasiliensis: Thailand (Seephueak et al. 2010)

\section{Lophodermium sp.}

On branch litter of $H$. brasiliensis: Thailand (Seephueak et al. 2011)

Macgarvieomyces juncicola (MacGarvie) Klaubauf, M.-H. Lebrun \& Crous, in Klaubauf et al., Stud. Mycol. 79: 107 (2014)

On leaf and branch litter of H. brasiliensis: Thailand as Dactylaria junci (Seephueak et al. 2010)

Mariannaea elegans (Corda) Samson, Stud. Mycol. 6: 75 (1974)

On branch litter of $H$. brasiliensis: Thailand (Seephueak et al. 2011)

Macrophomina phaseolina (Tassi) Goid., Annali Sper. Agr., N.S. 1(3): 457 (1947)

= Macrophomina phaseoli (Maubl.) S.F. Ashby, Trans. Br. Mycol. Soc. 12(2-3): 145 (1927)

$=$ Rhizoctonia bataticola (Taubenh.) E.J. Butler, in Briton-Jones, Bull. Minist. Agric. Egypt, Bot. Sect. 49: 65 (1925)

Associated with root rot diseases on root and stems of $H$. brasiliensis: India, Indonesia, Malay Peninsula, Malaysia, Sri Lanka, Uganda (Small 1928, Thompson \& Johnston 1953, Spaulding 1961)

\section{Macrophomina sp.}

On H. brasiliensis: Thailand (Giatgong 1980)

\section{Massariothea sp.}

On leaf litter of $H$. brasiliensis: Thailand (Seephueak et al. 2010)

Mastigosporium rubricosum (Dearn. \& Barthol.) Nannf., in Lundell \& Nannfeldt, Fungi Exsiccati Suecici: no. 876a (1939)

On leaf litter of H. brasiliensis: Thailand as Fusoma rubricosum (Seephueak et al. 2010)

Melomastia heveae Saccas, J. Agric. Trop. Bot. Appl. 1: 343 (1954)

On moribund branches and trunks of $H$. brasiliensis: French Equatorial Africa (Anonymous 1963)

Memnoniella oenanthes (M.B. Ellis) L. Lombard \& Crous, in Lombard, Houbraken, Decock, Samson, Meijer, Réblová, Groenewald \& Crous, Persoonia 36: 199 (2016) 
On branch litter of H. brasiliensis: Thailand as Stachybotrys oenanthes (Seephueak et al. 2011)

\section{Menispora sp.}

On leaf litter of $H$. brasiliensis: Thailand (Seephueak et al. 2010)

Menisporopsis profusa Piroz. \& Hodges, Can. J. Bot. 51(1): 164 (1973)

On leaf litter of H. brasiliensis: Thailand (Seephueak et al. 2010)

Menisporopsis theobromae S. Hughes, Mycol. Pap. 48 : 59 (1952)

On leaf litter of $H$. brasiliensis: Thailand (Seephueak et al. 2010)

Metacapnodium dennisii S. Hughes, Kew Bull. 31(3): 573 (1977)

On leaves of H. brasiliensis: Malaysia (Sivanesan 1984, Anonymous 1977)

Micropeltis heveae Bat. \& Peres, Publicações. Instituto de Micologia da Universidade do Recife \& Instituto Nacional de Pesquis 386: 59 (1963)

On leaves of H. brasiliensis: Brazil (Anonymous 1968)

Microthyrium fagi J.P. Ellis, Trans. Br. Mycol. Soc. 67(3): 387 (1977) [1976]

On branch litter of $H$. brasiliensis: Thailand (Seephueak et al. 2011)

\section{Monacrosporium sp.}

On leaf and branch litter of H. brasiliensis: Thailand (Seephueak et al. 2010, 2011)

\section{Monilinia sp.}

On H. brasiliensis: Thailand (Giatgong 1980)

Miladina lecithina (Cooke) Svrček [as 'lechithina'], Česká Mykol. 26(4): 214 (1972)

On branch litter of H. brasiliensis: Thailand as Actinospora megalospora (Seephueak et al. 2011)

Minimelanolocus hughesii (M.B. Ellis) R.F. Castañeda \& Heredia, in Castañeda Ruiz, Heredia, Reyes, Arias \& Decock, Cryptog. Mycol. 22(1): 9 (2001)

On leaf and branch litter of $H$. brasiliensis: Thailand as Pseudospiropes hughesii (Seephueak et al. 2010, 2011)

Minimelanolocus rousselianus (Mont.) R.F. Castañeda \& Heredia, in Castañeda Ruiz, Heredia, Reyes, Arias \& Decock, Cryptog. Mycol. 22(1): 10 (2001)

On branch litter of $H$. brasiliensis: Thailand as Pseudospiropes rousselianus (Seephueak et al. 2011)

Minimelanolocus subulifer (Corda) R.F. Castañeda \& Heredia [as 'subuliferus'], in Castañeda Ruiz, Heredia, Reyes, Arias \& Decock, Cryptog. Mycol. 22(1): 9 (2001)

On branch litter of $H$. brasiliensis: Thailand as Pseudospiropes subuliferus (Seephueak et al. 2011)

\section{Monochaetia sp.}

On leaf litter of H. brasiliensis: Thailand (Seephueak et al. 2010)

Monodictys cerebriformis G.Z. Zhao \& T.Y. Zhang, Mycosystema 23(3): 325 (2004)

On dead wood of $H$. brasiliensis: China (Zhao \& Zhang 2004) 
Monodictys glauca (Cooke \& Harkn.) S. Hughes, Can. J. Bot. 36: 785 (1958)

On leaf litter of $H$. brasiliensis: Thailand (Seephueak et al. 2010)

Monodictys nigriglobulosa G.Z. Zhao \& T.Y. Zhang, Mycosystema 26(3): 328 (2007)

On H. brasiliensis: China (Tianyu 2009)

Montagnula thailandica Mapook \& K.D. Hyde, in Mapook et al., Fungal Divers. 101: 35 (2020)

On dried twig of $H$. brasiliensis: Thailand (this study)

Muscodor heveae Siri-Udom \& Lumyong, Ann. Microbiol. 66(1): 437 (2015)

Isolated from $H$. brasiliensis: Thailand (Siri-udom et al. 2015)

Muyocopron dipterocarpi Mapook, Boonmee \& K.D. Hyde, in Mapook et al., Phytotaxa 265(3): 232 (2016)

On twig of $H$. brasilienesis: Thailand (Senwanna et al. 2019)

Muyocopron garethjonesii Tibpromma, Karun. \& K.D. Hyde, in Tibpromma et al., Mycosphere 7(9): 1485 (2016)

On twig of $H$. brasilienesis: Thailand (this study)

Muyocopron heveae Senwanna \& K.D. Hyde, in Senwanna et al., Mycol. Progr. 18(5): 747 (2019)

On twig of H. brasilienesis: Thailand (Senwanna et al. 2019)

Muyocopron sahnii Hern.-Restr. \& Crous, in Hernández-Restrepo et al., Persoonia 42: 219 (2019) 2011)

On branch litter of $H$. brasiliensis: Thailand as Mycoleptodiscus indicus (Seephueak et al.

Mycosphaerella heveana (Sacc.) M. Morelet, Ann. Soc. Sci. Nat. Arch. Toulon et du Var 20: 105 (1968)

On leaves of $H$. brasiliensis: Singapore, Mauritius as Sphaerella heveana (Petrak 1930, Orieux and Felix 1968)

Mycosphaerella heveicola Saccas [as 'hevicola'], Agronomía Trop. 8: 247 (1953)

Associated with leaf spot of $H$. brasiliensis: China, Democratic Republic of the Congo (Spaulding 1961)

Mystrosporiella litseae Munjal \& Kulshr., Mycopath. Mycol. Appl. 39: 357 (1969)

On leaf litter of $H$. brasiliensis: Thailand (Seephueak et al. 2010)

Myxocyclus sp.

On branch litter of $H$. brasiliensis: Thailand (Seephueak et al. 2011)

Nectria cinnabarina (Tode) Fr., Summa veg. Scand., Sectio Post. (Stockholm): 388 (1849)

On leaf litter of $H$. brasiliensis: Thailand as Tubercularia vulgaris (Seephueak et al. 2010)

Nectria diversispora Petch, Ann. R. bot. Gdns Peradeniya 3(1): 4 (1906)

On dead bark of H. brasiliensis: Sri Lanka, Myanmar (Petch 1906, Thaung 2007)

Nectria pseudotrichia Berk. \& M.A. Curtis, J. Acad. nat. Sci. Philad., N.S. 2(6): 289 (1854) [1853]

= Megalonectria pseudotrichia (Schwein.) Speg., Anal. Soc. Cient. Argent. 12(5): 217 (1881)

= Thyronectria pseudotrichia (Schwein.) Seeler, J. Arnold Arbor. 21: 438 (1940) 
On bark of $H$. brasiliensis: Fiji, Philippines, Ghana, Indonesia, Singapore, Thailand on branch litter (Reinking 1919, Firman 1972, Seifert 1985, Hirooka et al. 2012, Seephueak et al. 2011)

On dead branch of $H$. brasiliensis: Thailand (this study)

\section{Nectria sp.}

On H. brasiliensis: Ghana (Dade 1940)

Neocosmospora solani (Mart.) L. Lombard \& Crous, in Lombard et al., Stud. Mycol. 80: 228 (2015)

= Fusarium solani (Mart.) Sacc., Michelia 2(no. 7): 296 (1881)

= Fusarium javanicum Koord., Verh. K. Akad. Wet., tweede sect. 13(4): 247 (1907)

= Nectria haematococca Berk. \& Broome, J. Linn. Soc., Bot. 14(no. 74): 116 (1873) [1875]

Associated with root lesion, gummosis, witling and death of $H$. brasiliensis: China, India, Malaysia, Sri Lanka, Thailand, Papua New Guinea (Williams \& Liu 1976, Liyanage \& Dantanarayana 1983, Shaw 1984, Zhuang 2001, Seephueak et al. 2010, Huang et al. 2016, Spaulding 1961)

Neofusicoccum parvum (Pennycook \& Samuels) Crous, Slippers \& A.J.L. Phillips, in Crous et al., Stud. Mycol. 55: 248 (2006)

Associated with leaf spot of $H$. brasiliensis: China (Liu et al. 2017)

Neofusicoccum mangiferae (Syd. \& P. Syd.) Crous, Slippers \& A.J.L. Phillips, in Crous et al., Stud. Mycol. 55: 248 (2006)

Associated with foot canker and sudden wilt on seedling of $H$. brasiliensis: Sri Lanka as Nattrassia mangiferae (Jayasinghe and Silva 1994)

Neofusicoccum ribis (Slippers, Crous \& M.J. Wingf.) Crous, Slippers \& A.J.L. Phillips, in Crous et al., Stud. Mycol. 55: 249 (2006)

Associated with leaf blight of $H$. brasiliensis: Malaysia (Nyaka Ngobisa et al. 2013)

Neonectria coccinea (Pers.) Rossman \& Samuels, in Rossman et al., Stud. Mycol. 42: 158 (1999) On H. brasilienesis: Malaysia as Nectria coccinea (Singh 1980)

Neolinocarpon phayaoense Senwanna, \& K.D. Hyde, in Senwanna et al., Phytotaxa 362(1): 79 (2018)

On branch of $H$. brasilienesis: Thailand (Senwanna et al. 2018b)

Neopestalotiopsis cubana Maharachch., K.D. Hyde \& Crous, in Maharachchikumbura et al., Stud. Mycol. 79: 138 (2014)

Associated with leaf fall disease of $H$. brasiliensis: Thailand (Pornsuriya et al. 2020)

Neopestalotiopsis formicidarum Maharachch., K.D. Hyde \& Crous [as 'formicarum'], in Maharachchikumbura et al., Stud. Mycol. 79: 140 (2014)

Associated with leaf fall disease of $H$. brasiliensis: Thailand (Pornsuriya et al. 2020)

Neopseudocercospora zambiensis (Deighton) Crous \& U. Braun, in Braun et al., IMA Fungus 5(2): 204 (2014)

On branch litter of $H$. brasiliensis: Thailand as Sporidesmium zambiensis (Seephueak et al. 2011) 
Neoroussoella heveae Senwanna, Phookamsak \& K.D. Hyde, in Phookamsak et al., Fungal Divers. 95: 66 (2019)

On twigs of H. brasilienesis: Thailand (Phookamsak et al. 2019)

Neoroussoella leucaenae Jayasiri, E.B.G. Jones \& K.D. Hyde, Mycosphere 10(1): 1-186 (2019)

On dead twigs of $H$. brasilienesis: Thailand (Phookamsak et al. 2019)

Neoscytalidium dimidiatum (Penz.) Crous \& Slippers, in Crous et al., Stud. Mycol. 55: 244 (2006)

On H. brasilienesis: Malaysia as Hendersonula toruloidea (Singh 1980)

\section{Neottiosporella sp.}

On leaf litter of H. brasiliensis: Thailand (Seephueak et al. 2010)

Neovaginatispora fuckelii (Sacc.) A. Hashim., K. Hiray. \& Kaz. Tanaka, Stud. Mycol. 90: 188 (2018)

= Vaginatispora fuckelii (Sacc.) Thambug., Wanas., Kaz. Tanaka \& K.D. Hyde, Fungal Divers. 74: 242 (2015)

On branch litter of H. brasiliensis: Thailand as Lophiostoma fuckelii (Seephueak et al. 2011)

Nigrograna fuscidula (Sacc.) Jaklitsch \& Voglmayr, Stud. Mycol. 85: 54 (2016)

On H. brasilienesis: Ghana as Melanomma fuscidulum (Hughes 1953)

Nigrospora oryzae (Berk. \& Broome) Petch, J. Indian Bot. Soc. 4: 24 (1924)

On H. brasilienesis as Nigrospora sphaerica: Malaysia, Thailand (Williams \& Liu 1976, Seephueak et al. 2010)

Nitschkia tetraspora Nannf., Svensk bot. Tidskr. 69(3): 316 (1975)

On H. brasilienesis: Ghana (Nannfeldt 1975)

Nummularia anthracodes (Fr.) Cooke, (1883)

Associated with black bark on bark of H. brasilienesis: Dominican Republic, Ghana (Weir 1926, Hughes 1952, Ciferri 1961)

Nummularia broomeana (Berk. \& M.A. Curtis) J.H. Mill. [as 'broomeiana'], Mycologia 33(1): 77 (1941)

On H. brasilienesis: Haiti as Nummularia broomeiana (Benjamin \& Slot 1969)

Nummularia cincta Ferd. \& Winge, Bot. Tidsskr. 29(1): 15 (1908)

On H. brasilienesis: Dominican Republic (Ciferri 1961)

\section{Orbilia sp.}

On branch litter of H. brasiliensis: Thailand (Seephueak et al. 2011)

Ochrocladosporium elatum (Harz) Crous \& U. Braun, in Crous et al., Stud. Mycol. 58: 46 (2007) On leaf and branch litter of $H$. brasiliensis: Thailand as Cladosporium elatum (Seephueak et al. 2010, 2011)

Oedothea vismiae Syd., Ann. Mycol. 28(1/2): 203 (1930)

On leaf litter of $H$. brasiliensis: Thailand (Seephueak et al. 2010)

Oidium heveae B.A. Steinm., De Zickten en Ragen van Hevea brasiliensis in Nederlandsch-Indie: $91(1925)$ 
Associated with powdery mildew of $H$. brasilienesis: Brazil, Brunei Darussalam, Cambodia, Cameroon, China, Democratic Republic of the Congo, Ghana, India, Indonesia, Malawi, Malay Peninsula, Malaysia, Myanmar, Papua New Guinea, Sri Lanka, Tanzania, Thailand, Uganda, Viet Nam (Thompson \& Johnston 1953, Spaulding 1961, Amano 1986, Mendes et al. 1998, Limkaisang et al. 2005)

\section{Oidium sp.}

On leaves of H. brasilienesis: Cote d'Ivoire (Nandris et al. 1987)

Oidium tenerum B.A. Steinm., De Zickten en Ragen van Hevea brasiliensis in Nederlandsch-Indie: $91(1925)$

On leaves of $H$. brasilienesis: Ghana (Hughes 1952)

Ophiobolus heveae Henn., Hedwigia 43(4): 248 (1904)

Associated with leaf spot of $H$. brasilienesis: Brazil, Dominican Republic, Florida, Haiti (Ciferri 1961, Spaulding 1961, Benjamin \& Slot 1969, Alfieri et al. 1984)

Ophiostoma ulmi (Buisman) Nannf., in Melin \& Nannfeldt, Svensk Skogsvårdsförening Tidskr. 34: 408 (1934)

On leaf and branch litter of $H$. brasiliensis: Thailand as Ceratocystis ulmi (Seephueak et al. 2010, 2011)

\section{Oxydothis sp.}

On branch litter of $H$. brasiliensis: Thailand (Seephueak et al. 2011)

\section{Paecilomyces sp.}

On leaf and branch litter of H. brasiliensis: Thailand (Seephueak et al. 2010, 2011)

Panchanania jaipurensis Subram. \& N.G. Nair, Antonie van Leeuwenhoek 32: 382 (1966)

On leaf and branch litter of H. brasiliensis: Thailand (Seephueak et al. 2010, 2011)

Paraconiothyrium cyclothyrioides Verkley, in Verkley et al., Stud. Mycol. 50(2): 330 (2004) From soil under H. brasiliensis: Sri Lanka (Crous et al. 2015b)

Paradendryphiella salina (G.K. Sutherl.) Woudenb. \& Crous, Stud. Mycol. 75(1): 207 (2013)

On leaf and branch litter of H. brasiliensis: Thailand as Scolecobasidium salinum (Seephueak et al. 2010, 2011)

Paraeutypella citricola (Speg.) L.S. Dissan., Wijayaw., J.C. Kang \& K.D. Hyde, in Dissanayake, Wijayawardene, Dayarathne, Samarakoon \& Dai, Biodiversity Data Journal 9: e63864, 14 (2021)

On dead branch of $H$. brasiliensis: Thailand (this study)

Paragnomonia fragariae (Kleb.) Senan. \& K.D. Hyde, in Senanayake et al., Mycosphere 8 (1): 199 (2017)

On leaf litter of H. brasiliensis: Thailand as Gnomonia fragariae (Seephueak et al. 2010)

Paramyrothecium roridum (Tode) L. Lombard \& Crous, in Lombard et al., Persoonia 36: 211 (2016)

On leaf and branch litter of $H$. brasiliensis: Thailand as Myrothecium roridum (Seephueak et al. 2010, 2011)

\section{Parapleurotheciopsis sp.}


On branch litter of $H$. brasiliensis: Thailand (Seephueak et al. 2011)

Parascedosporium putredinis (Corda) Lackner \& de Hoog, IMA Fungus 2(1): 44 (2011)

On leaf litter of $H$. brasiliensis: Thailand as Graphium putredinis (Seephueak et al. 2010)

Parasympodiella podocarpi Crous \& Seifert, in Crous et al., S. Afr. J. Bot. 62(2): 92 (1996)

On leaf and branch litter of $H$. brasiliensis: Thailand (Seephueak et al. 2010)

Paratomenticola lanceolata (Cooke) M.B. Ellis [as 'lanceolatus'], More Dematiaceous Hyphomycetes (Kew): 175 (1976)

On leaf and branch litter of H. brasilienesis: Thailand (Seephueak et al. 2010, 2011)

Paratrichoconis chinensis (Hansf.) Deighton \& Piroz., Mycol. Pap. 128: 32 (1972)

On branch litter of $H$. brasilienesis: Thailand (Seephueak et al. 2011)

Passalora berkheyae (Syd. \& P. Syd.) U. Braun \& Crous, in Crous \& Braun, CBS Diversity Ser. (Utrecht) 1: 441 (2003)

On leaf litter of H. brasiliensis: Thailand as Fulvia berkheyae (Seephueak et al. 2010)

Passalora marmorata (Tranzschel) U. Braun \& Crous, in Crous \& Braun, CBS Diversity Ser. (Utrecht) 1: 267 (2003)

On branch litter of $H$. brasiliensis: Thailand as Phaeoramularia marmorata (Seephueak et al. 2011)

Passalora oldenlandiae (Hansf.) U. Braun \& Crous, in Crous \& Braun, CBS Diversity Ser. (Utrecht) 1: 297 (2003)

On branch litter of H. brasiliensis: Thailand as Phaeoramularia oldenlandiae (Seephueak et al. 2011)

Passalora pithecellobii (J.L. Mulder) U. Braun \& Crous, in Crous \& Braun, CBS Diversity Ser. (Utrecht) 1: 465 (2003)

On leaf and branch litter of $H$. brasiliensis: Thailand as Stenella pithecellobii (Seephueak et al. 2010)

Passalora solani-torvi (Gonz. Frag. \& Cif.) U. Braun \& Crous, in Crous \& Braun, CBS Diversity Ser. (Utrecht) 1: 380 (2003)

On branch litter of H. brasiliensis: Thailand as Mycovellosiella solani-torvi (Seephueak et al. 2011)

Passalora vaginae (W. Krüger) U. Braun \& Crous, in Crous \& Braun, CBS Diversity Ser. (Utrecht) 1: 417 (2003)

On leaf litter of $H$. brasiliensis: Thailand as Cercospora vaginae (Seephueak et al. 2010)

Penicillifer pulcher Emden, Acta Bot. Neerl. 17: 54 (1968)

On leaf litter of $H$. brasiliensis: Thailand (Seephueak et al. 2010)

Penicillium brevicompactum Dierckx, Ann. Soc. Sci. Bruxelles 25: 88 (1901)

Endophytic on living leaves and sapwood of H. brasiliensis: Peru (Gazis \& Chaverri 2010)

Penicillium chrysogenum Thom, Bull. U.S. Department of Agriculture, Bureau Animal Industry 118: 58 (1910)

Associated with leaf spot of $H$. brasilienesis: India (Ariharan et al. 2016) 
Penicillium dodgei Pitt, The Genus Penicillium and its teleomorph states Eupenicillium and Talaromyces (London): 117 (1980) [1979]

On branch litter of $H$. brasiliensis: Thailand as Eupenicillium brefeldianum (Seephueak et al. 2011)

Penicillium javanicum J.F.H. Beyma, Verh. K. Akad. Wet., tweede sect. 26(4): 17 (1929)

On branch litter of $H$. brasiliensis: Thailand as Eupenicillium javanicum (Seephueak et al. 2011)

Penicillium paxilli Bainier, Bull. Soc. Mycol. Fr. 23(2): 95 (1907)

Endophytic on living leaves and sapwood of H. brasiliensis: Peru (Gazis \& Chaverri 2010)

Penicillium sclerotiorum J.F.H. Beyma, Centbl. Bakt. ParasitKde, Abt. II 96(20-23): 416 (1937)

Endophytic on living leaves and sapwood of H. brasiliensis: Peru (Gazis \& Chaverri 2010)

\section{Penicillium spp.}

Associated with rubber tree seeds harvested of H. brasiliensis: Brazil (Theodoro \& Batista 2014)

Penzigomyces flagellatus (S. Hughes) Subram. [as 'flagellata'], Proc. Indian natn Sci. Acad., Part B. Biol. Sci. 58(4): 186 (1992)

On leaf litter of $H$. brasiliensis: Thailand as Sporidesmium flagellatum (Seephueak et al. 2010)

Penzigomyces nodipes (Penz. \& Sacc.) Subram., Proc. Indian natn Sci. Acad., Part B. Biol. Sci. 58(4): 186 (1992)

On leaf and branch litter of $H$. brasiliensis: Thailand as Sporidesmium nodipes (Seephueak et al. 2010, 2011)

Penzigomyces parvus (S. Hughes) Subram., Proc. Indian natn Sci. Acad., Part B. Biol. Sci. 58(4): 187 (1992)

On branch litter of $H$. brasiliensis: Thailand as Sporidesmium parvum (Seephueak et al. 2010)

Periconia byssoides Pers., Syn. meth. fung. (Göttingen) 2: 686 (1801)

= Periconia pycnospora Fresen., Beitr. Mykol. 1: 20 (1850)

On tips dead, seedling leaves of H. brasiliensis: Ghana, Haiti, Malaysia, Thailand (Hughes 1953, Benjamin \& Slot 1969, Liu 1977, Seephueak et al. 2011)

Periconia cambrensis E.W. Mason \& M.B. Ellis, Mycol. Pap. 56: 108 (1953)

On branch litter of $H$. brasiliensis: Thailand (Seephueak et al. 2011)

Periconia lateralis Ellis \& Everh., J. Mycol. 2(9): 104 (1886)

On branch litter of $H$. brasiliensis: Thailand (Seephueak et al. 2011)

Periconia jabalpurensis D.P. Tiwari \& P.D. Agrawal, Curr. Sci. 41(12): 463 (1972)

On branch litter of $H$. brasiliensis: Thailand (Seephueak et al. 2011)

Periconia heveae J.A. Stev. \& Imle, Mycologia 37(5): 580 (1945)

Associated with blight diseases on leaf, petiole and twigs of $H$. brasiliensis: Brazil, China,

Costa Rica, Mexico (Spaulding 1961, McGuire \& Crandall 1967, Zhuang 2001)

Associated with leaf spot of $H$. brasiliensis: Thailand (this study)

Periconia manihoticola (Vincens) Viégas, Bragantia 14(7): 63 (1955) 
Associated with leaf spot and blight on seedling of $H$. brasiliensis: Brazil, Malawi, Myanmar, India (Peregrine \& Siddiqi 1972, Mehrotra1988, Mendes et al 1998, Thaung 2008)

\section{Periconia sp.}

On H. brasiliensis: Mexico (Alvarez 1976)

Periconia tirupatiensis Subram., J. Indian Bot. Soc. 34: 356 (1955)

On branch litter of $H$. brasiliensis: Thailand (Seephueak et al. 2011)

Periconiella cyatheae M.B. Ellis, Mycol. Pap. 111: 19 (1967)

On branch litter of $H$. brasiliensis: Thailand (Seephueak et al. 2011)

Periconiella heveae M.B. Ellis, Mycol. Pap. 111: 34 (1967)

On leaves of H. brasiliensis: Malaysia (Ellis 1967)

\section{Periconiella sp.}

On H. brasiliensis: Malaysia (Williams \& Liu 1976)

Perisporiopsis lateritia P. Chaverri \& Gazis, Mycotaxon 113: 164 (2010)

On underside of decaying leaves of H. brasiliensis: Peru (Chaverri \& Gazis 2011)

Perisporiopsis melioloides (Berk. \& M.A. Curtis) Arx, in Müller \& von Arx, Beitr. Kryptfl. Schweiz 11(no. 2): 171 (1962)

Endophytic on living leaves and sapwoos of H. brasiliensis: Peru (Gazis \& Chaverri 2010)

Peroneutypa heteracanthoides Sacc., Bulletino dell'orto Botanico della R. Universitá di Napoli 6: 47 (1918)

On H. brasiliensis: Malaysia (Singh 1980)

Peroneutypa longiasca Senwanna, Phookamsak \& K.D. Hyde, in Senwanna et al., Mycosphere 8(10): 1848 (2017)

On dead twig of $H$. brasilienesis: Thailand (Senwanna et al. 2017)

Pestalosphaeria hansenii Shoemaker \& J.A. Simpson, Can. J. Bot. 59(6): 986 (1981)

On branch litter of $H$. brasiliensis: Thailand (Seephueak et al. 2011)

\section{Pestalotia sp.}

On leaves of H. brasiliensis: Brazil, Fiji, Ghana, Mexico, Thailand (Dade 1940, Firman 1972, Alvarez 1976, Mendes et al. 1998, Seephueak et al. 2010)

Pestalotiopsis adusta (Ellis \& Everh.) Steyaert, Trans. Br. Mycol. Soc. 36(2): 82 (1953)

On H. brasiliensis: Malaysia (Williams \& Liu 1976)

Pestalotiopsis disseminata (Thüm.) Steyaert, Bull. Jard. Bot. État Brux. 19: 319 (1949)

On leaf litter of $H$. brasiliensis: Thailand (Seephueak et al. 2010)

Pestalotiopsis guepinii (Desm.) Steyaert [as 'guepini'], Bull. Jard. Bot. État Brux. 19(3): 312 (1949)

On H. brasiliensis: Fiji, Thailand (Dingley et al. 1981, Seephueak et al. 2010)

Pestalotiopsis microspora (Speg.) G.C. Zhao \& Nan Li, Journal of Northeast Forestry University 23(4): 23 (1995)

Associated with leaf blight disease of H. brasiliensis: Cameroon (Nyaka Ngobisa et al. 2018) 
Pestalotiopsis palmarum (Cooke) Steyaert, Bull. Jard. bot. État Brux. 19(3): 322 (1949)

On H. brasiliensis: China, Malay Peninsula, Peru as endophytic on living leaf and sapwood (Thompson \& Johnston 1953, Zhuang 2001, Gasiz and Chervarri 2010, Selmaoui et al. 2014)

\section{Pestalotiopsis sp.}

On leaves of $H$. brasiliensis: Myanmar, Thailand (Thaung 2008, Seephueak et al. 2010)

Pestalotiopsis versicolor (Speg.) Steyaert, Bull. Jard. bot. État Brux. 19(3): 336 (1949)

On H. brasiliensis: Malaysia (Singh 1980)

\section{Peyronellaea sp.}

On leaf litter of H. brasiliensis: Thailand (Seephueak et al. 2010)

Piricauda pseudarthriae (Hansf.) M.B. Ellis, More Dematiaceous Hyphomycetes (Kew): 40 (1976)

On branch litter of $H$. brasiliensis: Thailand (Seephueak et al. 2011)

Pithomyces graminicola R.Y. Roy \& B. Rai, Trans. Br. Bycol. Soc. 51(1): 154 (1968)

On branch litter of $H$. brasiliensis: Thailand (Seephueak et al. 2011)

Phaeodactylium alpiniae (Sawada) M.B. Ellis, Dematiaceous Hyphomycetes (Kew): 215 (1971)

On branch litter of $H$. brasiliensis: Thailand (Seephueak et al. 2011)

Phaeodothis winteri (Niessl) Aptroot, Nova Hedwigia 60(3-4): 358 (1995)

On H. brasiliensis: Liberia, Malaysia (Aptroot 1995)

Phaeoisaria sparsa B. Sutton, Mycol. Pap. 132: 87 (1973)

On leaf litter of H. brasiliensis: Thailand (Seephueak et al. 2010)

Phaeoisariopsis cercosporoides (M.L. Farr) M.B. Ellis [as 'cercosporioides'], More Dematiaceous Hyphomycetes (Kew): 236 (1976)

On leaf and branch litter of H. brasiliensis: Thailand (Seephueak et al. 2010, 2011)

\section{Phaeoisariopsis sp.}

On leaf litter of H. brasiliensis: Thailand (Seephueak et al. 2010)

\section{Phaeosphaeria sp.}

On leaf and branch litter of H. brasiliensis: Thailand (Seephueak et al. 2010, 2011)

Phaeostilbella nigra (Sacc.) Seifert, CBS Biodiversity Series 12: 307 (2013)

On branch litter of H. brasiliensis: Thailand as Saccardaea atra (Seephueak et al. 2010, 2011)

Phoma pezizoides (Ellis \& Everh.) Boerema \& Kesteren, Persoonia 11(3): 322 (1981)

On leaf litter of $H$. brasiliensis: Thailand as Aposphaeria pezizoides (Seephueak et al. 2010)

\section{Phoma sp.}

On H. brasiliensis: Brazil, Papua New Guinea, Thailand (Mendes et al. 1998, Shaw 1984, Seephueak et al. 2010)

Phomatospora heveae Saccas, J. Agric. Trop. Bot. Appl. 1: 465 (1954)

On dead branches of $H$. brasiliensis: French Equatorial Africa (Anonymous 1963) 
Phomopsis heveae (Petch) Boedijn, Rec. Trav. Bot. Néerl. 26: 423 (1929)

Associated with dieback of young tissue of seedlings of $H$. brasiliensis: Brazil, China, India, Indonesia, Malay Peninsula, Malaysia, Mauritius, Myanmar, Sri Lanka, Thailand on branches of $H$. brasiliensis: Sri Lanka as Phoma heveae (Saccardo 1913, Spaulding 1961, Thaung 2008, Udayanga et al. 2011)

Phomopsis heveicola Li Ma, M.M. Xiang \& P.K. Chi, in Ma, Xiang, Chi \& Jiang, Mycosystema 23(4): 458 (2004)

On branches of H. brasiliensis: China (Ma et al. 2004, Chi et al. 2007)

Phomopsis ramicola (Petch) Aa, in van der Aa \& Vanev, A Revision of the Species Described in Phyllosticta (Utrecht): 392 (2002)

= Phyllosticta ramicola Petch, Ann. R. bot. Gdns Peradeniya 3(1): 5 (1906)

On living stems of $H$. brasiliensis: Sri Lanka, Malay Peninsula, Malaysia (Petch 1906, Thompson \& Johnston 1953, Turner 1971)

\section{Phomopsis sp.}

Associated with dieback and leaf diseases of $H$. brasiliensis: Brazil, Florida, Mexico, Thailand on leaf litter (Alvarez 1976, Alfieri et al. 1984, Mendes et al. 1998, Seephueak et al. 2010, Sittisart et al. 2017)

Phragmocephala elliptica (Berk. \& Broome) S. Hughes, N.Z. Jl Bot. 17(2): 164 (1979)

On leaf and branch litter of $H$. brasiliensis: Thailand as Endophragmia elliptica (Seephueak et al. 2010)

Phyllachora huberi Henn. 1900

= Catacauma huberi (Henn.) Theiss. \& Syd., Ann. Mycol. 13(3/4): 390 (1915)

Associated with tar spot disease of H. brasiliensis, Brazil, Costa Rica, Peru (Spaulding 1961)

Phyllosticta heveae Henn., Notizbl. Königl. bot. Gart. Museum Berlin 4(no. 34): 137 (1904)

Associated with of leaf spot on leaves of $\mathrm{H}$. brasiliensis: Brazil, China, Democratic Republic of the Congo, Cote d'Ivoire, Dominican Republic, Ethiopia, Fiji, Haiti, India, Indonesia, Malaysia, Philippines, Sri Lanka, Taiwan, Thailand, The Republic of Trinidad and Tobago, Uganda (Sawada 1943, Castellani \& Ciferri 1950, Resplandy et al. 1954, Ciferri 1961, Spaulding 1961, Dennis 1970, Firman 1972, Tai 1979, Giatgong 1980)

Phyllosticta heveana Saccas, Agronomía trop. 8: 259 (1953)

On H. brasiliensis: Central African Republic, Malaysia (Nag Raj 1993, Williams \& Liu 1976, Anonymous 1963)

\section{Phyllosticta sp.}

Associated with leaf spot on nursery plant of $H$. brasiliensis: Brazil, Cambodia, Malay Peninsula, Mexico, Papua New Guinea, Thailand on leaf litter (Thompson \& Johnston 1953, Litzenberger et al. 1962, McGuire \& Crandall 1967, Alvarez 1976, Shaw 1984, Mendes et al. 1998, Seephueak et al. 2010)

\section{Phyllostictina sp.}

On H. brasiliensis: Philippine (Weir 1926)

Physalospora heveae Saccas, Agronomía Trop. 8: 264 (1953)

On H. brasiliensis: French Equatorial Africa (Anonymous 1963) 
Pithomyces graminicola R.Y. Roy \& B. Rai, Trans. Br. Mycol. Soc. 51(1): 154 (1968)

On leaf litter of $H$. brasiliensis: Thailand (Seephueak et al. 2010)

Placophomopsis heveae Grove, Taxonomie und medizinische Bedeutung der zur Gattung Geotrichum Link gehorenden Arten (Med. Habil.-Schrift, Magdeburg) 59: 315 (1921)

On wood of $H$. brasiliensis: Uganda (Petrak 1921)

Plectosphaerella cucumerina (Lindf.) W. Gams, in Domsch \& Gams, Fungi in Agricultural Soils: 160 (1972)

On branch litter of $H$. brasiliensis: Thailand (Seephueak et al. 2011)

Pleonectria heveana Sacc., Bulletino dell'orto Botanico della R. Universitá di Napoli 24: 13 [repr.] (1918)

In decaying bark of the trunk of H. brasiliensis: Singapore, Malaysia (Saccardo 1928, Petrak 1930, Singh 1980)

Pleosphaerulina heveae Saccas, Agronomía Trop. 8: 267 (1953)

On H. brasiliensis: French Equatorial Africa (Anonymous 1963)

Pleopunctum heveae Senwanna, Cheewangkoon \& K.D. Hyde

On dried twig of $H$. brasiliensis: Thailand (this study)

\section{Pleospora sp.}

On branch litter of $H$. brasiliensis: Thailand (Seephueak et al. 2011)

Pleurophragmium acutum (Grove) M.B. Ellis, More Dematiaceous Hyphomycetes (Kew): 164 (1976)

On leaf litter of $H$. brasiliensis: Thailand (Seephueak et al. 2010)

Pleurophragmium capense (Thüm.) S. Hughes, Can. J. Bot. 36: 796 (1958)

On leaf litter of $H$. brasiliensis: Thailand as Spiropes capensis (Seephueak et al. 2010)

Pleurotheciopsis pusilla B. Sutton, Trans. Br. Mycol. Soc. 61(3): 418 (1973)

On leaf and branch litter of $H$. brasiliensis: Thailand (Seephueak et al. 2010, 2011)

Podocrea pezizoidea (Möller) Sacc. \& D. Sacc., Syll. Fung. (Abellini) 17: 799 (1905)

On branch litter of H. brasiliensis: Thailand as Hypocrea pezizoidea (Seephueak et al. 2011)

\section{Polyschema sp.}

On leaf litter of $H$. brasiliensis: Thailand (Seephueak et al. 2010)

\section{Polymorphum sp.}

On branch litter of $H$. brasiliensis: Thailand (Seephueak et al. 2011)

Protostegia heveae Charles, in Weir, U.S.D.A. Dept. Bull. 1380: 92 (1926)

In dead branches of H. brasiliensis: Amazonas (Weir 1926)

Pseudobeltrania penzigii Piroz., Mycol. Pap. 129: 53 (1972)

On leaf litter of $H$. brasiliensis: Thailand (Seephueak et al. 2010)

Pseudocercospora opuli (Höhn.) U. Braun \& Crous, in Crous \& Braun, CBS Diversity Ser. (Utrecht) 1: 299 (2003)

On leaf litter of $H$. brasiliensis: Thailand as Cercospora apuli (Seephueak et al. 2010) 
Pseudocercospora heveae (Vincens) Deighton 1976

= Cercospora heveae Vincens, Bull. Soc. Path. vég. Fr. 2: 25 (1915)

Associated with leaf spot of $H$. brasiliensis: Brazil, Brunei Darussalam, China, Costa Rica, Panama, Thailand (Chupp 1954, McGuire \& Crandall 1967, Giatgong 1980, Peregrine \& Ahmad1982, Mendes et al. 1998, Jayasinghe 1999a, Zhuang 2001, Piepenbring 2006)

Pseudocercospora pterocauli (Petr.) Deighton, in Ellis, More Dematiaceous Hyphomycetes (Kew): 177 (1976)

On branch litter of $H$. brasiliensis: Thailand (Seephueak et al. 2010)

Pseudocercospora ulei (Henn.) B.T. Hora \& Mizubuti, in Hora Júnior et al., PLOS ONE 9(8): e104750, 6 (2013)

= Dothidella ulei Henn., Hedwigia 43(4): 254 (1904)

$=$ Fusicladium heveae K. Schub. \& U. Braun, in Crous \& Braun, CBS Diversity Ser. (Utrecht) 1: 481 (2003)

Associated with leaf bright (South American leaf blight: SALB) of $H$. brasiliensis: Bolivia, Brazil, China, Cameroon, Central America, Colombia, Costa Rica, Ecuador, Florida, French Guiana, Guatemala, Guyana, Honduras, Malaysia, Mexico, Nicaragua, Panama, Papua New Guinea, Peru, Sri Lanka, Suriname, The Republic of Trinidad and Tobago, Venezuela, West Africa (Spaulding 1961, Williams \& Liu 1976, Alfieri et al. 1984, Shaw 1984, Mendes et al. 1998, Jayasinghe 1999a, Zhuang 2001, Hora Júnior et al. 2014, Guyot \& Le Guen 2018)

\section{Pseudodiplodia sp.}

On branch litter of $H$. brasiliensis: Thailand (Seephueak et al. 2010)

Pseudofusicoccum adansoniae Pavlic, T.I. Burgess \& M.J. Wingf., Mycologia 100(6): 855 (2008)

Endophytic on $H$. brasiliensis and associated with canker diseases of $H$. brasiliensis: Thailand (Trakunyingcharoen et al. 2015a, Senwanna et al. 2020)

Pseudofusicoccum ardesiacum Pavlic, T.I. Burgess \& M.J. Wingf., Mycologia 100(6): 858 (2008) Endophytic on $H$. brasiliensis and associated with canker diseases of $H$. brasiliensis: Thailand (Trakunyingcharoen et al. 2015a, Senwanna et al. 2020)

\section{Pseudogliomastix sp.}

On leaf litter of $H$. brasiliensis: Thailand (Seephueak et al. 2010)

Pseudogymnoascus pannorum (Link) Minnis \& D.L. Lindner, Fungal Biol. 117(9): 646 (2013)

On leaf litter of $H$. brasiliensis: Thailand as Chrysosporium pannorum (Seephueak et al. 2010)

Pseudopithomyces palmicola Jun F. Li, Ariyaw. \& K.D. Hyde, in Ariyawansa et al., Fungal Divers. 75: 27-274 (2015)

On dried leaf of $H$. brasiliensis: Thailand (this study)

Pseudorobillarda phragmitis (Cunnell) M. Morelet, Bull. Soc. Sci. nat. Arch. Toulon et du Var 175: 6 (1968)

On leaf litter of H. brasiliensis: Thailand as Robillarda phragmitis (Seephueak et al. 2010)

\section{Pseudorobillarda sp.}

On leaf litter of $H$. brasiliensis: Thailand (Seephueak et al. 2010)

Pseudospiropes obclavatus M.B. Ellis, More Dematiaceous Hyphomycetes (Kew): 219 (1976)

On leaf and branch litter of H. brasiliensis: Thailand (Seephueak et al. 2010, 2011) 
Pteroconium intermedium M.B. Ellis, More Dematiaceous Hyphomycetes (Kew): 479 (1976)

On leaf litter of H. brasiliensis: Thailand (Seephueak et al. 2010)

\section{Pucciniopsis sp.}

On leaf litter of H. brasiliensis: Thailand (Seephueak et al. 2010)

Pyricularia parasitica Ellis \& Everh., Proc. Acad. Nat. Sci. Philad. 45: 462 (1894) [1893]

On leaf litter of H. brasiliensis: Thailand as Elletevera parasitica (Seephueak et al. 2010)

Pyriculariopsis parasitica (Sacc. \& Berl.) M.B. Ellis, Dematiaceous Hyphomycetes (Kew): 207 (1971)

On branch litter of $H$. brasiliensis: Thailand (Seephueak et al. 2011)

\section{Pyriculariopsis sp.}

On branch litter of $H$. brasiliensis: Thailand (Seephueak et al. 2011)

Quadrisporella heveae Senwanna, Cheewangkoon \& K.D. Hyde

On dried twig of $H$. brasiliensis: Thailand (this study)

Ramichloridium apiculatum (J.H. Mill., Giddens \& A.A. Foster) de Hoog, Stud. Mycol. 15: 69 (1977)

On branch litter of $H$. brasiliensis: Thailand as Veronaea apiculata (Seephueak et al. 2011)

Ramularia aromatica (Sacc.) Höhn., Öst. bot. Z. 55(1): 23 (1905) 2010)

On leaf litter of $H$. brasiliensis: Thailand as Septocylindrium aromaticum (Seephueak et al.

Ramularia grevilleana (Tul. \& C. Tul. ex Oudem.) Jørst., Meld. Stat. Plantepat. Inst. Oslo 50: 17 (1945)

On leaf litter of H. brasiliensis: Thailand as Ramularia tulasnei (Seephueak et al. 2010)

Repetophragma aburiense (M.B. Ellis) Subram., Proc. Indian natn Sci. Acad., Part B. Biol. Sci. 58(4): 185 (1992)

On branch litter of $H$. brasiliensis: Thailand as Sporidesmium cambrense (Seephueak et al. 2011)

Repetophragma cambrense (M.B. Ellis) McKenzie, Mycotaxon 56: 22 (1995)

On leaf litter of $H$. brasiliensis: Thailand as Sporidesmium aburiense (Seephueak et al. 2010)

Repetophragma ellisii (Piroz.) R.F. Castañeda, McKenzie \& K.D. Hyde, in Castañeda-Ruíz et al., Mycosphere 2(3): 276 (2011)

On branch litter of H. brasiliensis: Thailand as Sporidesmium ellisii (Seephueak et al. 2011)

Repetophragma subulatum (Cooke \& Ellis) Subram. [as 'subulata'], Proc. Indian natn Sci. Acad., Part B. Biol. Sci. 58(4): 185 (1992)

On branch litter of $H$. brasiliensis: Thailand as Sporidesmium subulatum (Seephueak et al. 2011)

\section{Rhabdospora sp.}

On H. brasiliensis: Malaysia (Williams \& Liu 1976)

Rhexoacrodictys fuliginosa (B. Sutton) W.A. Baker \& Morgan-Jones, in Baker et al., Mycotaxon 82: 106 (2002) 
On branch litter of $H$. brasiliensis: Thailand as Acrodictys fuliginosa (Seephueak et al. 2011)

\section{Rhexoampullifera sp.}

On leaf litter of H. brasiliensis: Thailand (Seephueak et al. 2010)

\section{Rhinocladiella sp.}

On leaf and branch litter of H. brasiliensis: Thailand (Seephueak et al. 2010, 2011)

Rhombostilbella rosae Zimm., Centbl. Bakt. ParasitKde, Abt. I 8: 221 (1902)

On leaf litter of $H$. brasiliensis: Thailand (Seephueak et al. 2010)

Rhytidhysteron rufulum (Spreng.) Speg., Anal. Soc. Cient. Argent. 90(3-6): 177 (1921) [1920]

On H. brasiliensis: Ghana as Tryblidiella rufula (Hughes 1952)

Rhytidhysteron neorufulum Thambug. \& K.D. Hyde, in Thambugala et al., Cryptog. Mycol. 37(1): 110 (2016)

On branch of $H$. brasiliensis: Thailand (Huanraleuk et al. 2020, this study)

Rhytidhysteron tectonae Doilom \& K.D. Hyde, in Doilom et al., Fungal Divers. 82: 107-182 (2016)

On branch of $H$. brasiliensis: Thailand (this study)

Rosellinia africana Saccas, Agronomía Trop. 8: 269 (1953)

On H. brasiliensis: Central African Republic, French Equatorial Africa (Anonymous 1963, Petrini 2013)

Rosellinia bunodes (Berk. \& Broome) Sacc., Syll. Fung. (Abellini) 1: 254 (1882)

Associated with black root and crown rot of $H$. brasiliensis: Brazil, Indonesia, Mexico, Sri Lanka (Spaulding 1961, Alvarez 1976)

Rosenscheldiella heveae Junqueira \& J.L. Bezerra, Fitopatol. Brasil. 15(1): 26 (1990)

On leaves of H. brasiliensis: Amazonas (Junqueira \& Bezerra 1990)

Sarocladium strictum (W. Gams) Summerb., in Summerbell, Gueidan, Schroers, Hoog, Starink, Arocha Rosete, Guarro \& Scott 2011

On leaf and branch litter of H. brasiliensis: Thailand as Acremonium strictum (Seephueak et al. 2010, 2011)

Schizotrichum lobeliae McAlpine, Proc. Linn. Soc. N.S.W. 28(3): 562 (1903)

On branch litter of $H$. brasiliensis: Thailand (Seephueak et al. 2011)

Scolicotrichum heveae Vincens, Bull. Soc. Path. vég. Fr. 2: 17 (1915)

Associated with leaf spot of $H$. brasiliensis: Brazil (Spaulding 1961)

Scolecobasidiella avellanea (Sappa \& Mosca) M.B. Ellis, Mycol. Pap. 125: 10 (1971)

On leaf and branch litter of H. brasiliensis: Thailand (Seephueak et al. 2010, 2011)

\section{Scolecobasidiella sp.}

On branch litter of $H$. brasiliensis: Thailand (Seephueak et al. 2011)

Scolecobasidium anellii Graniti, G. bot. ital., n.s. 69(4-6): 364 (1963) [1962]

On branch litter of $H$. brasiliensis: Thailand (Seephueak et al. 2011) 
Scolecobasidium compactum M.B. Ellis, More Dematiaceous Hyphomycetes (Kew): 190 (1976)

On leaf litter of $H$. brasiliensis: Thailand (Seephueak et al. 2010)

Scolecobasidium dendroides Piroz. \& Hodges, Can. J. Bot. 51(1): 162 (1973)

On leaf and branch litter of $H$. brasiliensis: Thailand (Seephueak et al. 2010, 2011)

Scolecobasidium sp.

On leaf litter of H. brasiliensis: Thailand (Seephueak et al. 2010)

Scolecostigmina combreti (J. Kranz) U. Braun, Schlechtendalia 3: 35 (1999)

On leaf litter of H. brasiliensis: Thailand as Stigmina combreti (Seephueak et al. 2010)

Scolecostigmina combreticola (M.B. Ellis) U. Braun, Schlechtendalia 3: 37 (1999)

On leaf and branch litter of $H$. brasiliensis: Thailand as Stigmina combreticola (Seephueak et al. 2010, 2011)

Scolecostigmina crotonicola (M.B. Ellis) U. Braun, Schlechtendalia 3: 37 (1999)

On branch litter of $H$. brasiliensis: Thailand as Stigmina crotonicola (Seephueak et al. 2011)

Scolecostigmina kranzii (M.B. Ellis) U. Braun, Schlechtendalia 3: 37 (1999)

On leaf and branch litter of $H$. brasiliensis: Thailand as Stigmina kranzii (Seephueak et al. 2010, 2011)

Scolecostigmina mangiferae (Koord.) U. Braun \& Mouch., in Braun et al., N.Z. J1 Bot. 37(2): 323 (1999)

On branch litter of $H$. brasiliensis: Thailand as Stigmina mangiferae (Seephueak et al. 2011)

Scolecostigmina phaeocarpa (Mitter) U. Braun, Schlechtendalia 3: 39 (1999)

On branch litter of H. brasiliensis: Thailand as Stigmina phaeocarpa (Seephueak et al. 2011)

Scytalidium lignicola Pesante [as 'lignicolum'], Annali Sper. agr., N.S. 11(2, Suppl.): cclxv (1957)

On branch litter of H. brasiliensis: Thailand (Seephueak et al. 2011)

Selenodriella fertilis (Piroz. \& Hodges) R.F. Castañeda \& W.B. Kendr., Univ. Waterloo Biol. Ser. 33: 34 (1990)

On leaf and branch litter of $H$. brasiliensis: Thailand as Circinotrichum fertile (Seephueak et al. 2010, 2011)

\section{Selenosporella sp.}

On leaf litter of H. brasiliensis: Thailand (Seephueak et al. 2010)

Septonema fasciculare (Corda) S. Hughes, Can. J. Bot. 36: 803 (1958)

On branch litter of $H$. brasiliensis: Thailand (Seephueak et al. 2011)

\section{Septoria sp.}

On H. brasiliensis: Fiji (Dingley et al. 1981)

\section{Setodochium sp.}

On H. brasiliensis: Papua New Guinea (Shaw 1984)

\section{Seynesiella sp.}

On leaf litter of H. brasiliensis: Thailand (Seephueak et al. 2010) 
Sirosporium antenniforme (Berk. \& M.A. Curtis) Bubák \& Serebrian. [as 'antennaeforme'], Hedwigia 52: 273 (1912)

On leaf litter of H. brasiliensis: Thailand (Seephueak et al. 2010)

Sirosporium stylidii M.B. Ellis, Mycol. Pap. 111: 44 (1967)

On branch litter of $H$. brasiliensis: Thailand (Seephueak et al. 2011)

Spadicoides bina (Corda) S. Hughes [as 'binum'], Can. J. Bot. 36: 806 (1958)

On branch litter of $H$. brasiliensis: Thailand (Seephueak et al. 2011)

Spadicoides obovata (Cooke \& Ellis) S. Hughes, Can. J. Bot. 36: 806 (1958)

On branch litter of $H$. brasiliensis: Thailand (Seephueak et al. 2011)

Spegazzinia deightonii (S. Hughes) Subram., J. Indian Bot. Soc. 35: 78 (1956)

On leaf litter of H. brasiliensis: Thailand (Seephueak et al. 2010)

Spegazzinia parkeri Sivasith., Trans. Br. Mycol. Soc. 62(2): 427 (1974)

On branch litter of $H$. brasiliensis: Thailand (Seephueak et al. 2011)

Spegazzinia sundara Subram., J. Indian Bot. Soc. 35: 78 (1956)

On leaf litter of $H$. brasiliensis: Thailand (Seephueak et al. 2010)

\section{Spegazzinia sp.}

On branch litter of $H$. brasiliensis: Thailand (Seephueak et al. 2011)

Speiropsis hyalospora Subram. \& Lodha, Can. J. Bot. 42: 1062 (1964)

On leaf litter of $H$. brasiliensis: Thailand (Seephueak et al. 2010)

Speiropsis pedatospora Tubaki, J. Hattori bot. Lab. 20: 171 (1958)

On leaf litter of $H$. brasiliensis: Thailand (Seephueak et al. 2010)

Spermospora avenae (R. Sprague \& Aar.G. Johnson) R. Sprague, Diseases of Cereals and Grasses of North America: 430 (1950)

On leaf litter of $H$. brasiliensis: Thailand (Seephueak et al. 2010)

Spermospora subulata (R. Sprague) R. Sprague, Mycologia 40(2): 178 (1948)

On leaf litter of H. brasiliensis: Thailand (Seephueak et al. 2010)

Sphaerella heveae Petch, Ann. R. bot. Gdns Peradeniya 6(3): 223 (1917)

On leaves of H. brasiliensis: Sri Lanka, Andaman Islands, Malay Peninsula (Saccardo 1928,

Thompson \& Johnston 1953, Hosagoudar \& Mathew 2000)

Sphaeronaema album Petch, Ann. R. bot. Gdns Peradeniya 3(1): 5 (1906)

On decaying fruit of H. brasiliensis: Sri Lanka, Fiji (Petch 1906, Firman 1972)

Sphaeropsis eucalypticola A.J.L. Phillips, in Phillips, Alves, Abdollahzadeh, Slippers, Wingfield, Groenewald \& Crous, Stud. Mycol. 76: 158 (2013)

On twig of $H$. brasiliensis: Thailand (this study)

Sphaeropsis heveae Gonz. Frag. \& Cif., Boln Real Soc. Españ. Hist. Nat., Biologica 28: 139 (1928)

On leaves of H. brasiliensis: Dominican Republic (Petrak 1930, Saccardo 1972)

\section{Sphaerulina sp.}


On H. brasiliensis: Brunei Darussalam (Peregrine \& Ahmad1982)

Spiropes effusus (Pat.) M.B. Ellis, Mycol. Pap. 114: 10 (1968)

On leaf litter of H. brasiliensis: Thailand (Seephueak et al. 2010)

Spiropes fumosus (Ellis \& G. Martin) M.B. Ellis, Mycol. Pap. 114: 20 (1968)

On leaf litter of H. brasiliensis: Thailand (Seephueak et al. 2010)

Spiropes japonicus (Henn.) M.B. Ellis, Mycol. Pap. 114: 22 (1968)

On leaf litter of $H$. brasiliensis: Thailand (Seephueak et al. 2010)

Spiropes penicillium (Speg.) M.B. Ellis, Mycol. Pap. 114: 23 (1968)

On leaf litter of $H$. brasiliensis: Thailand (Seephueak et al. 2010)

\section{Spiropes sp.}

On leaf litter of H. brasiliensis: Thailand (Seephueak et al. 2010)

Spondylocladiella botrytioides Linder, Mycologia 26(5): 437 (1934)

On leaf and branch litter of H. brasiliensis: Thailand (Seephueak et al. 2010, 2011)

\section{Spondylocladiella sp.}

On leaf litter of $H$. brasiliensis: Thailand (Seephueak et al. 2010)

Sporendocladia bactrospora (W.B. Kendr.) M.J. Wingf., in Wingfield et al., Trans. Br. Mycol. Soc. 89(4): 515 (1987) 2011)

On branch litter of $H$. brasiliensis: Thailand as Phialocephala bactrospora (Seephueak et al.

Sporidesmiella hyalosperma (Corda) P.M. Kirk, Trans. Br. Mycol. Soc. 79(3): 481 (1982)

On branch litter of $H$. brasiliensis: Thailand as Endophragmia hyalosperma (Seephueak et al. 2011)

Sporidesmium australiense M.B. Ellis, More Dematiaceous Hyphomycetes (Kew): 94 (1976)

On branch litter of $H$. brasiliensis: Thailand (Seephueak et al. 2011)

Sporidesmium baccharidis (Syd.) M.B. Ellis, Mycol. Pap. 82: 46 (1961)

On leaf litter of $H$. brasiliensis: Thailand (Seephueak et al. 2010)

Sporidesmium coronatum Fuckel, Jb. nassau. Ver. Naturk. 27-28: 77 (1874) [1873-74]

On branch litter of H. brasiliensis: Thailand (Seephueak et al. 2011)

Sporidesmium ehrenbergii M.B. Ellis, Mycol. Pap. 70: 63 (1958)

On branch litter of $H$. brasiliensis: Thailand (Seephueak et al. 2011)

Sporidesmium faureae Piroz., Mycol. Pap. 129: 53 (1972)

On branch litter of H. brasiliensis: Thailand as Janetia faureae (Seephueak et al. 2011)

Sporidesmium ghanaense M.B. Ellis, Mycol. Pap. 70 : 50 (1958)

On branch litter of $H$. brasiliensis: Thailand (Seephueak et al. 2011)

Sporidesmium harknessii (Sacc.) M.B. Ellis, Mycol. Pap. 70: 24 (1958)

On leaf and branch litter of H. brasiliensis: Thailand (Seephueak et al. 2010, 2011) 
Sporidesmium hormiscioides Corda, Icon. Fung. (Prague) 2: 6 (1838)

On branch litter of $H$. brasiliensis: Thailand (Seephueak et al. 2011)

Sporidesmium jasminicola M.B. Ellis, Mycol. Pap. 70: 83 (1958)

On leaf and branch litter of $H$. brasiliensis: Thailand (Seephueak et al. 2010, 2011)

Sporidesmium longirostratum M.B. Ellis, Mycol. Pap. 70: 78 (1958)

On branch litter of $H$. brasiliensis: Thailand (Seephueak et al. 2011)

Sporidesmium murrayae (Henn.) Morgan-Jones \& W.B. Kendr., Can. J. Bot. 50(9): 1819 (1972)

On branch litter of H. brasiliensis: Thailand as Stigmina murrayae (Seephueak et al. 2011)

Sporidesmium njalaense M.B. Ellis, Mycol. Pap. 70 : 68 (1958)

On branch litter of $H$. brasiliensis: Thailand (Seephueak et al. 2011)

Sporidesmium penzigii M.B. Ellis, Mycol. Pap. 82: 45 (1961)

On branch litter of $H$. brasiliensis: Thailand (Seephueak et al. 2011)

Sporidesmium rubi M.B. Ellis, Mycol. Pap. 70: 64 (1958)

On leaf and branch litter of H. brasiliensis: Thailand (Seephueak et al. 2010, 2011)

Sporidesmium socium M.B. Ellis, Mycol. Pap. $70: 42$ (1958)

On leaf and branch litter of H. brasiliensis: Thailand (Seephueak et al. 2010, 2011)

Sporidesmium sp.

On leaf and branch litter of H. brasiliensis: Thailand (Seephueak et al. 2010, 2011)

Sporidesmium tenuisporum M.B. Ellis, Mycol. Pap. 70: 77 (1958)

On branch litter of $H$. brasiliensis: Thailand (Seephueak et al. 2011)

Sporidesmium tropicale M.B. Ellis, Mycol. Pap. $70: 58$ (1958)

Dried twig of $H$. brasiliensis: Thailand (this study)

Sporidesmium uvariicola M.B. Ellis, Mycol. Pap. $70: 35$ (1958)

On branch litter of $H$. brasiliensis: Thailand (Seephueak et al. 2011)

Sporoschisma uniseptatum Bhat \& W.B. Kendr., Mycotaxon 49: 71 (1993)

On branch litter of $H$. brasiliensis: Thailand (Seephueak et al. 2011)

Sporoschismopsis sp.

On leaf and branch litter of H. brasiliensis: Thailand (Seephueak et al. 2010, 2011)

Sporothrix schenckii Hektoen \& C.F. Perkins, J. Exp. Med. 5: 80 (1900)

On leaf litter of $H$. brasiliensis: Thailand (Seephueak et al. 2010)

Stachybotrys parvisporus S. Hughes [as 'parvispora'], Mycol. Pap. 48 : 74 (1952)

On branch litter of $H$. brasiliensis: Thailand (Seephueak et al. 2011)

Stachybotrys sansevieriae G.P. Agarwal \& N.D. Sharma [as 'sansevierii'], in Sharma \& Agarwal, J. Indian Bot. Soc. 53(1-2): 78 (1974)

On branch litter of $H$. brasiliensis: Thailand (Seephueak et al. 2011)

\section{Stachybotrys sp.}

On leaf litter of $H$. brasiliensis: Thailand (Seephueak et al. 2010) 
Stanjehughesia larvata (Cooke \& Ellis) Subram., Proc. Indian natn Sci. Acad., Part B. Biol. Sci. 58(4): 184 (1992) 2011)

On branch litter of $H$. brasiliensis: Thailand as Sporidesmium larvatum (Seephueak et al.

Staphylotrichum coccosporum J.A. Mey. \& Nicot, Bull. trimest. Soc. Mycol. Fr. 72(4): 323 (1957) [1956]

On branch litter of $H$. brasiliensis: Thailand (Seephueak et al. 2011)

\section{Staphylotrichum sp.}

On branch litter of $H$. brasiliensis: Thailand (Seephueak et al. 2011)

Stigmina celata (Welw. \& Curr.) M.B. Ellis, Mycol. Pap. 111: 41 (1967)

On branch litter of $H$. brasiliensis: Thailand (Seephueak et al. 2011)

Stigmina hartigiana (Sacc.) M.B. Ellis, Mycol. Pap. 72: 45 (1959)

On leaf and branch litter of H. brasiliensis: Thailand (Seephueak et al. 2010, 2011)

Stigmina obtecta (Petr. \& Esfand.) M.B. Ellis, Mycol. Pap. 111: 42 (1967)

On branch litter of $H$. brasiliensis: Thailand (Seephueak et al. 2011)

Stigmina rauvolfiae M.B. Ellis, More Dematiaceous Hyphomycetes (Kew): 118 (1976)

On branch litter of $H$. brasiliensis: Thailand (Seephueak et al. 2011)

\section{Stigmina sp.}

On branch litter of $H$. brasiliensis: Thailand (Seephueak et al. 2011)

Stigmina sudanensis M.B. Ellis, Mycol. Pap. $72: 47$ (1959)

On branch litter of $H$. brasiliensis: Thailand (Seephueak et al. 2011)

Stilbella heveae Zimm., in Hennings, Hedwigia 41: 148 (1902)

On H. brasiliensis: Indonesia (Hennings 1902)

\section{Stilbospora sp.}

On leaf litter of H. brasiliensis: Thailand (Seephueak et al. 2010)

Strumella coryneoidea Sacc. \& G. Winter, in Rabenhorst, Hedwigia 22: 175 (1883)

On leaf litter of H. brasiliensis: Thailand (Seephueak et al. 2010)

Subulispora britannica B. Sutton, Trans. Br. Mycol. Soc. 61(3): 422 (1973)

On branch litter of $H$. brasiliensis: Thailand (Seephueak et al. 2011)

Subulispora procurvata Tubaki, in Tubaki \& Yokoyama, Trans. Mycol. Soc. Japan 12(1): 20 (1971)

On leaf and branch litter of $H$. brasiliensis: Thailand (Seephueak et al. 2010, 2011)

\section{Subulispora sp.}

On leaf and branch litter of H. brasiliensis: Thailand (Seephueak et al. 2010, 2011)

\section{Sympodiella sp.}

On branch litter of $H$. brasiliensis: Thailand (Seephueak et al. 2011)

Taeniolella breviuscula (Berk. \& M.A. Curtis) S. Hughes, Can. J. Bot. 36: 817 (1958) 
On branch litter of $H$. brasiliensis: Thailand (Seephueak et al. 2011)

Taeniolella scripta (P. Karst.) S. Hughes, Can. J. Bot. 36: 817 (1958)

On leaf litter of H. brasiliensis: Thailand (Seephueak et al. 2010)

Taeniolina centaurii (Fuckel) M.B. Ellis, More Dematiaceous Hyphomycetes (Kew): 62 (1976)

On leaf litter of H. brasiliensis: Thailand (Seephueak et al. 2010)

Talaromyces flavus (Klöcker) Stolk \& Samson, Stud. Mycol. 2: 10 (1972)

On leaf litter of H. brasiliensis: Thailand (Seephueak et al. 2010)

Tetraploa aristata Berk. \& Broome, Ann. Mag. Nat. Hist., Ser. 2 5: 459 (1850)

On leaf and branch litter of H. brasiliensis: Thailand (Seephueak et al. 2010, 2011)

Tetraploa ellisii Cooke, Grevillea 8(no. 45): 12 (1879)

On branch litter of $H$. brasiliensis: Thailand (Seephueak et al. 2011)

Tetraposporium asterinearum S. Hughes, Mycol. Pap. 46: 25 (1951)

On branch litter of $H$. brasiliensis: Thailand (Seephueak et al. 2011)

Tetraposporium sp.

On leaf and branch litter of H. brasiliensis: Thailand (Seephueak et al. 2010, 2011)

Thyridaria heveae Saccas, Agronomía Trop. 8: 275 (1953)

On H. brasiliensis: French Equatorial Africa (Anonymous 1963)

Thyridaria sambucina (Peck) Wehm., Lloydia 4: 253 (1941)

On leaf and branch litter of $\mathrm{H}$. brasiliensis: Thailand as Ceratocystis ulmi (Seephueak et al. 2010, 2011)

Thyridium flavum Petch, Ann. R. bot. Gdns Peradeniya 6(3): 226 (1917)

On dead branches of H. brasiliensis: Sri Lanka (Saccardo 1928)

\section{Thyrsidina sp.}

On branch litter of $H$. brasiliensis: Thailand (Seephueak et al. 2011)

\section{Tiarosporella sp.}

On leaf litter of H. brasiliensis: Thailand (Seephueak et al. 2010)

Torrubiella rubra Pat. \& Lagerh., in Patouillard \& Lagerheim, Bull. Soc. Mycol. Fr. 9(3): 154 (1893)

On H. brasiliensis: Dominican Republic (Ciferri 1961)

Torula fici Crous, IMA Fungus 6 (1): 192 (2015)

On dried twig of $H$. brasiliensis: Thailand (this study)

Torula herbarum (Pers.) Link, Mag. Gesell. naturf. Freunde, Berlin 3(1-2): 19 (1809)

On leaf and branch litter of H. brasiliensis: Thailand (Seephueak et al. 2010, 2011)

\section{Torula sp.}

On branch litter of $H$. brasiliensis: Thailand (Seephueak et al. 2011)

\section{Tretospora sp.}


On leaf and branch litter of H. brasiliensis: Thailand (Seephueak et al. 2010, 2011)

Trematosphaeria pertusa Fuckel, Jb. nassau. Ver. Naturk. 23-24: 161 (1870) [1869-70]

On branch litter of $H$. brasiliensis: Thailand (Seephueak et al. 2011)

Triadelphia heterospora Shearer \& J.L. Crane, Mycologia 63(2): 247 (1971)

On leaf litter of H. brasiliensis: Thailand (Seephueak et al. 2010)

Triadelphia uniseptata (Berk. \& Broome) P.M. Kirk, Trans. Br. Mycol. Soc. 80(3): 464 (1983) 2010)

On leaf litter of $H$. brasiliensis: Thailand as Sporidesmium uniseptatum (Seephueak et al.

Trichocladium griseum (Traaen) X. Wei Wang \& Houbraken, in Wang et al., Stud. Mycol. 93: 141 (2018)

On leaf and branch litter of $H$. brasiliensis: Thailand as Humicola grisea (Seephueak et al. 2010, 2011)

Trichoderma amazonicum P. Chaverri \& Gazis, Mycologia 103(1): 146 (2011)

Endophytic on living sapwood of H. brasiliensis: Peru (Chaverri et al. 2011)

Trichoderma citrinoviride Bissett, Can. J. Bot. 62(5): 926 (1984)

On H. brasiliensis: Japan as Hypocrea schweinitzii (Kobayashi 2007)

Trichoderma harzianum Rifai, Mycol. Pap. 116: 38 (1969)

Endophytic on living leaves and sapwood of H. brasiliensis: Peru (Chaverri et al. 2011)

Trichoderma koningiopsis Samuels, Carm. Suárez \& H.C. Evans, in Samuels et al., Stud. Mycol. 56: 117 (2006)

Endophytic on living leaves of H. brasiliensis: Peru (Chaverri et al. 2011)

Trichoderma pezizoides (Berk. \& Broome) Samuels, Jaklitsch \& Voglmayr, Mycotaxon 126: 152 (2014)

Associated with H. brasiliensis: Thailand (Surawut et al. 2021)

\section{Trichoderma spp.}

Associated with rubber tree seeds harvested of H. brasiliensis: Brazil (Theodoro \& Batista 2014)

Trichoderma viride Pers., Neues Mag. Bot. 1: 92 (1794)

On branch litter of H. brasiliensis: Thailand as Hypocrea rufa (Seephueak et al. 2011)

Trichodochium disseminatum Syd., Annls Mycol. 25(1/2): 159 (1927)

On leaf and branch litter of H. brasiliensis: Thailand (Seephueak et al. 2010, 2011)

Trichothecium roseum (Pers.) Link, Mag. Gesell. naturf. Freunde, Berlin 3(1-2): 18 (1809)

On H. brasiliensis: Myanmar, Thailand on leaf litter (Thaung 2008, Seephueak et al. 2010)

Tricladium angulatum Ingold, Trans. Br. Mycol. Soc. 25(4): 393 (1942) [1941]

On leaf litter of H. brasiliensis: Thailand (Seephueak et al. 2010)

Tricladium castaneicola B. Sutton, Trans. Br. Mycol. Soc. 64(3): 422 (1975)

On leaf litter of $H$. brasiliensis: Thailand (Seephueak et al. 2010) 
Tricladium fuscum Nawawi, Trans. Br. Mycol. Soc. 85(1): 180 (1985)

On leaf and branch litter of H. brasiliensis: Thailand (Seephueak et al. 2010, 2011)

Tricladium sp.

On branch litter of $H$. brasiliensis: Thailand (Seephueak et al. 2011)

Tridentaria implicans Drechsler, Mycologia 32(4): 466 (1940)

On branch litter of $H$. brasiliensis: Thailand (Seephueak et al. 2011)

\section{Tridentaria sp.}

On branch litter of $H$. brasiliensis: Thailand (Seephueak et al. 2011)

Trimmatostroma betulinum (Corda) S. Hughes, Can. J. Bot. 31: 628 (1953)

On leaf litter of $H$. brasiliensis: Thailand (Seephueak et al. 2010)

Tripospermum myrti (Lind) S. Hughes, Mycol. Pap. 46: 18 (1951)

On branch litter of $H$. brasiliensis: Thailand (Seephueak et al. 2011)

Triscelophorus acuminatus Nawawi, Trans. Br. Mycol. Soc. 64(2): 346 (1975)

On leaf and branch litter of H. brasiliensis: Thailand (Seephueak et al. 2010, 2011)

Triscelophorus monosporus Ingold, Trans. Br. Mycol. Soc. 26(3-4): 152 (1943)

On leaf and branch litter of H. brasiliensis: Thailand (Seephueak et al. 2010, 2011)

Triscelophorus ponapensis Matsush., Matsush. Mycol. Mem. 2: 19 (1981)

On leaf and branch litter of $H$. brasiliensis: Thailand (Seephueak et al. 2010, 2011)

Trisulcosporium acerinum H.J. Huds. \& B. Sutton, Trans. Br. mycol. Soc. 47(2): 200 (1964)

On leaf litter of H. brasiliensis: Thailand (Seephueak et al. 2010)

\section{Truncatella sp.}

On leaf litter of $H$. brasiliensis: Thailand (Seephueak et al. 2010)

Tryblidiella mindanaoensis Henn. [as 'mindanaoënsis'], Hedwigia 47: 261 (1908)

On H. brasiliensis: Philippines (Reinking 1919)

Tubercularia lateritia (Berk.) Seifert, Stud. Mycol. 27: 119 (1985)

On H. brasiliensis: Indonesia (Seifert 1990)

Tubeufia cerea (Berk. \& M.A. Curtis) Höhn., Sber. Akad. Wiss. Wien, Math.-naturw. Kl., Abt. 1 128(7-8): 562 (1919)

On branch litter of $H$. brasiliensis: Thailand as Helicosporium vegetum (Seephueak et al. 2011)

Uniseta sp.

On branch litter of H. brasiliensis: Thailand (Seephueak et al. 2011)

Urnula mexicana (Ellis \& Holw.) M. Carbone, Agnello, A.D. Parker \& P. Alvarado, Ascomycete.org 5(1): 14 (2012)

On branch litter of H. brasiliensis: Thailand as Bulgaria mexicana (Seephueak et al. 2011)

Ustulina deusta (Hoffm.) Lind, Danish Fungi (Copenhagen): 252 (1913) 
Associated with root rot disease of $H$. brasiliensis: Brazil, China, Democratic Republic of the Congo, Fiji, Ghana, India, Indonesia, Malaysia, Papua New Guinea, Seychelles, Sierra Leone (Spaulding 1961)

Uwemyces elaeidis (Steyaert) Hern.-Restr., Sarria \& Crous, in Crous et al., Persoonia 36: 455 (2016)

On branch litter of H. brasiliensis: Thailand as Cercospora elaeidis (Seephueak et al. 2011)

Vaginatispora amygdali A. Hashim., K. Hiray. \& Kaz. Tanaka, in Hashimoto et al., Stud. Mycol. 90: 179 (2018)

On branch of $H$. brasiliensis: Thailand (this study)

\section{Valsa sp.}

On H. brasiliensis: Malaysia (Williams \& Liu 1976)

Varicosporium elodeae W. Kegel, Ber. Dt. Bot. Ges. 24: 213 (1906)

On leaf litter of H. brasiliensis: Thailand (Seephueak et al. 2010)

Venturia crataegi Aderh., Ber. Dt. Bot. Ges. 20: 200 (1902)

On branch litter of $H$. brasiliensis: Thailand (Seephueak et al. 2011)

Veronaea coprophila (Subram. \& Lodha) M.B. Ellis, More Dematiaceous Hyphomycetes (Kew): $210(1976)$

On H. brasiliensis: Thailand (Seephueak et al. 2011)

Veronaea botryosa Cif. \& Montemart., Atti Ist. Bot. Univ. Lab. crittog. Pavia, sér. 5 15: 68 (1957)

On leaf and branch litter of H. brasiliensis: Thailand (Seephueak et al. 2010, 2011)

Veronaea carlinae M.B. Ellis, More Dematiaceous Hyphomycetes (Kew): 212 (1976)

On leaf and branch litter of H. brasiliensis: Thailand (Seephueak et al. 2010, 2011)

Veronaea coprophila (Subram. \& Lodha) M.B. Ellis, More Dematiaceous Hyphomycetes (Kew): $210(1976)$

On leaf and branch litter of H. brasiliensis: Thailand (Seephueak et al. 2010, 2011)

\section{Veronaea sp.}

On leaf litter of $H$. brasiliensis: Thailand (Seephueak et al. 2010)

Verruconis heveae Huanrluek, Senwanna, Jayawardena \& K.D. Hyde, in Huanraluek et al., Phytotaxa 403(1): 50 (2019)

On dried latex on bark of $H$. brasiliensis: Thailand (Huanraluek et al. 2019, this study)

Verruconis phayaoensis Senwanna, Cheewangkoon \& K.D. Hyde

On dried latex on bark and twig of $\mathrm{H}$. brasiliensis: Thailand (this study)

Verticillium dahliae Kleb., Mykol. Zentbl. 3: 66 (1913)

On leaf litter of H. brasiliensis: Thailand (Seephueak et al. 2010)

\section{Verticillium sp.}

On leaf litter of H. brasiliensis: Thailand (Seephueak et al. 2010)

\section{Wentiomyces sp.}

On H. brasiliensis: Brunei Darussalam (Peregrine \& Ahmad1982) 
Wiesneriomyces laurinus (Tassi) P.M. Kirk, Trans. Br. Mycol. Soc. 82(4): 748 (1984)

On leaf litter and bark of $H$. brasiliensis: Thailand as Wiesneriomyces javanicus (Seephueak et al. 2010, Hongsanan et al. 2020)

Xylaria allantoidea (Berk.) Fr., Nova Acta R. Soc. Scient. upsal., Ser. 3 1(1): 127 (1851) [1855]

On H. brasiliensis: Thailand (Srihanant \& Petcharat 2015)

Xylaria anisopleura (Mont.) Fr., Nova Acta R. Soc. Scient. upsal., Ser. 3 1(1): 127 (1851) [1855]

On H. brasiliensis: Thailand (Srihanant \& Petcharat 2015)

Xylaria apiculate Cooke, Grevillea 8(no. 46): 66 (1879)

On H. brasiliensis: Thailand (Srihanant \& Petcharat 2015)

Xylaria arbuscula Sacc., Michelia 1(no. 2): 249 (1878)

On H. brasiliensis: Thailand (Srihanant \& Petcharat 2015)

Xylaria caespitulosa Ces., Atti Accad. Sci. Fis. Mat. Napoli 8(8): 15 (1879)

On branch litter of $H$. brasiliensis: Thailand (Seephueak et al. 2011)

Xylaria cubensis (Mont.) Fr., Nova Acta R. Soc. Scient. Upsal., Ser. 3 1(1): 126 (1851) [1855]

On H. brasiliensis: Thailand (Srihanant \& Petcharat 2015)

Xylaria cynoglossa Cooke, Grevillea 12(no. 61): 1 (1883)

On H. brasiliensis: Malaysia (Singh 1980)

Xylaria deserticola Speg., Anal. Mus. Nac. B. Aires, Ser. 3 1: 70 (1902)

Associated with root rot disease of H. brasiliensis: Malaysia (Spaulding 1961)

Xylaria fastigiata (Speg.) Mussat, in Saccardo, Syll. Fung. (Abellini) 15: 452 (1901)

On H. brasiliensis: Haiti (Benjamin \& Slot 1969)

Xylaria feejeensis (Berk.) Fr., Nova Acta R. Soc. Scient. Upsal., Ser. 3 1(1): 128 (1851) [1855]

On H. brasiliensis: Malaysia (Singh 1980)

Xylaria hypoxylon (L.) Grev., Fl. Edin.: 355 (1824)

On H. brasiliensis: Thailand (Srihanant \& Petcharat 2015)

Xylaria hypsipoda Massee, Bull. Misc. Inf., Kew: 174 (1899)

On branch litter of $H$. brasiliensis: Thailand (Seephueak et al. 2011)

Xylaria laevis Lloyd, Mycol. Notes (Cincinnati) 65(no. 5): 8 (1918)

On H. brasiliensis: Thailand (Srihanant \& Petcharat 2015)

Xylaria multiplex (Kunze) Fr., Nova Acta R. Soc. Scient. Upsal., Ser. 3 1(1): 127 (1851) [1855]

On H. brasiliensis: Haiti, Malaysia, Thailand (Benjamin \& Slot 1969, Singh 1980, Seephueak et al. 2011)

Xylaria mesenterica (Möller) M. Stadler, Læssøe \& J. Fourn., Mycol. Progr. 7(1): 67 (2008)

Endophytic on living leaves and sapwood of $H$. brasiliensis: Peru as Entonaema pallida

(Gazis \& Chaverri 2010)

Xylaria obovata (Berk.) Berk., Nova Acta R. Soc. Scient. Upsal., Ser. 3 1(1): 127 (1851) [1855]

On H. brasiliensis: Malaysia (Singh 1980) 
Xylaria scopiformis Mont. ex Berk. \& Broome [as 'scopaeformis'], J. Linn. Soc., Bot. 14(no. 74): 119 (1875) [1873]

On dead trees of $H$. brasiliensis as Xylaria scopiformis var. heveana: Malaysia, Singapore (Saccardo 1928, Singh 1980, Petrak 1930)

\section{Xylaria sp.}

On leaf and branch litter of H. brasiliensis: Thailand (Seephueak et al. 2010, 2011)

Xylaria terricola Y.M. Ju, H.M. Hsieh \& W.N. Chou, in Chou, Hsieh \& Ju, Fungal Science, Taipei 32(1): 3 (2017)

Associated with $H$. brasiliensis: Thailand (Surawut et al. 2021)

Xylaria thwaitesii Berk. \& Cooke, Grevillea 12(no. 61): 1 (1883)

Associated with root rot disease of $H$. brasiliensis: China, India, Indonesia, Sri Lanka (Spaulding 1961)

Xylona heveae Gazis \& P. Chaverri, in Gazis et al., Mol. Phylogen. Evol. 65(1): 302 (2012)

Isolated from sapwood of $H$. brasiliensis: Peru (Gazis et al. 2012)

Zanclospora brevispora S. Hughes \& W.B. Kendr., N.Z. J1 Bot. 3: 156 (1965)

On leaf litter of H. brasiliensis: Thailand (Seephueak et al. 2010)

\section{Zanclospora sp.}

On leaf litter of $H$. brasiliensis: Thailand (Seephueak et al. 2010)

Zasmidium musigenum Videira \& Crous, in Videira et al., Stud. Mycol. 87: 361 (2017)

On leaf and branch litter of $H$. brasiliensis: Thailand as Veronaea musae (Seephueak et al. 2010, 2011)

Zukaliopsis heveae Petch, Ann. R. Bot. Gdns Peradeniya 7(4): 299 (1922)

On leaves of H. brasiliensis: Sri Lanka (Petrak 1930, Saccardo 1972)

Zygosporium deightonii M.B. Ellis, More Dematiaceous Hyphomycetes (Kew): 344 (1976)

On leaf litter of H. brasiliensis: Thailand (Seephueak et al. 2010)

Zygosporium echinosporum Bunting \& E.W. Mason, in Mason, Annot. Acct Fungi rec'd Imp. Mycol. Inst. 2(3): 135 (1941)

On leaf litter of H. brasiliensis: Thailand (Seephueak et al. 2010)

Zygosporium gibbum (Sacc., M. Rousseau \& E. Bommer) S. Hughes, Can. J. Bot. 36: 825 (1958)

On leaf litter of $H$. brasiliensis: Thailand (Seephueak et al. 2010)

Zygosporium majus Piroz., Mycol. Pap. 129: 60 (1972)

On leaf litter of $H$. brasiliensis: Thailand (Seephueak et al. 2010)

Zygosporium masonii S. Hughes, Mycol. Pap. 44: 15 (1951)

On leaf litter of H. brasiliensis: Thailand (Seephueak et al. 2010)

Zygosporium minus S. Hughes, Mycol. Pap. 44: 6 (1951)

On branch litter of $H$. brasiliensis: Thailand (Seephueak et al. 2011)

Zygosporium oscheoides Mont., Annls Sci. Nat., Bot., sér. 2 17: 121 (1842)

On H. brasiliensis: Ghana, Samoa (Dade 1940, Dingley et al. 1981) 
On leaf litter of H. brasiliensis: Thailand (Seephueak et al. 2010)

Zygosporium paraense Vincens, Bull. Soc. Path. vég. Fr. 2: 19 (1915)

Associated with leaf spot of H. brasiliensis: Brazil, Dominican Republic (Saccardo 1931, Ciferri 1961)

\section{Phylum: Basidiomycota}

Acanthophysium oakesii (Berk. \& M.A. Curtis) Parmasto, Eesti NSV Tead. Akad. Toim., Biol. seer 16(4): 378 (1967)

On branch litter of H. brasiliensis: Thailand as Aleurodiscus oakesii (Seephueak et al. 2011)

Aleurodiscus mirabilis (Berk. \& M.A. Curtis) Höhn., Sber. Akad. Wiss. Wien, Math.-naturw. Kl., Abt. 1 118: 818 (1909)

On branch litter of $H$. brasiliensis: Thailand (Seephueak et al. 2011)

Amauroderma scopulosum (Berk.) Imazeki, Bull. Gov. Forest Exp. Stn Tokyo 57: 99 (1952)

On H. brasiliensis: Malaysia as Microporus scopulosus (Singh 1980)

Armillaria mellea (Vahl) P. Kumm., Der Führer in die Pilzkunde: 134 (1871)

On H. brasiliensis: Democratic Republic of the Congo, Malawi, Uganda (Wiehe 1953, Spaulding 1961)

Athelia rolfsii (Curzi) C.C. Tu \& Kimbr. 1978

Associated with root crown rot and seedling blight of seedling of $H$. brasiliensis: East Indies as Pellicularia rolfsii, Malaysia as Corticium rolfsii (Spaulding 1961, Singh 1980)

Auricularia auricula-judae (Bull.) Quél., Enchir. Fung. (Paris): 207 (1886)

On H. brasiliensis: Ghana, Thailand on branch litter (Hughes 1953, Seephueak et al. 2011)

Auricularia brasiliensis Nomen dubium

On dead stems and branches of H. brasiliensis: Malaysia (Singh 1980)

Auricularia fuscosuccinea (Mont.) Henn. [as 'fusco-succinea'], Bot. Jb. 17: 19 (1893)

On branch litter of $H$. brasiliensis: Thailand (Seephueak et al. 2011)

Auricularia nigricans (Sw.) Birkebak, Looney \& Sánchez-García, in Looney et al. N. Am. Fungi 8 (6): 12 (2013)

On dead trunks and branches and decaying wood of $H$. brasiliensis as Auricularia polytricha: Philippines, Thailand (Musngi et al. 2005, Seephueak et al. 2011)

\section{Auricularia sp.}

On branch litter of $H$. brasiliensis: Thailand (Seephueak et al. 2011)

Byssomerulius corium (Pers.) Parmasto, Eesti NSV Tead. Akad. Toim., Biol. seer 16(4): 383 (1967)

On branch litter of H. brasiliensis: Thailand as Meruliopsis corium (Seephueak et al. 2011)

Ceriporiopsis hypolateritia (Berk. ex Cooke) Ryvarden [as 'hypolateritius'], Syn. Fung. (Oslo) 33: 9 (2015)

Associated with root rot diseases of $H$. brasiliensis as Poria hypolateritia: India, Sri Lanka (Spaulding 1961) 
Coriolopsis occidentalis (Klotzsch) Murrill, Bull. Torrey bot. Club 32(7): 358 (1905)

On H. brasiliensis: Ghana as Polystictus occidentalis, Malaysia (Hughes 1953, Singh 1980)

Coriolopsis polyzona (Pers.) Ryvarden, Norw. J1 Bot. 19: 230 (1972)

On H. brasiliensis: India (Sarbhoy \& Agarwal 1990)

Cerioporus squamosus (Huds.) Quél., Enchir. Fung. (Paris): 167 (1886)

On branch litter of $H$. brasiliensis: Thailand as Polyporus retirugus (Seephueak et al. 2011)

Coriolus hirsutus (Wulfen) Pat., Cat. Rais. Pl. Cellul. Tunisie (Paris): 47 (1897)

On H. brasiliensis: Malaysia (Singh 1980)

Corticium koleroga (Cooke) Höhn., Sber. Akad. Wiss. Wien, Math.-naturw. Kl., Abt. 1 119: 395 (1910)

= Pellicularia koleroga Cooke, Grevillea 4(no. 31): 116 (1876)

Associated with thread blight, bark lesions on branches and leaf blight of $H$. brasiliensis: Argentina, East Indies (Spaulding 1961)

\section{Corticium sp.}

On H. brasiliensis: Papua New Guinea (Shaw 1984)

Cryptomarasmius micraster (Petch) T.S. Jenkinson \& Desjardin, Mycologia 106(1): 92 (2014)

On branch litter of H. brasiliensis: Thailand as Marasmius micraster (Seephueak et al. 2011)

Cryptomarasmius sphaerodermus (Speg.) T.S. Jenkinson \& Desjardin, Mycologia 106(1): 92 (2014)

On H. brasiliensis: Dominican Republic as Poria floridae (Ciferri 1961)

Cyathus poeppigii Tul. \& C. Tul., Annls Sci. Nat., Bot., sér. 3 1: 77 (1844)

On H. brasiliensis: Ghana (Hughes 1953)

Cymatoderma dendriticum (Pers.) D.A. Reid 1959 1980)

On H. brasiliensis: Malaysia, Philippines as Cladoderris dendritica (Reinking 1919, Singh

Cyphella heveae Massee, Bull. Misc. Inf., Kew (4): 157 (1914)

On bark of $H$. brasiliensis: Malay Peninsula, Thailand (Thompson \& Johnston 1953, Giatgong 1980)

Dacryopinax spathularia (Schwein.) G.W. Martin, Lloydia 11: 116 (1948)

On branch litter of $H$. brasiliensis: Thailand (Seephueak et al. 2011)

Daedalea dochmia (Berk. \& Broome) T. Hatt., Mycoscience 46(5): 307 (2005)

On H. brasiliensis: Malaysia as Ganoderma ferreum (Singh 1980)

Earliella scabrosa (Pers.) Gilb. \& Ryvarden, Mycotaxon 22(2): 364 (1985)

$=$ Trametes corrugata (Pers.) Bres., Hedwigia 51(4): 316 (1912)

Associated with trunk rot of $H$. brasiliensis: Brazil, Brunei Darussalam, Ghana, India, Indonesia, Malaysia, Thailand on branch litter as Trametes scabrosa (Hughes 1953, Spaulding 1961, Turner 1971, Peregrine \& Ahmad 1982, Sarbhoy \& Agarwal 1990, Seephueak et al. 2011) 
Eichleriella tenuicula (Lév.) Spirin \& Malysheva, in Malysheva \& Spirin, Fungal Biology 121(8): 709 (2017)

On H. brasiliensis: Philippines as Heterochaete tenuicula (Teodoro 1937)

Entoloma repens (Petch) Blanco-Dios, Tarrelos 19: 29 (2017)

On branch litter of $H$. brasiliensis: Thailand as Claudopus repens (Seephueak et al. 2011)

Erythricium salmonicolor (Berk. \& Broome) Burds. 1985

= Corticium salmonicolor Berk. \& Broome, J. Linn. Soc., Bot. 14(no. 74): 71 (1873) [1875]

= Phanerochaete salmonicolor salmonicolor (Berk. \& Broome) Jülich, Persoonia 8(3): 294 (1975)

= Pellicularia salmonicolor (Berk. \& Broome) Dastur, Curr. Sci. 15(7): 193 (1946)

Associated with pink disease on branches and trunks of $H$. brasiliensis: Brazil, Brunei Darussalam, Cambodia, Costa Rica, Fiji, Guatemala, Malay Peninsula, Mexico, Nigeria, Papua New Guinea, Thailand (Spaulding 1961, Dingley et al. 1981, Shaw 1984, Mendes et al. 1998)

Favolus grammocephalus (Berk.) Imazeki, Bull. Tokyo Sci. Mus. 6: 95 (1943)

On H. brasiliensis: Philippines as Favolus tener, Malaysia as Polyporus grammocephalus (Reinking 1919, Singh 1980)

Favolus spatulatus (Jungh.) Lév. [as 'spathulatus'], Annls Sci. Nat., Bot., sér. 3 2: 203 (1844) On H. brasiliensis: Philippines (Teodoro 1937)

\section{Fibulocoela sp.}

On leaf litter of H. brasiliensis: Thailand (Seephueak et al. 2010)

Flavodon flavus (Klotzsch) Ryvarden, Norw. J1 Bot. 20(1): 3 (1973)

On branch litter of $H$. brasiliensis: Malaysia, Thailand as Irpex flavus (Singh 1980, Seephueak et al. 2011)

\section{Fomes sp.}

On H. brasiliensis: Fiji, Papua New Guinea (Firman 1972, Dingley et al. 1981, Shaw 1984)

Fomitopsis lignea (Berk.) Ryvarden, Norw. Jl Bot. 19: 231 (1972)

Associated with root rot disease of H. brasiliensis: Brazil as Fomes ligneus (Spaulding 1961)

Fulvifomes umbrinellus (Bres.) Y.C. Dai, Fungal Divers. 45: 203 (2010)

On H. brasiliensis: Haiti as Poria umbrinella (Benjamin \& Slot 1969)

Fuscocerrena portoricensis (Fr.) Ryvarden, Trans. Br. Mycol. Soc. 79(2): 280 (1982)

On dead branches of $H$. brasiliensis: Brazil as Irpex farinaceous (Weir 1926)

Ganoderma applanatum (Pers.) Pat., Hyménomyc. Eur. (Paris): 143 (1887)

On H. brasiliensis: Malaysia (Singh 1980)

Ganoderma australe (Fr.) Pat., Bull. Soc. Mycol. Fr. 5(2,3): 65 (1889)

= Fomes annularis Lloyd, Mycol. Writ. 4(Letter 40): 6 (1912)

Associated with rot disease of H. brasiliensis: Brazil, Malaysia (Spaulding 1961)

Ganoderma lucidum (Curtis) P. Karst., Revue Mycol., Toulouse 3(no. 9): 17 (1881)

Associated with heart rot and white rot disease of $H$. brasiliensis: Brunei Darussalam, East Indies, Malaysia, Sri Lanka, Thailand (Spaulding 1961, Cherdchim \& Satansat 2016) 
Ganoderma philippii (Bres. \& Henn. ex Sacc.) Bres., Iconogr. Mycol. 21: tab. 1014 (1932)

= Fomes pseudoferreus Wakef. [as 'pseudo-ferreus'], Bull. Misc. Inf., Kew: 208 (1918)

= Ganoderma pseudoferreum (Wakef.) Overeem \& B.A. Steinm., Bull. Jard. Bot. Buitenz, 3 Sér. 7: 437 (1925)

Associated with rot diseases of $H$. brasiliensis: Brazil, China, Democratic Republic of the Congo, India, Indonesia, Myanmar, Nigeria, Malay Peninsula, Malaysia, Sri Lanka, Thailand (Saccardo 1925, West 1938, Thompson \& Johnston 1953, Spaulding 1961, Tai 1979, Giatgong 1980, Jayasinghe 1999a, Mendes et al. 1998, Thaung 2007, Ogbebor et al. 2010)

\section{Ganoderma sp.}

On H. brasiliensis: Papua New Guinea (Shaw 1984)

Geastrum velutinum Morgan [as 'Geaster'], J. Cincinnati Soc. Nat. Hist. 18: 38 (1895)

On H. brasiliensis: Ghana (Hughes 1953)

Gloeophyllum concentricum G. Cunn., Bull. N.Z. Dept. Sci. Industr. Res. 164: 263 (1965)

On H. brasiliensis: Samoa (Dingley et al. 1981)

Gloeophyllum striatum (Fr.) Murrill, Bull. Torrey Bot. Club 32(7): 370 (1905)

Associated with brown rot of H. brasiliensis: Thailand (Cherdchim \& Satansat 2016)

Haplotrichum croceum (Mont.) Partr. \& Morgan-Jones, in Partridge et al., Mycotaxon 82: 51 (2002)

On H. brasiliensis: Ghana as Allescheriella crocea (Hughes 1952)

Helicobasidium longisporum Wakef., Bull. Misc. Inf., Kew (nos 9 \& 10): 310 (1917)

= Helicobasidium compactum (Boedijn) Boedijn, Arch. voor de Thee Cultuur 1: 10 (1930)

Associated with root rot disease of $H$. brasiliensis: Costa Rica, East Indies, Mexico (Spaulding 1961, McGuire \& Crandall 1967)

Helicobasidium purpureum (Tul.) Pat., Bull. Soc. Bot. Fr. 32: 172 (1885)

On H. brasiliensis: Mexico, Sri Lanka (Alvarez 1976, Jayasinghe 1999a)

Hexagonia thwaitesii Berk. \& M.A. Curtis, Proc. Amer. Acad. Arts \& Sci. 4: 122 (1860)

On H. brasiliensis: Philippines (Teodoro 1937)

Hexagonia umbrinella Fr., Summa veg. Scand., Sectio Prior (Stockholm): 137 (1845)

On H. brasiliensis: Ghana (Dade 1940)

Hobsonia mirabilis (Peck) Linder, Ann. Mo. Bot. Gdn 16: 340 (1929)

On leaf litter of $H$. brasiliensis: Thailand (Seephueak et al. 2010)

Hyalodendron sp.

On branch litter of $H$. brasiliensis: Thailand (Seephueak et al. 2011)

Hydnum duriusculum Lloyd, Mycol. Writ. 6(Letter 64): 1002 (1920) [1921]

On H. brasiliensis: Malaysia (Singh 1980)

Hymenochaete noxia Berk. ex Cooke, Grevillea 8(no. 48): 150 (1880)

On H. brasiliensis: Philippines (Teodoro 1937)

\section{Hypochnus sp.}

On H. brasiliensis: Malay Peninsula (Thompson \& Johnston 1953) 
Inonotus rickii (Pat.) D.A. Reid, Kew Bull. [12](2): 141 (1957)

Associated with canker and decay in trunk of H. brasiliensis: China (Dai et al. 2010)

Lactarius hygrophoroides Berk. \& M.A. Curtis, Ann. Mag. nat. Hist., Ser. 3 4: 293 (1859)

On branch litter of $H$. brasiliensis: Thailand (Seephueak et al. 2011)

Lentinus connatus Berk., London J. Bot. 1(3): 145 (1842)

On branch litter of $H$. brasiliensis: Thailand (Seephueak et al. 2011)

Lentinus squarrosulus Mont., Annls Sci. Nat., Bot., sér. 2 18: 21 (1842)

On H. brasiliensis: Malaysia (Liu 1977)

Lentinus velutinus Fr., Linnaea 5: 510 (1830)

On H. brasiliensis: Malaysia (Singh 1980)

Leiotrametes menziesii (Berk.) Welti \& Courtec., in Welti et al., Fungal Divers. 55(1): 60 (2012)

On H. brasiliensis: Malaysia as Polystictus vittatus (Singh 1980)

Lopharia cinerascens (Schwein.) G. Cunn., Trans. Roy. Soc. N.Z. 83(4): 622 (1956)

On dead branch of H. brasiliensis: Malaysia as Lopharia mirabilis (Singh 1980)

Marasmiellus candidus (Fr.) Singer, Pap. Mich. Acad. Sci. 32: 129 (1948) [1946]

On branch litter of $H$. brasiliensis: Thailand (Seephueak et al. 2011)

Marasmiellus scandens (Massee) Dennis \& D.A. Reid, Kew Bull. [11](2): 289 (1957)

Associated with Thread blight of $H$. brasiliensis: Malaysia, Nigeria as Marasmius scandens

(West 1938, Turner 1971)

Marasmius arborescens (Henn.) Beeli, Bull. Soc. R. Bot. Belg. 60(2): 156 (1928)

On branch litter of $H$. brasiliensis: Thailand (Seephueak et al. 2011)

Marasmius cyphella Dennis \& D.A. Reid, Kew Bull. [12](2): 288 (1957)

On leaves and branches of H. brasiliensis: Malaysia (Johnston 1960, Anonymous 1963)

Marasmius crinis-equi F. Muell. ex Kalchbr., in Kalchbrenner, Grevillea 8(no. 48): 153 (1880)

= Marasmius equicrinis F. Muell. ex Berk., Grevillea 8(no. 48): 153 (1880)

Associated with horsehair blight and white thread blight on branches, twigs and leaves of $H$.

brasiliensis: Brazil, East Indies, Malay Peninsula, Malaysia (Thompson \& Johnston 1953, Spaulding 1961, Turner 1966, 1971)

Marasmius florideus Berk. \& Broome, J. Linn. Soc., Bot. 14(no. 73): 39 (1873) [1875]

On branch litter of $H$. brasiliensis: Thailand (Seephueak et al. 2011)

Marasmius palmivorus Sharples, Malay. Agric. Journal 16(nos 9-10): [1] (1928)

Associated with white fan blight of $H$. brasiliensis: Malay Peninsula, Malaysia (Thompson \&

Johnston 1953, Holiday 1980)

Marasmius pulcherripes Peck, Ann. Rep. N.Y. St. Mus. 24: 77 (1872) [1871]

On branch litter of H. brasiliensis: Thailand (Seephueak et al. 2011)

Marasmius siccus (Schwein.) Fr., Epicr. Syst. Mycol. (Upsaliae): 382 (1838) [1836-1838]

On branch litter of $H$. brasiliensis: Thailand (Seephueak et al. 2011) 


\section{Marasmius sp.}

Associated with white thread blight on branched of $H$. brasiliensis: Ghana, Sri Lanka, on branch litter: Thailand (Dade 1940, Jayasinghe 1999a, Seephueak et al. 2011)

Mycena stylobates (Pers.) P. Kumm., Führ. Pilzk. (Zerbst): 108 (1871)

On branch litter of H. brasiliensis: Thailand (Seephueak et al. 2011)

Naucoria conicopapillata (Henn.) Sacc. \& P. Syd., Syll. fung. (Abellini) 16: 101 (1902)

On branch litter of $H$. brasiliensis: Thailand as Marasmius conicopapillatus (Seephueak et al. 2011)

Navisporus floccosus (Bres.) Ryvarden [as 'floccosa'], in Ryvarden \& Johansen, Prelim. Polyp. Fl. E. Afr. (Oslo): 443 (1980)

On H. brasiliensis: Ghana as Trametes floccosa (Hughes 1953)

\section{Ozonium sp.}

On dead branches of $H$. brasiliensis: Philippines (Weir 1926, Teodoro 1937)

Panus similis (Berk. \& Broome) T.W. May \& A.E. Wood, Mycotaxon 54: 148 (1995)

On branch litter of $H$. brasiliensis: Thailand as Lentinus similis (Seephueak et al. 2011)

Pilatoporus hemitephrus (Berk.) Zmitr., Folia Cryptogamica Petropolitana (Sankt-Peterburg) 6: 89 (2018)

On H. brasiliensis: Brunei Darussalam as Fomitopsis hemitephra (Peregrine \& Ahmad1982)

Podoscypha nitidula (Berk.) Pat., in Duss, Enum. Champ. Guadeloupe (Lons-le-Saunier): 21 (1903)

On branch litter of $H$. brasiliensis: Thailand (Seephueak et al. 2011)

Poria hypobrunnea Petch, Ann. R. bot. Gdns Peradeniya 6(1): 137 (1916)

Associated with red root rot disease of $H$. brasiliensis: India, Malaysia, Sri Lanka (Johnston 1960, Spaulding 1961)

Pseudofavolus tenuis (Fr.) G. Cunn., Bull. N.Z. Dept. Sci. Industr. Res. 164: 185 (1965)

On H. brasiliensis as Hexagonia tenuis: Malaysia, Thailand (Chipp 1921, Seephueak et al. 2011)

Pycnoporus sanguineus (L.) Murrill, Bull. Torrey Bot. Club 31(8): 421 (1904)

On branch of $H$. brasiliensis: Thailand, Malaysia (Singh 1980, Seephueak et al. 2011)

Pyrrhoderma lamaoense (Murrill) L.W. Zhou \& Y.C. Dai [as 'lamaënse'], in Zhou et al., Mycologia 110(5): 882 (2018)

On H. brasiliensis as Fomes lamaoensis: Democratic Republic of the Congo, Cote d'Ivoire,

East Indies, Ghana, India, Malaysia, Philippines, Sri Lanka, Fiji as Phellinus lamaoensis (Spaulding 1961, Dingley et al. 1981)

Pyrrhoderma noxium (Corner) L.W. Zhou \& Y.C. Dai, in Zhou et al., Mycologia 110(5): 882 (2018)

= Phellinus noxius (Corner) G. Cunn., Bull. N.Z. Dept. Sci. Industr. Res. 164: 221 (1965)

Associated with brown root rot of $H$. brasiliensis: Brazil, Cote d'Ivoire, Fiji, Myanmar, Papua New Guinea, Thailand; on root of H. brasiliensis as Fomes noxius: Ghana, Malay Peninsula, Nigeria (West 1938, Dade 1940, Thompson \& Johnston 1953, Giatgong 1980, Dingley et al. 1981, 
Shaw 1984, Nandris et al. 1987, Holliday 1995, Mendes et al. 1998, Thaung 2007, Ogbebor et al. 2010)

Rhizoctonia anceps (Bres., Syd. \& P. Syd.) Oberw., R. Bauer, Garnica \& R. Kirschner, Mycol. Prog. 12: 774 (2013)

On H. brasiliensis: Brazil as Ceratobasidium anceps (Mendes et al. 1998)

Rhizoctonia solani J.G. Kühn, Ann. Sper. Agr., N.S.: 224 (1858)

$=($ Pat.) D.P. Rogers, Farlowia 1(1): 113 (1943) [1943-1944]

On $H$. brasiliensis as Thanatephorus cucumeris: Brazil, Malaysia, Papua New Guinea; associated with web blight on host stem at soil surface or dead roots of $H$. brasiliensis as Pellicularia filamentosa: Bolivia, Brazil, Colombia, Costa Rica, Honduras, Peru, Sri Lanka, (Spaulding 1961, Liu 1977, Shaw 1984, Mendes et al. 1998)

\section{Rhizoctonia sp.}

On H. brasiliensis: Brazil (Mendes et al. 1998)

\section{Rhizoctonia spp.} 2014)

Associated with rubber tree seeds harvested of $H$. brasiliensis: Brazil (Theodoro \& Batista

Rigidoporus lineatus (Pers.) Ryvarden, Norw. J1 Bot. 19: 236 (1972)

= Berk., Ann. Mag. nat. Hist., Ser. 1 10: 375 (1843) [1842]

Associated with heart rot of heartwood of H. brasiliensis: Brazil as Polyporus zonalis, Papua New Guinea (Spaulding 1961, Shaw 1984)

Rigidoporus microporus (Sw.) Overeem, Icon. Fung. Malay. 5: 1 (1924)

= Fomes lignosus (Klotzsch) Bres., Hedwigia 4(39): 519 (1912)

= Fomes semitostus (Berk.) Cooke, Grevillea 14(no. 69): 21 (1885)

= Leptoporus lignosus (Klotzsch) R. Heim, Annals Cryptog. Exot. 7: 22 (1934)

= Polyporus lignosus Klotzsch, Linnaea 8(4): 485 (1833)

= Rigidoporus lignosus (Klotzsch) Imazeki, Bull. Gov. Forest Exp. Stn Tokyo 57: 118 (1952)

Associated with white root rot disease H. brasiliensis: Africa, Brazil, China, Democratic Republic of the Congo, Costa Rica, Cote d'Ivoire, Equatorial Guinea, Ghana, India, Indonesia, Malay Peninsula, Malaysia, Mexico, Myanmar, Nigeria, Papua New Guinea, Philippines, Sri Lanka, Thailand, West Africa (West 1938, Dade 1940, Hughes 1953, Thompson \& Johnston 1953, Spaulding 1961, Giatgong 1980, Oghenekaro et al. 2014)

Schizophyllum commune Fr. [as 'Schizophyllus communis'], Observ. Mycol. (Havniae) 1: 103 (1815)

On decaying logs and branches of $H$. brasiliensis: Ghana, Malaysia, Philippines, Thailand (Teodoro 1937, Hughes 1953, Williams \& Liu 1976, Seephueak et al. 2011)

Schizophyllum umbrinum Berk., Hooker's J. Bot. Kew Gard. Misc. 3: 15 (1851)

On H. brasiliensis: Dominican Republic, Haiti (Ciferri 1961, Benjamin \& Slot 1969)

Scytinostroma duriusculum (Berk. \& Broome) Donk, Fungus 26: 20 (1956)

On H. brasiliensis: Malaysia as Stereum duriusculum (Williams \& Liu 1976)

Septobasidium atratum Pat., Bull. Soc. Mycol. Fr. 16(4): 181 (1900)

On H. brasiliensis: Brazil (Mendes et al. 1998) 
Septobasidium bogoriense Pat., in Hennings in Warburg, Monsunia 1: 138 (1899) [1900]

On H. brasiliensis: Malaysia (Singh 1980)

Septobasidium heveae Couch ex L.D. Gómez \& Henk, Lankesteriana 4(1): 84 (2004)

On bark of H. brasiliensis associated with Coccoidea: Amazonas (Gómez \& Henk 2004)

\section{Septobasidium sp.}

On H. brasiliensis: Malaysia, Thailand (Turner 1971, Giatgong 1980)

Stereopsis hiscens (Berk. \& Ravenel) D.A. Reid, Beih. Nova Hedwigia 18: 298 (1965)

On H. brasiliensis: Malaysia as Stereum cuneoforme (Singh 1980)

Stilbum heveae Zimm., Bulletin Inst. Bot. Buitenzorg 10: 21 (1901)

On dead branches of H. brasiliensis: Indonesia (Saccardo 1902)

\section{Stilbum sp.}

On H. brasiliensis: Thailand (Giatgong 1980)

\section{Tilletiopsis sp.}

On H. brasiliensis: Papua New Guinea (Shaw 1984)

Tinctoporellus epimiltinus (Berk. \& Broome) Ryvarden, Trans. Br. Mycol. Soc. 73(1): 18 (1979)

On H. brasiliensis: Dominican Republic as Poria borbonica, Haiti as Poria epimiltina (Ciferri 1961, Benjamin \& Slot 1969)

Trametes apiaria (Pers.) Zmitr., Wasser \& Ezhov, in Zmitrovich, Ezhov \& Wasser, Int. J. Med. Mushrooms 14(3): 317 (2012)

On branch litter of $H$. brasiliensis: Thailand as Hexagonia apiaria (Seephueak et al. 2011)

Trametes cingulata Berk., Hooker's J. Bot. Kew Gard. Misc. 6: 164 (1854)

On H. brasiliensis: Brunei Darussalam (Peregrine \& Ahmad1982)

Trametes elegans (Spreng.) Fr., Epicr. Syst. Mycol. (Upsaliae): 492 (1838) [1836-1838]

On H. brasiliensis as Lenzites elegan: Malaysia, Thailand on branch litter (Singh 1980, Seephueak et al. 2011)

Trametes hirsuta (Wulfen) Lloyd, Mycol. Writ. 7(Letter 73): 1319 (1924)

On branch litter of H. brasiliensis: Thailand as Coriolus hirsutus (Seephueak et al. 2011)

Trametes persoonii (Mont.) Pat., Bull. Soc. Mycol. Fr. 23: 80 (1907)

On H. brasiliensis: Philippines (Teodoro 1937)

Tremella fuciformis Berk., Hooker's J. Bot. Kew Gard. Misc. 8: 277 (1856)

On branch litter of $H$. brasiliensis: Thailand (Seephueak et al. 2011)

Typhula ishikariensis S. Imai, Trans. Sapporo nat. Hist. Soc. 11(1): 75 (1930) [1929]

On branch litter of $H$. brasiliensis: Thailand (Seephueak et al. 2011)

Xeromphalina campanella (Batsch) Kühner \& Maire, in Konrad \& Maublanc, Icones selectae Fungorum, 6 Texte general 6: 284 (1934)

On branch litter of $H$. brasiliensis: Thailand (Seephueak et al. 2011) 


\section{Phylum: Oomycota}

Globisporangium splendens (Hans Braun) Uzuhashi, Tojo \& Kakish., Mycoscience 51(5): 363 (2010)

On H. brasiliensis: Malaysia as Pythium splendens (Liu 1977)

Phytophthora botryosa Chee, Trans. Br. Mycol. Soc. 52(3): 428 (1969)

Associated with abnormal leaf fall disease and stripe canker on petioles of $\mathrm{H}$. brasiliensis: Malaysia, Thailand as black strip and phytophthora leaf fall, Viet Nam (Drenth et al. 2004, Deechouy 2013)

Phytophthora cactorum (Lebert \& Cohn) J. Schröt., in Cohn, Krypt.-Fl. Schlesien (Breslau) 3.1(916): 236 (1886) [1889]

Associated with seedling blight of $H$. brasiliensis: China, India, Indonesia, Sri Lanka, USSR (Spaulding 1961, Erwin \& Ribeiro 1996)

Phytophthora capsici Leonian, Phytopathology 12(9): 403 (1922)

Associated with black stripe and stem canker of $H$. brasiliensis: Brazil, China, Nigeria, Thailand (Mendes et al. 1998, Yu 1998, Drenth et al. 2004)

Phytophthora citricola Sawada, Report of the Department of Agriculture, Government Research Institute of Formosa 27: 21 (1927)

On H. brasiliensis: Sri Lanka (Erwin \& Ribeiro 1996)

Phytophthora citrophthora (R.E. Sm. \& E.H. Sm.) Leonian, Am. J. Bot. 12: 445 (1925)

Associated with abnormal leaf fall disease of $H$. brasiliensis: Brazil, China, Cote d'Ivoire, Indonesia, Thailand (Erwin \& Ribeiro 1996, Mendes et al. 1998, Laohasakul et al. 2017)

Phytophthora colocasiae Racib., Parasit. Alg. Pilze Java's (Jakarta) 1: 9 (1900)

Associated with leaf fall, stem canker and black stripe of $H$. brasiliensis: China (Erwin \& Ribeiro 1996)

Phytophthora meadii McRae, J. Bombay nat. Hist. Soc. 25: 760 (1918)

Associated with abnormal leaf fall, pod rot, stripe canker and black stripe of $H$. brasiliensis: Brazil, Cambodia, Cameroon, China, Democratic Republic of the Congo, Costa Rica, Ghana, India, Indonesia, Liberia, Malay Peninsula, Malaysia, Myanmar, Nicaragua, Nigeria, Peru, Philippines, Sri Lanka, Thailand, Venezuela, Viet Nam (Thompson \& Johnston 1953, Tai 1979, Erwin \& Ribeiro 1996, Drenth et al. 2004)

Phytophthora nicotianae Breda de Haan, Meded. Lds PlTuin, Batavia 15: 57 (1896)

= Phytophthora nicotianae var. parasitica (Dastur) G.M. Waterh., Mycol. Pap. 92: 14 (1963)

= Phytophthora parasitica Dastur, Memoirs of the Dept. Agric. India, Bot. Ser. 5(4): 226 (1913)

Associated with abnormal leaf fall, pod rot, stripe canker and black stripe of $H$. brasiliensis: China, Nigeria, India, Malaysia, Thailand (Giatgong 1980, Erwin \& Ribeiro 1996, Drenth et al. 2004, Rubber Research Institute of Thailand 2010, Latifah et al. 2017)

Phytophthora palmivora (E.J. Butler) E.J. Butler, Science Rep. Agric. Res. Inst. Pusa: 82 (1919) [1918] 555 (1913)

= Phytophthora arecae (L.C. Coleman) Pethybr., Scientific Proc. R. Dublin Soc., N.S. 13: = Phytophthora faberi Maubl., Agriculture prat. Pays chauds 79: 315 (1909) 
= Phytophthora heveae A.W. Thomps., Malay. agric. Journal 17(3-4): 77 (1929)

Associated with abnormal leaf fall, patch canker, stripe canker, pod rot and rot disease on bark, seedling and fruit of $H$. brasiliensis: Brazil, Cambodia, China, Democratic Republic of the Congo, Costa Rica, Ghana, India, Indonesia, Liberia, Malay Peninsula, Malaysia, Mexico, Myanmar, Nigeria, Papua New Guinea, Philippines, Samoa, Sri Lanka, Thailand as black strip and phytophthora leaf fall, Viet Nam (Thompson \& Johnston 1953, Teodoro 1937, West 1938, Spaulding 1961, Litzenberger et al. 1962, McGuire \& Crandall 1967, Dingley et al. 1981, Shaw 1984, Erwin \& Ribeiro 1996, Drenth et al. 2004, Thaung 2008, Deechouy 2013)

Phytophthora palmivora var. palmivora (E.J. Butler) E.J. Butler, Science Rep. Agric. Res. Inst. Pusa: 82 (1919) [1918]

On H. brasiliensis: Brazil, Cameroon, China, Democratic Republic of the Congo, Costa Rica, Fiji, India, Indonesia, Liberia, Malaysia, Myanmar, Papua New Guinea, Philippines, Sri Lanka, Thailand, Uganda (Erwin \& Ribeiro 1996)

Phytophthora phaseoli Thaxt., Bot. Gaz. 14(11): 274 (1889)

Associated with seedling blight of $H$. brasiliensis: Philippines (Erwin \& Ribeiro 1996)

\section{Phytophthora sp.}

On H. brasiliensis: Cote d'Ivoire, India, Malaysia, Mexico as die-back of young budded shoots of seedling, Thailand on leaves, Viet Nam (West 1938, Alvarez 1976, Nandris et al. 1987, Drenth et al. 2004, Seephueak et al. 2010, Martin et al. 2014)

Phytopythium vexans (de Bary) Abad, de Cock, Bala, Robideau, A.M. Lodhi \& Lévesque, Persoonia 34: 37 (2014)

Associated with patch canker on bark and root rot of $H$. brasiliensis: China as Pythium vexans, Malay Peninsula as Pythium complectens (Thompson \& Johnston 1953, Spaulding 1961, Zeng et al. 2005)

Pythium acanthicum Drechsler, J. Wash. Acad. Sci. 20: 408 (1930)

On H. brasiliensis: China (Yu 1998)

\section{Pythium sp.}

On H. brasiliensis: Cote d'Ivoire (Nandris et al. 1987)

\section{Division: Zygomycota}

Choanephora cucurbitarum (Berk. \& Ravenel) Thaxt., Rhodora 5: 99 (1903)

On branches, leaves and stems of H. brasiliensis: Liberia, Malaysia, Papua New Guinea (Turner 1971, Schreurs 1972, Shaw 1984)

Mortierella polycephala Coem., Bull. Soc. R. Bot. Belg., sér. 2 16: 536 (1863)

On leaves of $H$. brasiliensis: Thailand (Seephueak et al. 2010)

\section{Rhizopus spp.} 2014)

Associated with rubber tree seeds harvested of $H$. brasiliensis: Brazil (Theodoro \& Batista

\section{Umbelopsis sp.}

Endophytic on living leaves and sapwood of H. brasiliensis: Peru (Gazis \& Chaverri 2010) 


\section{Discussion}

Para rubber plantations have been expanding rapidly throughout Southeast Asia and especially in Thailand (Herrmann et al. 2016, Vongkhamheng et al. 2016). The tree is a favorable host for many pests and diseases, especially fungi (Jayasinghe 2000, Gazis \& Chaverri 2010, Ariharan et al. 2015). In this study, 167 fungal specimens were collected from Chiang Mai, Chiang Rai, Loei, Phayao, Ranong, and Sukhothai provinces in Thailand. We collected symptomatic and asymptomatic ascomycetes associated with Hevea brasiliensis and identified them based on morphology together with multi-gene phylogeny. Fifty-one collections were isolated, and five were sequenced directly from fruiting structures. There were 36 taxa distributed among 21 families in 12 orders. Twenty-four taxa are accommodated in seven orders, 14 families and 19 genera in Dothideomycetes, which included one new genus, four new species, 12 new host records, one sexual morph record and one reference specimen. Twelve taxa are accommodated in five orders, seven families and nine genera in Sordariomycetes, which includes three new species, eight new host records and one asexual morph record. Of these, Pleosporales and Diaporthales were the dominant orders in Dothideomycetes and Sordariomycetes yielding ten and six taxa, respectively.

Although studies of fungi in Thailand have resulted in large numbers of novel taxa (Hyde et al. 2018), this was not the case with rubber trees. The reason for this may be that 1) as rubber trees were introduced to Thailand, they may have been colonized by a weed-like consortium of fungi, 2) twigs and branches attached to trees were mostly collected or 3) that fungal discovery in Thailand is coming to an end. This does not appear to be the case (Hyde et al. 2020c), but it will be interesting to establish the reasons for lack of novelty.

Fungi show high ecological as well as functional diversity (Walker et al. 2014, Braunsdorf et al. 2016, Raja et al. 2017, Lücking et al. 2020, Chethana et al. 2021). The term "host-jump" and "host-shift" were proposed by Roy (2001) for fungal taxa that colonized unrelated or related host species. Some species such as Neoroussoella heveae, Muyocopron dipterocarpi and Pernoeutypa longiasca isolated from Para rubber formed appressoria on agar (Senwanna et al. 2017, 2019, Phookamsak et al. 2019). Appressoria are functionally specialized cells found in certain plant pathogens and endophytes (Chethana et al. 2021) and may indicate adaptations for an endophytic lifestyle (Konta et al. 2016, Phukhamsakda et al. 2016, Senwanna et al. 2017, 2019, Demoor et al. 2019, Chethana et al. 2021). In this study, the appressoria-like structures were found in Allocryptovalsa cryptovalsoidea, Hermatomyces sphaericus, Paraeutypella citricola, Pleopunctum heveae, Pseudopithomyces palmicola and Verruconis phayaoensis. Most previous studies of fungi on Para rubber focused on endophytes, symptomatic material, and saprobes on decaying substrates (Weir 1926, Spaulding 1961, Jayasinghe 1999a, Gazis \& Chaverri 2010, Seephueak et al. 2010, 2011, Trakunyingcharoen et al. 2015a). We collected symptomatic and asymptomatic branches and twigs attached to the Para rubber trees, for the present study. Corynespora cassiicola, Lasiodiplodia theobromae and Periconia heveae found in our study have also been also reported from Amazon Forest areas (Spaulding 1961). which are the original areas for Para rubber. Corynespora cassiicola and Lasiodiplodia theobromae are common cosmopolitan species on various hosts with diverse life modes (Lopez et al. 2018, Pujade-Renaud et al. 2019, Salvatore et al. 2020a, b, Farr and Rossman 2021). Periconia heveae is commonly found on Hevea causing leaf spot and blight disease (Spaulding 1961, Farr \& Rossman 2021). Most other taxa found on rubber trees have previously been collected on other plants in Thailand, such as Bauhinia purpurea, Chromolaena odorata, Coffea arabica, Dimocarpus longan, Mangifera indica, Pandanus spp., Persea americana, and Tectona grandis (Trakunyingcharoen et al. 2015a, b, Doilom et al. 2017, Tibpromma et al. 2016, 2018, Phookamsak et al. 2019, Mapook et al. 2020). The fungi associated with Para rubber are interesting as they have been subjected to few molecular studies. Furthermore, with modern multigene approaces, approach, there is a likelihood of discovering asexual/sexual morph connections, e.g., Cytospora diopuiensis, Gloniopsis leucaenae and Pseudofusicoccum adansoniae (Senwanna et al. 2020). Para rubber is not a native plant to Thailand and therefore, the fungi occurring on this host have most likely jumped from surrounding hosts plants. 
According to the U.S. National Fungus Collections Fungus-Host Database (Farr \& Rossman 2020), together with relevant literature, there are 785 species and 180 taxa identified to genus on Para rubber from 59 countries. These species are classified in four phyla: (i) Ascomycota: 672 species and 163 taxa named only to genus, in 44 orders, 124 families and 434 genera, (ii) Basidiomycota: 97 species and 13 taxa named only to genus, in 19 orders, 38 families and 71 genera, (iii) Oomycota: 14 species and two taxa named only to genus, in Peronosporales, two families and four genera, and (iv) Zygomycota: two species and two taxa named only to genus, in three orders, four families and four genera. The largest number of reports are from Thailand (670 taxa) and Malaysia (128 taxa); however, most previous taxa were identified based on morphology. The most commonly reported genera are Colletotrichum (associated with leaves and commonly known as anthracnose disease), followed by Xylaria, Sporidesmium, Curvularia, Phytophthora, Cladosporium and Fusarium species. These taxa on Para rubber are plant pathogens and endophytes, or are associated with degrading plant material or soil in plantations. However, different species show varying abundance for different plant parts (Seephueak et al. 2010, 2011, Araújo et al. 2020). Many taxa on Para rubber are asexual forms and mostly occur on decomposing plant debris (Lodge 1977). Asexual states have more frequently been isolated from plant litter (Shanthi \& Vittal 2010, Osono 2020), and via isolation from tree leaf litter and decaying branch litter (Seephueak et al. 2010, 2011). Studies revealed that the abundant species on Para rubber are Ascomycota followed by Basidiomycota (Venkatachalam et al. 2006, Gazis \& Chaverri 2010, Chaverri et al. 2011, Rocha et al. 2011, Déon et al. 2012a, b, Cai et al. 2013, Sunpapao \& Pornsuriya 2014, Monkai et al. 2017, Meeboon \& Takamatsu 2020).

This study focused on fungi collected from specimens that were attached to Para rubber trees. Only $48 \%$ of our collections were successfully sequenced and therefore included in this report. Another $52 \%$ of our collections have morphological data. However, we were unable to obtain sequence data as the spores of some species did not germinate, or we could not extract DNA from the fungal structures. The information of diversity and geographic distribution of fungi on rubber is currently incomplete. Thus, studies of fungi on Para rubber and surrounding plants should be continued.

\section{Acknowledgements}

Chiang Mai University and the Mushroom Research Foundation is thanked for partially supporting this work. K.D. Hyde thanks Chiang Mai University for the award of Visiting Professor, the 2019 high-end foreign expert introduction plan to Kunming Institute of Botany (Granted by the Ministry of Science and Technology of the People's Republic of China, Grant No. G20190139006), the future of specialist fungi in a changing climate: baseline data for generalist and specialist fungi associated with ants, Rhododendron species and Dracaena species (Grant No. DBG6080013), Impact of climate change on fungal diversity and biogeography in the Greater Mekong Subregion (Grant No. RDG6130001). We thank Dr. Rungtiwa Phookamsak, Dr. Dhanushka N. Wansinghe, Dr. Saowaluck Tibpromma, Sirinapa Konta, Nimali Indeewari de Silva, and Qiu-Ju Shang for their valuable suggestions and help. Dr. Shaun Pennycook is thanked for his essential nomenclatural review.

\section{References}

Adamčík S, Cai L, Chakraborty D, Chen XH et al. 2015 - Fungal biodiversity profiles 1-10. Cryptogamie, Mycologie 36, 121-166.

Ahrends A, Hollingsworth PM, Ziegler AD, Fox JM et al. 2015 - Current trends of rubber plantation expansion may threaten biodiversity and livelihoods. Global Environmental Change 34, 48-58.

Alfieri SA Jr., Langdon KR, Wehlburg C, Kimbrough JW. 1984 - Index of Plant Diseases in Florida (Revised). Florida, Division of Plant Industry, Florida Department of Agriculture \& Consumer Services. Bulletin 11, 1-389. 
Alvarez MG. 1976 - Primer catalogo de enfermedades de plantas Mexicanas. Fitofilo 71, 1-169.

Alves A, Crous PW, Correia A, Phillips AJ. 2008 - Morphological and molecular data reveal cryptic speciation in Lasiodiplodia theobromae. Fungal Diversity 28, 1-3.

Amano K. 1986 - Host range and geographical distribution of the powdery mildew fungi. Japan Scientific Societies Press, Tokyo, 741 pages.

Anonymous. 1963 - Index of Fungi Vol. 2; 1950-1960. Commonwealth Mycological Institute: Kew, Surrey, England.

Anonymous. 1968 - Index of Fungi Vol. 3; 1961-1966. Commonwealth Mycological Institute: Kew, Surrey, England.

Anonymous. 1977 - Index of Fungi; Vol. 4; 1971-1980, Part 13. Commonwealth Mycological Institute: Kew, Surrey, England.

Aoki T, Kasson MT, Berger MC, Freeman S et al. 2018 - Fusarium oligoseptatum sp. nov., a mycosymbiont of the ambrosia beetle Euwallacea validus in the Eastern US and typification of $F$. ambrosium. Fungal Systematics \& Evolution 1, 23-39.

Aoki T, Smith JA, Kasson MT, Freeman S et al. 2019 - Three novel Ambrosia Fusarium Clade species producing clavate macroconidia known ( $F$. floridanum and $F$. obliquiseptatum) or predicted ( $F$. tuaranense) to be farmed by Euwallacea spp. (Coleoptera: Scolytinae) on woody hosts. Mycologia 111, 919-935.

Aptroot A. 1995 - Redisposition of some species excluded from Didymosphaeria (Ascomycotina). Nova Hedwigia 60, 325-379.

Araújo KS, Brito VN, Veloso TG, de Leite TS et al. 2020 - Diversity and distribution of endophytic fungi in different tissues of Hevea brasiliensis native to the Brazilian Amazon Forest. Mycological Progress 19, 1057-1068.

Ariharan VN, Meena Devi VN, Nagendra Prasad P, Parameswaran NK. 2016 - Occurrence of leaf spot disease in Hevea brasiliensis (Rubber tree). Asian Journal of Pharmaceutical and Clinical Research 9, 324-326.

Ariyawansa HA, Hyde KD, Jayasiri SC, Buyck B et al. 2015 - Fungal diversity notes 111-252taxonomic and phylogenetic contributions to fungal taxa. Fungal Diversity 75, 27-274.

Ariyawansa HA, Tanaka K, Thambugala K, Phookamsak R et al. (2014) A molecular phylogenetic reappraisal of the Didymosphaeriaceae (= Montagnulaceae). Fungal Diversity 68, 69-104.

Ariyawansa HA, Kang J-C, Alias SA, Chukeatirote E, Hyde KD. 2013 - Towards a natural classifcation of Dothideomycetes: the genera Dermatodothella, Dothideopsella, Grandigallia, Hysteropeltella and Gloeodiscus (Dothideomycetes incertae sedis). Phytotaxa 147, 35-47.

Arnold GRW. 1986 - Lista de Hongos Fitopatogenos de Cuba. Ministerio de Cultura Editorial Cientifico-Tecnica, 207 pages.

Barr ME. 1990 - Some dictyosporous genera and species of Pleosporales in North America. Memoirs of the New York Botanical Garden 62, 1-92.

Batista E, Lopes A, Alves A. 2021 - What Do We Know about Botryosphaeriaceae? An Overview of a Worldwide Cured Dataset. Forests 12, 313.

Benjamin CR, Slot A. 1969 - Fungi of Haiti. Sydowia 23, 125-163.

Boehm EW, Mugambi GK, Miller AN, Huhndorf SM et al. 2009 - A molecular phylogenetic reappraisal of the Hysteriaceae, Mytilinidiaceae and Gloniaceae (Pleosporomycetidae, Dothideomycetes) with keys to world species. Studies in Mycology 64, 49-83.

Boonmee S, Bhat DJ, Maharachchikumbura SS, Hyde KD. 2014 - Clavatispora thailandica gen. et sp. nov., a novel taxon of Venturiales (Dothideomycetes) from Thailand. Phytotaxa 176, 092101.

Boonmee S, Wanasinghe DN, Calabon MS, Huanraluek N et al. 2021 - Fungal diversity notes 1387-1511: taxonomic and phylogenetic contributions on genera and species of fungal taxa. Fungal Diversity 111, 1-335. 
Braganca CAD, Damm U, Baroncelli R, Massola Jr. NS, Crous PW. 2016 - Species of the Colletotrichum acutatum complex associated with anthracnose diseases of fruit in Brazil. Fungal Biology 120, 547-561.

Brayford D. 1987 - Fusarium bungicourtii sp. nov., and its relationship to $F$. tumidum and $F$. tumidum var. coeruleum. Transactions of the British Mycological Society 89, 347-351.

Braun U, Crous PW, Nakashima C. 2014 - Cercosporoid fungi (Mycosphaerellaceae) 2. species on monocots (Acoraceae to Xyridaceae, excluding Poaceae). IMA fungus 5, 203-390.

Braunsdorf C, Mailänder-Sánchez D, Schaller M. 2016 - Fungal sensing of host environment. Cellular microbiology 18, 1188-1200.

Brown AE, Soepena H. 1994 - Pathogenicity of Colletotrichum acutatum and C. gloeosporioides on leaves of Hevea spp. Mycological Research 98, 264-266.

Burgess TI, Barber PA, Mohali S, Pegg G et al. 2006 - Three new Lasiodiplodia spp. from the tropics, recognized based on DNA sequence comparisons and morphology. Mycologia 98, 423-435.

Cai ZY, Li G, Lin C, Shi T, Zhai L et al. 2013 - Identifying pathogenicity genes in the rubber tree anthracnose fungus Colletotrichum gloeosporioides through random insertional mutagenesis. Microbiological research 168, 340-350.

Cai ZY, Liu YX, Huang GX, Zhou M et al. 2014 - First report of Alternaria heveae causing black leaf spot of rubber tree in China. Plant Disease 98, 1011.

Cai ZY, Liu YX, Li GH, Wang YF, Zhou M. 2015 - First report of Alternaria alternata causing black leaf spot of rubber tree in China. Plant Disease 99, 290.

Cai ZY, Liu YX, Shi YP, Dai LM et al. 2019 - Alternaria yunnanensis sp. nov., a new Alternaria species causing foliage spot of rubber tree in China. Mycobiology 47, 66-75.

Cai ZY, Liu YX, Shi YP, Mu HJ, Li GH. 2016 - First report of leaf anthracnose caused by Colletotrichum karstii of rubber tree in China. Plant Disease 100, 2528-2529.

Cao X, Xu X, Che H, West JS, Luo D. 2019 - Three Colletotrichum species, including a new species, are associated to leaf anthracnose of rubber tree in Hainan, China. Plant Disease 103, $117-124$.

Carbone I, Kohn LM. 1999 - A method for designing primer sets for speciation studies in filamentous ascomycetes. Mycologia 91, 553-556.

Castellani E, Ciferri R. 1950 - Mycoflora Erythraea, Somala et Aethipica Suppl. 1. Atti Ist. Bot. Lab. Crittog. Univ. Pavia, 52 pages.

Chaverri P, Gazis RO. 2011 - Linking ex planta fungi with their endophytic stages: Perisporiopsis, a common leaf litter and soil fungus, is a frequent endophyte of Hevea spp. and other plants. Fungal Ecology 4, 94-102.

Chaverri P, Gazis RO, Samuels GJ. 2011 - Trichoderma amazonicum, a new endophytic species on Hevea brasiliensis and H. guianensis from the Amazon basin. Mycologia 103, 139-151.

Chen H, Yi ZF, Schmidt-Vogt D, Ahrends A et al. 2016 - Pushing the limits: The pattern and dynamics of rubber monoculture expansion in Xishuangbanna, SW China. PLOS ONE 11, $\mathrm{e} 0150062$.

Cherdchim B, Satansat J. 2016 - Influences of ethylene stimulation of rubber trees (Hevea brasilliensis) on the extractives and fungal resistance of lumber. Cerne 22, 223-232.

Chethana KWT, Jayawardena RS, Chen YJ, Konta S et al. 2021 - Appressorial interactions with host and their evolution. Fungal Diversity 110, 75-107.

Chi P, Jiang Z, Xiang M. 2007 - Flora Fungorum Sinicorum. Vol. 34. Phomopsis. Science Press, Beijing, 186 pages.

Chipp TF. 1920 - The fungus flora of Hevea brasiliensis, in the Gardens' Bulletin, Straits Settlement 2, 186-192.

Chipp TF. 1921 - A list of the fungi of the Malay Peninsula, in the Gardens' Bulletin, Straits Settlement 2, 311-417.

Chupp C. 1954 - Monograph of the fungus genus Cercospora. Published by the Author, Ithaca, New York, 667 pages. 
Ciferri R. 1929 - Micoflora Domingensis. Lista de los hongos hasta la fecha indicados en Santo Domingo. Estación Agronómica de Moca Ser. B, Botánica 14, 1-260.

Ciferri R. 1961 - Mycoflora Domingensis Integrata. Quaderno. Laboratorio Crittogamico, Istituto Botanico della Università di Pavia 19, 1-539.

Crous PW. 2002 - Taxonomy and pathology of Cylindrocladium (Calonectria) and allied genera. American Phytopathological Society, St. Paul, Minnesota, 278 pages.

Crous PW, Carris LM, Giraldo A, Groenewald JZ et al. 2015a - The Genera of Fungi-fixing the application of the type species of generic names-G2: Allantophomopsis, Latorua, Macrodiplodiopsis, Macrohilum, Milospium, Protostegia, Pyricularia, Robillarda, Rotula, Septoriella, Torula, and Wojnowicia. IMA Fungus 6, 163-198.

Crous PW, Groenewald JZ, Shivas RG, Edwards J et al. 2011 - Fungal Planet description sheets: 69-91. Persoonia 26, 108-156.

Crous PW, Luangsa-Ard JJ, Wingfeld MJ, Carnegie AJ et al. 2018a - Fungal Planet description sheets: 785-867. Persoonia 41, 238-417.

Crous PW, Schumache RK, Akulov A, Thangavel R et al. 2019 - New and Interesting Fungi. 2. Fungal Systematcs and Evolution 3, 57-134.

Crous PW, Schumacher RK, Wingfield MJ, Lombard L et al. 2015b - Fungal systematics and evolution: FUSE 1. Sydowia 67, 81-118.

Crous PW, Wingfeld MJ, Burgess TI, Hardy GESJ et al. 2016 - Fungal planet description sheets: 469-557. Persoonia 37, 218-403.

Crous PW, Wingfield MJ, Burgess TI, Hardy GESJ et al. 2018b - Fungal Planet description sheets: 716-784. Persoonia 40, 240-393.

Dade HA. 1940 - A revised list of Gold Coast fungi and plant diseases. XXIX. Bulletin of Miscellaneous Information (Royal Botanic Gardens, Kew) 6, 205-247.

Damm U, Cannon PF, Woudenberg JHC, Johnston PR et al. 2012a - The Colletotrichum boninense species complex. Studies in Mycology 73, 1-36.

Damm U, Cannon PF, Woudenberg JHC, Crous PW. 2012b - The Colletotrichum acutatum species complex. Studies in Mycology 73, 37-113.

Dayarathne MC, Jones EBG, Maharachchikumbura SSN, Devadatha B et al. 2020 - Morphomolecular characterization of microfungi associated with marine based habitats. Mycosphere $11,1-188$.

de Almeida DAC, Gusmão LFP, Miller AN. 2016 - Taxonomy and molecular phylogeny of Diatrypaceae (Ascomycota, Xylariales) species from the Brazilian semi-arid region, including four new species. Mycological Progress 15, 1-27.

Deechouy S. 2013 - Soil and leaf litter fungi in plant protected area at Rajjaprabha dam, Suratthani Province and their antagonistic activities against para rubber pathogens. Doctoral dissertation, Prince of Songkla University (in Thai).

Demoor A, Silar P, Brun S. 2019 - Appressorium: the breakthrough in Dikarya. Journal of Fungi 5, 72.

Dennis RWG. 1970 - Fungus flora of Venezuela and adjacent countries (Kew bulletin. [New] additional series / Royal Botanic Gardens, Kew).

Déon M, Bourré Y, Gimenez S, Berger A et al. 2012a - Characterization of a cassiicolin-encoding gene from Corynespora cassiicola, pathogen of rubber tree (Hevea brasiliensis). Plant Science. 185, 227-237.

Déon M, Fumanal B, Gimenez S, Bieysse D et al. 2014 - Diversity of the cassiicolin gene in Corynespora cassiicola and relation with the pathogenicity in Hevea brasiliensis. Fungal Biology 118, 32-47.

Déon M, Scomparin A, Tixier A, Mattos C et al. 2012b - First characterization of endophytic Corynespora cassiicola isolates with variant cassiicolin genes recovered from rubber trees in Brazil. Fungal Diversity 54, 87e99.

Dingley JM, Fullerton RA, McKenzie EHC. 1981 - Survey of Agricultural Pests and Diseases. Technical Report Volume 2. Records of Fungi, Bacteria, Algae, and Angiosperms Pathogenic 
on Plants in Cook Islands, Fiji, Kiribati, Niue, Tonga, Tuvalu, and Western Samoa. F.A.O., 485 pages.

Dissanayake AJ, Phillips AJL, Hyde KD, Yan JY, Li XH. 2017a - The current status of species in Diaporthe. Mycosphere 8, 1106-1156.

Dissanayake AJ, Phillips AJL, Li XH, Hyde KD. 2017b - Botryosphaeriaceae: Current status of genera and species. Mycosphere 7, 1001-1073.

Dissanayake LS, Wijayawardene NN, Dayarathne MC, Samarakoon MC et al. 2021 Paraeutypella guizhouensis gen. et sp. nov. and Diatrypella longiasca sp. nov. (Diatrypaceae) from China. Biodiversity Data Journal 9, e63864.

Doilom M, Dissanayake AJ, Wanasinghe DN, Boonmee S et al. 2017 - Microfungi on Tectona grandis (teak) in Northern Thailand. Fungal Diversity 82, 107-182.

Doilom M, Shuttleworth LA, Roux J, Chukeatirote E, Hyde KD. 2015 - Botryosphaeriaceae associated with Tectona grandis (teak) in Northern Thailand. Phytotaxa 233, 1-026.

Dou ZP, He W, Zhang Y. 2017 - Lasiodiplodia chinensis, a new holomorphic species from China. Mycosphere 8, 521-532.

Drenth A, Guest DI. 2004 - Diversity and management of Phytophthora in Southeast Asia. Asia. Australian Centre for International Agricultural Research (ACIAR) 114, 1-238.

Ellis MB. 1967 - Dematiaceous Hyphomycetes VIII. Periconiella, Trichodochium, etc. Mycological papers 111, 1-46.

Ellis MB. 1971 - Dematiaceous hyphomycetes. Commonwealth, Mycological Institute Kew, Kew, Surrey, England, 608 pages.

Ellis MB. 1972 - Dematiaceous Hyphomycetes: XI. Commonwealth Mycological Institute Kew, Kew, Surrey, England.

Erwin DC, Ribeiro OK. 1996 - Phytophthora Diseases Worldwide. American Phytopathological Society (APS Press), St. Paul, Minnesota, 562 pages.

Evueh GA, Ogbebor NO. 2008 - Use of phylloplane fungi as biocontrol agent against Colletotrichum leaf disease of rubber (Hevea brasiliensis Muell. Arg.). African Journal of Biotechnology 7, 2569-2572.

Fan XL, Bezerra JDP, Tian CM, Crous PW. 2020 - Cytospora (Diaporthales) in China. Persoonia 45, $1-45$.

FAO. 2011 Protection against South American leaf blight of rubber in Asia and the Pacific region Column II. Food and Agriculture Organization of the United Nations Regional Office for Asia and the Pacific.

Farr DF, Rossman AY. 2021 - Fungal Databases, U.S. National Fungus Collections, ARS, USDA. https://nt.ars-grin.gov/fungaldatabases/ (Accessed January 5, 2020).

Firman ID. 1972 - A list of fungi and plant parasitic bacteria, viruses and nematodes in Fiji. Phytopathological Papers 15, 1-36.

Fitzpatrick HM. 1923 - Monograph of the Nitschkieae. Mycologia 15, 45-67.

Fitzpatrick HM. 1924 - The genus Fracchiaea. Mycologia 16, 101-114.

Florence U, Fashoranti E. 2018 - Corynespora leaf fall of Hevea brasilensis: Challenges and prospect. African Journal of Agricultural Research 13, 2098 - 2103.

Fox J, Castella JC, Ziegler AD, Westley SB. 2014 - Rubber plantations expand in mountainous Southeast Asia: what are the consequences for the environment?. Asia Pacific Issues 114. Honolulu: East-West Center.

French AM. 1989 - California Plant Disease Host Index. Calif. Dept. Food Agric., Sacramento, 394 pages.

Gadgil PD, Dick M. 2007 - Fungi Silvicolae Novazelandiae: 7. New Zealand Journal of Forestry Science 37, 329-335.

Gams W. 1975 - Cephalosporium-Like Hyphomycetes: Some Tropical Species. Transactions of the British Mycological Society 64, 389-404. 
Gasparotto L, Ferreira FA, Dos Santo AF, Rezende PJ, Furtado EL. 2012 - Capítulo 3: Doenças das folhas. In L Gasparotto, RJC Pereira (Eds.), Doenças da seringueira no Brasil Brasília, DF: EMBRAPA Amazônia Occidental, 39-176.

Gazis R, Chaverri P. 2010 - Diversity of fungal endophytes in leaves and stems of wild rubber trees (Hevea brasiliensis) in Peru. Fungal Ecology 3, 240-254.

Gazis R, Miadlikowska J, Arnold B, Lutzoni F, Chaverri P. 2012 - Culture-based study of endophytes associated with rubber trees in Peru reveals a new class of Pezizomycotina (Xylonomycetes). Molecular Phylogenetics and Evolution 65, 294-304.

Ghazali NIB. 2013 - Isolation and Identification of Fungi Associated with Leaf Disease of Hevea brasiliensis. Project Report (B.Sc.), Universiti Malaysia Sarawak.

Giatgong P. 1980 - Host Index of Plant Diseases in Thailand. Second Edition. Mycology Branch, Plant Pathology and Microbiology Division, Department of Agriculture and Cooperatives, Bangkok, Thailand (in Thai).

Giauque H, Hawkes CV. 2013 - Climate affects symbiotic fungal endophyte diversity and performance. American Journal of Botany 100, 1435-1444.

Giraldo A, Crous PW, Schumacher RK, Cheewangkoon R et al. 2017 - The Genera of Fungi-G3: Aleurocystis, Blastacervulus, Clypeophysalospora, Licrostroma, Neohendersonia and Spumatoria. Mycological Progress 16, 325-348.

Glass NL, Donaldson GC. 1995 - Development of primer sets designed for use with the PCR to amplify conserved genes from filamentous ascomycetes. Applied and Environmental Microbiology 61, 1323-1330.

Glez-Peña D, Gómez-BlancoD, Reboiro-Jato M, Fdez-Riverola F, Posada D. 2010 - ALTER: program-oriented format conversion of DNA and protein alignments. Nucleic Acids Research. Web Server issue. ISSN, $0305-1048$.

Gomes RR, Glienke C, Videira SIR, Lombard L et al. 2013 - Diaporthe: a genus of endophytic, saprobic and plant pathogenic fungi. Persoonia 31, 1-41.

Gómez LD, Henk DA. 2004 - Validation of the species of Septobasidium (Basidiomycetes) described by John N. Couch. Lankesteriana 4, 75-96: Jardón Botánico Lankester, Universidad de Costa Rica.

Griffon WM, Maublanc A. 1909 - Sur une maladie du cacaoyer. Bulletin de la Société Mycologique de France 25, 51-58.

Groenewald JZ, Nakashima C, Nishikawa J, Shin HD et al. 2013 - Species concepts in Cercospora: spotting the weeds among the roses. Studies in Mycology 75, 115-170.

Guu JR, Ju YM, Hsieh HJ. 2007 - Nectriaceous fungi collected from forests in Taiwan. Botanical Studies 48, 187-203.

Guyot J, Le Guen V. 2018 - A review of a century of studies on South American leaf blight of the rubber tree. Plant Disease 102: 1052-1065.

Hall TA.1999 - BioEdit: a user-friendly biological sequence alignment editor and analysis program for Windows 95/98/NT. Nucleic Acids Symposium Series 41, 95 -98.

Hansford CG. 1961 - The Meliolineae: a monograph. Beihefte zur Sydowia 2, 1-806.

Hashimoto A, Hirayama K, Takahashi H, Matsumura M et al. 2017 - Resolving the Lophiostoma bipolare complex: generic delimitations within Lophiostomataceae. Studies Mycology 90, 161-189.

Hennings P. 1902 - Fungi javanici novi a cl. Prof. Dr. Zimmermann collecti. Hedwigia. 41, 140149.

Herrera CS, Rossman AY, Samuels GJ, Lechat C, Chaverri P. 2013 - Revision of the genus Corallomycetella with Corallonectria gen. nov. for C. jatrophae (Nectriaceae, Hypocreales). Mycosystema 32, 518-544.

Hernández-Restrepo M, Giraldo A, van Doorn R, Wingfield MJ et al. 2020 - The Genera of FungiG6: Arthrographis, Kramasamuha, Melnikomyces, Thysanorea, and Verruconis. Fungal Systematics and Evolution 6, 1-24. 
Herrmann L, Lesueur D, Bräu L, Davison J et al. 2016 - Diversity of root-associated arbuscular mycorrhizal fungal communities in a rubber tree plantation chronosequence in Northeast Thailand. Mycorrhiza 26, 863-877.

Hieu ND, Nghia NA, Chi VTQ, Dung P. 2014 - Genetic diversity and pathogenicity of Corynespora cassiicola isolates from rubber trees and other hosts in Vietnam. Journal of Rubber Research 17, 187-203.

Hirooka Y, Rossman AY, Samuels GJ, Lechat C, Chaverri P. 2012 - A monograph of Allantonectria, Nectria, and Pleonectria (Nectriaceae, Hypocreales, Ascomycota) and their pycnidial, sporodochial, and synnematous anamorphs. Studies in Mycology 71: 1-210.

Ho YWH, Hyde KD. 2001 - Fungal communities on decaying palm fronds in Australia, Brunei, and Hong Kong. Paper presented at the Asian Mycological Congress 2000 (AMC 2000), incorporating the $2^{\text {nd }}$ Asia-Pacific Mycological Congress on Biodiversity and Biotechnology, and held at the University of Hong Kong on 9-13 July 2000. Mycological Research 105, 1458-1471.

Holliday P. 1995 - Fungus diseases of tropical crops. Courier Corporation.

Hosagoudar VB, Mathew S. 2000 - A preliminary report on the mycoflora of the Andaman \& Nicobar Islands, India. Journal of Economic and Taxonomic Botany 24, 631-640.

Hongsanan S, Hyde KD, Phookamsak R, Wanasinghe DN et al. 2020a - Refined families of Dothideomycetes: orders and families incertae sedis in Dothideomycetes. Fungal Diversity $105,17-318$.

Hongsanan S, Hyde KD, Phookamsak R, Wanasinghe DN et al. 2020b - Refined families of Dothideomycetes: Dothideomycetidae and Pleosporomycetidae. Mycosphere 11, 1553-2107.

Hora Júnior BTd, de Macedo DM, Barreto RW, Evans HC et al. 2014 - Erasing the Past: A New Identity for the Damoclean Pathogen Causing South American Leaf Blight of Rubber. PLOS ONE 9, e104750.

Huang SK, Hyde KD, Maharachchikumbura SSN, McKenzie EHC, Wen TC 2021 - Taxonomic studies of Coronophorales and Niessliaceae (Hypocreomycetidae). Mycosphere 12, 875-992.

Huanraluek N, Jayawardena RS, Thambugala KM, Tian Q. 2020 - New host records for three saprobic Dothideomycetes in Thailand. Asian Journal of Mycology 3, 345-361.

Huanraluek N, Phukhamsakda C, Senwanna C, Hongsanan S et al. 2019 - Verruconis heveae, a novel species from Hevea brasiliensis in Thailand. Phytotaxa 403, 47-54.

Huelsenbeck JP, Ronquist F. 2001 - MRBAYES: Bayesian inference of phylogenetic trees. Bioinformatics 17, 754-755.

Hughes SJ. 1952 - Fungi from the Gold Coast. I. Mycological Papers 48, 1-91.

Hughes SJ. 1953 - Fungi from the Gold Coast. II. Mycological Papers 50, 1-104.

Hunupolagama DM, Chandrasekharan NV, Wijesundera WSS, Kathriarachchi HS et al. 2017 Unveiling members of Colletotrichum acutatum species complex causing Colletotrichum leaf disease of Hevea brasiliensis in Sri Lanka. Current Microbiology 74, 747-756.

Hyde KD, Chaiwan N, Norphanphoun C, Boonmee S et al. 2018 - Mycosphere notes 169-224. Mycosphere 9, 271-430.

Hyde KD, Dong Y, Phookamsak R, Jeewon R et al. 2020a - Fungal diversity notes 1151-1276: taxonomic and phylogenetic contributions on genera and species of fungal taxa. Fungal Diversity 100: 5-277.

Hyde KD, Jeewon R, Chen YJ, Bhunjun CS et al. 2020c - The numbers of fungi: is the descriptive curve flattening? Fungal Diversity 103, 219-271.

Hyde KD, Jones EBG, Liu JK, Ariyawansa HA et al. 2013 - Families of Dothideomycetes. Fungal Diversity 63, 1-313.

Hyde KD, Norphanphoun C, Abreu VP, Bazzicalupo A et al. 2017 - Fungal diversity notes 603708: taxonomic and phylogenetic notes on genera and species. Fungal Diversity 87, 1-235.

Hyde KD, Norphanphoun C, Chen J, Dissanayake AJ et al. 2018 - Thailand's amazing diversity up to $96 \%$ of fungi in northern Thailand are novel. Fungal Diversity 93, 215-239. 
Hyde KD, Norphanphoun C, Maharachchikumbura SSN, Bhat DJ et al. 2020b - Refined families of Sordariomycetes. Mycosphere 11, 305-1059.

Hyde KD, Soytong K. 2007 - Understanding microfungal diversity: a critique. Cryptogamie Mycologie 28, 281-289.

Hytönen J, Nurmi J, Kaakkurivaara N, Kaakkurivaara T. 2019 - Rubber tree (Hevea brasiliensis) biomass, nutrient content, and heating values in southern Thailand. Forests 10, 638.

Index Fungorum. 2020 - http://www.indexfungorum.org/ Names/Names.asp. (accessed 2020)

Jayasinghe CK. 1999a - Pests and diseases of Hevea rubber and their geographical distribution. Bulletin Rubber Restoration Institute Sri Lanka 40, 1-8.

Jayasinghe CK. 1999b - Rubber diseases to be cautious in the next millennium and strategies in prevention and control. Bulletin Rubber Restoration Institute Sri Lanka 40, 32-38.

Jayasinghe CK. 2000 - Checklist of Rubber Pathogens in Sri Lanka. National Science Foundation Colombo.

Jayasinghe CK, Silva WPK, Nishantha N. 2009 - Occurance of Cylindrocladium quinqueseptatum Leaf Spot on Hevea brasiliensis in Sri Lanka. Ceylon Journal of Science (Biological Sciences) 38.

Jayasiri SC, Hyde KD, Jones EBG, McKenzie EHC et al. 2019 - Diversity, morphology and molecular phylogeny of Dothideomycetes on decaying wild seed pods and fruits. Mycosphere 10, 1-186.

Jayawardena RS, Hyde KD, Chen YJ, Papp V et al. 2020 - One stop shop IV: taxonomic update with molecular phylogeny for important phytopathogenic genera: 76-100. Fungal Diversity $103,87-218$.

Jayawardena RS, Hyde KD, Damm U, Cai L et al. 2016 - Notes on currently accepted species of Colletotrichum. Mycosphere 7, 1192-1260.

Jiang GZ, Gao F, Liu J, Liu YX, Shi YP, Cai ZY. 2019 - First report of black root disease caused by Chaetomium globosum on rubber tree seedlings in Yunnan, China. Plant Disease 103, 763-764.

Jiang N, Voglmayr H, Tian C. 2018 - New species and records of Coryneum from China. Mycologia 110, 1172-1188.

Jiang N, Yang Q, Fan X-L, Tian C-M. 2020 - Identification of six Cytospora species on Chinese chestnut in China. MycoKeys 62, 1-25.

Jinji P, Xin Z, Yangxian Q, Yixian X, Huiqiang Z, He Z. 2007 - First record of Corynespora leaf fall disease of Hevea rubber tree in China. Australasian Plant Disease Notes 2, 35-36.

Johnston A. 1960 - A supplement to a host list of plant diseases in Malaya. Mycological papers 77, $1-30$.

Junqueira NTV, Bezerra JL. 1990 - Nova doença foliar em seringueira (Hevea spp.), causada por Rosenscheldiella heveae sp. (Loculoascomycetes, Dothideales, Stigmateaceae). Fitopatologia Brasileira 15, 24-28.

Kaewchai S, Wang HK, Lin FC, Hyde KD, Soytong K. 2009 - Genetic variation among isolates of Rigidoporus microporus causing white root disease of rubber trees in southern Thailand revealed by ISSR markers and pathogenicity. African Journal of Microbiology Research 3, 641-648.

Kamal. 2010 - Cercosporoid fungi of India. Bishen Singh Mahendra Pal Singh, Dehra Dun, India, 351 pages.

Katoh K, Rozewicki J, Yamada KD. 2019 - MAFFT online service: multiple sequence alignment, interactive sequence choice and visualization, Briefings in Bioinformatics 20, 1160-1166.

Karunanayake KOLC, Adikaram NKB. 2020 - Stem-end rot in major tropical and sub-tropical fruit species. Ceylon Journal of Science 49, 327.

Kobayashi T. 2007 - Index of fungi inhabiting woody plants in Japan. Host, Distribution and Literature. Zenkoku-Noson-Kyoiku Kyokai Publishing Co., Ltd., 1227 pages.

Konta S, Hongsanan S, Tibpromma S, Thongbai B et al. 2016 - An advance in the endophyte story: Oxydothidaceae fam. nov. with six new species of Oxydothis. Mycosphere 7, 1425-1446. 
Konta S, Maharachchikumbura SSN, Senanayake IC, McKenzie EHC et al. 2020 - A new genus Allodiatrype, five new species and a new host record of diatrypaceous fungi from palms (Arecaceae). Mycosphere 11, 239-268.

Koukol O, Delgado G, Hofmann TA, Piepenbring M. 2018 - Panama, a hot spot for Hermatomyces (Hermatomycetaceae, Pleosporales) with five new species, and a critical synopsis of the genus. IMAFungus 9, 107-141.

Kumar S, Singh R. 2016 - Biodiversity, Distribution and Taxonomy of Conidial Fungus Corynespora (Corynesporascaceae) Associated With Malvaceae. Journal of Biodiversity \& Endangered Species 4, 1000166.

Kumar S, Stecher G, Tamura K. 2015 - MEGA7: Molecular Evolutionary Genetics Analysis version 7.0 for bigger datasets. Molecular Biology \& Evolution 33, 1870-1874.

Jacob CK. 2006 - Corynespora Leaf Disease of Hevea Brasiliensis, Strategies for Management. Kottayam: Rubber Research Institute of India.

Laohasakul B, Boonyapipat P, Plodpai P. 2017 - First report of Phytophthora citrophthora causing leaf fall of para rubber tree (Hevea brasiliensis) in Thailand. Plant Disease 101, 1057.

Latifah M, Zainal Abidin MA, Kamaruzaman S, Nusaibah SA. 2017 - Cross-infectivity of oil palm by Phytophthora spp. isolated from perennial crops in Malaysia. Forest Pathology 47, e12374.

Li BX, Shi T, Liu XB, Lin CH, Huang GX. 2014 - First report of rubber tree stem rot cause by Fusarium oxysporum in China. Plane Disease 98, 1008.

Li GJ, Hyde KD, Zhao RL, Hongsanan S, et al. 2016 - Fungal diversity notes 253-366: taxonomic and phylogenetic contributions to fungal taxa. Fungal Diversity 78, 1-237.

Li H, Aide TM, Ma Y, Liu W, Cao M. 2006 - Demand for rubber is causing the loss of high diversity rain forest in SW China. In: DL Hawksworth, AT Bull (Eds.), Plant Conservation and Biodiversity 16. Springer, Dordrecht. pp. 157-171.

Li JF, Phookamsak R, Jeewon R, Bhat DJ et al. 2017 - Molecular taxonomy and morphological characterization reveal new species and new host records of Torula species (Torulaceae, Pleosporales). Mycoogical Progress 16, 447-461.

Liang X, Peng Y, Liu Y, Wang M et al. 2019 - First report of Bipolaris bicolor causing a leaf spot disease on rubber tree. Journal of Phytopathology 167, 553-557.

Lieberei R. 2007 - South American leaf blight of the rubber tree (Hevea spp.): new steps in plant domestication using physiological features and molecular markers. Annals of Botany 100, $1125-1142$.

Limkaisang S, Kom-un S, Furtado EL, Liew KW et al. 2005 - Molecular phylogenetic and morphological analyses of Oidium heveae, a powdery mildew of rubber tree. Mycoscience 46, 220-226.

Litzenberger SC, Farr ML, Lip HT. 1962 - A preliminary list of Cambodian plant diseases. Division of Agriculture and Natural Resources, United States Agency for International Development to Cambodia, Phnom-Penh, Cambodia, 29 pages.

Liu JK, Phookamsak R, Doilom M, Wikee S et al. 2012 - Towards a natural classification of Botryosphaeriales. Fungal Diversity 57, 149-210.

Liu LN, Razaq A, Atri NS, Bau T et al. 2018a - Fungal systematics and evolution: FUSE 4. Sydowia 70, 211-286.

Liu NG, Hyde KD, Bhat DJ, Jumpathong J, Liu JK. 2019 - Morphological and phylogenetic studies of Pleopunctum gen. nov. (Phaeoseptaceae, Pleosporales) from China. Mycosphere $10,757-775$.

Liu PSW. 1977 - A supplement to a host list of plant diseases in Sabah, Malaysia. Phytopathology Paper 21, 1-49.

Liu X, Li B, Cai L, Zheng X et al. 2018b - Colletotrichum Species Causing Anthracnose of Rubber Trees in China. Science Reports 8, 10435.

Liu YJ, Whelen S, Hall BD. 1999 - Phylogenetic relationships among ascomycetes: evidence from an RNA polymerse II subunit. Molecular Biology and Evolution 16, 1799-1808. 
Liu YX, Shi YP, Cai ZY. 2016a - A first report of rubber tree leaf spot caused by Exserohilum rostratum in China. Plant Disease 100, 2167-2168.

Liu YX, Shi YP, Deng YY, Cai ZY. 2016b - First report of leaf spot caused by Bipolaris setariae on rubber tree in China. Plant Disease 100, 1240.

Liu YX, Shi YP, Deng YY, Li LL, Dai LM, Cai ZY. 2017 - First report of Neofusicoccum parvum causing rubber tree leaf spot in China. Plant Disease 101, 1545.

Liyanage ADS. 1985 - Diseases of rubber and their control [Hevea brasiliensis]. Rubber Research Institute of Sri Lanka Bulletin.

Liyanage ADS, Dantanarayana DM. 1983 - Association of Fusarium solani with root lesions of rubber (Hevea brasiliensis) showing leaf wilt in Sri Lanka. Transactions of the British Mycological Society 80, 565-567.

Liyanage KK, Khan S, Mortimer PE, Hyde KD et al. 2016 - Powdery mildew disease of rubber tree. Forest Pathology 46, 90-103.

Lodge DJ. 1997 - Factors related to diversity of decomposer fungi in tropical forests. Biodiversity \& Conservation 6, 681-688.

Lombard L, van der Merwe NA, Groenewald JZ, Crous PW. 2015 - Generic concepts in Nectriaceae. Studies Mycology 80, 189-245.

Lopez D, Ribeiro S, Label P, Fumanal B et al. 2018 - Genome-wide analysis of Corynespora cassiicola leaf fall disease putative effectors. Frontiers in microbiology 9, 276.

Lücking R, Aime MC, Robbertse B, Miller AN et al. 2020 - Unambiguous identification of fungi: where do we stand and how accurate and precise is fungal DNA barcoding?. IMA fungus 11, $1-32$.

Luttrell ES. 1951 - Taxonomy of pyrenomycetes. University of Missouri Studies 24, 1-120.

Ma L, Xiang MM, Chi PK, Jiang ZD. 2004 - Three new species of Phomopsis from Xishuangbanna, China. Mycosystema 23, 457-460.

MacKenzie KJ, Sumabat LG, Xavier KV, Vallad GE. 2018 - A review of Corynespora cassiicola and its increasing relevance to tomato in Florida. Plant Health Progress 19, 303-309.

Manamgoda DS, Cai L, Bahkali AH, Chukeatirote E, Hyde KD. 2011 - Cochliobolus: an overview and current status of species. Fungal Diversity 51, 3-42.

Manamgoda DS, Rossman AY, Castlebury LA, Crous PW et al. 2014 - The genus Bipolaris. Studies in Mycology 79, 221-288.

Manju MJ, Idicula SP, Jacob CK, Vinod KK et al. 2001 - Incidence and severity of Corynespora leaf fall (CLF) disease of rubber in coastal Karnataka and North Malabar region of Kerala. Indian Journal of Natural Rubber Research 14, 137-141.

Mapook A, Hyde KD, Dai DQ, Li J et al. 2016 - Muyocopronales, ord. nov., (Dothideomycetes, Ascomycota) and a reappraisal of Muyocopron species from northern Thailand. Phytotaxa $265,225-237$.

Mapook A, Hyde KD, McKenzie EH, Jones EG et al. 2020 - Taxonomic and phylogenetic contributions to fungi associated with the invasive weed Chromolaena odorata (Siam weed). Fungal Diversity 101, 1-175.

Marin-Felix Y, Groenewald JZ, Cai L, Chen Q et al. 2017 - Genera of phytopathogenic fungi: GOPHY 1. Studies in Mycology 86, 99-216.

Markovskaja S, Kačergius A. 2013 - Morphological and molecular characterisation of Periconia pseudobyssoides sp. nov. and closely related P. byssoides. Mycological Progress 13, 291302.

Martin FN, Blair JE, Coffey MD. 2014 - A combined mitochondrial and nuclear multilocus phylogeny of the genus Phytophthora. Fungal Genetics \& Biology 66, 19-32.

Martin WJ. 1947 - Diseases of the Hevea Rubber tree in Mexico, 1943-1946. Plant Disease Reporter 31, 155-168.

Massee G. 1910 - FUNGI EXOTICI: X. Bulletin of Miscellaneous Information. Kew 1, 1-5. 
Matheny PB, Liu YJ, Ammirati JF, Hall BD. 2002 - Using RPB1 sequences to improve phylogenetic inference among mushrooms (Inocybe, Agaricales). American Journal of Botany 89, 688-698.

Mathur RS. 1979 - The Coelomycetes of India. Bishen Singh Mahendra Pal Singh, Delhi, India, 460 pages.

Mazlan S, Jaafar NM, Wahab A, Rajandas H, Zulperi D. 2019 - Major Diseases of Rubber (Hevea brasiliensis) in Malaysia. Pertanika Journal of Scholarly Research Reviews 5, 10-21.

McGuire JU Jr., Crandall BS. 1967 - Survey of insect pests and plant diseases of selected food crops of Mexico, Central America and Panama. Int. Agric. Dev. Serv., ARS, USDA, AID, 157 pages.

Meeboon J, Takamatsu S. 2020 - Hosts of asexual morph of Erysiphe quercicola from Thailand. Tropical Plant Pathology 45, 122-135.

Meijide A, Badu CS, Moyano F, Tiralla N et al. 2018 - Impact of forest conversion to oil palm and rubber plantations on microclimate and the role of the 2015 ENSO event. Agricultural and forest meteorology 252, 208-219.

Mendes MAS, da Silva VL, Dianese JC. 1998 - Fungos em Plants no Brasil. EmbrapaSPI/Embrapa-Cenargen, Brasilia, 555 pages.

Mehrabi M, Hemmati R, Vasilyeva LN, Trouillas FP. 2015 - A new species and a new record of Diatrypaceae from Iran. Mycosphere 6, 60-68.

Mehrabi M, Hemmati R, Vasilyeva LN, Trouillas FP. 2016 - Diatrypella macrospora sp. nov. and new records of diatrypaceous fungi from Iran. Phytotaxa 252, 43-55.

Meswaet Y, Mangelsdorff R, Yorou NS, Piepenbring M. 2021 - Unravelling unexplored diversity of cercosporoid fungi (Mycosphaerellaceae, Mycosphaerellales, Ascomycota) in tropical Africa. MycoKeys 81, 69-138.

Miller MA, Pfeiffer W, Schwartz T. 2010 - Creating the CIPRES science gateway for inference of large phylogenetic trees. Proceedings of the Gateway Computing Environments Workshop (GCE) 1: 1-8.

Monkai J, Chukeatirote E, Chamyuang S, Synytsya A et al. 2013 - Antimicrobial activity of some saprobic fungi isolated from Magnolia liliifera and Cinnamomum iners leaves. Mycology 4, $82-84$.

Monkai J, Hyde KD, Xu J, Mortimer PE. 2017 - Diversity and ecology of soil fungal communities in rubber plantations. Fungal Biology Reviews 31, 1-11.

Mugambi GK, Huhndorf SM. 2010 - Multigene phylogeny of the Coronophorales: morphology and new species in the order. Mycologia 102, 185-210.

Musngi RB, Abella EA, Lalap AL, Reyes RG. 2005 - Four species of wild Auricularia in Central Luzon, Philippines as sources of cell lines for researchers and mushroom growers. Journal of Agricultural Technology 1, 279-299.

Nag Raj TR. 1993 - Coelomycetous anamorphs with appendage-bearing conidia. Mycologue Publications, Waterloo, Ontario, 1-1101 pages.

Nakashima C, Araki I, Kobayashi T. 2011 - Addition and re-examination of Japanese species belonging to the genus Cercospora and allied genera. X: newly recorded species from Japan (5). Mycoscience 52, 253-259.

Nandris D, Nicole M, Geiger JP. 1987 - Root rot diseases of rubber trees. Plant Disease 71, 298306.

Nannfeldt JA. 1975 - Stray studies in the Coronophorales (Pyrenomycetes) 4-8. Svensk Botanisk Tidskrift. 69, 289-335.

Narayanan C, Mydin KK. 2012 - Breeding for disease resistance in Hevea spp.-status, potential threats, and possible strategies. In: RA Sniezko, AD Yanchuk, JT Kliejunas, KM Palmieri, JM Alexander, SJ Frankel (Eds.), Proceedings of the fourth international workshop on the genetics of host-parasite interactions in forestry: Disease and insect resistance in forest trees. GEneral Technical Report PSW-GTR-240. Albany, CA: Pacific Southwest Research Station, Forest Service, US Department of Agriculture. pp. 240-251. 
Nguyen TT, Do TT, Harper R, Pham TT et al. 2020. Soil health impacts of rubber farming: The implication of conversion of degraded natural forests into monoculture plantations. Agriculture 10, 357.

Nguyen V, Guan G, Zhao F, Tang S, Li Y, Liu S. 2018 - Erysiphe deutziae causing powdery mildew on Deutzia parviflora var. amurensis in China. Forest Pathology 48, e12454.

Norphanphoun C, Raspé O, Jeewon R, Wen TC, Hyde KD. 2018 - Morphological and phylogenetic characterisation of novel Cytospora species associated with mangroves. MycoKeys 38, 93-120.

Nyaka Ngobisa AIC, Abidin MAZ, Wong MY, Noordin MW. 2013 - Neofusicoccum ribis associated with leaf blight on rubber (Hevea brasiliensis) in Peninsular Malaysia. The Plant Pathology Journal 29, 10-16.

Nyaka Ngobisa AIC, Owona NPA, Doungous O, Godswill N et al. 2018 - Characterization of Pestalotiopsis microspora, the causal agent of rubber leaf blight disease in Cameroon. Rubber Science 31, 112-120.

O’Donnell K, Cigelnik E. 1997 - Two divergent intragenomic rDNAITS2 types within a monophyletic lineage of the fungus Fusarium are nonorthologous. Molecular Phylogenetics \& Evolution 7, 103-116.

O’Donnell K, Kistler HC, Cigelnik E, Ploetz RC. 1998 - Multiple evolutionary origins of the fungus causing Panama disease of banana: Concordant evidence from nuclear and mitochondrial gene genealogies. Proceedings of the National Academy of Sciences, USA 95, 2044-2049.

Ogbebor ON. 2010 - The status of three common leaf disease of Para Rubber in Nigeria. Journal of Animal \& Plant Sciences 6, 567-570.

Ogbebor N, Adekunle AT. 2005 - Inhibition of conidial germination and mycelial growth of Corynespora cassiicola (Berk and Curt) of rubber (Hevea brasiliensis muell. Arg.) using extracts of some plants. African Journal of Biotechnology 4, 996-999.

Ogbebor N, Adekunle A, Eghafona N, Ogboghodo A. 2010 - Ganoderma psuedoferreum: biological control possibilities with microorganisms isolated from soils of rubber plantations in Nigeria. African Journal of Agricultural Research 6, 301-305.

Oghenekaro AO, Miettinen O, Omorusi VI, Evueh GA et al. 2014 - Molecular phylogeny of Rigidoporus microporus isolates associated with white rot disease of rubber trees (Hevea brasiliensis). Fungal Biology 118, 495-506.

Orieux L, Feliz S. 1968 - List of plant diseases in Mauritius. Phytopathology Paper 7, 1-48.

Orwa C, Mutua A, Kindt R, Jamnadass R, Anthony S. 2009 - Agroforest tree Database: a tree reference and selection guide version 4.0. World Agroforestry Centre, Kenya.

Osono T. 2020 - Functional diversity of ligninolytic fungi associated with leaf litter decomposition. Ecological Research 35, 30-43.

Pande A. 2008 - Ascomycetes of Peninsular India. Scientific Publishers (India), Jodhpur: 584.

Pang KL, Hyde KD, Alias SA, Suetrong S, Jones EBG. 2013 - Dyfrolomycetaceae, a new family in the Dothideomycetes, Ascomycota. Cryptogamie, Mycologie 34, 223-232.

Pansak W. 2015 - Assessing rubber intercropping strategies in Northern Thailand using the water, nutrient, light capture in agroforestry systems model. Kasetsart Journal (Natural Science) 49, 785-794.

Pavlic D, Wingfield MJ, Barber P, Slippers B et al. 2008 - Seven new species of the Botryosphaeriaceae from baobab and other native trees in Western Australia. Mycologia 100, 851-866.

Pem D, Jeewon R, Bhat DJ, Doilom M et al. 2019c - Mycosphere Notes 275-324: A morphotaxonomic revision and typification of obscure Dothideomycetes genera (incertae sedis). Mycosphere 10, 1115-1246.

Perdomo H, Sutton DA, García D, Fothergill AW et al. 2011 - Spectrum of clinically relevant Acremonium species in the United States. Journal of Clinical Microbiology. 49, 243-256. 
Peregrine WTH, Ahmad KB. 1982 - Brunei: A first annotated list of plant diseases and associated organisms. Phytopathology Paper 27, 1-87.

Peregrine WTH, Siddiqi MA. 1972 - A revised and annotated list of plant diseases in Malawi. Phytopathology Paper 16, 1-51.

Perera RH, Hyde KD, Persoh D, Jones EBG, Liu JK, Liu ZY. 2018 - Additions to wild seed and fruit fungi 1: the sexual morph of Diaporthe rosae on Magnolia champaca and Senna siamea fruits in Thailand. Mycosphere 9, 256-270.

Petch T. 1906 - Descriptions of new Ceylon fungi. Annals of the Royal Botanic Gardens of Peradeniya 3, 1-10.

Petch T. 1917 - Additions to Ceylon fungi. Annals of the Royal Botanic Gardens Peradeniya. 6, 195-256

Petrak F. 1921 - Petrak's List 2: List of new species and varieties of Fungi, new combinations and new names published. The Commonwealth Mycological Institute, Kew, Surrey.

Petrak F. 1930 - Petrak's List 5. List of new species and varieties of Fungi, new combinations and new names published. The Commonwealth Mycological Institute, Kew, Surrey.

Petrini LE. 2013 - Rosellinia - a world monograph. Bibliotheca Mycologica 205, 410 pages.

Phillips AJ, Alves A, Abdollahzadeh J, Slippers B et al. 2013 - The Botryosphaeriaceae: genera and species known from culture. Studies in Mycology 76,51-167.

Phillips AJL, Alves A, Pennycook SR, Johnston PR et al. 2008. Resolving the phylogenetic and taxonomic status of dark-spored teleomorph genera in the Botryosphaeriaceae. Persoonia 21, $29-55$.

Phillips AJL, Hyde KD, Alves A, Liu JK. 2019 - Families in Botryosphaeriales: a phylogenetic, morphological and evolutionary perspective. Fungal Diversity 94, 1-22.

Phookamsak R, Hyde KD, Jeewon R, Bhat DJ et al. 2019 - Fungal diversity notes 929-1035: taxonomic and phylogenetic contributions on genera and species of fungi. Fungal Diversity 95, 1-273.

Phukhamsakda C, Ariyawansa HA, Phillips AJL, Wanasinghe DN et al. 2016 - Additions to Sporormiaceae: introducing two novel genera, Sparticola and Forliomyces, from Spartium. Cryptogamie Mycologie 37, 75-97.

Phukhamsakda C, McKenzie EHC, Phillips AJL, Jones EBG et al. 2020 - Microfungi associated with Clematis (Ranunculaceae) with an integrated approach to delimiting species boundaries. Fungal Diversity 102, 1-203.

Picos-Muñoz PA, García-Estrada RS, León-Félix J, Sañudo-Barajas A, Allende-Molar R. 2015 Lasiodiplodia theobromae en cultivos agrícolas de México: Taxonomía, hospedantes, diversidad y control. Revista mexicana de fitopatología 33, 54-74.

Piepenbring M. 2006 - Checklist of fungi in Panama, preliminary version. Natura Revista Científicay Humanística de la Universidad Autónoma de Chiriquí, Panama, vol. 11

Pinho DB, Honorato Junior H, Firmino AL, Hora Junior BT et al. 2014 - Reappraisal of the black mildews (Meliolales) on Hevea brasiliensis. Tropical Plant Pathology 39, 89-94.

Piyaboon O, Thunyamada S, Numsiripongpan W, Pattayanan K et al. 2013 - Application of endophytic fungi from para rubber tree as high ability in inhibitors of against Phytophthora botryosa, the pathogen of leaf-fall disease in para rubber tree. Journal of Agricultural Technology 9, 1179-1187.

Ploetz RC. 2007 - Diseases of tropical perennial crops: challenging problems in diverse environments. Plant Disease 91, 644-663.

Pornsuriya C, Chairin T, Thaochan N, Sunpapao A. 2020 - Identification and characterization of Neopestalotiopsis fungi associated with a novel leaf fall disease of rubber trees (Hevea brasiliensis) in Thailand. Journal of Phytopathology 168, 416-427.

Pujade-Renaud V, Déon M, Gazis R, Ribeiro S et al. 2019 - Endophytes from wild rubber trees as antagonists of the pathogen Corynespora cassiicola. Phytopathology 109, 1888-1899.

Qiao M, Tian W, Castañeda-Ruiz RF, Xu J, Yu Z. 2019 - Two new species of Verruconis from Hainan, China. MycoKeys 48, 41-53. 
Raja HA, Miller AN, Pearce CJ, Oberlies NH. 2017 - Fungal identification using molecular tools: a primer for the natural products research community. Journal of natural products. 80, 756770.

Rambaut A. 2016 - FigTree, version 1.4.3. University of Edinburgh, Edinburgh.

Rands RD. 1924 - South American leaf disease of Para rubber. US Department of Agriculture.

Rannala B, Yang Z. 1996 - Probability distribution of molecular evolutionary trees: a new method of phylogenetic inference. Journal of Molecular Evolution 43, 304-311.

Rappaz F. 1987 - Taxonomy and nomenclature of the octosporous Diatrypaceae. Mycologia Helvetica 2, 285-648.

Rehner SA. 2001 - Primers for elongation factor 1-alpha (EF1-alpha). Available from: http://ocid.nacse.org/research/deephyphae/EF1primer.pdf. (accessed December 2018)

Reinking OA. 1919 - Host Index of Diseases of Economic Plants in the Philippines. The Philippine Agricultural Scientist 8, 38-54.

Ren GC, Wanasinghe DN, Monkai J, Mortimer PE et al. 2021 - Novel saprobic Hermatomyces species (Hermatomycetaceae, Pleosporales) from Thailand and China (Yunnan Province). MycoKeys 82: 57-79.

Resplandy R, Chevaugeon J, Delassus M, Luc M. 1954 - Premiere liste annotee de champignons parasites de plantes cultivees en Cote d'Ivoire. Annales Des Épiphyties 1, 1-61.

Rippel MM, Galembeck F. 2009 - Nanostructures and Adhesion in Natural Rubber: New Era for a Classic. Journal of the Brazilian Chemical Society 20, 1024-1030.

Rocha AC, Garcia D, Uetanabaro AP, Carneiro RT et al. 2011 - Foliar endophytic fungi from Hevea brasiliensis and their antagonism on Microcyclus ulei. Fungal Diversity 47: 75-84.

Rodesuchit A, Suchatgul S, Klaewklong B, Damnoi S. 2012 - Efficacy of Fertilizers to Control White Root Disease of Rubber Caused by Rigidoporus microporus at The Early Planting Stages. RUBBER THAI JOURNAL 1, 62-72.

Rondon MN, Lawrence K. 2021 - The fungal pathogen Corynespora cassiicola: A review and insights for target spot management on cotton and Soya bean. Journal of Phytopathology 169, 329-338.

Rosado AW, Machado AR, Freire FD, Pereira OL. 2016 - Phylogeny, identification, and pathogenicity of Lasiodiplodia associated with postharvest stem-end rot of coconut in Brazil. Plant Disease 100, 561-568.

Rossman AY, Samuels GJ, Rogerson CT, Lowen R. 1999 - Genera of Bionectriaceae, Hypocreaceae and Nectriaceae (Hypocreales, Ascomycetes). Studies in Mycology 42, 1-248.

Roy BA. 2001 - Patterns of association between crucifers and their flower-mimic pathogens: host jumps are more common than coevolution or cospeciation. Evolution 55, 41-53.

Rubber Research Institute of Thailand. 2010 - Thailand rubber statistics. (Annual report). Ministry of Agriculture Bangkok, Thailand, 39, 29 pages.

Saccardo PA. 1880a - Conspectus generum fungorum Italiae inferiorum nempe ad Sphaeropsideas, Melanconieas et Hyphomyceteas pertinentium systemate sporologico dispositorum. Michelia $2,1-38$

Saccardo PA. 1880b - Fungi gallici, ser. II. Michelia 2, 38-135.

Saccardo PA. 1902 - Sylloge Fungorum Vol. XVI. Padova.

Saccardo PA. 1913 - Sylloge Fungorum Vol. XXII. Padova.

Saccardo PA. 1925 - Sylloge Fungorum Vol. XXIII. Padova.

Saccardo PA. 1928 - Sylloge Fungorum Vol. XXIV. Padova.

Saccardo PA. 1931 - Sylloge Fungorum Vol. XXV. Abellini.

Saccardo PA. 1972 - Sylloge Fungorum Vol. XXVI. New York, London.

Saha T, Kumar A, Ravindran M, Jacobs K et al. 2002 - Identification of Colletotrichum acutatum from rubber using random amplified polymorhic DNAs and ribosomal DNA polymorphisms. Mycological Research 106, 215-221.

Saikia UN. 1982 - Phytopathogenic fungi of India - I. Indian Phytopathology 35: 733-735. 
Salvatore MM, Alves A, Andolfi A. 2020a - Secondary metabolites of Lasiodiplodia theobromae: Distribution, chemical diversity, bioactivity, and implications of their occurrence. Toxins 12, 457.

Salvatore MM, Andolfi A, Nicoletti R. 2020b - The thin line between pathogenicity and endophytism: The case of Lasiodiplodia theobromae. Agriculture 10, 488.

Samerpitak K, Van der Linde E, Choi HJ, Gerrits van den Ende AHG et al. 2014 - Taxonomy of Ochroconis, genus including opportunistic pathogens on humans and animals. Fungal Diversity 65, 89-126.

Sarbhoy AK, Agarwal DK. 1990 - Descriptions of Tropical Plant Pathogenic Fungi. Malhotra Publishing House.

Sawada K. 1943 - Descriptive catalogue of the Formosan fungi. Part IX. Rep. Dept. Agric. Gov. Res. Inst. Formosa 86, 1-178.

Schreurs J, 1972 - Black thread disease, control measures and yield stimulation in Hevea brasiliensis in Liberia.

Seephueak P, Petcharat V, Phongpaichit S. 2010 - Fungi associated with leaf litter of para rubber (Hevea brasiliensis). Mycology 1, 213-227.

Seephueak P, Phongpaichit S, Hyde KD, Petcharat V. 2011 - Diversity of saprobic fungi on decaying branch litter of the rubber tree (Hevea brasiliensis). Mycosphere 2, 307-330.

Seifert KA. 1985 - A monograph of Stilbella and some allied Hyphomycetes. Studies in Mycology $27,1-234$.

Seifert KA. 1990 - Synnematous hyphomycetes. Pages 109-154 in Samuels GJ, and al. et. Contributions toward a mycobiota of Indonesia: Hypocreales, synnematous Hyphomycetes, Aphyllophorales, Phragmobasidiomycetes, and Myxomycetes. Memoirs of the New York Botanical Garden 59, 1-180.

Selmaoui K, Touati J, Chliyeh M, TouhamiI AO et al. 2014 - Study of Pestalotiopsis palmarum pathogenicity on Washingtonia robusta (Mexican palm). International Journal of Pure \& Applied Bioscience 2, 138-145.

Senwanna C, Hongsanan S, Phookamsak R, Tibpromma S et al. 2019 - Muyocopron heveae sp. nov. and $M$. dipterocarpi appears to have host-jumped to rubber. Mycological Progress 18, 741-752.

Senwanna C, Hongsanan S, Hyde KD, Cheewangkoon R et al. 2021 - First report of the sexual morph of Pseudofusicoccum adansoniae Pavlic, T.I. Burgess \& M.J. Wingf. on Para rubber. Cryptogamie, Mycologie 41, 133-146.

Senwanna C, Hyde KD, Phookamsak R, Jones EBG, Cheewangkoon R. 2018a - Coryneum heveanum sp. nov. (Coryneaceae, Diaporthales) on twigs of Para rubber in Thailand. MycoKeys 43, 75-90.

Senwanna C, Wanasinghe DN, Bulgakov TS, Wang Y et al. 2019 - Towards a natural classification of Dothidotthia and Thyrostroma in Dothidotthiaceae (Pleosporineae, Pleosporales). Mycosphere 10, 701-738.

Senwanna C, Phookamsak R, Bahkali AH, Elgorban AM et al. 2018b - Neolinocarpon phayaoense sp. nov. (Linocarpaceae) from Thailand. Phytotaxa 362, 77-86.

Senwanna C, Phookamsak R, Doilom M, Hyde KD, Cheewangkoon R. 2017 - Novel taxa of Diatrypaceae from Para rubber (Hevea brasiliensis) in northern Thailand; introducing a novel genus Allocryptovalsa. Mycosphere 8, 1835-1855.

Senanayake IC, Crous PW, Groenewald JZ, Maharachchikumbura SSN et al. 2017 - Families of Diaporthales based on morphological and phylogenetic evidence. Studies in Mycology 86, 217-296.

Senanayake IC, Jeewon R, Chomnunti P, Wanasinghe DN et al. 2018 - Taxonomic circumscription of Diaporthales based on multigene phylogeny and morphology. Fungal Diversity 93, 241443. 
Senanayake IC, Rathnayaka AR, Marasinghe DS, Calabon MS et al. 2020 - Morphological approaches in studying fungi: collection, examination, isolation, sporulation and preservation. Mycosphere 11, 2678-2754.

Shang QJ, Hyde KD, Camporesi E, Maharachchikumbura SSN et al. 2020 - Additions to the genus Cytospora with sexual morph in Cytosporaceae. Mycosphere 11, 189-224.

Shanthi S, Vittal BP. 2010 - Fungi associated with decomposing leaf litter of cashew (Anacardium occidentale). Mycology 1, 121-129.

Shaw DE. 1984 - Microorganisms in Papua New Guinea. Department of Primary Industry, Papua New Guinea. Research bulletin 33, 1-344.

Shi YP, Liu YX, Li LL, Dai LM, Cai ZY. 2019 - First report of Colletotrichum laticiphilum causing anthracnose of rubber tree in China. Plant Disease 103, 579-580.

Silva WP, Karunanayake EH, Wijesundera RL, Priyanka UM. 2003 - Genetic variation in Corynespora cassiicola: a possible relationship between host origin and virulence. Mycological research 107, 567-571.

Singh KG. 1980 - A check list of host and disease in Malaysia. Bulletin Ministry of Agriculture, Malaysia.

Sittisart P, Yossan S, Prasertsan P. 2017 - Antifungal property of chili, shallot and garlic extracts against pathogenic fungi, Phomopsis spp., isolated from infected leaves of para rubber (Hevea brasiliensis Muell. Arg.). Agriculture and Natural Resources 51, 485-491.

Siri-udom S, Suwannarach N, Lumyong S. 2015 - Existence of Muscodor vitigenus, M. equiseti and $M$. heveae sp. nov. in leaves of the rubber tree (Hevea brasiliensis Müll.Arg.), and their biocontrol potential. Annals of Microbiology 66, 437-448.

Sittisart P, Yossan S, Prasertsan P. 2017 - Antifungal property of chili, shallot and garlic extracts against pathogenic fungi, Phomopsis spp., isolated from infected leaves of para rubber (Hevea brasiliensis Muell. Arg.). Agriculture and Natural Resources 51, 485-491.

Sivanesan A. 1984 - The bitunicate Ascomycetes and their anamorphs. J. Cramer, Vaduz, 701 pages.

Sivanesan A. 1985 - The Mycosphaerella teleomorph of Cercospora dioscoreae-pyrifoliae. Transactions of the British Mycological Society 85, 743-747.

Slippers B, Boissin E, Phillips AJL, Groenewald JZ et al. 2013 - Phylogenetic lineages in the Botryosphaeriales: a systematic and evolutionary framework. Studies in Mycology 76, 31-49.

Small W. 1928 - On Rhizoctonia bataticola (Taub.) Butler as a cause of root disease in the tropics. Transactions of the British Mycological Society 13, 40-68.

Somrithipol S, Chatmala I, Jones EBG. 2002 - Cirrenalia nigrospora sp. nov. and C. tropicalis from Thailand. Nova Hedwigia 75, 477-485.

Souza LM, Mantello CC, Santos MO, de Souza Gonçalves P, Souza AP. 2009 - Microsatellites from rubber tree (Hevea brasiliensis) for genetic diversity analysis and cross-amplification in six Hevea wild species. Conservation Genetics Resources 1, 75-79.

Spaulding P. 1961 - Foreign Diseases of Forest Trees of the World. US Department of Agriculture Handbook 197, 1-361.

Spegazzini CL. 1881 - Fungi argentini additis nonnullis brasiliensibus montevideensibusque. Pugillus quartus (Continuacion). A Soc Cien Arg 12, 97-117.

Srihanant N, Petcharat V. 2015 - Some Xylaria species in oil palm and para rubber plantation in southern Thailand. Khon Kaen Agriculture Journal 43 SUPPL. 1 (in Thai).

Stadler M, Læssøe T, Fournier J, Decock C et al. 2014 - A polyphasic taxonomy of Daldinia (Xylariaceae). Studies in mycology 77, 1-143.

Stamatakis A. 2014 - RAxML version 8: a tool for phylogenetic analysis and post-analysis of large phylogenies. Bioinformatics 30, 1312-1313.

Stamatakis A, Hoover P, Rougemont J. 2008 - A rapid bootstrap algorithm for the RAxML web servers. Systematic Biology 57, 758-771. 
Stanaszek-Tomal E. 2020 - Environmental Factors Causing the Development of Microorganisms on the Surfaces of National Cultural Monuments Made of Mineral Building Materials. Coatings 10, 1203.

Sterling A, Galindo-Rodríguez LC, Suárez-Córdoba YD, Velasco-Anacona G et al. 2019 - Early assessing performance and resistance of Colombian rubber tree genotypes under high South American Leaf Blight pressure in Amazon. Industrial Crops and Products 141, 111775.

Sterling A, Gómez-Torres AK, Suárez-Córdoba YD, Loaiza-Molina LC, Sierra-Hayer JF. 2020 Standard area diagrams to assess black crust (Phyllachora huberi) severity on rubber tree leaflets. European Journal of Plant Pathology 156, 827-837.

Stevenson JA, Imle EP. 1945 - Periconia Blight of Hevea. Mycologia 37, 576-581.

Strouts RG. 1972 - Canker of cypresses caused by Coryneum cardinale Wag. in Britain. European Journal of Forest Pathology 3, 13-24 pp.

Su XJ, Luo ZL, Jeewon R, Bhat DJ et al. 2018 - Morphology and multigene phylogeny reveal new genus and species of Torulaceae from freshwater habitats in northwestern Yunnan, China. Mycological Progress 17, 531-545.

Sumabat LG, Kemerait Jr. RC, Brewer MT. 2018 - Phylogenetic diversity and host specialization of Corynespora cassiicola responsible for emerging target spot disease of cotton and other crops in the southeastern United States. Phytopathology 108, 892-901.

Sunpapao A, Pornsuriya C. 2014 - Effects of chitosan treatments on para rubber leaf fall disease caused by Phytophthora palmivora Butler-a laboratory study. Songklanakarin Journal of Science \& Technology 36, 507-512.

Sutton BC. 1980 - The Coelomycetes Fungi imperfect with pycnidia, acervuli and stromata. Commonwealth Mycological Institute, Kew, UK.

Świderska-Burek U, Daub ME, Thomas E, Jaszek M et al. 2020 - Phytopathogenic Cercosporoid Fungi - From Taxonomy to Modern Biochemistry and Molecular Biology. International Journal of Molecular Sciences 21, 8555.

Tai FL. 1979 - Sylloge Fungorum Sinicorum. Science Press, Academia Sinica, Peking, 1527 pages.

Takamatsu S, Katsuyama S, Shinoda T. 2018 - First record of Erysiphe quercicola (Ascomycota: Erysiphales) on species of Quercus subgenus Cyclobalanopsis (evergreen oaks, Fagaceae). Mycoscience 59, 105-109.

Talde UK. 1970 - Ascomycetes of India. Sydowia 24, 278-281.

Tam LTT, Cuong HV, Khue NM, Tri MV et al. 2016 - First report of powdery mildew caused by Erysiphe quercicola on Hevea brasiliensis in Viet Nam. Plant Disease 100, 1239.

Tanaka K, Hashimoto A, Matsumura M, Sato T. 2017 - Brevicollum, a new genus in Neohendersoniaceae, Pleosporales. Mycologia 109, 608-619.

Tanaka K, Hirayama K, Yonezawa H, Sato G et al. 2015 - Revision of the Massarineae (Pleosporales, Dothideomycetes). Studies in Mycology 82, 75-136.

Teodoro NG. 1937 - An Enumeration of Philippine Fungi. Techn. Bull. Dept. Agric. Comm. Manila 4, 1-585.

Thambugala KM, Hyde KD, Eungwanichayapant PD, Romero AI, Liu ZY. 2016 - Additions to the genus Rhytidhysteron in Hysteriaceae. Cryptogamie, Mycologie 37, 99-116.

Thambugala KM, Hyde KD, Tanaka K, Tian Q et al. 2015 - Towards a natural classification and backbone tree for Lophiostomataceae, Floricolaceae, and Amorosiaceae fam. nov. Fungal Diversity 74, 199-266.

Thaochan N, Pornsuriya C, Chairin T, Sunpapao A. 2020 - Roles of systemic fungicide in antifungal activity and induced defense responses in rubber tree (Hevea brasiliensis) against leaf fall disease caused by Neopestalotiopsis cubana. Physiological and Molecular Plant Pathology 111, 101511.

Thaung MM. 2006 - Biodiversity of phylloplane ascomycetes in Burma. Australasian Mycologist $24,5-23$.

Thaung MM. 2007 - A preliminary survey of macromycetes in Burma. Australasian Mycologist $26,16-36$. 
Thaung MM. 2008 - Biodiversity survey of coelomycetes in Burma. Australasian Mycologist 27, 74-110.

Theodoro GDF, Batista TS. 2014 - Detection of fungi in rubber tree (Hevea brasiliensis) seeds harvested in northeast of Mato Grosso do Sul, Brazil. Agrarian 7, 365-368.

Thompson A, Johnston A. 1953 - A host list of plant diseases in Malaya. Mycological papers 52, $1-38$.

Thompson SM, Tan YP, Shivas RG, Neate SM et al. 2015 - Green and brown bridges between weeds and crops reveal novel Diaporthe species in Australia. Persoonia 35, 39-49.

Tianyu Z. 2009 - Flora Fungorum Sincorum Vol. 31: 26 Genera of Dematiaceous Dictyosporous Hyphomycetes Excluding Alternaria. Science Press, Beijing 31, 231.

Tibpromma S, Hyde KD, McKenzie EHC, Bhat DJ et al. 2018. Fungal diversity notes 840-928: micro-fungi associated with Pandanaceae. Fungal Diversity 93, 1-160.

Tibpromma S, McKenzie EHC, Karunarathna SC, Mortimer PE et al. 2016 - Muyocopron garethjonesii sp. nov. (Muyocopronales, Dothideomycetes) on Pandanus sp. Mycosphere 7, 1480-1489.

Trakunyingcharoen T, Cheewangkoon R, To-anun C. 2015a - Phylogenetic study of the Botryosphaeriaceae species associated with avocado and para rubber in Thailand. Chiang Mai University Journal of Natural Sciences 42, 104-116.

Trakunyingcharoen T, Chewangkoon R, To-anun C, Crous PW et al. 2014 - Botryosphaeriaceae associated with diseases of mango (Mangifera indica). Australasian Plant Pathology 43, 425438.

Trakunyingcharoen T, Lombard L, Groenewald JZ, Cheewangkoon R et al. 2015b - Caulicolous Botryosphaeriales from Thailand. Persoonia 34, 87-99.

Trouillas FP, Pitt WM, Sosnowski MR, Huang R et al. 2011 - Taxonomy and DNA phylogeny of Diatrypaceae associated with Vitis vinifera and other woody plants in Australia. Fungal Diversity 49, 203-223.

Tongkaemkaew U, Patanothai A. 2013 - Expansion of rubber plantations in Northeast Thailand: Income and living status of full-time hired labor. Khon Kaen Agriculture Journal 41, 497506.

Turner GJ. 1966 - New records of plant diseases in Sarawak for the years 1963 and 1964. Technical Document Plant Protection Committee for the South East Asia and Pacific Region (FAO) 52.

Turner GJ. 1971 - Fungi and Plant Disease in Sarawak. Phytopathological papers 13, 1-55.

Udayanga D, Castlebury LA, Rossman AY, Chukeatirote E, Hyde KD. 2015 - The Diaporthe sojae species complex: phylogenetic re-assessment of pathogens associated with soybean, cucurbits and other field crops. Fungal Biology 119, 383-407.

Udayanga D, Liu X, McKenzie EHC, Chukeatirote E et al. 2011 - The genus Phomopsis: biology, applications, species concepts and names of common phytopathogens. Fungal Diversity 50, 189-225.

Valdetaro DC, Oliveira LS, Guimarães LM, Harrington TC et al. 2015 - Genetic variation, morphology and pathogenicity of Ceratocystis fimbriata on Hevea brasiliensis in Brazil. Tropical Plant Pathology 40, 184-192.

Vasilyeva L, Chernyshev A, Stephenson SL. 2010 - Pyrenomycetes of the Russian Far East 4: family Nitschkiaceae (Coronophorales, Ascomycota). Mycologia 102, 233-247.

Venkatachalam P, Jayashree R, Rekha K, Sushmakumari S et al. 2006 - Rubber Tree (Hevea brasiliensis Muell. Arg). In: K Wang (Ed.), Agrobacterium Protocols Second Edition Volume 2. Methods in Molecular Biology 344. Humana Press. pp. 153-164.

Větrovský T, Kohout P, Kopecký M, Machac A et al. 2019 - A meta-analysis of global fungal distribution reveals climate-driven patterns. Nature Communications 10, 5142.

Videira SI. 2018 - Mycosphaerellaceae revisited. Doctoral dissertation, Wageningen University and Research). 
Videira SI, Groenewald JZ, Nakashima C, Braun U et al. 2017 - Mycosphaerellaceae-Chaos or clarity?. Studies in Mycology 87, 257-421.

Vilgalys R, Hester M. 1990 - Rapid genetic identification and mapping of enzymatically amplified ribosomal DNA from several Cryptococcus species. Journal of Bacteriology 172, 4238-4246.

Vincens PF. 1915 - Contribution à l'étude des maladies de l'Hevea brasiliensis dans la vallée de l'Amazone. Bulletin de la Société de Pathologie Végétale de France 2, 11-27.

Vongkhamheng C, Zhou JH, Beckline M, Phimmachanh S. 2016 - Socioeconomic and Ecological Impact Analysis of Rubber Cultivation in Southeast Asia. Open Access Library Journal 3, e2339.

Walker DM, Castlebury LS, Rossman AY, Struwe L. 2014 - Host conservatism or host specialization? Patterns of fungal diversification are influenced by host. Biological Journal of the Linnean Society 111, 1-16.

Wanasinghe DN, Phukhamsakda C, Hyde KD, Jeewon R et al. 2018 - Fungal diversity notes 709839: taxonomic and phylogenetic contributions to fungal taxa with an emphasis on fungi on Rosaceae. Fungal Diversity 89, 1-236.

Wangpimool W, Pongput K, Tangtham N, Prachansri S, Gassman PW. 2017 - The impact of para rubber expansion on streamflow and other water balance components of the Nam Loei River basin, Thailand. Water 9, 1.

Warren-Thomas E, Dolman PM, Edwards DP. 2015 - Increasing demand for natural rubber necessitates a robust sustainability initiative to mitigate impacts on tropical biodiversity. Conservation Letters 8, 230-241.

Weir JR. 1926 - A pathological survey of the para rubber tree (Hevea Brasiliensis) in the Amazon Valley. US Department of Agriculture. 1-130.

West J. 1938 - A preliminary list of plant diseases in Nigeria. Bulletin of Miscellaneous Information (Royal Botanic Gardens, Kew).

White T, Bruns T, Lee S, Taylor J. 1990 - Amplification and direct sequencing of fungal ribosomal RNA genes for phylogenetics. In: Innis M, Gelfand D, Shinsky J, White T (Eds.) PCR protocols: a guide to methods and applications. Academic Press, New York, 315-322 pp.

Wiehe PO. 1953 - The plant diseases of Nyasaland. Phytopathological papers 53: 1-39.

Wijayawardene NN, McKenzie EHC, Hyde KD. 2012 - Towards incorporating anamorphic fungi in a natural classification-checklist and notes for 2012. Mycosphere 3, 157-228.

Wijayawardene NN, Hyde KD, Al-Ani LKT, Tedersoo L et al. 2020 - Outline of Fungi and fungus-like taxa. Mycosphere 11, 1060-1456.

Williams TH, Liu PSW. 1976 - A host list of plant diseases in Sabah, Malaysia. Phytopathological papers $19,1-67$.

Willis JC. 1906 - Annals of the Royal Botanic Gardens, Peradeniya, Vol. 3.

Worapattamasri J, Ninsuwan N, Chuenchit S, Petcharat V. 2009 - Anamorphs of Cochliobolus on disease plants in Southern Thailand. Journal of Agricultural Technology 5, 143-155.

Wu H, Pan Y, Di R, He Q et al. 2019 - Molecular identification of the powdery mildew fungus infecting rubber trees in China. Forest Pathology 49, e12519.

Wu HX, Schoch CL, Boonmee S, Bahkali AH, Chomnunti P, Hyde KD. 2011 - A reappraisal of Microthyriaceae. Fungal Divers 51, 189-248.

Wu N, Dissanayake AJ, Manawasinghe IS, Rathnayaka AR et al. 2021 https://botryosphaeriales.org/, an up-to-date classification and account of taxa of Botryosphaeriales. Database (in press)

Yu YN. 1998 - Flora Fungorum Sinicorum. Vol. 6. Peronosporales. Science Press, Beijing, 530 pages.

Zeng HC, Ho HH, Zheng FC. 2005 - Pythium vexans causing patch canker of rubber trees on Hainan Island, China. Mycopathologia 159, 601-606.

Zhang Y, Crous PW, Schoch CL, Bahkali AH et al. 2011 - A molecular, morphological and ecological re-appraisal of Venturiales - a new order of Dothideomycetes. Fungal Diversity 51, 249-277. 
Zhao GZ, Zhang TY. 2004 - Notes on dictyosporic hyphomycetes from China V. The genus Monodictys. Mycosystema 23, 324-327.

Zhaxybayeva O, Gogarten JP. 2002 - Bootstrap, Bayesian probability and maximum likelihood mapping: exploring new tools for comparative genome analyses. BMC Genomics 3, 1-15.

Zhu J, Zhang Z. 2009 - Ethylene stimulation of latex production in Hevea brasiliensis. Plant signaling \& behavior 4, 1072-1074.

Zhuang WY. 2001 - Higher Fungi of Tropical China. Mycotaxon Limited, Ithaca, NY, 485 pages. 